Historic, archived document

Do not assume content reflects current scientific knowledge, policies, or practices. 

asDil

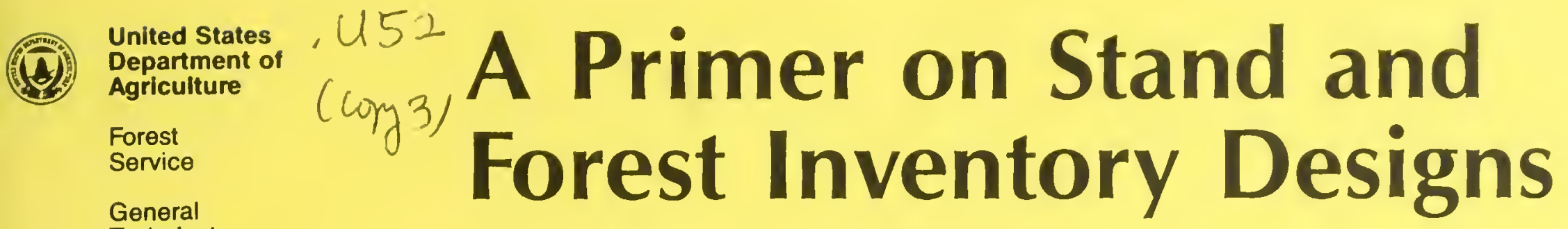

Technical

Report

WO-54

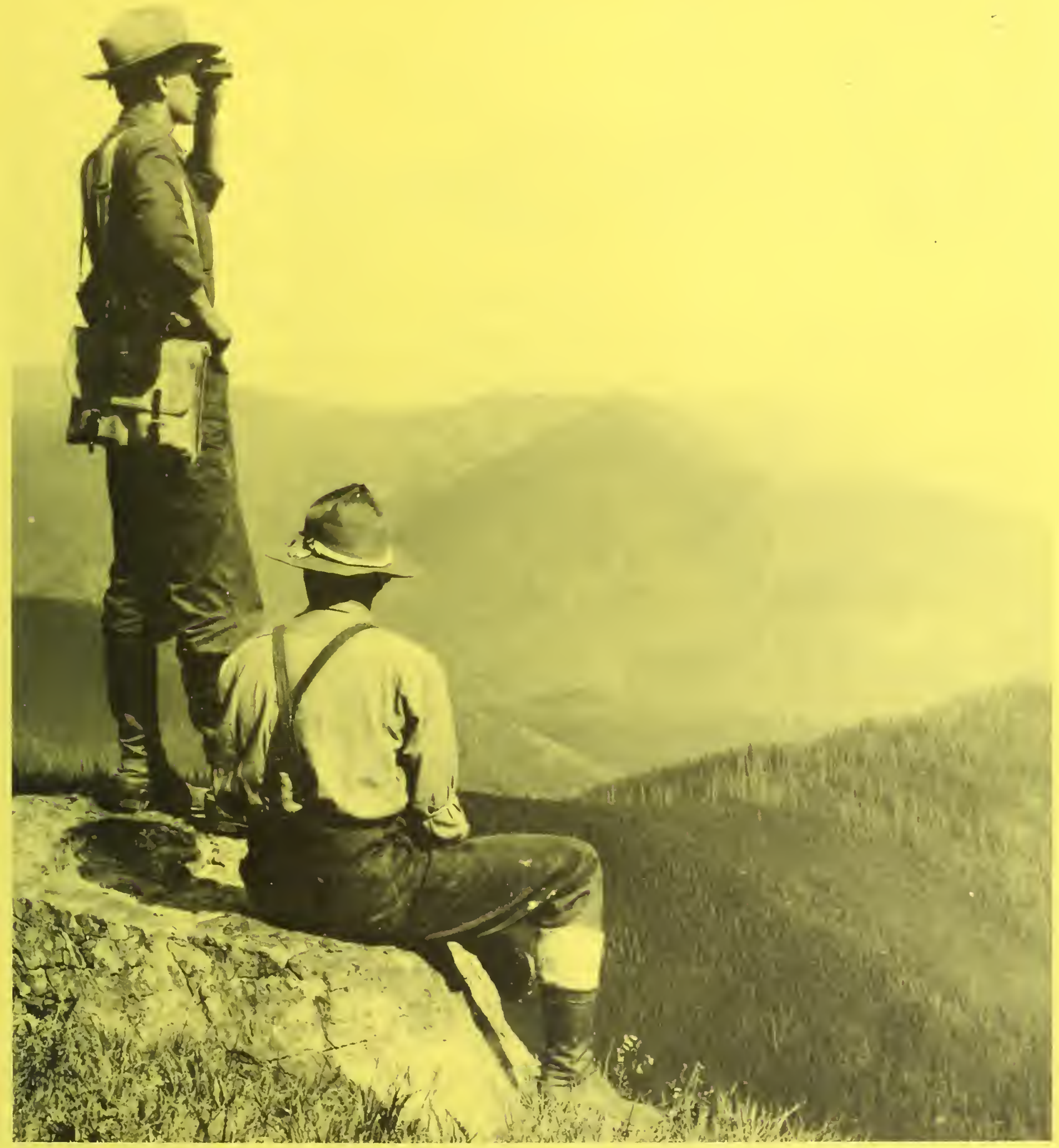


USDA, Netonal Agriauturat Library

NAL Sldg

10301 Baithore Blvd

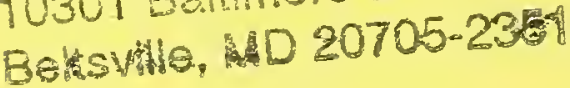


United States

Department of

Agriculture

Forest

Service

General Technical

Report WO-54

September 1989

\section{A Primer on Stand and Forest Inventory Designs}

H. Gyde Lund

and

Charles E. Thomas

The authors, both with the USDA Forest Service, are respectively Forester, Timber Management, Washington, DC, and Research Forester, Southern Forest Experiment Station, Institute for Quantitative Studies, New Orleans, LA. 


\section{Acknowledgments}

The authors extend special thanks to Jim Brickell, Forester, USDA Forest Service (Region 1), Dr. Albert Stage (Intermountain Forest and Range Experiment Station), and Dr. Pieter De Vries, Wageningen Agricultural University, the Netherlands, who provided considerable statistical assistance in the development of this publication. The authors also gratefully acknowledge the many individuals who reviewed the manuscript and made valuable suggestions. 


\section{Contents}

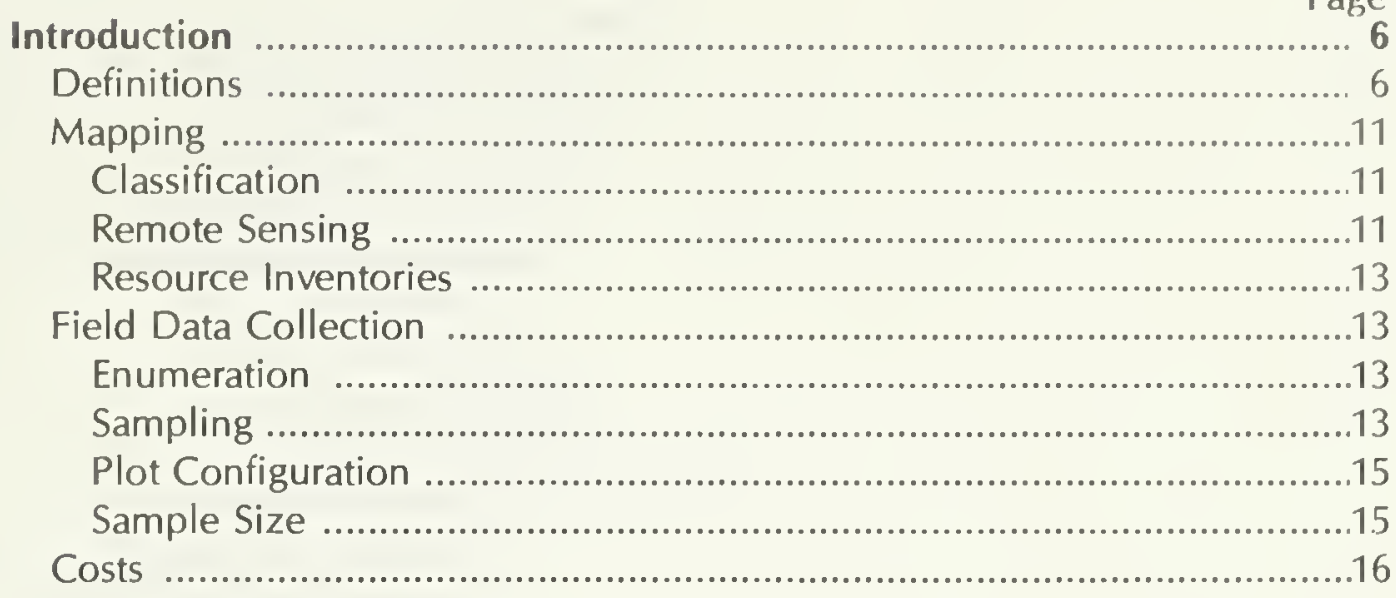

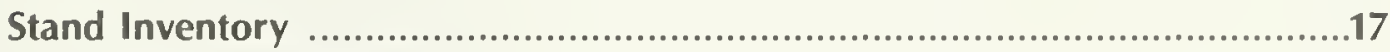

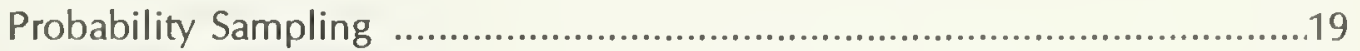

Random Distribution ..................................................................19

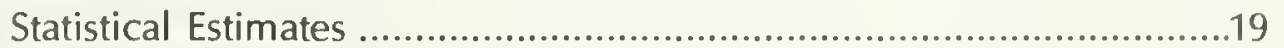

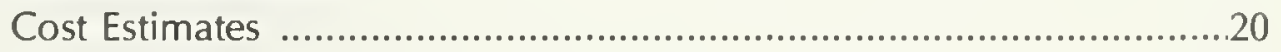

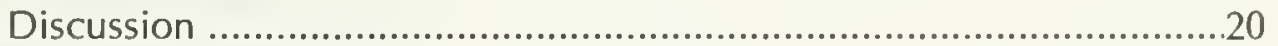

Line Transect Distribution ................................................................20

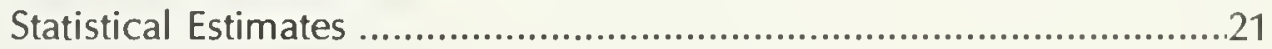

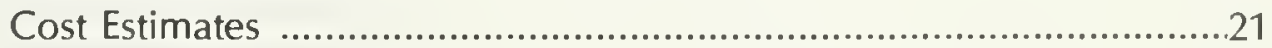

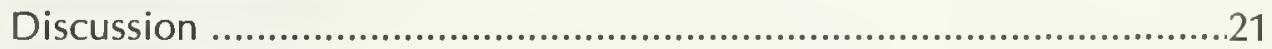

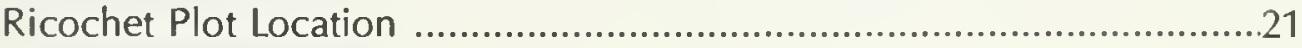

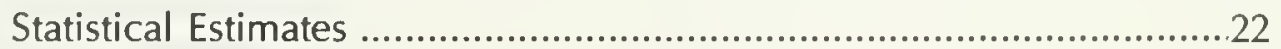

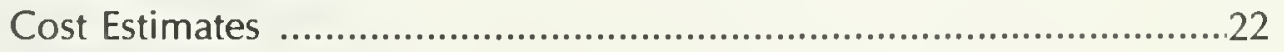

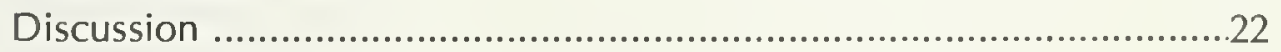

Systematic Distribution with a Random Start ......................................222

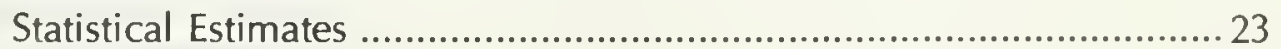

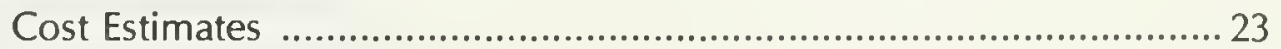

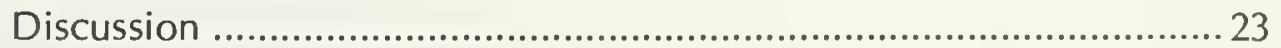

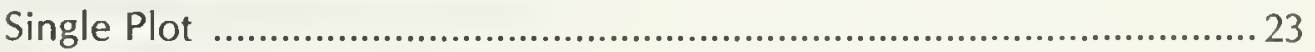

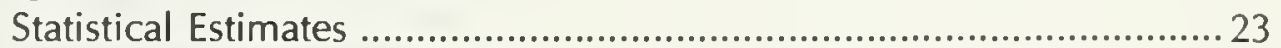

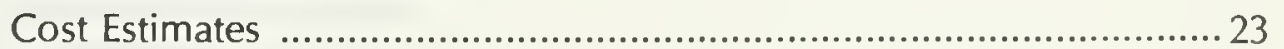

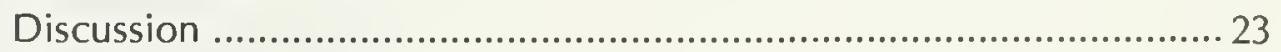

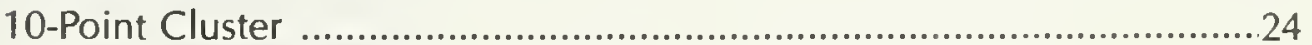

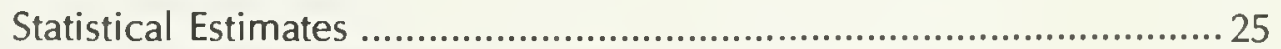

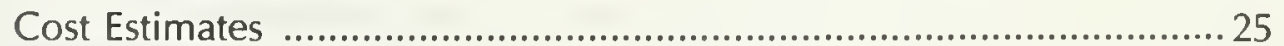

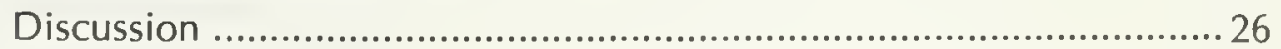

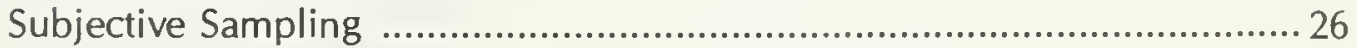

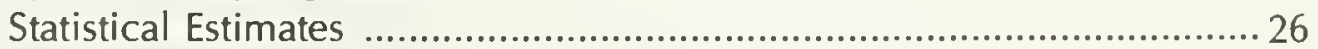

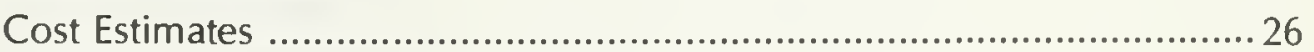

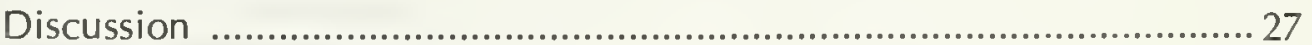

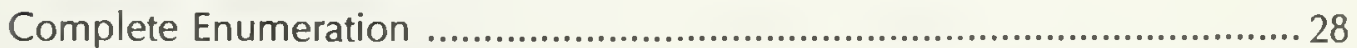

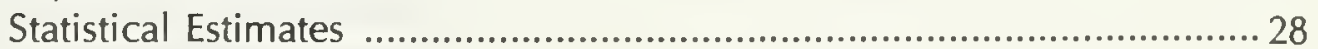

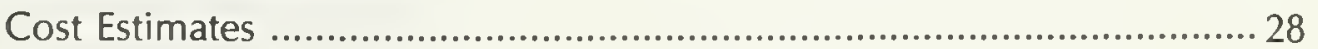

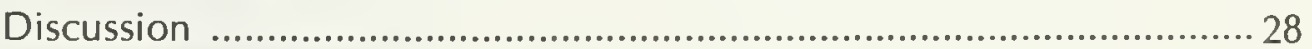

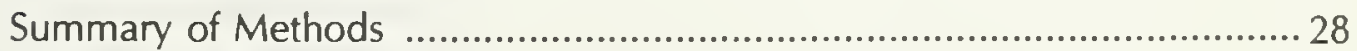

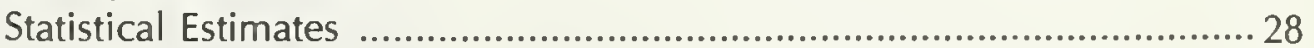

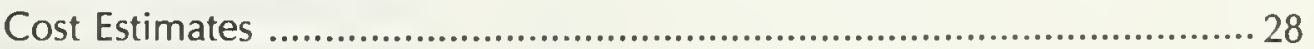

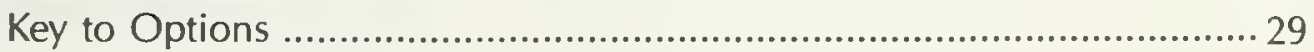




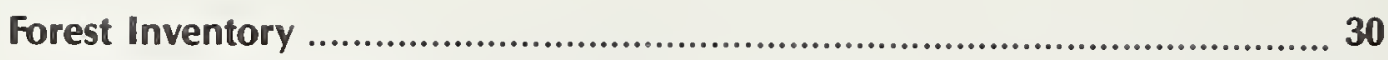

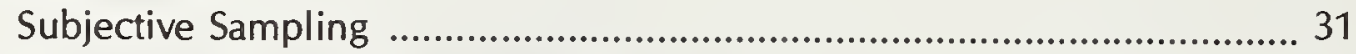

Inventories Without Prior Stand Mapping ………........................................ 31

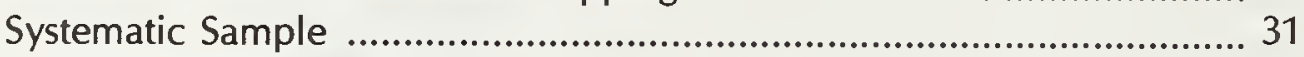

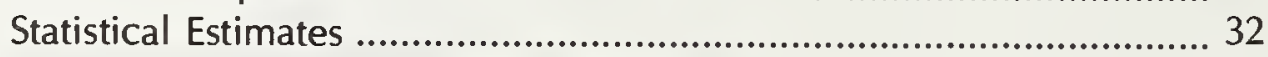

Mapping and Unmeasured Area Estimates ........................................ 33

Cost Estimates .............................................................................. 35

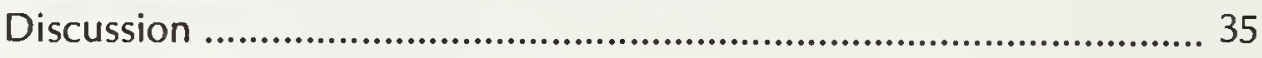

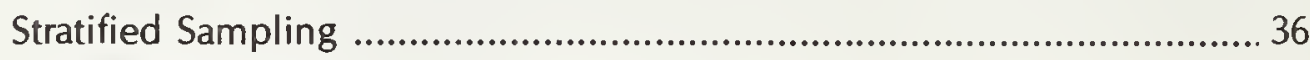

Poststratification ……….................................................................. 37

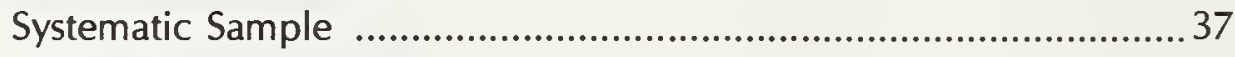

Statistical Estimates ........................................................................... 37

Mapping and Unmeasured Area Estimates ...................................... 38

Cost Estimates ……................................................................ 38

Discussion .............................................................................. 38

Strip Cruising ..................................................................................... 39

Statistical Estimates ………………………................................. 39

Mapping and Unmeasured Area Estimates .........................................4 41

Cost Estimates ……….............................................................. 41

Discussion ...................................................................... 41

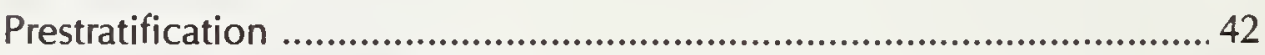

Stratified Double Sampling .................................................................4 43

Statistical Estimates .............................................................................. 43

Mapping and Unmeasured Area Estimates .......................................45

Cost Estimates .............................................................................4 45

Discussion ................................................................... 47

Use of Satellite Imagery ........................................................................ 48

Statistical Estimates …………………………………………........ 49

Mapping and Unmeasured Area Estimates .......................................52

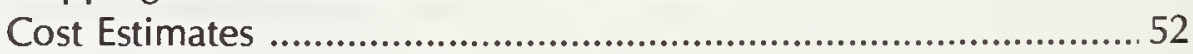

Discussion ........................................................................... 53

Inventories With Prior Stand Mapping …………………….......................... 53

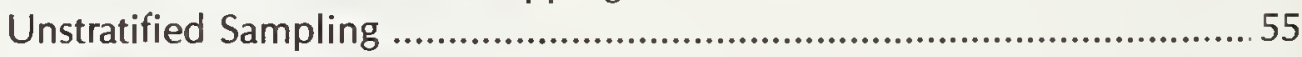

Equal Probability Sampling (e.p.s.) ………………………………........ 55

Statistical Estimates ……………………………………………... 55

Stand Estimates ............................................................................ 57

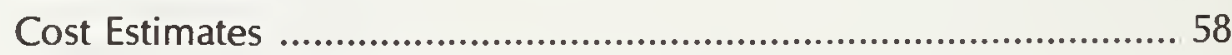

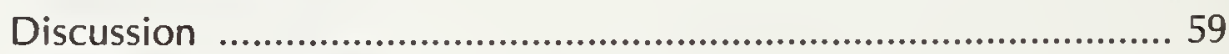

Probability Proportional to Size (p.p.s.) Sampling ………….................. 59

Statistical Estimates ........................................................................... 60

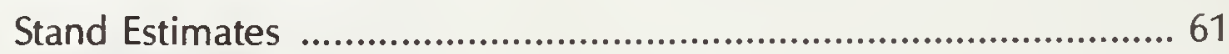

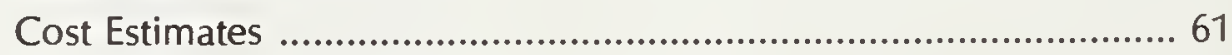

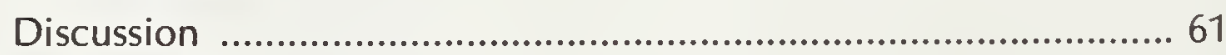

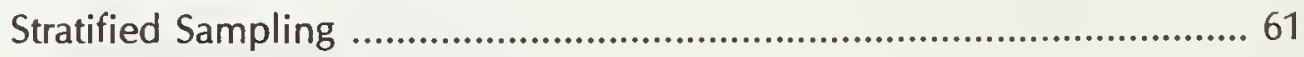

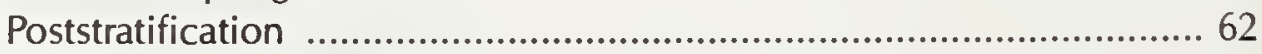

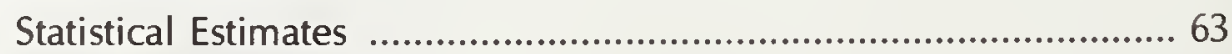

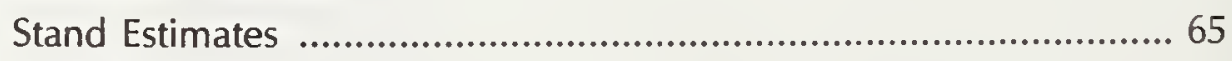

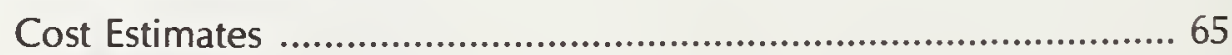

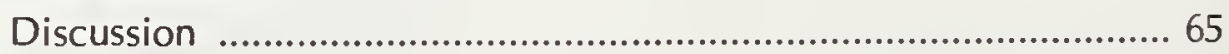

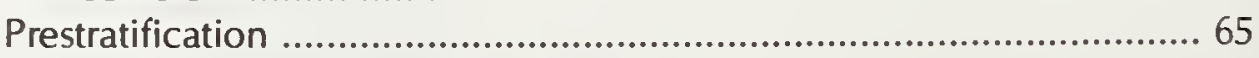

Equal Probability Sampling (e.p.s.) ...................................................... 66 


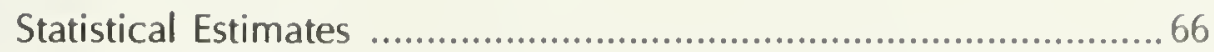

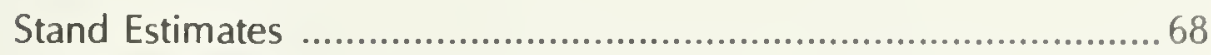

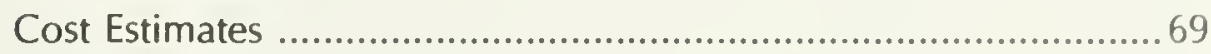

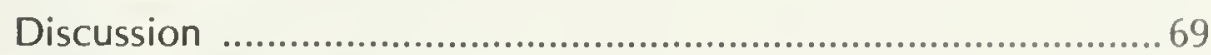

Probability Proportional to Size (p.p.s.) Sampling .......................... 70

Statistical Estimates ............................................................. 70

Stand Estimates .................................................................. 72

Cost Estimates .................................................................... 72

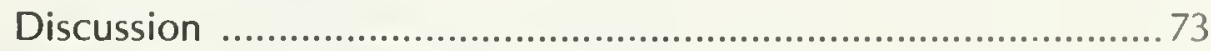

Inventories Using Existing Stand Information ...................................... 73

Use of the Stand as a Sampling Unit ............................................... 74

Combining Inventories ................................................................ 74

Statistical Estimates ................................................................... 75

Stand Estimates ........................................................................ 78

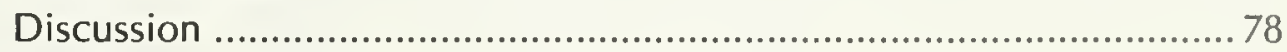

Complete Enumeration ..................................................................... 78

Statistical Estimates ..................................................................... 79

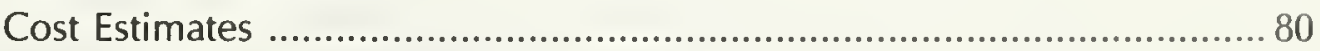

Summary of Forest Inventories ...................................................... 80

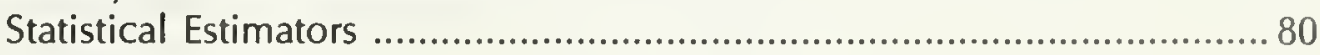

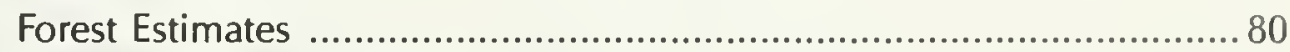

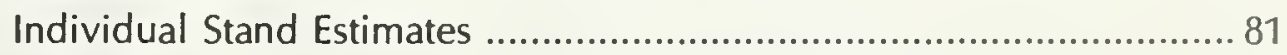

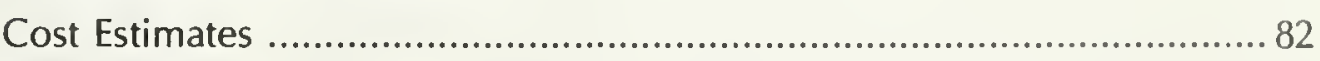

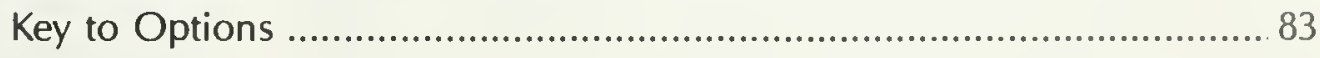

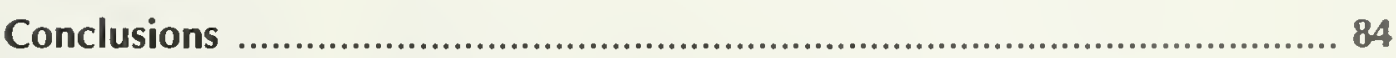

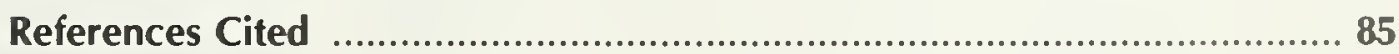

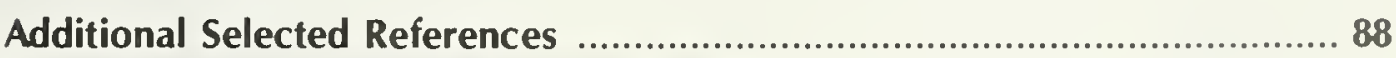

Mapping, Classification, Remote Sensing .............................................. 88

Statistics and Sampling ................................................................ 88

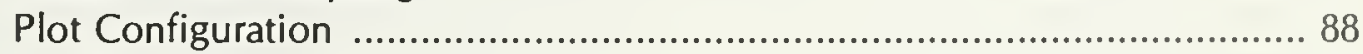

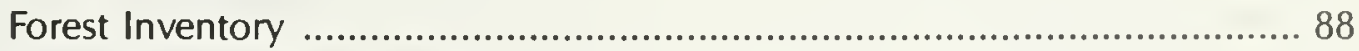

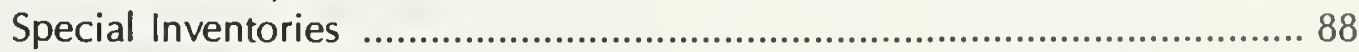

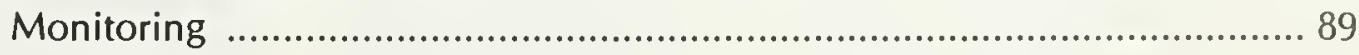

Appendix 1: Equations and Formulas Used in Text ................................... 90

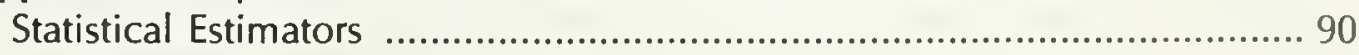

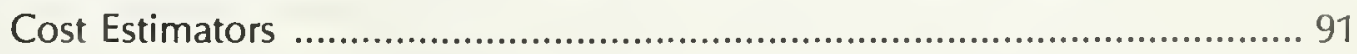

Appendix 2: Stand Characteristics of the Enchanted Forest ........................ 93

Appendix 3: Stand Estimates by Various Inventory Designs ....................... 95 
Land managers need to know the location, the extent, quantity, and condition of the natural resources that they manage and how those resources are changing over time. Stand inventories provide this kind of information for areas generally 100 acres or less as a prelude to treatment. Forest inventories provide similar information over large areas for resource planning purposes.

A recent analysis of inventory expenditures in the USDA Forest Service National Forest System (Lund 1987) showed that up to 76 percent of the total costs of doing an inventory may be spent in data collection. Such costs are a function of the inventory design. Today's resource managers need statistically valid, cost-effective, and defensible inventories (Laux et al. 1984).

Stand and forest inventories consist of at least three phases: mapping, sampling, and analysis. Mapping alone cannot provide the information usually required by the decision maker. Sampling in the field is also needed.

Mapping shows the locations of the resources and their extent and may be done before sampling, during the course of sampling, or after sampling. Sampling is used to obtain detailed data about part of the inventory unit. Analysis implies the calculation of estimates of certain parameters, variance, and confidence intervals. Analysis of the data is also used to make decisions regarding the management of the inventory unit.

There are many excellent references available covering forest inventories. The material in Avery and Burkhart (1983), in Section 7 of the Society of American Foresters' Forestry Handbook (Wenger 1984), and in De Vries (1986) are among the most recent and the best. In addition, a recent contribution to computer simulation of inventory design may yield useful insights into application of various designs for given forest conditions (Arvenitis and Reich 1988). This report concentrates on commonly used and available options for doing stand and forest inventories. The major portion of the report is devoted to examining the more common sampling designs available to the Federal land management agencies and their costs.

The objective of this report is to provide resource managers and beginning inventory designers with an understanding of the range of options available and the costs to:

- Sample within mapped entities.

- Use mapped polygons as sampling units.
- Generate maps and inventory statistics from sample data.

Sampling within individual mapped stands and among mapped stands, and sampling and creating spatial information where no stand maps exist are discussed.

Example inventories of a mythical Enchanted Forest using many of the designs in use by the Forest Service are presented. Detailed illustrations and step-by-step instructions for each design are given to help beginning inventory specialists understand how the designs are implemented and how the statistical estimators are generated.

English units of measure are used in this text unless otherwise specified. Metric conversions are as follows:

1 inch $=25.4$ millimeters $(\mathrm{mm})$.
1 inch $=0.0254$ meter $(\mathrm{m})$.
1 foot $=0.3048$ meter $(\mathrm{m})$.
1 mile $=1.6093$ kilometers $(\mathrm{km})$.
1 acre $=0.4047$ hectare $(\mathrm{ha})$.

100 cubic feet $(1 \mathrm{ccf})=2.83$ cubic meters $\left(\mathrm{m}^{3}\right)$.

100 cubic feet per acre $(1 \mathrm{ccf} / \mathrm{acre})=7.00$ cubic meters per hectare.

This report incorporates much recent literature and summarizes many of the techniques being used by the USDA Forest Service National Forest System (NFS) Regions and by Research Forest Inventory and Analysis (FIA) Units (fig. 1). The proceedings from the In-place Resource Inventories Workshop (Brann, House, and Lund 1982), and the Forest Land Inventory Workshop (Lund 1984) were the principal documents reviewed. Even though timber situations are discussed and illustrated, the options presented are equally useful for the inventory of other vegetative resources such as wildlife habitat or range production.

\section{Definitions}

The following definitions will be helpful in using this report:

Accuracy: The closeness of a set of observations to the quantity intended to be observed (Kendall and Buckland 1971). The degree of accuracy is calculated by statistical inference.

Allowable error: Also called the allowable sampling error or tolerance specification. The largest acceptable size of the standard error of the estimate usually specified before a sample is drawn to determine sample size. 


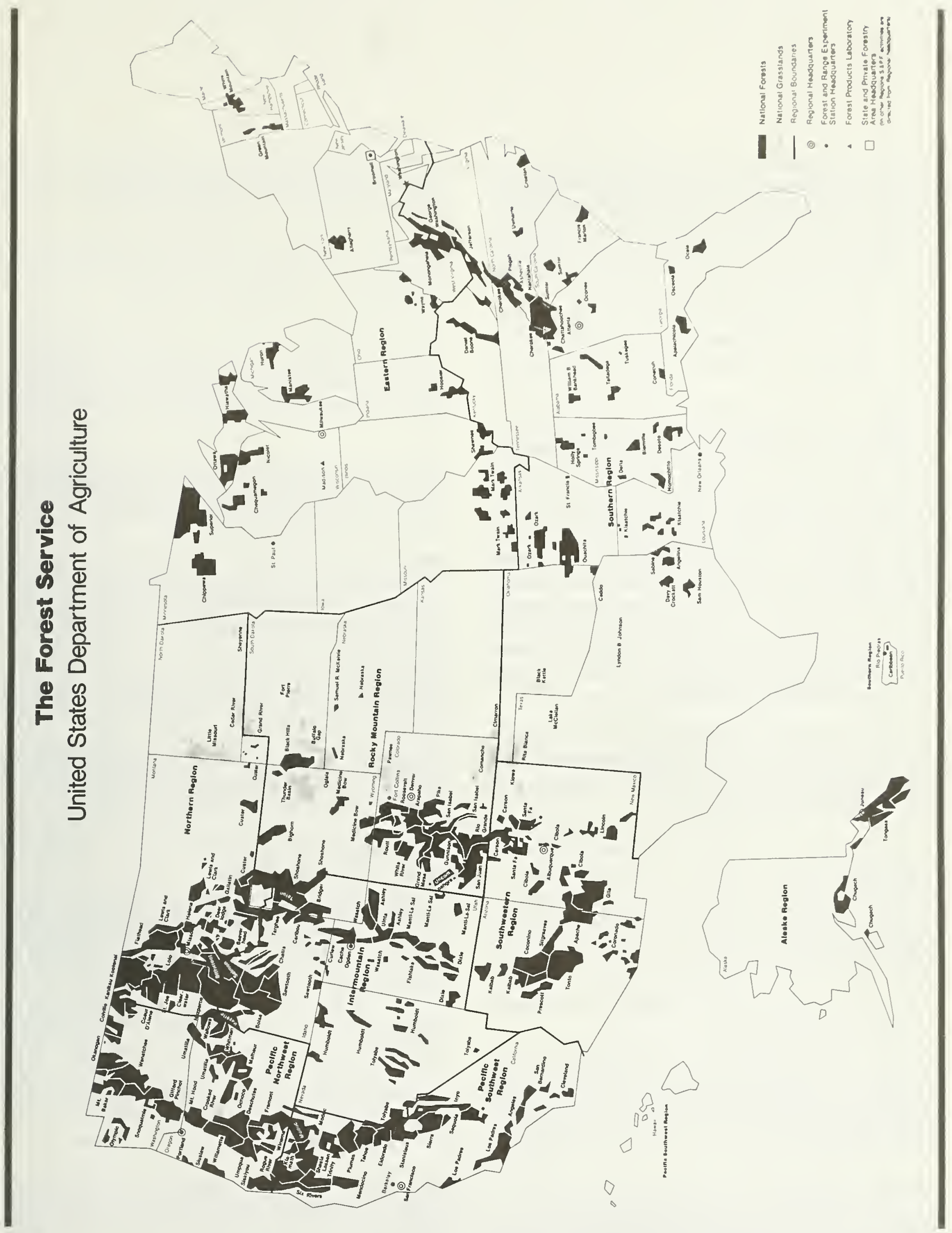

Figure 1-Field units of the USDA Forest Service. 
Attributes (properties): The differentiating characteristics that must be discovered, measured, described, delineated, or derived to fulfill the objectives of the inventory (Valentine 1984). Species, height, and diameter are examples of tree attributes that are usually measured or observed. Volume per acre, basal area per acre, forest type, and stand size are stand attributes that are usually derived.

Bias: A systematic difference between a statistical result and a parameter that is being estimated. (Kendall and Buckland 1971).

Classification: The process of describing categories for mapped or sampled objects (such as species, organisms, stands, sites, landforms, pedons, structures, or geographical units). The categories may be based on natural affinities of the objects for one another with respect to characters of interest, such as potentials, productivities, or inherent qualities or structures. Often the inherent quality or discrete structure of an object describes the category. The grouping of stands into forest types or trees into size classes is an example of a classification based on continuous quantitative characters. These two types of classifications are not strictly the same, and care must be taken in constructing the classes in the latter case.

Cluster: A sampling unit comprising two or more elements or subunits (Canadian Forest Inventory Committee 1978). The subunits are observed as part of the single primary sampling unit (Scott 1982).

Coefficient of variation: The ratio of the standard deviation to the mean.

Confidence interval: The range of values within which one might expect to find the parameter with some degree of assurance.

Cost effective: Achieving specified objectives under given conditions for the least cost.

Delineators: Attributes used to locate or define an inventory unit or a stand's boundary on a map or aerial photo, usually based on vegetative changes or topographic features (Mehl 1984).

Double sampling: See multistage sampling.

Estimate: The particular value yielded by an estimator in a given set of circumstances (Kendall and Buckland 1971).
Estimator: The rule or method of estimating a constant of a parent population. It is generally expressed as a function of sample values (Kendall and Buckland 1971).

Extrapolate: To estimate the value of a variable or descriptor outside its tabulated or observed range. To infer an unknown from something that is known.

Forest compartment: A basic territorial unit of a forest permanently defined for purposes of location, description, and record, and a basis for management (Ford-Robertson 1971). A compartment consists of a grouping of forest stands.

Forest inventory: A generally periodic survey covering all the forested land base used to support land and resource management planning and implementation.

Forest stand: A community of forest vegetation possessing sufficient uniformity in regard to composition, constitution, age, spatial arrangement, or condition, to be distinguishable from adjacent communities, so forming a management entity (Ford-Robertson 1971).

Identifier (label): A code, symbol, letter, or number that links a mapped delineation to a legend, text, or data base.

Integrated inventory: An inventory or group of inventories designed to meet multilocation, multidecision level, multiresource, or monitoring needs (Lund 1986a).

Interpolate: To insert, estimate, or find an intermediate term in a sequence or matrix.

Inventory: To account quantitatively for goods on hand or provide a descriptive list of articles giving, at a minimum, the quantity or quality of each, such as the number of trees in a stand or volume of timber within a forest.

Inventory (survey) unit: The land unit containing the population for which information will be summarized and analyzed. The unit may consist of any area of land such as grazing allotments; compartments; watersheds; 40-acre parcels; stands; National, State, or private forests; counties; States; or even nations.

Isoline: A line representing equality with respect to a given single variable-used to relate points on a map such as elevation contours, precipitation amounts, and temperature regimes. 
Mapped stand (site delineation): An area delineated on a map or imagery containing at least one symbol (color, alpha, or numeric) and bounded by a continuous line (Valentine 1984). The delineation represents an area of land possessing some degree of internal homogeneity of attributes with respect to characteristics defined by a particular system. The mapped stand is identified by a set of delineators and is described by a set of descriptors.

Mapping: The identification of selected features, the determination of their boundaries, and the delineation of those boundaries on a suitable base using predefined criteria (Shiflet and Snyder 1982).

Measuring: Ascertaining the extent, characteristics, dimension, or quantity of a population element such as the number of trees within a stand or compartment.

Monitoring: The process of observing and measuring over a period of time to detect change or to predict trends.

Multiphase sampling: A design in which some information collected from all of the units of a sample and additional and usually more detailed information is gathered from a subsample of the units constituting the original sample. Generally the sampling frame consists of a list of sampling units that remain the same size and at the same location in each phase of the sample. A sample that selects a 1-acre plot on an aerial photograph from a list of such plots and that also selects the same colocated, 1-acre field plot is an example of multiphase sampling.

Multistage sampling: A design in which the sampling frame consists of a list of sampling units (primary sampling units) that in turn are made up of smaller units (secondary sampling units) that in turn may again be made up of smaller sampling units (Nichols 1979). An inventory that selects stands from a forest or compartment, 1-acre plots within the sample stands, and 0.1-acre subplots within the sample plots is an example of a three-stage sampling design.

Parameter: A variable entering into the mathematical form of any distribution such that the possible values of the variable describe or yield different distributions.

Permanent plot: A sampling unit established and documented so as to permit repeated measurements of the same variables at the same exact places but at different times.
Pixel: Contraction for picture element. The smallest, most elementary areal unit considered by an investigator in digital image (also called a resolution cell). Pixels may be represented digitally by shades of gray, colors, or alphanumeric characters and are comparable to one of the many dots making up the picture on a television screen.

Plot configuration: The size and shape of the sampling unit (plot) and the spatial arrangement of subplots within that unit in the case of a cluster of plots.

Population: Any finite or infinite collection of individuals such as trees in a stand or stands within a forest (Cochran 1977). A sample frame must relate to its population.

Precision: A measure of the way in which repeated observations conform to themselves. In general the precision of an estimator varies with the square root of the number of observations upon which it is based (Kendall and Buckland 1971). It is a reflection of the sample size and the care taken and techniques used when measuring inventory attributes.

Primary sampling unit (psu): The sampling units chosen in the first stage of a multistage sampling design.

Probability limits (levels): Upper and lower limits assigned to an estimated value for the purpose of indicating the range within which the true value is supposed to lie according to some statement of probabilistic character (Kendall and Buckland 1971).

Probability (random) sampling: Any method of selection of a sample based on the theory of probability (degree of belief); at any stage of the operation of selection the probability of any set of units being selected must be known. It is the only general method known that can provide a measure of precision of the estimate (Kendall and Buckland 1971).

Resource inventory: The collection of data for description and analysis of the status, quantity, quality, or productivity of a resource. Such inventories usually include some descriptive data, numeric data, and at times, maps showing the extent of the inventory unit and location of sample units.

Sample plot: A sampling unit or element of known area and shape such as a one-acre circular plot (Canadian Forest Inventory Committee 1978). 
Sample size: The number of sampling units that are to be included in the sample. In the case of a multistage sample, this number refers to the number of units in the final stage of the sampling (Kendall and Buckland 1971).

Sampling: The act or process of selecting a subset from a population (a stand from all stands, or a plot from all possible plots) for estimating, analyzing, classifying, or characterizing.

Sampling (inventory) design: The specification of a configuration of sampling units and the method used to determine which sampling units will be measured, such as systematic sampling, stratified sampling, and multistage sampling.

Sampling error: That part of the difference between a population value and an estimate thereof, derived from a random sample, which is due to the fact that only a sample of values is observed. The totality of sample estimates in all possible samples of the same size generates the sampling distribution of the statistic which is being used to estimate the parent value (Kendall and Buckland 1971).

Sampling frame: (See also population). The complete aggregate or list of sampling units from which the samples will be drawn, such as all possible plots within a stand or a listing of all stands within a compartment or forest.

Sampling intensity: The number of sampling units established per unit area (e.g., 1 plot per 3,000 acres) or the percentage of the population sampled.

Sampling unit (plot): One of the units into which an aggregate is divided or regarded as divided for the purposes of sampling, each unit being regarded as individual and indivisible when the selection is made (Kendall and Buckland 1971). A specified part (such as a fixed-area plot, or mapped stand unit) of the inventory unit.

Sampling with replacement: The return of a sampling unit, drawn from a finite population, to that population after its characteristics have been recorded and before the next unit is drawn (Kendall and Buckland 1971).

Sampling without replacement: The failure to return a sampling unit, drawn from a finite population, to that population.
Secondary sampling unit: The sampling unit chosen during the second stage or step of a multistage sampling design.

Stand descriptors: Attributes that provide information about the stand but do not determine a stand's boundary (Mehl 1984).

Stand (silvicultural) examination (stand inventory): The collecting of data within a given stand to determine treatment needs or, if after treatment, to verify results.

Standard deviation: The measure of dispersion of a frequency distribution equal to the positive square root of the variance (Kendall and Buckland 1971).

Standard error: The positive square root of the variance of the sampling distribution of a statistic (Kendall and Buckland 1971).

Statistically valid design: A design that permits inferences based on logical analysis, the premises, and the data to a well defined population. An inventory design that provides samples that permit the calculation of estimates of population parameters and of their respective variances and standard errors.

Stratification: The division of an inventory unit into more homogeneous sub-units to improve the efficiency of the inventory.

Stratified sample: A sample selected from a population which has been divided into parts. Stratification is done by dividing the general population into homogeneous subpopulations so that more sampling effort can be put into heterogeneous strata or in strata of more interest than others, or to reduce the error by minimizing variation within. Stratification may be undertaken on a geographical basis by dividing the survey area into subareas on a map or through interpretation and classification of points from remote sensing imagery.

Stratum: Any division of the population for which a separate estimate is desired (Kendall and Buckland 1971). Plural of stratum is strata.

Systematic sample: A sample obtained by making observations at equally spaced intervals, such as taking a sample every 100 feet along a transect line. 
Timber cruise: A survey to estimate the quantity and value of timber on a given area according to species, size, quality, and possible products prior to the harvesting of the timber or before land is exchanged or acquired.

Update: A method used to make current inventory estimates by manipulation of the inventory data base through accounting procedures, projection models, or by adjustment of a base inventory by subsampled data.

Variance: The measure of dispersion of individual unit values about their mean (Freese 1962).

\section{Mapping}

Mapping is used to define and show: inventory unit and stand boundaries; location of resource; and the results of an inventory keyed to a legend or data base. Forest stands are usually mapped according to forest type, average size of trees (stand size), volume classes, and density of the overstory.

Maps and inventories are used to answer two questions: 1) where are stands having certain attributes located? and 2) what are the attributes at a given location? In the first case, the attributes sought are known, but the locations are unknown. In the second case, the locations are known, but attributes are unknown. Both situations are considered in this report.

Classification-Two classification approaches may be used to develop the maps to answer the questions (Valentine 1984). A unifying system such as Daubenmire's (1968) habitat types is useful for answering the first question. Most of the information is displayed on the map or in the legend. Such a system requires multiple categories and numerous classes. All classes have to be fully defined. The classification process is an integral part of the mapping program. Some information may be lost when generalized into broader classes.

Descriptive systems are often applied through multilayering of diverse maps and are better at answering the second question. A number of single-attribute classifications may be used to describe a piece of land.

In a descriptive system all information is attached to a polygon, pixel, or acre through an identifier or label. The identifier provides access to a data base. This system is simple, fast, and direct but is difficult to use to compare one area with another without rigorous analysis. Table 1 shows the kinds of timber-related data than can be stored
Table 1-Examples of stand data stored in a descriptive classification system (adapted from Mehl 1984)

\begin{tabular}{lll}
\hline Location attributes & Vegetation attributes & Other attributes \\
Stand number & Ecological type & Elevation \\
Region & Range type and & Aspect \\
State & condition & Slope percent \\
County & Forest type & Landform class \\
Administrative Forest & Percent crown cover & Mineral status \\
Proclaimed Forest & Stand structure & Soil series \\
Management area & Stand age & Rock, litter, duff \\
number & Average tree height & percent \\
Analysis area & Average tree d.b.h. & Fuel load \\
number & Basal area per acre & Dominant wildlife \\
Capability area & Number of trees per & species \\
number & acre & Recreation \\
Land use class & Net cubic foot & opportunity \\
Land cover class & volume & spectrum \\
Year of last inventory & Dominant shrub & Average annual \\
Source of inventory & species & precipitation \\
& Dominant grass & Site index \\
& species & Planned treatments
\end{tabular}

using a descriptive system. The mapping of such detailed information through a unifying system is difficult.

Maps should be constructed using uniform standards and conventions including: the specification of features to be displayed; minimum size of area to be delineated; and the handling of special situations such as stringers of vegetation along riparian zones, road rights-of-way, etc.

Remote Sensing-Mapping may be done in the field, from aerial photos or other types of imagery, or automatically by satellite reconnaissance systems. If done in the field, the inventory or collection of data within the typed polygons may be done at the same time as the delineation of boundaries. A stratified sampling system is often used to collect the field data, after using aerial photography or satellite reconnaissance imagery for land classification.

For forest management, map units are usually based on delineations of potential vegetation, current vegetation on phoiographs, or by aggregating pixels having common band characteristics. Inventory data inay be stored by these three kinds of mapping units. Table 2 presents advantages and disadvantages of each. The mapping of potential vegetation, such as habitat type, requires considerable field expertise and effort. Mapping of current vegetation, such as timber stand mapping, is usually done by interpreting aerial photography with some field checking. 
Table 2-Evaluation of possible common data collection and map storage units

\begin{tabular}{|c|c|c|}
\hline Common storage units & Strengths & Weaknesses \\
\hline $\begin{array}{l}\text { Ecological (habitat) type } \\
\text { map units (potential vege- } \\
\text { tation). }\end{array}$ & $\begin{array}{l}\text { Stable. Reflect long term opportunities, neutral units } \\
\text { for competing resources. Visible to land manager. } \\
\text { Allow variable sampling intensity. }\end{array}$ & $\begin{array}{l}\text { High skill level required for delineation. Criteria variables } \\
\text { may be subjective. Difficult to automate. Lack complete } \\
\text { coverage. Require strong inter-resource coordination. }\end{array}$ \\
\hline Existing vegetation. & $\begin{array}{l}\text { Widely used, well understood, large, flexible data base } \\
\text { system. Focus on primary resource for managment } \\
\text { activity. Easily recognizable on the ground. }\end{array}$ & $\begin{array}{l}\text { Criteria for delineation change geographically over time } \\
\text { depending on many variables. Excessive focus on com- } \\
\text { modity resources. }\end{array}$ \\
\hline Cells, pixels. & $\begin{array}{l}\text { Good sampling design possible by using groups of like } \\
\text { pixels. Spatial display. Minimal inter-resource coordi- } \\
\text { nation needed. Stable over time. Automated. }\end{array}$ & $\begin{array}{l}\text { Require geographical information system (GIS). Groups } \\
\text { of cells may not reflect resource pattern. Synthesis may } \\
\text { not be recognizable on-the-ground. Pixels provide } \\
\text { graphic displays of areas that have been digitized for } \\
\text { computer storage, which may include such mixed enti- } \\
\text { ties as stands and ecological types or any other defined } \\
\text { areas. }\end{array}$ \\
\hline
\end{tabular}

Generally, aerial photography at a scale of $1: 20,000$ or larger is suitable for the detection of most variables of interest for forestry purposes. These variables include stand size, tree heights, crown diameter, and number of trees. Measurements of these same variables from aerial photography generally requires imagery twice as large (i.e., 1:10,000 or larger) (Lund 1986a).

Cover type and overstory closure can be detected and measured from scales as small as 1:125,000. Satellite imagery has been used to measure these two items. Digital information, such as that from satellite reconnaissance, also maps the current situation.

Satellite imagery provides wall-to-wall coverage with resolution available down to pixel size ( 1.1 acres for Landsat). For large areas, however, coverage of a selected forest type region may require several satellite scenes. Pixels may overlap traditional stand boundaries and often must be grouped to give map displays similar to those obtained through photo interpretation. Satellite imagery and to some extent aerial photography may be interpreted automatically as well as visually.

Table 3 (adapted from Hoffer 1982) lists some considerations to determine if computer classification or visual interpretations should be used for mapping. Lachowski (1984) provides guidance on selecting the appropriate kind and scale of aerial photography to use. Regardless of the type of mapping performed, consideration should be given to entering the data into a geographic information system (GIS). Hanson (1979) provides guidance on preparation of maps for manual digitizing.
Table 3-Considerations in determining computer-assisted or manual mapping procedures

\begin{tabular}{ll}
\hline $\begin{array}{l}\text { Computer classification } \\
\text { tentially suitable if: }\end{array}$ & $\begin{array}{l}\text { Manual interpretation }{ }^{2} \text { or field ex- } \\
\text { amination probably more suitable if: }\end{array}$
\end{tabular}

Geographic area of interest is very large (state, country).

Geographic area is relatively small (town, county).

Informational categories of interest are spectrally separable.

Spectral characteristics of data are complex and difficult to characterize.

Spectral characteristics of data are relatively simple (spectral classes are reasonably homogeneous and relatively few in number).

Spatial relationships are not required to achieve identification.

Requirement for detailed spatial information exceeds capabilities of multispectral scanning systems, thereby indicating a need for geographical data and manual interpretation.

Required information is contained in spatial characteristics of the data (lineaments, circular features, etc.).

Convergence of evidence principle or correlation analysis is required to identify features of interest.

1 - Computer classification of multispectral scanner data, probably from spacecraft altitudes.

2 - Manual interpretation might involve aerial photography, multispectral scanner data (individual, combined wavelength bands, or enhanced), or radar data. 
Resource Inventories - Inventories can be conducted with and without stand mapping. Inventories without stand mapping are usually a prelude to further data collection and in the past were called Stage I inventories in the Forest Service. Follow-up inventories using stand mapping were called Stage II (USDA Forest Service 1962). Common data collection forms and reports were and still are used to tie the inventories together (Costello and Lund 1978).

Because stand boundaries change over time, the use of stands for sampling units has been avoided in the past. Grosenbaugh (1955) recommended that instead of stands, operating areas with meaningful permanent boundaries and convenient size should be established as the minimum unit for forest management records.

Changing technology, particularly in the form of geographic information systems (GIS), now allows inventory specialists to create maps based on sample data and to use stand maps more effectively for resource inventories. Over time, spatial data and descriptive data in a GIS can be updated for use in continuous management programs (Langley 1983). Because of this emerging technology, more and more Forest Service Regions are combining the sampling efficiencies of the Stage I inventory with the mapping of the Stage II inventories. Similarly, some FIA units are exploring ways of using their existing inventories to provide mapped information across the entire survey unit.

Various techniques are shown in this report to illustrate how sample data can be spatially extrapolated to the whole inventory unit.

\section{Field Data Collection}

Any inventory requires either a complete enumeration or a sample of the population of interest.

Enumeration-Complete enumeration requires visiting and observing all individuals or data items in a population, such as measuring each and every tree in a stand or all stands within a compartment or forest.

Complete enumeration of trees within a stand is generally restricted to areas of very high value. Complete enumeration of stands within a compartment or a forest is common in areas that have been under intensive management for quite some time such as the Southern (Belcher 1984) and Eastern Regions (Johnson 1984). In these two cases, even though all stands are visited, sampling within the stands is used to obtain estimates.
Questions to be asked when considering complete enumeration include (Cunia 1982); (1) is the real objective of the survey such that it would require the examination of each individual of the population? (2) must the results of the survey be presented separately for each individual of the population or is their presentation as averages or totals sufficiently satisfactory? (3) will complete enumeration provide unbiased results or will there be falloff due to measurement errors and lower quality of work that may occur when large numbers of individuals have to be measured?

Complete enumeration is costly and time consuming. It is used only when a small population is involved or when the population has a very high value. Surprisingly, the results from a sample may be more accurate than the results from complete enumeration. Measurements of many characteristics may not be error-free and the collection of data on a large number of objects may be subject to measurement errors.

Because complete enumeration requires considerable time, different people may have to be used, some of who may have less training or dedication than others. One person having to make the same measurements over and over again tends to become negligent in quality control. Units may be missed and measurements made haphazardly. The errors tend to accumulate. Because fewer observations are required in sampling, quality control is easier to maintain and the measurement errors decrease (Cunia 1982).

Sampling-When one cannot afford a census of a population, a subset of the population is sampled (some of the trees in a stand, some plots within a stand, or some of the stands in a compartment or forest are measured). The sampling units (trees, plots, or stands) are measured for the characteristics of interest and the resulting measurements are analyzed. The conclusions drawn are representative of and applicable to the entire population and are based on inferential logic.

Sampling may take on one of the two forms: subjective sampling or probability sampling. Subjective sampling is also referred to as purposive, nonprobability, or judgement sampling. 
Subjective sampling may be accomplished with or without preconceived bias (Mueller-Dombois and Ellenberg 1974). Preconceived bias indicates the investigator consciously avoids certain nonconformities or deviations in vegetation cover. The Southern Region (Belcher 1984) selects sample plots that appear to have average stand conditions.

"Without preconceived bias" indicates that the investigator measures stand conditions that attempt to include the extremes of the population of interest. Foresters have employed this technique as a sort of stratification. It is often used to construct tree volume tables to ensure a wide range of diameter classes are measured. In a forest inventory, stands representing the extreme conditions are visited rather than areas representing average condition of the compartment or forest. Norton et al. (1982) used this technique to inventory riparian vegetation.

Subjective sampling is justified when (Cunia 1982):

- The variation between the elements of a population is very large and the sampling is extremely expensive.

- The needs for information about some population of interest are immediate and decisions are not sensitive to biases in estimates.

- The available funds to do a complete enumeration or statistical sample are very low.

- The subjective sample is to be used for planning a statistical sample.

- Estimates of precision are not needed.

- The results are not likely to be contested in a court of law.

Subjective samples should be limited to a single purpose and for a short term.

For resource inventories serving multiple decisions over long periods of time, statistically valid samples are required. Therefore, probability sampling is preferred for most inventories. The reliability of the sample estimators can be calculated and expressed in probability terms when statistical sampling is used, whereas the reliability of subjective sampling cannot be determined.
It will often be useful to distinguish two levels of numerical estimates from sample surveys, those used in computation and final reported values. Computations often carry many additional digits reflecting the accuracy of the computer procedures used to obtain the estimates. Final reported figures tabulate the estimate, rounded to a reasonable number of digits, which should be based on the accuracy of the sampled data. A secondary consideration is that the reported figures should have a consistent number of decimal places and/or be nearly additive. In this report we often carry additional computational digits in the text. Figures reported in the tables are rounded to two or three decimal places or truncated to the last whole number. Rounding will follow the rule that the digit prior to the level of rounding is considered the last reliable digit. Ignore succeeding digits and round up if the rounding digit is greater than 5; round down if it is less than 5. If the rounding digit is exactly 5 , round to the nearest even digit; thus $2.25=2.2$, and $2.15=2.2$.

Statistically valid data can often be used for purposes other than those originally intended and at different points in time. Even if resource management objectives change, statistically valid inventories retain much of their value. This is usually not the case with subjective inventories.

The basic assumptions for probability sampling are that the sampling procedure has been clearly defined in simple terms and if repeatedly applied to the same population, the following conditions are satisfied (Cunia 1982): (1) the set of all possible samples that may arise, as well as the particular individuals that enter in each of these samples, are known or can be known; (2) the population of individuals is completely covered by this set of samples, that is, each individual of the population must belong to at least one of these samples; (3) each sample in this set has a probability of occurrence that is known and nonzero; and (4) unique estimates of the population parameters of interest can be calculated from the data of each sample.

Note that it is not usually necessary to explicitly write down the set of all possible samples and the associated set of probabilities; it may suffice to know that it can theoretically be done.

In the sampling process, data are collected from a sample of the population and the results expanded to the inventory unit. The sampling process may vary from visiting all trees in the inventory unit and making measurements on a few to visiting only a portion of the inventory unit, establishing sample plots, and measuring some of the trees on those plots. 
In 3P sampling (i.e., sampling with probability proportional to a predicted value), all trees in a stand are visited and only that portion is measured that is selected with probability proportional to predicted volumes. Wiant (1976) gives an excellent discussion of the use of 3P sampling.

Sample tree selection methods include the use of such devices as colored or numbered marbles, dice, or random number tables. When visiting every individual in a population is not desirable, data are collected from sample plots.

Plot Configuration-Sizes and shapes of field plots are commonly determined on the basis of custom, tradition, and experience. The most efficient configuration is one which has the smallest size in relation to the variability produced (Avery 1975). Simple plots having a fixed size are usually rectangular or circular in shape. Rectangular or strip plots are often oriented to cross maximum variation, to reduce between plot variance, and to increase within plot variation.

Myers and Shelton (1980) consider practicality in locating plot boundaries and taking measurements, edge bias, and the balance of effort between measuring a few large plots or many small plots as the primary considerations for choosing a plot design. Fixed-area plots are particularly useful for measuring change.

Combined plots (a grouping of subplots) are often used for sampling different types of vegetation in the same inventory. For example, a $1 / 10$-acre plot may be used to tally sawtimber trees and a 1/300-acre plot established at the same plot center may be used to count seedlings. These two plots are often described as nested, concentric, or collocated.

A variable radius (Bitterlich or point sample) is commonly used in timber inventories. This is an example of a combined plot composed of nested circular plots with the plot radius of each being a constant multiple of tree diameter (Bitterlich 1959).

A cluster of plots is also a form of a combined plot in which the area of the sampling unit is spread out in some fixed geometric pattern around an initial plot reference point. The 10-point cluster commonly used in the USDA Forest Service is an example.
Strip transects (a series of long, narrow rectangular plots placed end to end), are also examples of combined plots common in vegetation inventories. Strips are more likely to sample variation in nonuniform vegetation. The disadvantage of strip transects is the large amount of edge in relation to area, which introduces a strong possibility of edge bias (Myers and Shelton 1980).

Line plot sampling (Loetch and Haller 1964) may also be considered a form of combined plots. A line transect defines a common centerline where sample plots are spaced at regular intervals along the line.

In general, when using combined plots, the subcomponents must be placed in the same geometric relationship to one another each time a plot is established. In addition, because the combined plot is an integral unit, the subplots are combined, rather than treated separately, to produce a composite plot estimate (Myers and Shelton 1980).

Francis (1978), Morris (1982), Scott (1982), and Conant et al. (1983) provide good reviews of various plot configurations in use for inventories of the vegetative resources.

Subsampling should be used to observe time consuming attributes such as number of logs per tree, tree quality, age, and defect. Some plots should be monumented and remeasured for monitoring and modeling (Scott 1984). For future use or for monitoring, plot coordinates should be determined and stored in a data base. Plot configuration, subsampling, and monumenting are important but are not discussed further in this report.

Sample Size-The question of sample size must be considered. At least two sample units per inventory unit (stand, compartment, or forest) are required if one wants to compute the reliability of the inventory. The need for additional plots varies with the objective. Traditionally 10 to 20 plots are established within a stand or 10 percent of a compartment or forest is inventoried. Ten to 20 plots per stand may be excessive if no immediate treatments are planned or if all that is needed is an estimate of what is in a particular area (Ek, Rose, and Gregerson 1984). 
Freese (1962), Hamilton (1979), and LaBau (1981) provide excellent discussions of determining sample size. Factors to consider include the consequences of errors in inventory estimates and the inventory costs. The resource manager should define and quantify the consequences of errors in the estimates. The inventory specialist should calculate the costs and determine the estimate of optimal precision.

Costs

The costs and methods of calculation presented in this report are given principally to illustrate the examples, but also to show the relative expenses of conducting invento- vies by various methods. They are typical of those incurred by the USDA Forest Service Regions (Lond 1987).

The cost estimates include, where applicable, purchase of imagery, interpretation and mapping, and establishing and measuring field plots. These vary by design and size of the inventory unit. Additional expenses one needs to consider when developing an inventory are planning costs, overhead costs, costs of purchasing and maintaining equipmont, per diem, data entry, editing, processing, data base, inventory documentation, and maintenance and storage. These may also vary by the design of the inventory and size of the inventory unit.

16 
Inventories are often required of the smallest management unit a landowner has. These units may be stands, pastures, woodlots or parcels and could be termed mapped polygons in a geographic information system (GIS). Inventories within these mapped polygons are needed to determine what, how, and when specific treatments are to be made (Lund 1985). The treatments may be timber harvest, pasture improvement, precommercial thinning, etc.

The mapped polygon may also have been selected as part of a broader, more extensive inventory, such as the inventory of a compartment or a forest.

For the following discussions of collecting data within polygons or stands, assume: mapping is up to date and correct; that either complete enumeration or sampling is required; and if statistical sampling is used, at least two sample units will be observed. Remember, however, that serious objections can be raised concerning these assumptions and that they need to be addressed in some organized and orderly fashion for each inventory and not merely dismissed out of hand. Results for the examples are summarized to illustrate the advantages and disadvantages of the various options and to demonstrate how different techniques can yield different estimates of the same population.

This section describes methods of locating sample plots within a polygon using stand number 97 of the Enchanted Forest as an example (fig. 2). Options range from subjective sampling to statistical sampling to complete enumeration. Each option is discussed through the use of examples and simulated plot data to determine volume in hundreds of cubic feet (ccf). Many of the other attributes listed in table 1 could be obtained by the sampling options presented here. A summary of techniques is presented.

Statistical estimators for the various methods of sampling stand 97 are given for each option where (Freese 1962):

$A=$ The total area of the inventory unit in acres.

$\mathrm{a}=$ The area of a sampling unit or a plot in acres.

$\mathrm{n}=$ The number of sampling units or plots established.

$y_{i}=$ The value for item of interest, such as volume per acre (ccf), observed or observed at each plot location.

$N=$ The total number of possible sampling units in the entire population where:

$N=A / a$ $\bar{y}=$ The estimated mean value of interest such as volume per acre (ccf) where:

$\bar{y}=\left(\Sigma y_{i}\right) / n$

$s_{y}{ }^{2}=$ The estimate variance of individual values of $y$ where:

$s_{y}{ }^{2}=\left\{\Sigma y_{i}{ }^{2}-\left(\Sigma y_{i}\right)^{2} / n\right\} /(n-1)$

$s_{y}=$ The estimated standard deviation of $y$ where:

$$
s_{y}=\left(s_{y}{ }^{2}\right)^{1 / 2}
$$

$\mathrm{s}_{\bar{y}}=$ The estimated standard error of the mean for a simple random sample. For sampling without replacement $\left({ }^{*}\right)$ :

$\mathrm{s}_{\overline{\mathrm{y}}}{ }^{*}=\left\{\left(\mathrm{s}_{\mathrm{y}}{ }^{2} / \mathrm{n}\right) *[1-(\mathrm{n} / \mathrm{N})]\right\}^{1 / 2}$

or for where sampling is with replacement:

$s_{\bar{y}}=\left(s_{y}{ }^{2} / n\right)^{1 / 2}$

The expression $[1-(n / N)]$ in equation (5) is the finite population correction or f.p.c. If $(n / N)$ is less than 0.05 , it is commonly ignored and equation (6) is used (Freese 1962).

$\mathrm{s}_{\mathrm{e}}=$ The estimated sampling error of the mean value such as mean volume per acre (ccf) where:

$s_{e}=s_{\bar{y}} / \bar{Y}$

$\% \mathrm{~s}_{\mathrm{e}}=$ The estimated sampling error of the mean value (such as mean ccf volume per acre) expressed as a percent where:

$\% \mathrm{~s}_{\mathrm{e}}=\left(\mathrm{s}_{\mathrm{e}}\right) * 100$

$\hat{Y}=$ The estimated total value (such as total ccf volume) in the population where:

$\hat{\mathrm{Y}}=\overline{\mathrm{y}} * \mathrm{~A}$

Cost estimators are determined as follows. It is assumed that the inventory unit (the stand) is already mapped. Therefore the cost of acquisition of remote sensing, interpretation and mapping is not included. Only field costs are considered. Stand 97, consisting of 75 acres, is the inventory unit.

Field costs are a function of: the size of the crew (C): the hourly wage $(W)$ per person; the time per crew to measure 
each sampling unit $(M)$, the number of sampling units to be measured ( $n)$; travel time between sampling units (L), and the daily travel time to and from the inventory unit (D). To compute cost estimates, the following assumptions are made:

Size of crew $(C)=1$ person for subjective samples; 2 persons for statistical samples and complete enumeration.

Hourly wage $(W)=\$ 9.00$ per person.

Plot measurement time $(M)$ in hours $=0.167$ hour for subjective samples; 0.5 hour for statistical samples; and 1 hour for complete enumeration.

Number of sampling units $(n)=$ varies with design.
Time (in hours) traveling between sampling units (L) varies with distance or interval between plots (I) or (i) and number of sampling units $(\mathrm{N})$. It is assumed that a crew travels at a speed of 10,560 feet per hour through the woods. For statistical sampling:

$$
L=[(n-1) i] / 10,560
$$

where $\mathrm{i}=$ interval in feet between sample plots or points. Daily travel time to and from the inventory unit in hours (D) must be added to the between plot travel for each crew. For simplicity it is assumed that for each 8 hours spent within the inventory unit, 1 hour is spent in total travel time to and from the inventory unit.

Thus $\mathrm{D}=[\mathrm{L}+\mathrm{n}(\mathrm{M})] / 8$

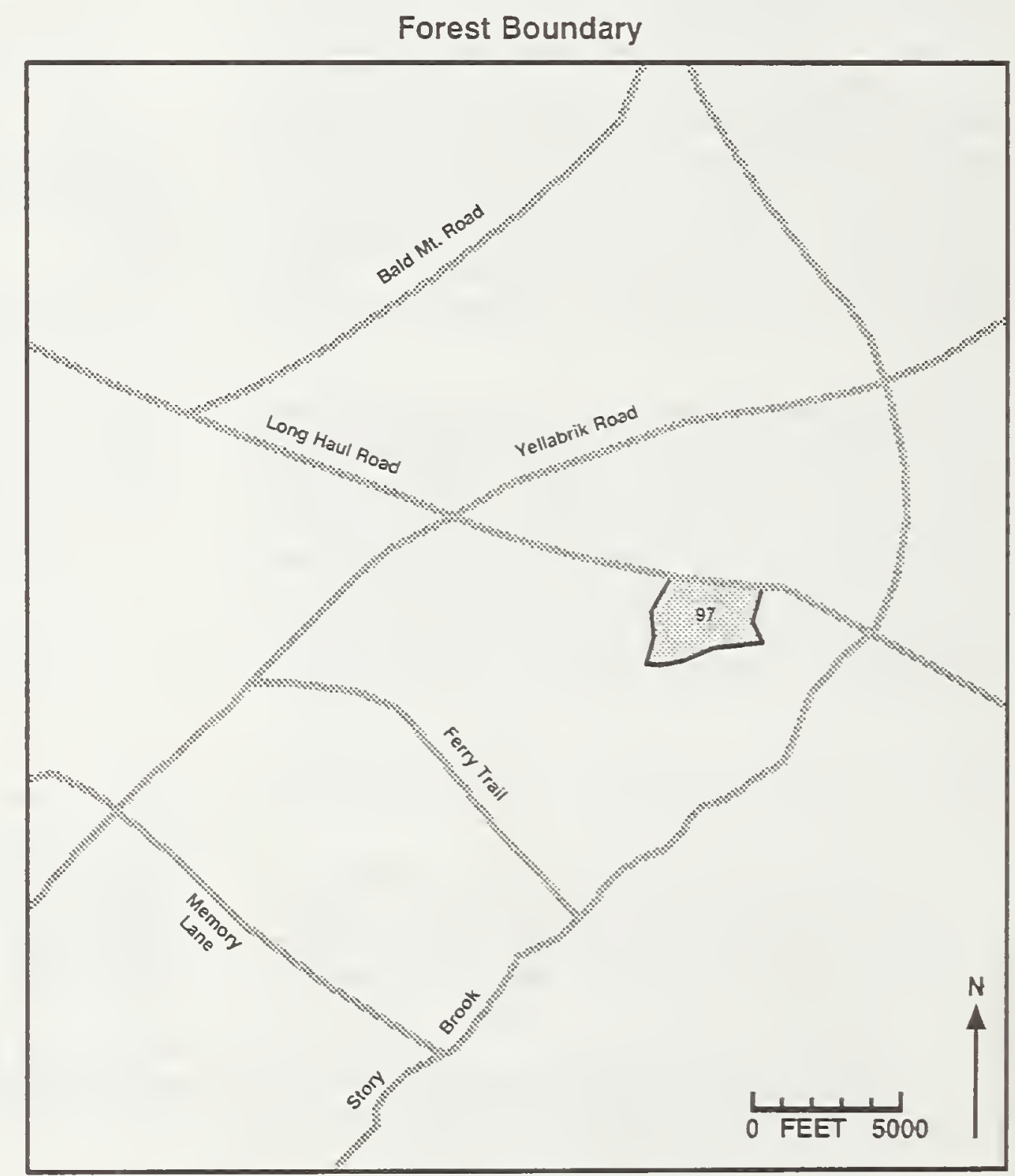

Figure 2-Location of stand number 97 (shaded) in the Enchanted forest. Total area of the stand is 75 acres. 
The general equation for field cost $(F)$ is

$$
\begin{aligned}
F= & C W\{[L+n(M)]+D\}= \\
& 1.25 * C W^{*}\left[L+n^{*}(M)\right]
\end{aligned}
$$

A listing of all equations and formulas used in this report is found in Appendix 1.

\section{Probability Sampling}

Probability sampling depends on some form of randomization of the location of observations to be made. In the simplest form equal probability is assigned to each potential plot location and one or more of these selected by some random process. A certain amount of care should be exercised so that selection is indeed equally probable for each location. Throwing a dart at the aerial photo or map might be an option, but it might tend to exclude plots at the edge of the map. Another selection process may be random initial plot choice by dropping a grid over the mapped stand and then using random numbers to select a coordinate or grid intersection.

Random processes for making selections in the field are also possible, but they must be rigorously enforced so that field personnel understand the importance of the randomization process and do not substitute their "feeling of representativeness" for the random process consciously or unconsciously. One possible method of making the selection in the field is to enter the stand at a point, choose a random azimuth and distance into the stand using a table of random numbers, and establish the initial plot at the distance and direction.

Random Distribution-In this example, an initial, 1-acre plot is randomly located within the stand. Additional 1-acre plot centers are located at fixed distances (614 feet) but at random directions from one another (fig. 3 ). If the random direction makes the next plot fall outside the stand, the azimuth is rotated back into the stand according to some previously established rule or another angle is randomly picked. Figure 3 suggests that this method may be slow to disperse over an entire area.

Statistical Estimates-This example provides a random sample for which the sampling formulae 2 to 9 are applicable. The results of an inventory of stand 97 using 10 randomly selected plots are as follows:

$\begin{array}{cc}\text { Plot } & \text { ccf per acre } \\ 1 & 17 \\ 2 & 15 \\ 3 & 15 \\ 4 & 16 \\ 5 & 15 \\ 6 & 25 \\ 7 & 24 \\ 8 & 16 \\ 9 & 17 \\ 10 & 16\end{array}$

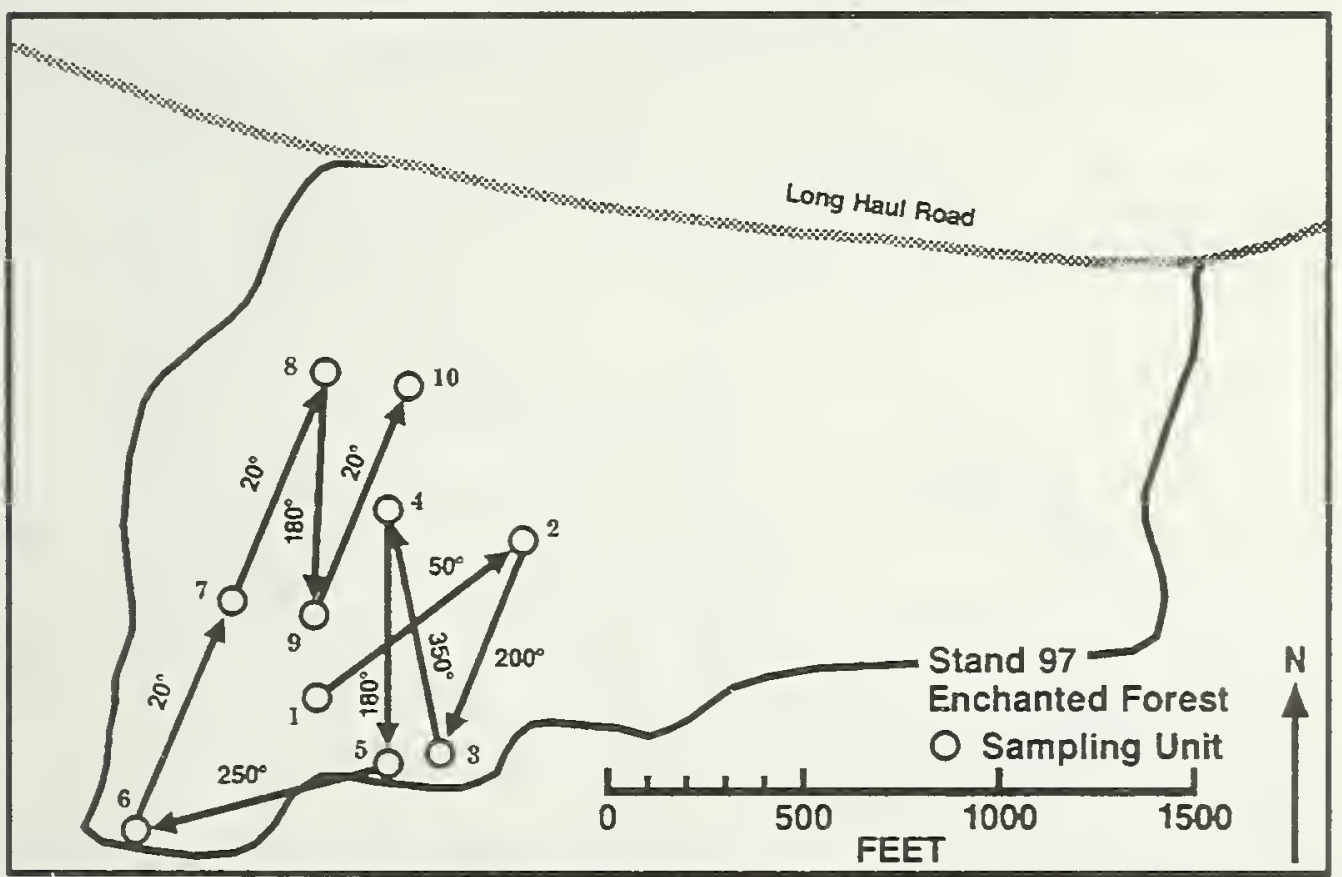

Figure 3-Location of sampling units using randomly selected azimuths and fixed distances (614 feet). 
$\bar{y}=(17+15+\ldots 16) / 10=17.6$ ccf per acre. $\begin{aligned} s_{y}{ }^{2}= & \left\{\left(17^{2}+15^{2}+\ldots 16^{2}\right)-(17+15+\ldots 16)^{2} /\right. \\ & 10\} /(10-1)=13.8222 .\end{aligned}$

$\mathrm{s}_{\bar{y}}=(13.822 / 10)^{1 / 2}=1.1757 \mathrm{ccf}$ per acre. The equation for sampling with replacement is appropriate as the same 1-acre plot may be chosen more than once.

$\% s_{e}=(1.757 / 17.6) * 100= \pm 6.68 \%$.

$\hat{Y}=17.6 * 75=1,320 \mathrm{ccf}$ for the stand.

Cost Estimates-Numbers of plots and intervals ( $\mathrm{n}=10$, $i=614$ feet) provide estimates of costs as before:

$$
\begin{aligned}
L= & {[(10-1) 614] / 10,560=0.523 \text { hour. } } \\
D= & {[0.523+10(0.5)] / 8=0.6904 \text { hour. } } \\
F= & 2(9)[0.523+10(0.5)+0.6904]=\$ 111.84 \text {, or } \\
& \$ 1.491 \text { per acre. }
\end{aligned}
$$

These results portray a useful estimate of the cost of inventorying the current stand and might be used to estimate sampling other stands in the forest.

Discussion-Variations in sample selection may include selecting random distances as well as directions. Because it is difficult to implement in the field, this technique is seldom used in stand or forest inventories.
Line Transect Distribution-Line transects can be laid out using any of the following rules:

- Run the line through a randomly selected direction and point.

- Run the line through a randomly selected point and along the contours.

- Run the line through a randomly selected point and across the contours.

- Run the line through a randomly selected point and along the longest axis of the stand (fig. 4).

A line is drawn through a randomly selected point on the aerial photograph or stand map and the length measured. The length is divided by the number of plots to be established. The result is the interval between plot centers. The randomly selected point is usually plot 1. Additional plots are established along the transect line at the calculated intervals on either side of plot 1 . Sampling is without replacement.

Figure 4 shows the distribution of one-acre plots established at random azimuth through plot 1 . The length of the transect line is 2,785 feet. Plots are established at 278 -foot intervals.

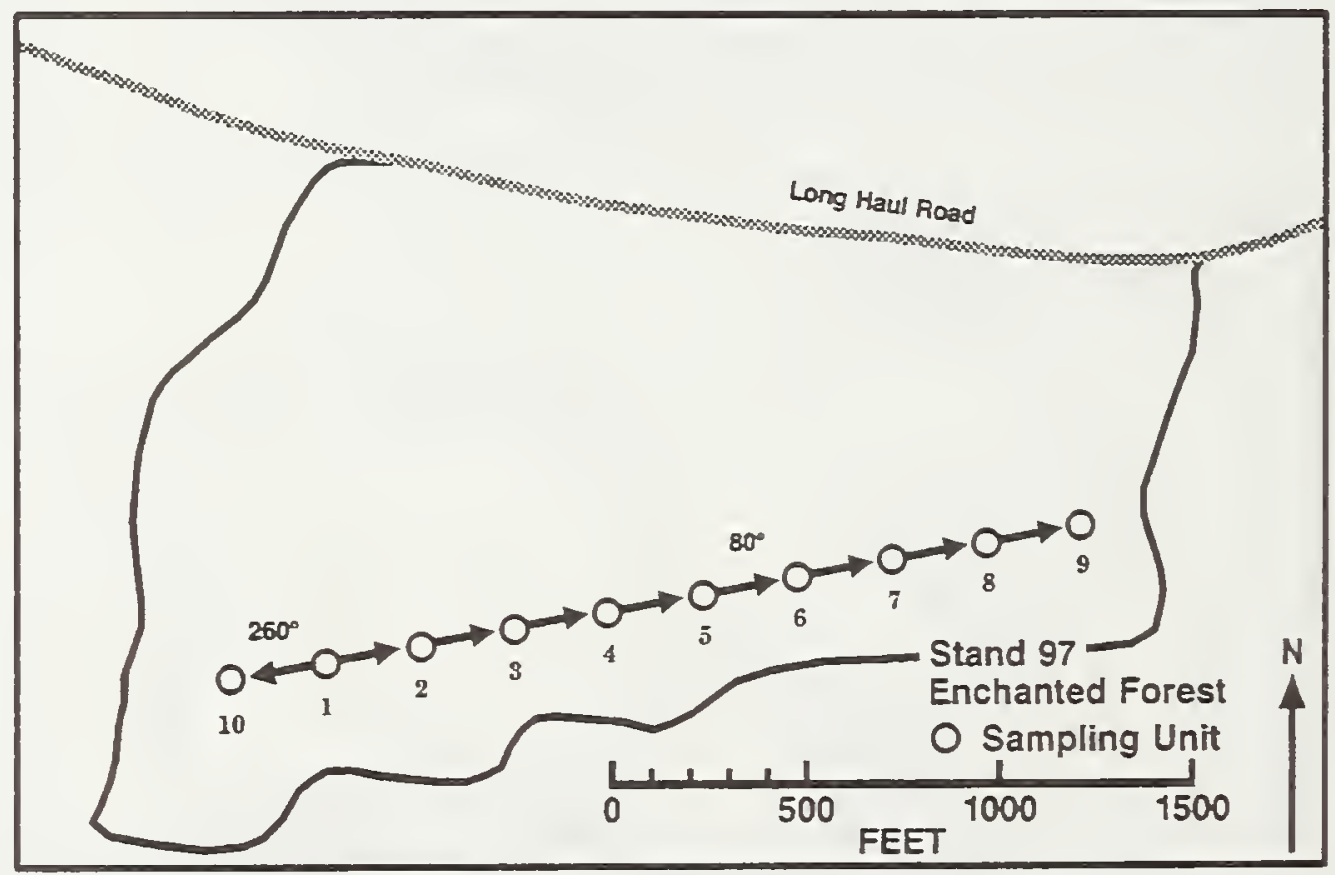

Figure 4-Location of sampling units along a randomly selected line transect. Plots are 278 feet apart. 
Statistical Estimates-The results of an inventory of stand 97 using a line transect are as follows:

$\begin{array}{cc}\text { Plot } & \text { ccf per acre } \\ 1 & 17 \\ 2 & 16 \\ 3 & 15 \\ 4 & 15 \\ 5 & 19 \\ 6 & 19 \\ 7 & 22 \\ 8 & 21 \\ 9 & 23 \\ 10 & 24\end{array}$

Equations 1 to 9 are applied to obtain the statistical estimates.

$$
\begin{aligned}
N= & 75 / 1=75 \text { possible } 1 \text {-acre plots. } \\
\bar{y}= & (7+16+\ldots 24) / 10=19.10 \mathrm{ccf} \text { per acre. } \\
\mathrm{s}_{y}{ }^{2}= & \left\{\left(17^{2}+16^{2}+\ldots 24^{2}\right)-(17+16+\ldots 24)^{2} /\right. \\
& 10\} /(10-1)=10.99 . \\
s_{\bar{y}}= & \{10.99 / 10 *[1-(10 / 75)]\}^{1 / 2}=0.9759 \mathrm{ccf} \text { per } \\
& \text { acre. } \\
\% \mathrm{~s}_{\mathrm{e}}= & (0.9759 / 19.10) * 100= \pm 5.11 \% . \\
\hat{\mathrm{Y}}= & 19.1 * 75=1,432.5 \mathrm{ccf} \text { for the stand. }
\end{aligned}
$$

Cost Estimates-Applying equations a through $\mathbf{c}$ and using $\mathrm{n}=10, \mathrm{i}=278$ feet.

$$
\begin{aligned}
L= & {[(10-1) 278] / 10,560=0.237 \text { hour. } } \\
D= & {[0.237+10(0.5)] / 8=0.655 \text { hour. } } \\
F= & 2(9)[0.237+10(0.5)+0.655]=\$ 106.06 \text { or } \\
& \$ 1.414 \text { per acre. }
\end{aligned}
$$

Discussion-Both the U.S. Department of Interior Bureau of Land Management (Baker 1982) and the U.S. Department of Agriculture Soil Conservation Service (Steers and Hajek 1979) have employed this technique.

Ricochet Plot Location-The ricochet technique was developed in 1978 by the USDA Forest Service Resource Evaluation Techniques program and is a modification of the line transect. The length of the line transect varies within the size of the stand and the chosen direction, while with the ricochet method the length is fixed. The ricochet transect starts at a randomly selected point and is run in a cardinal direction until the line hits the stand boundary. At that point, the line is rotated back into the stand at 45-degree increments. Plot centers are established at fixed intervals along the line with the initial random point being plot 1 . The rules for establishment do not allow crossing a previous transect line unless there is no alternative. Sampling is considered to be without replacement.

Figure 5 shows the distribution of 10 1-acre plots laid out using the ricochet technique. Plots were established at 614-foot intervals; distribution of plots is improved over random azimuth or distance method.

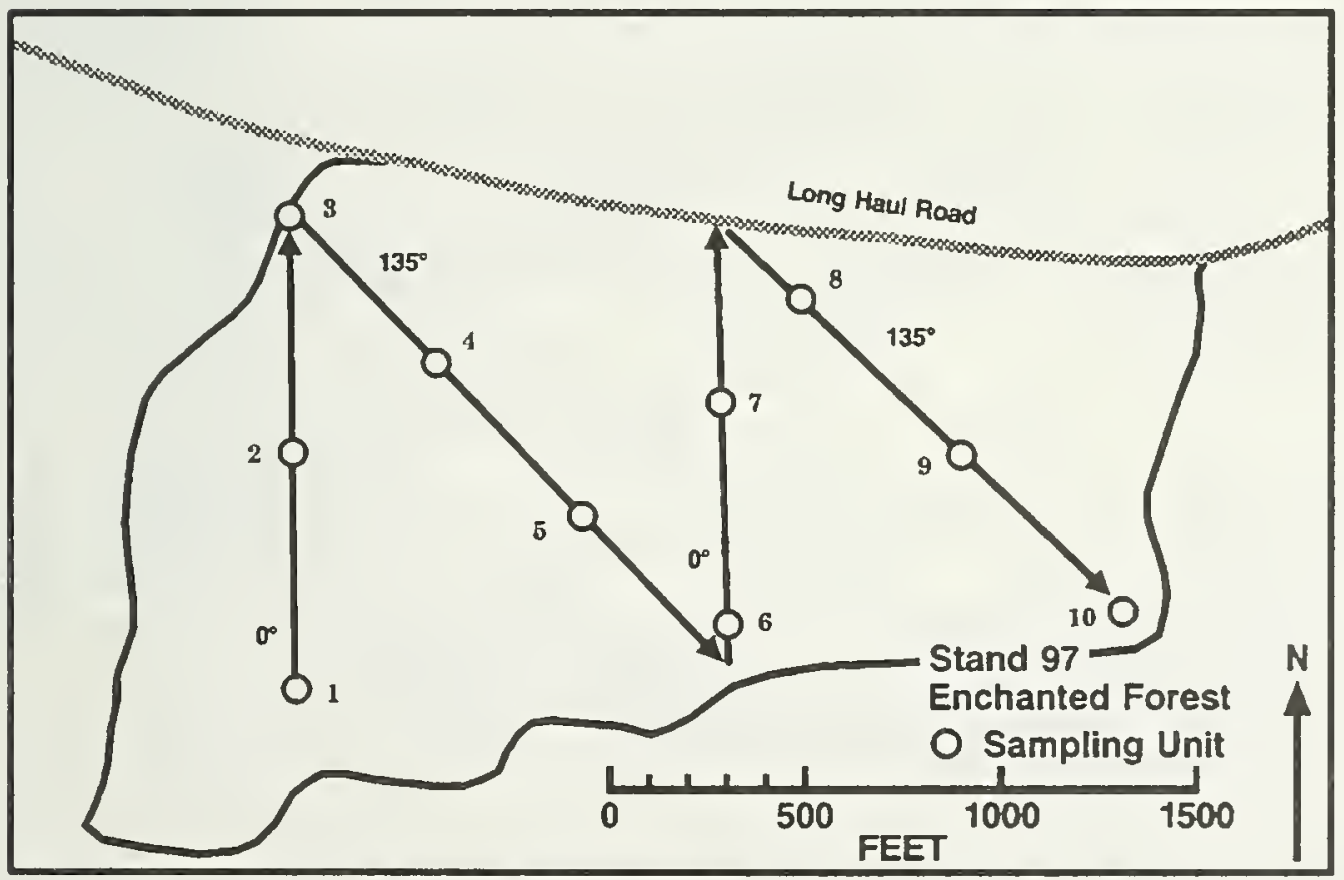

Figure 5-Location of sampling units within stand 97 using the ricochet method. Plots are located at distances of 614 feet. 
Statistical Estimates-The results of an inventory of stand 97 using the ricochet technique are as follows:

$\begin{array}{rr}\text { Plot } & \text { cf per } \\ 1 & 17 \\ 2 & 16 \\ 3 & 21 \\ 4 & 17 \\ 5 & 19 \\ 6 & 19 \\ 7 & 18 \\ 8 & 20 \\ 9 & 22 \\ 10 & 23\end{array}$

The sample design allows for all plots to be selected, hence, $N=75$.

$$
\begin{aligned}
\bar{y}= & (17+16+\ldots 23) / 10=19.20 \mathrm{ccf} \text { per acre. } \\
\mathrm{s}_{\mathrm{y}}{ }^{2}= & \left\{\left(17^{2}+16^{2}+\ldots 23^{2}\right)-(17+16+\ldots 23)^{2} /\right. \\
& 10\} /(10-1)=5.2889 . \\
\mathrm{s}_{\bar{y}}{ }^{*}= & \{(5.2889 / 10) *[1-(10 / 75)]\}^{1 / 2}=0.6770 \mathrm{ccf} \\
& \text { per acre. } \\
\% \mathrm{~s}_{\mathrm{e}}= & (0.6770 / 19.20) * 100= \pm 3.53 \% . \\
\hat{\mathrm{Y}}= & 19.2 * 75=1,440 \mathrm{ccf} \text { for the stand. }
\end{aligned}
$$

Cost Estimates-Finally estimates of the cost for the inventory are obtained from equations a through $\mathrm{c}$, for $\mathrm{n}=10$, $\mathrm{i}=614$ feet.

$$
\begin{aligned}
L= & {[(10-1) 614] / 10,560=0.523 \text { hour. } } \\
D= & {[0.523+10(0.5)] / 8=0.6904 \text { hour. } } \\
F= & 2(9)[0.523+10(0.5)+0.6904]=\$ 111.84 \text { or } \\
& \$ 1.491 \text { per acre. }
\end{aligned}
$$

Discussion-While this technique has not been employed, except for the initial development phase, it appears to have properties that might be preferred where it is important to measure edge or ecotone conditions as part of the stand inventory.

Systematic Distribution With a Random Start-Starting at a randomly selected point, plots are located at fixed directions and distances throughout the stand The distance between plot centers varies according to the size of the stand, the number of plots to be established, and layout. Variations in layout include use of squares, parallel line transects (Stage and Alley 1972), and equilateral triangles as shown in figure 6. An equation (Lund 1979) for computing the interval between points using equilateral triangles is:

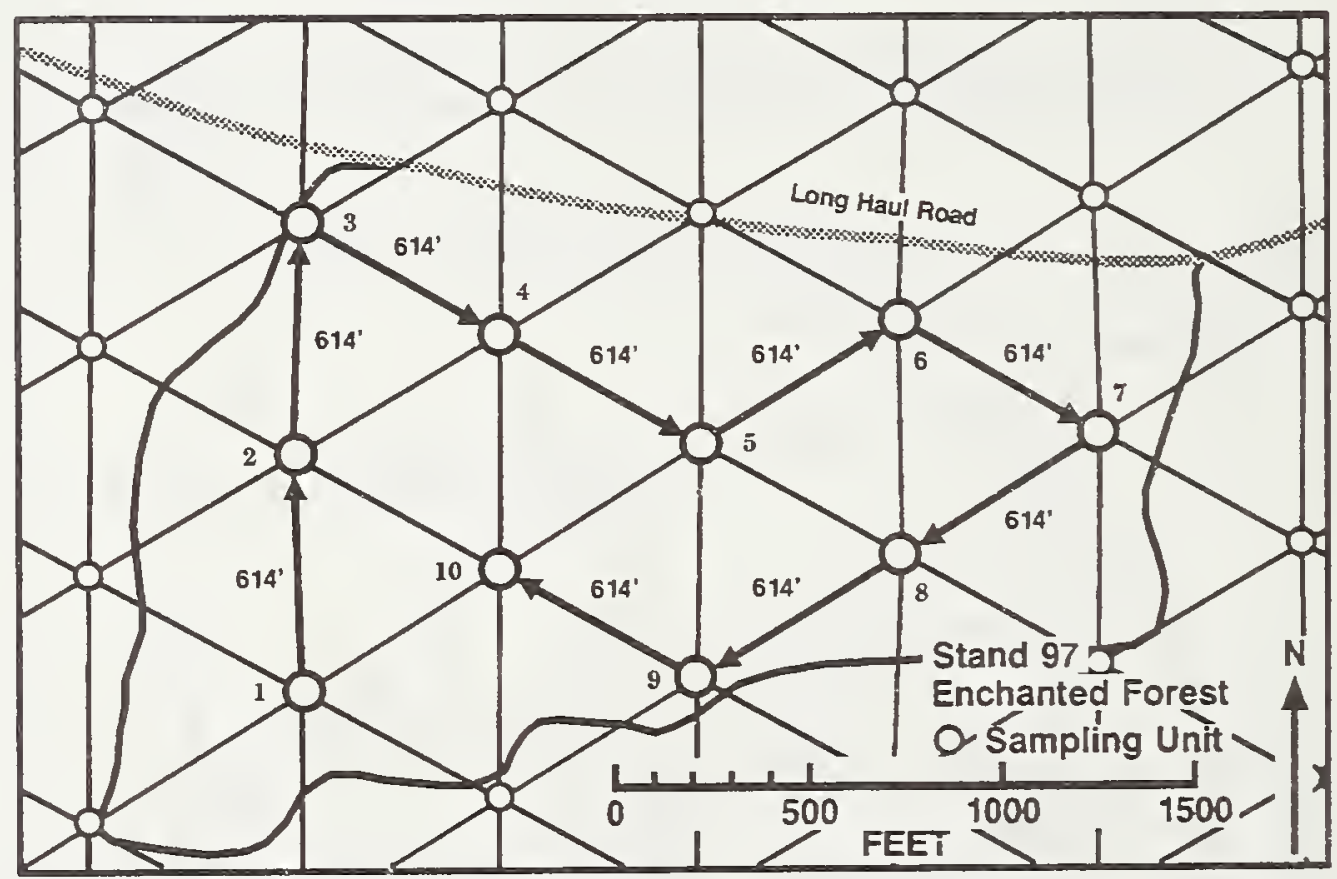

Figure 6-Location of sampling units using a grid or systematic distribution. Plots are located at 60 degrees and 614 feet from one another. 


$$
I=224.272 *(A / n)^{1 / 2}
$$

where $\quad 1$ = interval between plot centers in feet.

$A=$ area of the stand in acres.

$n=$ number of plots to be established.

The area of stand 97 is 75 acres. Assuming 10 plots are to be established, the interval between plot centers would be 614 feet located at 60 degrees to one another.

The metric equivalent is:

$$
I=107.456^{*}(\mathrm{~A} / \mathrm{n})^{1 / 2}
$$

where $I$ is expressed in meters and $A$ in hectares.

Statistical Estimates-The results of an inventory of stand 97 using a systematic distribution of sample plots are as follows:

$\begin{array}{cc}\text { Plot } & \text { ccf per acre } \\ 1 & 17 \\ 2 & 16 \\ 3 & 21 \\ 4 & 20 \\ 5 & 18 \\ 6 & 20 \\ 7 & 23 \\ 8 & 22 \\ 9 & 19 \\ 10 & 15\end{array}$

Estimates are obtained as usual using equations 1-9, $N=75$ 1-acre plots.

$$
\begin{aligned}
\bar{y}= & (17+16+\ldots 15) / 10=19.10 \mathrm{ccf} \text { per acre. } \\
\mathrm{s}_{\mathrm{y}}{ }^{2}= & \left\{\left(17^{2}+16^{2}+\ldots 15^{2}\right)-(17+16+\ldots 15)^{2} /\right. \\
& 10\} /(10-1)=6.7667 . \\
\mathrm{s}_{\bar{y}}{ }^{2}= & \{(6.7667 / 10) *[1-(10 / 75)]\}^{1 / 2}=0.7658 \mathrm{ccf} \\
& \text { per acre. } \\
\% \mathrm{~s}_{\mathbf{e}}= & (0.7658 / 19.10) * 100= \pm 4.01 \% . \\
\hat{\mathrm{Y}}= & 19.1 * 75=1,432.50 \mathrm{ccf} \text { for the stand. }
\end{aligned}
$$

Cost Estimates-Using the standard equations with $\mathrm{n}=$ $10, i=614$ feet.

$$
\begin{aligned}
L= & {[(10-1) 614] / 10,560=0.523 \text { hour. } } \\
D= & {[0.523+10(0.5)] / 8=0.6904 \text { hour. } } \\
F= & 2(9)[0.523+10(0.5)+0.6904]=\$ 111.84 \text {, or } \\
& \$ 1.491 \text { per acre. }
\end{aligned}
$$

Discussion-Simple random sampling formulae are almost always used to compute statistics for a single random start. When random sampling equations are used with a systematic sample, the calculated variance for forestry examples frequently overestimates the variance in the population. Therefore the estimate can be considered somewhat conservative, to err on the safe side. However, the inventory analyst must be alert for unusual spatial patterns that might coincide with the distribution of samples. Property lines, superhighway rights-of-way, and township lines could coincide with systematic samples to the detriment of a systematic sample.

The systematic sampling technique is without replacement and provides the most uniform distribution of plots throughout the stand. The disadvantage is that, assuming all other things are equal, it may be one of the most costly to do. The distance between plot centers is often the greatest (Matern 1960), hence travel time is the highest. The Intermountain (Myers 1984) and Northern Regions (Brickell 1984) employ this sampling design within stands.

Single Plot-A single point does not an inventory sample make. However, a single plot will occasionally be the only sample for a stratum that was judged to be unimportant prior to the inventory and then still requires an estimate for the sake of completeness. Figure 7 shows a single plot; its location was selected by a random process. The observed volume is $17 \mathrm{ccf}$ per acre.

Statistical Estimates-This can hardly be considered a statistical estimate, but for this plot, $\hat{Y}=17 * 75=1,275$ ccf total volume in the stand. Unless additional random samples are added it is not possible to compute the sampling error. However, if this is the result of a single point strata in a larger inventory, for which estimates of similar strata are available, a statistician might conjure up a Stein or simulation type estimate of the variance (Thomas 1986).

Cost Estimates-Selection of a single plot for an inventory is highly unlikely, hence a cost estimate for a single plot is not likely to yield relevant information.

Discussion-Often a cluster of subplots is used in lieu of a single plot. One or more subplot centers are systematically distributed near a randomly selected starting point. The random point is usually the first plot in the cluster or the center. A cluster is used in situations where travel costs are high or accessibility is limited, it is difficult to build a sampling frame, or where interest lies in a primary sam- 
pling unit that is expensive to observe in total (Ek et al. 1984). It is very efficient if variability within the cluster is high and when the variation within the inventory unit (in this case, the stand) is expected be low.

10-Point Cluster-A 10-point cluster (fig. 8) is a common layout in the USDA Forest Service. Subplots are located at 70 feet and 60 degrees from one another. A 5-point,
L-shaped cluster is now used in California (Bowlin 1984) and a 19-point cluster is being used in a survey of Alaska (Larson 1984). Other configurations are outlined by Scott (1982). The pattern for the cluster is established prior to the inventory. In general, one should observe as many subplots as widely spaced as possible as time would allow to get maximum dispersion on measure of variation across the stand (Ek et al. 1984).

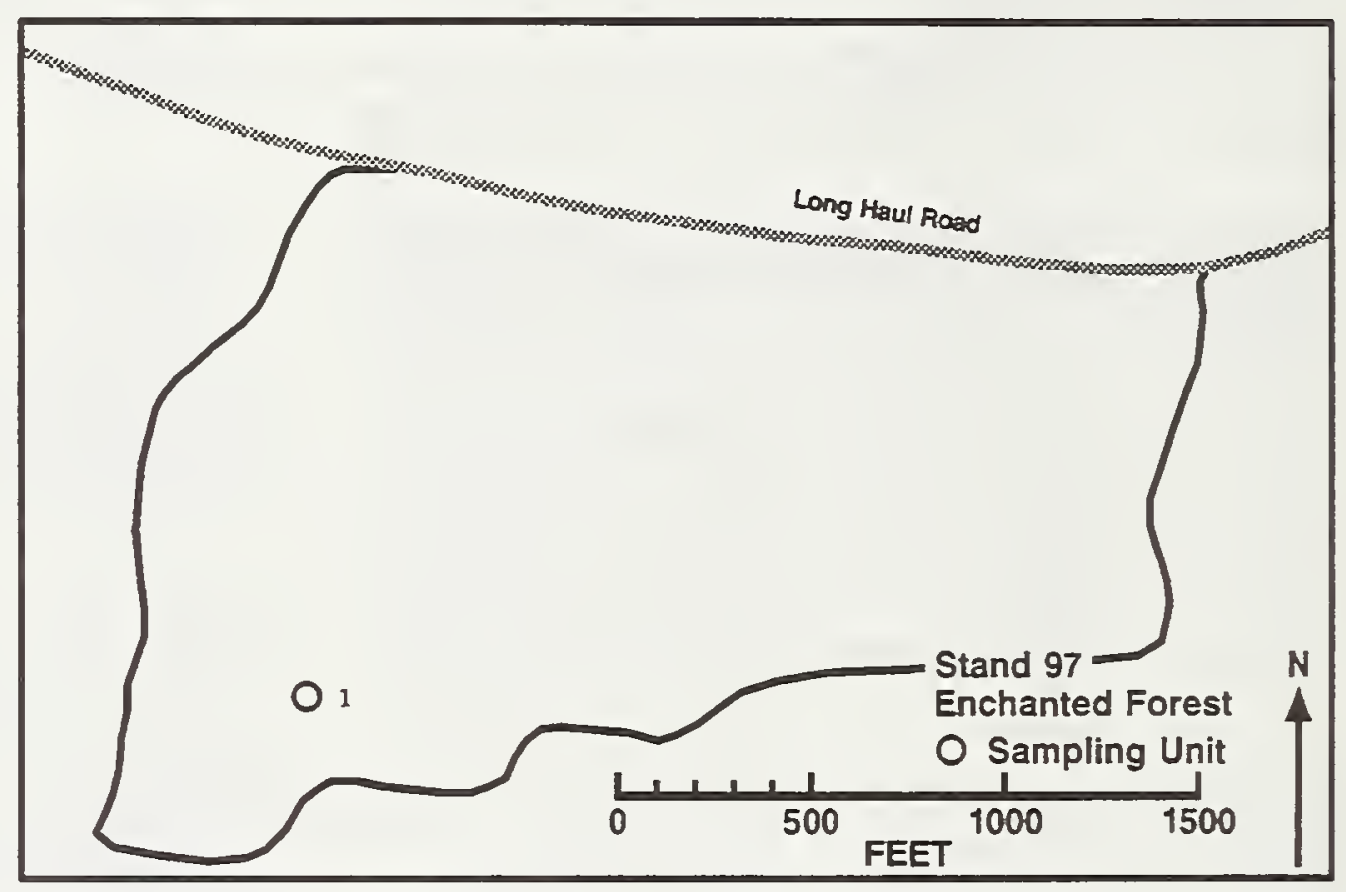

Figure 7-Location of a single sampling unit within stand 97 using random selection.

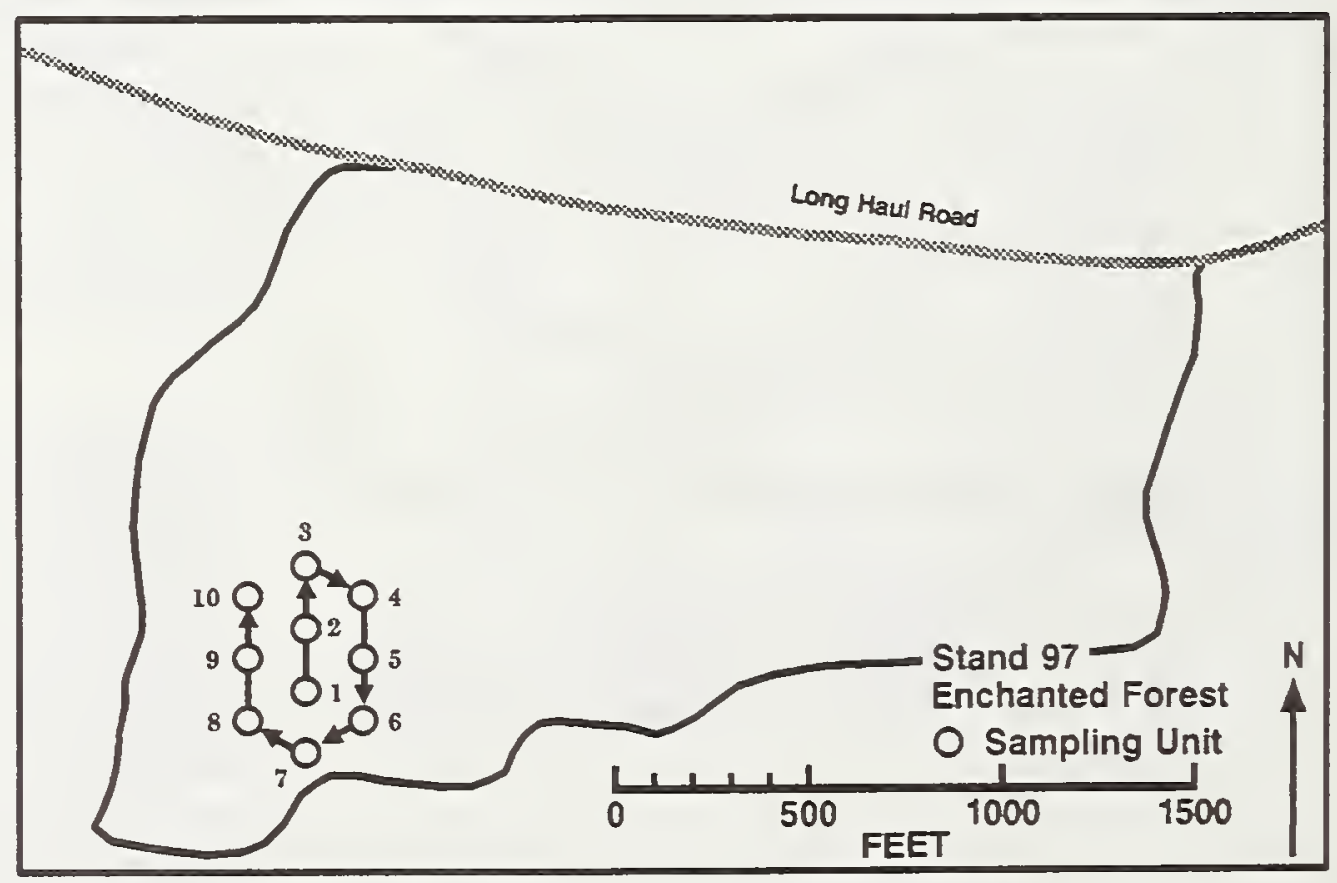

Figure 8-Location of a randomly-located, 10 point cluster. Subplots are located at 70 feet from one another. 
If the initial point falls close to the edge of the stand, some subplots may fall into adjoining stands. When validation of the mapping or classification is important, substitute plots established according to previously defined rules are normally used (fig. 9).

In the inventory of stand 97, a 10-point cluster is established as shown in figure 8 . Each subplot represents about 0.10 acre.

Statistical Estimates - A good deal of care must be taken in the consideration of the statistical nature of the estimates. For some sample clusters it is possible that a mean and variance for the stand would be meaningful. This is probably not the case for the example. The results of the inventory of stand 97 using a single 10-point cluster are as follows:

$\begin{array}{cc}\text { Subplot } & \text { ccf per acre } \\ 1 & 17 \\ 2 & 17 \\ 3 & 17 \\ 4 & 17 \\ 5 & 16 \\ 6 & 15 \\ 7 & 17 \\ 8 & 17 \\ 9 & 17 \\ 10 & 17\end{array}$

There are $N=751$-acre plots if each cluster occupies about 1 acre.

$$
\begin{aligned}
\bar{y}= & (17+17+\ldots 17) / 10-16.7 \text { ccf per acre. } \\
s_{y}{ }^{2}= & \left\{\left(17^{2}+17^{2}+\ldots 17^{2}\right)-(17+17+\ldots 17)^{2} / 10\right\} / \\
& (10-1)=0.4556 . \\
s_{\bar{y}}{ }^{*}= & \left\{(0.4556 / 10)^{*}[1-(10 / 750)]\right\}^{1 / 2}=0.212 \text { ccf per } \\
& \text { acre. }
\end{aligned}
$$

As this represents a single cluster the sampling formula without replacement of points is applied. Values for estimated percent error and total stand volume are computed as:

$$
\begin{aligned}
\% s_{e} & =(0.212 / 16.7) * 100= \pm 1.27 \% \\
\hat{Y} & =16.7^{*} 75=1,252.5 \mathrm{ccf} \text { for the stand }
\end{aligned}
$$

This estimate should carry very little more weight in terms of actual information about the stand than a single point, and you may notice that it is not a very accurate estimate of the stand's true volume.

Cost Estimates-Like the single plot estimate for a stand, the cost can be computed, but its informational value to an inventory forester is minimal. For a single cluster, $n=10$, $i=70$ feet.

$$
\begin{aligned}
L= & {[(10-1) 70] / 10,560=0.060 \text { hour. } } \\
D= & {[0.060+10(0.5)] / 8=0.6325 \text { hour. } } \\
F= & 2(9)[0.060+10(0.5)+0.6325]=\$ 102.46, \text { or } \\
& \$ 1.366 \text { per acre. }
\end{aligned}
$$

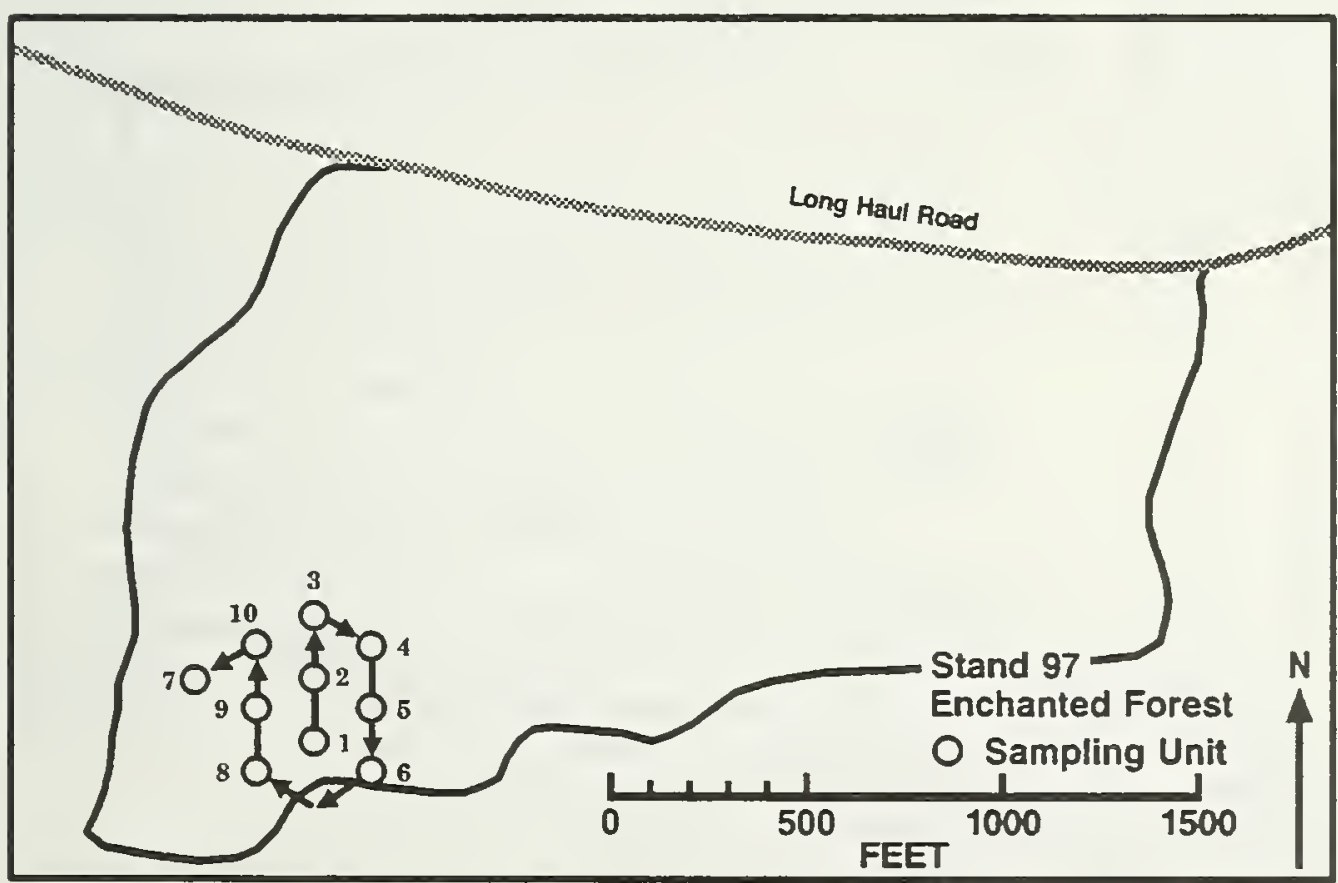

Figure 9-Location of substitute subplots in a 10 point cluster. 
Discussion-As applied by the USDA Forest Service FIA units, the variation among the 10 subplots is not calculated because it has been found to be small compared to the variation between clusters. The values from the subplots are simply averaged. It should be noted that the variability of a single cluster may be significantly more than a sample from a single point and the variability is not always insignificant. The cluster sample should not be routinely treated as a single plot as it often is. For our examples, the results are considered as being from a single plot in further computations.

Because the 10 subplots within a cluster are located close to one another, the subplots are frequently similar to each other. The cluster therefore may provide less information than randomly located plots that are truly independent. This reduces the precision of estimates, but cost savings from clustering frequently yield the most cost effective inventories because the total travel time is reduced.

The 10-point cluster plot is frequently used in extensive forest inventories and where maps of stands are not available. When the population of interest is highly variable, then a sampling system that provides the opportunity for a greater distribution of plots throughout the inventory unit is preferred. The following are some other options for sampling within a stand. When used as a part of a forest inventory, each of the options may be considered a form of cluster sampling.

\section{Subjective Sampling}

Subjective sampling is not recommended in this primer. There may be occasions in which such a sample has been acquired and the analyst must make do with it. Our recommendation is to attempt to relate the sample to a probability sample.

Statistical Estimates_Figure 10 shows plot locations based upon extremes observed within the stand (sampling without preconceived bias). Observations yield estimates of 14 and $25 \mathrm{ccf}$ per acre. The results of the inventory using the observation of extreme values are:

$$
\begin{aligned}
& \bar{Y}=(14+25) / 2=19.5 \mathrm{ccf} \text { per acre. } \\
& \hat{Y}=19.5 * 75=1,462.5 \mathrm{ccf} \text { total volume in the stand. }
\end{aligned}
$$

Cost Estimates - To develop an equation to compute (L), assume the stand to be square and that the crew would traverse it diagonally 3.0 times for sampling without preconceived bias. The diagonal distance of a 1-acre square is 295.16 feet. The diagonal distance across a 75 -acre square stand is $295.16(75)=22,137$ feet.

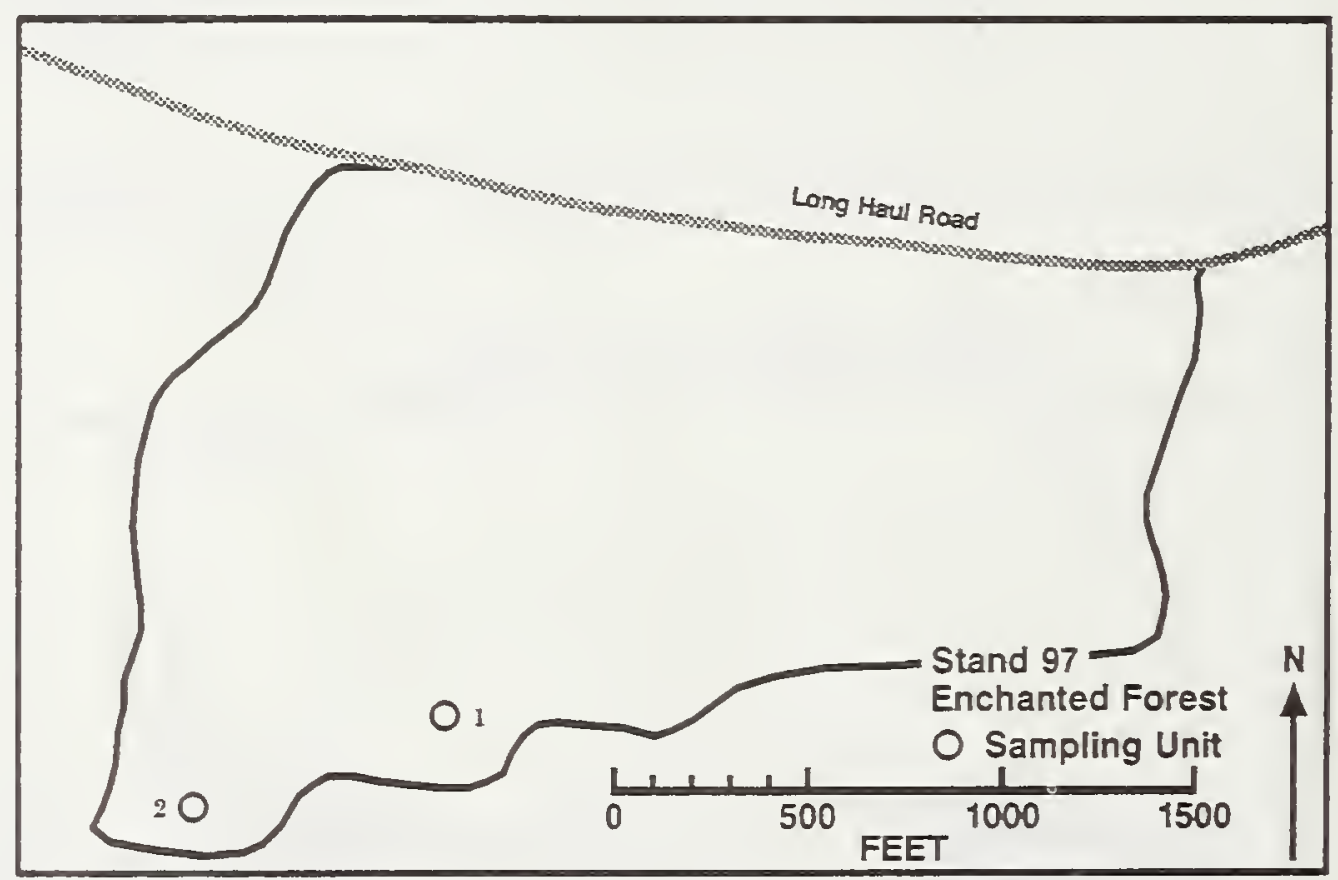

Figure 10-Location of sampling units within stand 97 using subjective sampling without preconceived bias. Plots were located in portions of the stand representing extremes in volume per acre. 
Without preconceived bias, two plots (n) are established and equations a through $\mathrm{c}$ are employed to obtain costs.

$$
\begin{aligned}
L= & {[3(22,137)] / 10,560=6.289 \text { hours. } } \\
D= & {[6.289+2(0.167)] / 8=0.828 \text { hour. } } \\
F= & 1(9)[6.289+2(0.167)+0.828]=\$ 67.06 \text { or } \\
& \$ 0.894 \text { per acre. }
\end{aligned}
$$

Discussion-A justification often given for this type of sampling is that it is quicker than statistical sampling. This may be the case, but to select the average condition or the extremes it may be necessary to traverse the entire stand several times. Travel time within the stand may be equal to or greater than that required for probability based sampling, but time needed to establish plots may be substantially reduced particularly if the observations are also subjectively made.

One cannot compute a sampling error to evaluate the reliability of an estimate based on the extremes. The only way to determine how good the estimates are is by comparing the results with total enumeration.

While it is seldom advisable to use subjective sampling without preconceived bias, the method may be useful for obtaining a rough estimate of the variation within the stand or inventory unit which, in turn, could be used to determine the sampling intensity necessary to achieve a desired precision. The following illustrates how this may be done.

Snedecor and Cochran (1974) provide an equation for determining sample size where:

$$
n=\left[\left(t^{*} s_{\gamma}\right) /\left(s_{e}{ }^{*} \bar{y}\right)\right]^{2}
$$

where:

$\mathrm{n}=$ The estimated number of sampling units necessary to sample within certain prescribed precision and confidence limits.

$\mathrm{t}=$ Student's " $\mathrm{t}$," which is a value establishing a level of probability. The values of " $\mathrm{t}$ " have been tabulated and are available in most statistical textbooks, including those referenced in this report.

Where past inventory information is lacking, the standard deviation $\left(s_{y}\right)$ may be estimated by:

$$
s_{y b}=B / 3
$$

where:

$B=$ the estimated range from the smallest to the largest value likely to be encountered in sampling.

Note: Statistical arguments for using either 3 or 4 in equation (11) may be made and both have been suggested by respected sources.

Using the subjective samples of 14 and 25 ccf per acre and:

$$
\bar{Y}=(14+25) / 2=19.5 \text { ccf per acre. }
$$$$
s_{y}=(25-14) / 3=3.67 \text { cof per acre. }
$$

To compute the number of samples $(n)$ required to be within \pm 15 percent sampling error $\left(\% \mathrm{~s}_{\mathrm{e}}\right)$ at the 95 percent probability level, we need to estimate the degrees of freedom so that we can obtain a value for "t." Past experience has shown that in similar stands we can use 10 plots and still be within the allowable sampling error. The degrees of freedom are $10-1=9$. Using a table showing the distribution of Student's " $t$ " we find that for the 95-percent probability level and 9 degrees of freedom, $" t "=2.262$. Using equation (10) and the information given above:

$$
\begin{aligned}
n= & {[(2.262 * 3.67) /(0.15 * 19.5)]^{2}=8.055, \text { or } 9 } \\
& \text { samples. }
\end{aligned}
$$

If the number of plots had changed by an order of magnitude, we might need to recompute the number of plots allowing for the change in ' $n$. ' That is, if 20 plots had been required our degrees of freedom would change from about 9 to 19 and it would be advisable to solve (10) again using the new value for "t." More information regarding sample intensity formulation is found in Freese (1962) and in the statistics and sampling references listed at the end of this report. 


\section{Complete Enumeration}

Figure 11 shows the mapped results of a complete enumeration. All trees were measured in the stand.

Statistical Estimates-Stand 97 has a total volume of $1,425 \mathrm{ccf}$, or $19 \mathrm{ccf}$ per acre.

Cost Estimates $-\mathrm{n}=$ area of stand or 75 acres, $\mathrm{i}=0$ feet.

$\mathrm{L}=0$ hours.

$D=[0+75(1)] / 8=9.375$ hours.

$F=2(9)[0+75(1)+9.375]=\$ 1,518.75$, or $\$ 20.25$ per acre.

Discussion-The complete enumeration will serve as ground truth for summarizing the results obtained by the other options.

\section{Summary of Methods}

Table 4 shows the results of sampling stand 97 by the methods discussed. There is no sampling error for the complete enumeration because each stand in the population was sampled. There may be error within a stand, but for this discussion, we have chosen to ignore it (as do most introductory treatises). A sampling error for the subjective technique cannot be computed because the plots were not chosen randomly. A sampling error cannot be computed for the single plot because at least two samples or prior information are needed. Similarly, the 10-point cluster is considered a single sample so the variance for the stand cannot be estimated, although the variance for the plot can be and was computed.

Statistical Estimates-A direct comparison is not possible because the data are replicated only once for each technique. However, some general comments or observations can be made.

As may be expected, the 10-point cluster design, being considered a single plot, had the least variation. Intuitively the systematic distribution should best represent the stand and the single plot or cluster sample should be the least representative. A systematically distributed sample usually encompasses more variation than does a randomly distributed sample. This will usually be the case unless some cyclic variation in the population chances to coincide with the periodicity in the sample.

Cost Estimates-Table 4 also shows the costs encountered for each simulated option and the cost $\left(\$ \mathrm{~S}_{\mathrm{eD}}\right)$ that would be required to achieve a desired percent sampling error $\left(\% \mathrm{se}_{\mathrm{D}}\right)$. This is computed by the following equation:

$$
\$ \mathrm{~S}_{\mathrm{eD}}=\$ *\left(\% \mathrm{~s}_{\mathrm{e}} / \% \mathrm{~S}_{\mathrm{eD}}\right)^{2}
$$

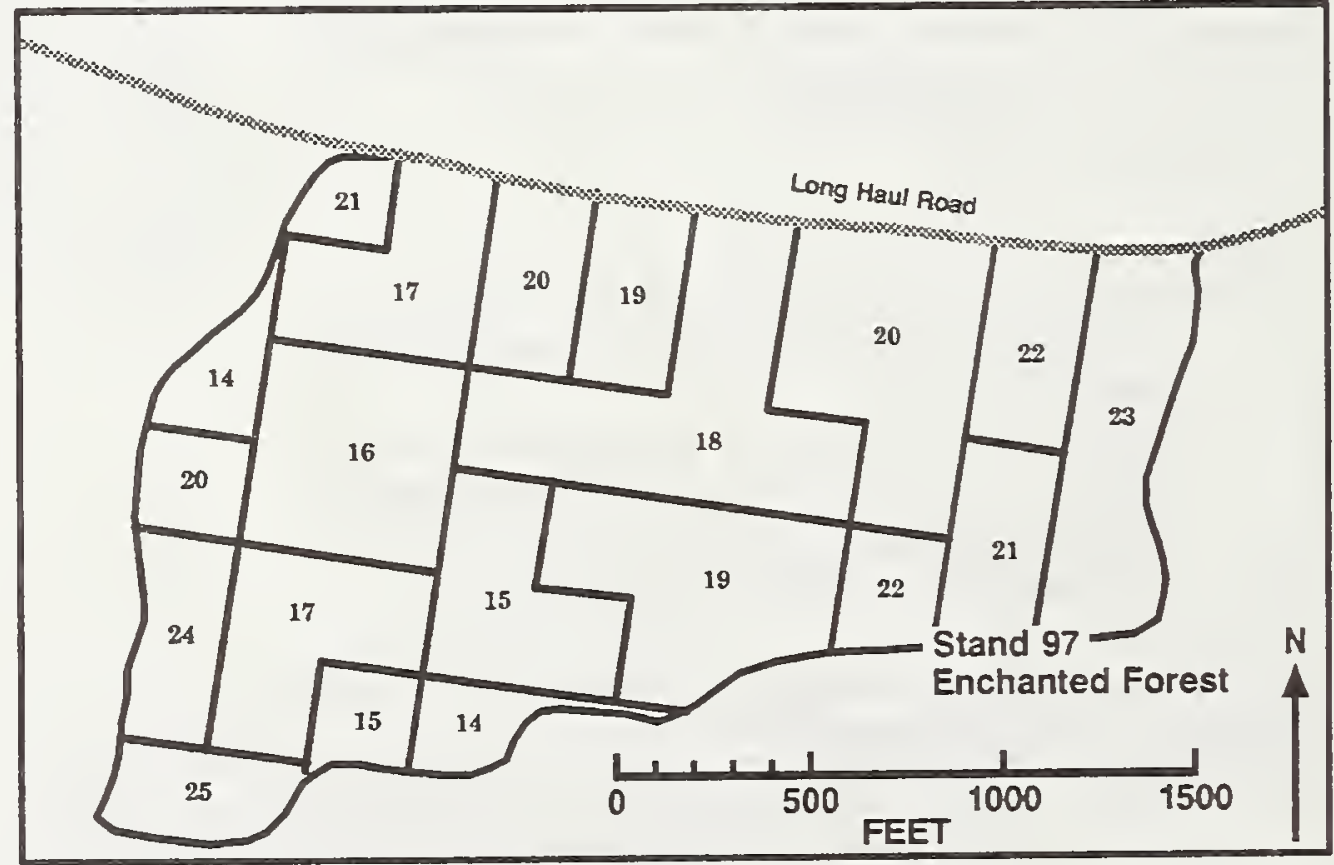

Figure 11-Complete enumeration and ground truth for stand 97 showing the approximate volume (cct) per acre distribution. The total volume for the stand is 1,425 ccf, or 19 ccf per acre. 
Table 4-Volume per acre (cct) and costs for various sampling methods for stand 97

\begin{tabular}{|c|c|c|c|c|c|c|c|c|}
\hline Statistic & Random & $\begin{array}{c}\text { Line } \\
\text { transect }\end{array}$ & Ricochet & Systematic & Single plot & Cluster & $\begin{array}{c}\text { Subjective } \\
\text { without } \\
\text { bias }\end{array}$ & $\begin{array}{c}\text { Complete } \\
\text { enumeration }\end{array}$ \\
\hline$\dot{Y}(\mathrm{ccl})$ & $1,320.00$ & $1,432.50$ & $1,440.00$ & $1,432.50$ & $1,275.00$ & $1,252.50$ & $1,462.50$ & $1,425.00$ \\
\hline $8(\mathrm{ccl})$ & 17.60 & 19.10 & 19.20 & 19.10 & 17.00 & 16.70 & 19.50 & 19.00 \\
\hline$s_{y}^{2}$ & 13.82 & 10.99 & 5.29 & 6.77 & & 0.46 & & 0.00 \\
\hline$s_{\bar{y}}$ & 1.18 & 0.98 & 0.68 & 0.77 & & 0.21 & & 0.00 \\
\hline$\% \mathrm{~s}_{\theta}$ & 6.68 & 5.11 & 3.53 & 4.01 & b & 1.27 & a & 0.00 \\
\hline Total cost $(\$)$ & 111.84 & 106.06 & 111.84 & 111.84 & & 102.46 & 67.06 & $1,518.75$ \\
\hline Cost per acre $(\$)$ & 1.49 & 1.41 & 1.49 & 1.49 & & 1.37 & 0.89 & 20.25 \\
\hline Total cost @ $5 \%$ sample error ${ }^{c}$ & 199.62 & 110.78 & 55.75 & 71.94 & & 6.61 & & \\
\hline
\end{tabular}

a-Sampling errors are not knowable for subjectively drawn samples.

b-A sampling error cannot be computed for only one sample.

c-Computed by using equation ( $f$ ).

where $\$$ = total cost in dollars for a particular option.

Assume we would like to know what it would cost to achieve a desired sampling error of \pm 5 percent $\left(\% \mathrm{~s}_{\mathrm{eD}}=5\right)$. Using the random sample technique, we achieved $\mathrm{a} \pm 6.68$ percent sampling error at a total cost of $\$ 102.47$. While direct comparisons of the costs are probably not advisable, we have scaled the data to a common sampling error base for each method and adjusted the costs accordingly. Thus for the random sample we find that:

$$
\$ S_{e D}=102.47 *(6.68 / 5)^{2}=\$ 199.62 .
$$

In other words, we would have to put more plots into the stand using a random distribution technique to lower the sampling error to 5 percent. The total cost for doing so would have been $\$ 199.62$.

When considering the actual costs, the single plot and 10-point cluster samples may be the cheapest to establish because the travel distance between points may be the least. The line transect may be the next cheapest to do and the ricochet, random, and systematic distribution should be increasingly time consuming (Matern 1960).

When considering the costs required to achieve a \pm 5 percent sampling error in this particular stand, and disregarding the cluster sample, the ricochet distribution was the least costly, the systematic sample next, followed by the line transect. The random distribution for the example given is the most costly to do. If it is laid out properly, the field crews can end close to the starting point at the end of the stand inventory when using the systematic distribution. This may result in further travel cost savings in many inventory situations.

Key to Options - The following is offered as a rough guide and key to the selection of a plot distribution technique.

1. Variation tends to be in the middle of the stand or polygon.

a. Yes. Use line transect.

b. No. Go to 2 .

2. Variation is greater at the edges of the polygon.

a. Yes. Use the ricochet technique.

b. No. Use the systematic distribution.

While the random distribution can be used in any situation, it is seldom employed in stand inventories. The single plot or 10-point cluster may result from post stratification of inventoried forest stands. There are new techniques available for combining inventory information from different sampling, simulation, and growth model sources that might improve the value of a single plot (cluster) for an estimate of the polygon resource value. (Hansen and Hahn 1983, Hansen 1984, Green and Strawderman 1988). 
Often inventory objectives are to obtain estimates for compartments or forests for planning purposes rather than for developing stand prescriptions. This section describes various design options that provide both forest and location estimates. Initially this discussion assumes minimal information and then progresses to the more complex designs using stratified mapped stands.

The objectives of these simulated inventories are to determine:

- The total wild life area used by a fictitious creature, the red-spotted snaileater (Lund 1986b).

- The total volume (ccf) of standing timber.

- The area and timber volume by vegetation type in the 15,300 acre Enchanted Forest.

We also wish to show the spatial distribution of timber volume in the Forest.

The calculation of forest-wide statistics is discussed first, followed by a discussion of the expansion of sample data to all areas within the Forest.

We will now issue a brief caveat, which will be repeated. Selection of a sampling design and associated statistical estimators are not independent. Nor are they independent of the population for which the estimates are required. Computation of estimates for several different sampling designs on a single simulated forest is not justified. The comparisons do not imply that one method is better than another. The results may inform us as to designs that are more appropriate for the Enchanted Forest, given its peculiar characteristics. However, the techniques presented do not lend themselves to adequate comparisons directly. Statistical simulations (a statistical forest sampling simulator has been recently prepared by Arvanitis and Reich 1988) of sampling designs and computational algorithms would be required to make realistic evaluations of the appropriateness of the various techniques. Still, as an example of the application of the various techniques, the Enchanted Forest is a useful tool.

The options and equations for obtaining compartment or forest estimates are similar to those for obtaining and generating information within a stand. The sampling strategy options are somewhat similar to those used in the stand inventory and range from subjective sampling to statistical sampling and on to complete enumeration and vary with the amount of available stand information. The reader is cautioned that all the designs in this section are simulated. Many of the inventory schemes were purposely laid out in such a manner that the same field locations were chosen to show the effect that different designs could have on the estimates generated on a particular stand.

Mapping and unmeasured area estimates for any attributes measured or observed on sample plots or stands can be extrapolated to other areas within the inventory unit. Extrapolation of sample information to the remaining stands in an inventory is usually quite simple. However, care must be taken especially when recombination of sample units or restratification of the population may occur. It is usually advisable to maintain identification of the measured units as being different from those units that are strictly predicted in a database.

Note that in the figures associated with the various stratified sampling schemes discussed in this report, both sampled volumes and stratum averages are displayed. This has been done primarily to show the source of the estimates. In actual practice, only stratum averages are usually displayed in the mapping process.

Cost estimates given in this section are similar to those incurred by the Forest Service Regions (Lund 1987). Cost assumptions are as follows:

Remote sensing acquisition is assumed to be $1: 15,840$ color aerial photography and digital tapes of satellite imagery of the Enchanted Forest. A coordinated purchase of complete coverage for several million acres is assumed. These assumptions make costs per acre, similar to those found for a real National Forest.

Aerial photography $=\$ 0.032$ per acre, or $\$ 489.60$ for the Enchanted Forest.

Digital satellite imagery $=\$ 0.004$ per acre, or $\$ 61.20$ for the Forest.

Interpretation including aerial photography or satellite imagery.

Aerial photography $=\$ 0.02$ per point or acre, or $\$ 306$ for the Forest.

Satellite imagery $=\$ 0.025$ per acre, or $\$ 382.50$ for the Forest.

Mapping, including stand delineation, transfer to stable base, and determination of stand area. 
Using aerial photography $=\$ 0.075$ per acre, or $\$ 1,147.50$ for the Forest.

Using satellite imagery $=\$ 0.02$ per acre, or $\$ 306.00$ for the Forest.

Field cost assumptions are the same as discussed under the stand inventory section.

\section{Subjective Sampling}

The disadvantages of using subjective sampling have been discussed previously. The danger of bias in the various subjective sampling methods cannot be overemphasized. For an individual stand, a mistaken prescription might not be a calamity, but a consistent bias over all (or most) stands in a compartment or forest could lead to some unworkable management plans. Therefore, subjective sampling should not be used for forest-wide inventories except possibly to estimate the coefficient of variation prior to probability sampling.

Assume that subjective sampling without preconceived bias of the Enchanted Forest yields estimates of $0 \mathrm{ccf}$ and 30 ccf per acre. Further assume that 15 percent is an acceptable sampling error at the 20-percent probability level $(t=1.325$ at 19 degrees of freedom). An estimate of the number of samples $(n)$ needed to inventory the forest may be determined using the subjective sample data as follows:

$$
\begin{aligned}
\bar{y} & =(0+30) / 2=15 \mathrm{ccf} \text { per acre. } \\
s_{y} & =(30-0) / 3=10 \mathrm{ccf} \text { per acre. } \\
n & =[(1.325 * 10) /(0.20 * 15)]^{2}=19.51 \text { or } 20 \text { samples. }
\end{aligned}
$$

Sample intensity equations for specific designs are found in the references listed at the end of this report.

\section{Inventories Without Prior Stand Mapping}

Inventories without stand mapping are usually conducted for broad area assessments where location information is not needed or as a prelude to the further development of the resource. Such inventories focus on the resource stock and the land's capability to produce on a sustained yield basis. The examples given in this report include the use of systematic sampling, poststratification, strip cruises, stratified double sampling, and stratification of satellite imagery. The inventory units are usually based upon political or administrative boundaries. Broad management goals and objectives and financial plans for the organization are the eventual products (Lund 1985).
If the inventories are conducted so that the field plots are established and documented for remeasurement, it may be considered a continuous forest inventory or CFI. These inventories are typical of the Forest Inventory and Analysis units.

While stand maps may not be available at the start of a forest inventory, there are several tools available to produce forest volume and area estimates and location maps until stand mapping can be done. These techniques are also illustrated in this section. Sampled volumes, stratum averages, and predicted values are often shown in the figures in this report. In actual practice, however, only stratum averages or predicted values are usually displayed in the mapping process. When using such maps, resource managers need to be aware of the source of the information and the sampling errors associated with averages and predictions.

Costs include purchase and interpretation of remote sensing, where appropriate, plus field costs. For field costs, a plot consists of 10 subplots located 70 feet apart. It takes 0.5 hours for the two-person crew to measure 1 subplot. A total of 20 plots are established in each of the following examples.

The time to measure $(M) 1$ plot (includes subplots) is:

$M=\{[(n-1)(i)] / 10,560\}+n(0.5)$

where $\mathrm{n}$ is the number of subplots and $\mathrm{i}$ is the interval in feet between subplots.

Solving for $M=\{[(10-1)(70)] / 10,560\}+10(0.5)=$ 5.06 hours.

The plots are located systematically through the Forest at 60 degrees from one another. The interval between plots (l) is:

$I=224.272\left[(15,300 / 20)^{1 / 2}\right]=6,203$ feet.

$\mathrm{L}=[(20-1) 6,203] / 10,560=11.161$ hours.

$\mathrm{D}=[11.161+20(5.06)] / 8=14.045$ hours.

$F=2(9)[11.161+20(5.06)+14.045]=\$ 2,275.31$, or $\$ 0.149$ per acre.

Systematic Sample-This is a simple, intuitively appealing inventory design. A grid is superimposed across the forest 
(fig. 12). Plots are established at the grid intersections. Once the initial plot is established or the grid is fixed on the area, the remaining design is fixed. For this reason it is not truly a random sample. Traditionally, random sampling formulae have been applied to this type of sample allocation, assuming that a random process is associated with distribution of the forest variates of interest. Experience indicates that in most cases estimates of variance will be conservative. Hence the practicing forester is usually safe in applying this type of design, unless there is some regular variation in the forest that is correlated with the sample placement. A second consideration is that there is no possibility that a plot once chosen will recur in the sample, hence, this is sampling without replacement. For this example, the field plots are assumed to be 10-point clusters covering an area one acre in size. The within-plot variance is not considered.

Statistical Estimates-Assume we want to compute the acreage of lands having a particular wildlife use such as that of the red-spotted, snaileater. To compute the estimate for areas having wildlife use, all plots classed as having evidence of snaileater use in the field are assigned a value of 1 and all other plots are given a value of zero. The results are shown in table 5 .

$\mathrm{N}=15,300 / 1=15,300$ possible 1 acre plots.

$\bar{y}=(0+1+\ldots 0) / 20=0.55$ or $55 \%$ of the area shows wildlife use.

Forest Boundary

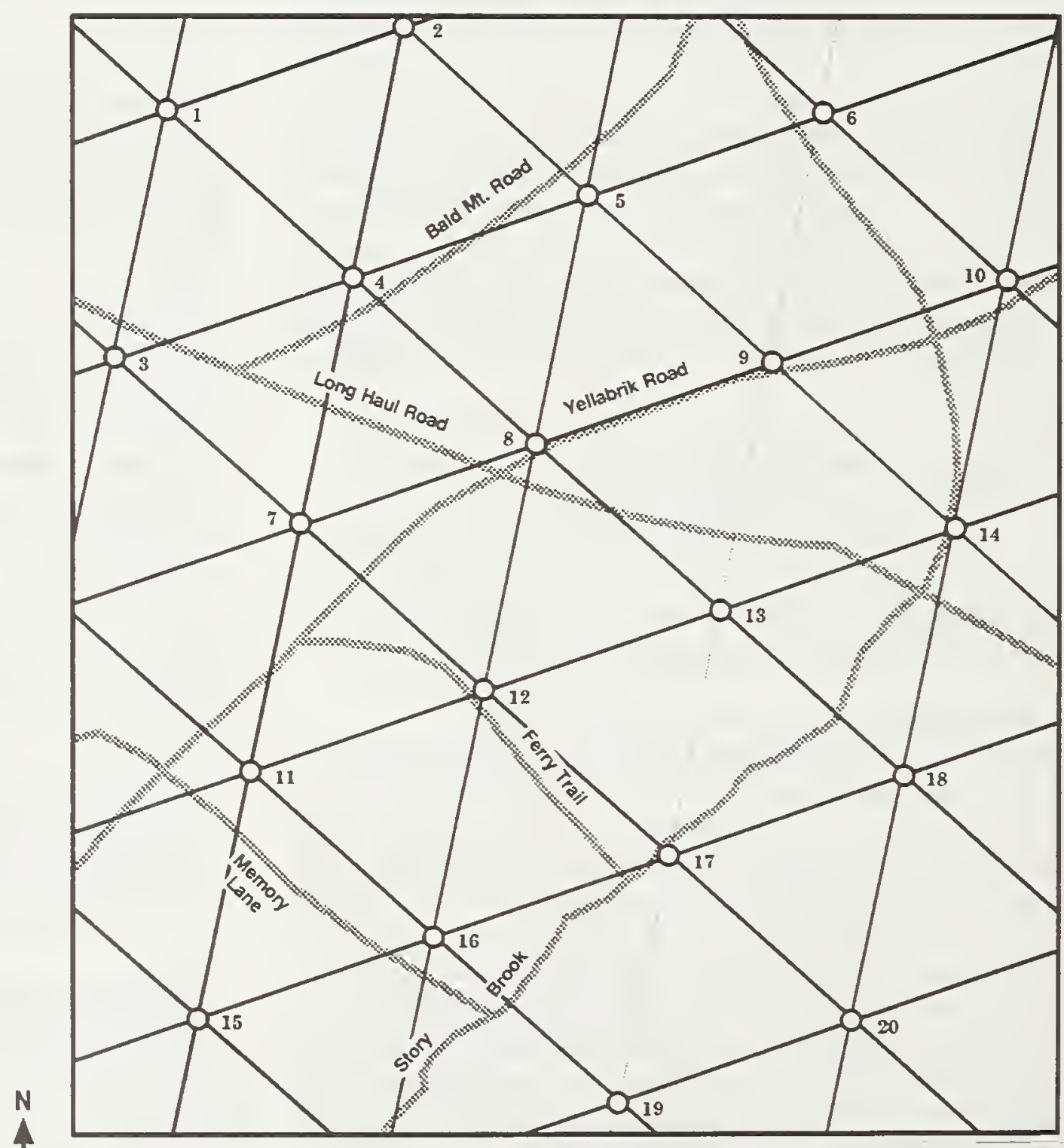

Figure 12-Location of sampling units using a systematic grid over the Enchanted Forest. Sampling unit centers are located at 60 degrees and O Field Plot 6,203 feet from one another. 
Table 5-Results of an inventory of the Enchanted Forest using a systematic sample; volumes are in ccf

\begin{tabular}{|c|c|c|c|c|c|}
\hline Plot & $\begin{array}{l}\text { Vegetation } \\
\text { type }\end{array}$ & $\begin{array}{l}\text { Wildlife } \\
\text { use }\end{array}$ & $\begin{array}{l}\text { Wildlife } \\
\text { estimators }\end{array}$ & $\begin{array}{c}\text { Volume/ } \\
\text { acre }\end{array}$ & $\begin{array}{l}\text { Volume } \\
\text { estimators }\end{array}$ \\
\hline 1 & Hardwood & 0 & & 7 & \\
\hline 2 & Conifer & 1 & & 31 & \\
\hline 3 & Hardwood & 1 & & 8 & \\
\hline 4 & Hardwood & 0 & & 3 & \\
\hline 5 & Brush/open & 1 & & 3 & \\
\hline 6 & Hardwood & 1 & & 7 & \\
\hline 7 & Hardwood & 1 & & 10 & \\
\hline 8 & Conifer & 1 & & 19 & \\
\hline 9 & Hardwood & 0 & & 10 & \\
\hline 10 & Conifer & 0 & & 34 & \\
\hline 11 & Conifer & 1 & & 29 & \\
\hline 12 & Conifer & 0 & & 14 & \\
\hline 13 & Hardwood & 1 & & 17 & \\
\hline 14 & Conifer & 0 & & 8 & \\
\hline 15 & Hardwood & 1 & & 13 & \\
\hline 16 & Hardwood & 1 & & 21 & \\
\hline 17 & Brush/open & 1 & & 6 & \\
\hline 18 & Conifer & 0 & & 18 & \\
\hline 19 & Hardwood & 0 & & 0 & \\
\hline 20 & Hardwood & 0 & & 20 & \\
\hline$\Sigma n$ & & 11 & & 278 & \\
\hline$g$ & & & 0.550 & & 13.900 \\
\hline$s_{y}{ }^{2}$ & & & 0.260 & & 92.305 \\
\hline$s_{\bar{y}}$ & & & 0.114 & & 2.148 \\
\hline$\% \mathrm{~s}_{\mathrm{e}}$ & & & $\begin{array}{l} \pm 20.75 \\
8,415\end{array}$ & & $\begin{array}{l} \pm 15.46 \\
212,670 .\end{array}$ \\
\hline
\end{tabular}

$$
\begin{aligned}
\mathrm{s}_{\mathrm{y}}{ }^{2}= & \left\{\left(0^{2}+1^{2}+\ldots 0^{2}\right)-(0+1+\ldots 0)^{2} / 20\right\} / \\
& (20-1)=0.2605 .
\end{aligned}
$$

$\mathrm{s}_{\bar{y}}=(0.2605 / 20)^{1 / 2}=0.1141$ is the standard error of mean wildlife use (this is a proportion and as such it is difficult to refer to it in terms that are completely clear in meaning).

The equation for sampling without replacement is appropriate because the plots do not have a chance of being selected again.

$$
\begin{aligned}
\% s_{e}= & (0.1141 / 0.55) * 100= \pm 20.75 \text { percent. } \\
\hat{Y}= & 0.5500 * 15,300=8,415 \text { acres of wildlife use } \\
& \text { in the Forest. }
\end{aligned}
$$

Total volume estimators are calculated as follows:

$$
\begin{aligned}
N= & 15,300 \text { possible } 1 \text { acre plots. } \\
\bar{y}= & (7+31+\ldots 20) / 20=13.90 \text { ccf per acre. } \\
s_{y}{ }^{2}= & \left\{\left(7^{2}+31^{2}+\ldots 20^{2}\right)-\left[(7+31+\ldots 20)^{2} /\right.\right. \\
& 20]\} / 20-1)=92.3053 .
\end{aligned}
$$

$$
\begin{aligned}
\mathrm{S}_{\bar{y}} & =(92.3053 / 20)=2.1483 \mathrm{ccf} \text { per acre. } \\
\% \mathrm{~S}_{\mathrm{e}} & =(2.1483 / 13.90) * 100= \pm 15.46 \% . \\
\hat{Y} & =13.90 * 15,300=212,670 \mathrm{ccf} \text { for the Forest. }
\end{aligned}
$$

Area and total volume estimates by vegetation type are computed similarly. For the conifer type, all plots not classed as conifer are assigned a value of 0 for volume and area. Table 6 lists the estimates for the conifer vegetation type. The areas are: for conifer type 5,355 acres, for

\begin{tabular}{|c|c|c|c|c|}
\hline Plot & Volume/acre & Volume estimators & Type & Type estimators \\
\hline 1 & 0 & & 0 & \\
\hline 2 & 31 & & 1 & \\
\hline 3 & 0 & & 0 & \\
\hline 4 & 0 & & 0 & \\
\hline 5 & 0 & & 0 & \\
\hline 6 & 0 & & 0 & \\
\hline 7 & 0 & & 0 & \\
\hline 8 & 19 & & 1 & \\
\hline 9 & 0 & & 0 & \\
\hline 10 & 34 & & 1 & \\
\hline 11 & 29 & & 1 & \\
\hline 12 & 14 & & 1 & \\
\hline 13 & 0 & & 0 & \\
\hline 14 & 8 & & 1 & \\
\hline 15 & 0 & & 0 & \\
\hline 16 & 0 & & 0 & \\
\hline 17 & 0 & & 0 & \\
\hline 18 & 18 & & 1 & \\
\hline 19 & 0 & & 0 & \\
\hline 20 & 0 & & 0 & \\
\hline$\Sigma \mathrm{n}$ & 153 & & 7 & \\
\hline g & & 7.650 & & 0.350 \\
\hline$s_{y}^{2}$ & & 143.818 & & 0.239 \\
\hline$s_{\bar{y}}$ & & 2.682 & & 0.109 \\
\hline$\% \mathrm{~s}_{\mathrm{e}}$ & & \pm 35.05 & & \pm 31.26 \\
\hline$\hat{\mathrm{Y}}$ & & $117,045$. & & 5,355 \\
\hline
\end{tabular}
hardwoods 8,415 acres, and for brush/open 1,530 acres.

The volume of timber in the conifer type is $117,045 \mathrm{ccf}$; in the hardwood type the volume is 88,740 ccf; and in the brush/open type, the estimated volume is $6,885 \mathrm{ccf}$.

Mapping and Unmeasured Area Estimates-Maps showing the approximate location or distribution of the resources can be generated by the use of cells, isolines, or by partial field mapping.

Table 6-Results and estimates for conifer vegetation type using a systematic sample of the Enchanted Forest; volumes are in ccf 
Figure 13 illustrates the use of cells. Each field plot has an area expansion factor (EF) where:

$$
\mathbf{E F}=\mathbf{A} / \mathbf{n}
$$

The expansion factor for the plots established in this sample design is:

$$
E F=15,300 / 20=765 \text { acres per plot. }
$$

The 765 acres surrounding each plot center are characterized as the same as the plot itself. Because the plots in the example above were established using a grid of equilateral triangles, the cells take on the form of hexagons. Areas outside the plot locations are assumed to have the average characteristics of the Forest as a whole. Thus those areas are assumed to have $13.90 \mathrm{cof}$ per acre. Mapping suitable red-spotted snail eater habitat is a challenging task. The presence or absence of indicators of habitat even in sampled stands may not represent the proportion of the area actually utilized. Because the sampling fraction is quite small it may be most informative simply to associate the estimated proportion with each stand instead of indicating the presence or absence of habitat for the sampled stands. An alternative is to employ an advanced multivariate classification procedure to the sampled stands and predict presence or absence based on these findings.

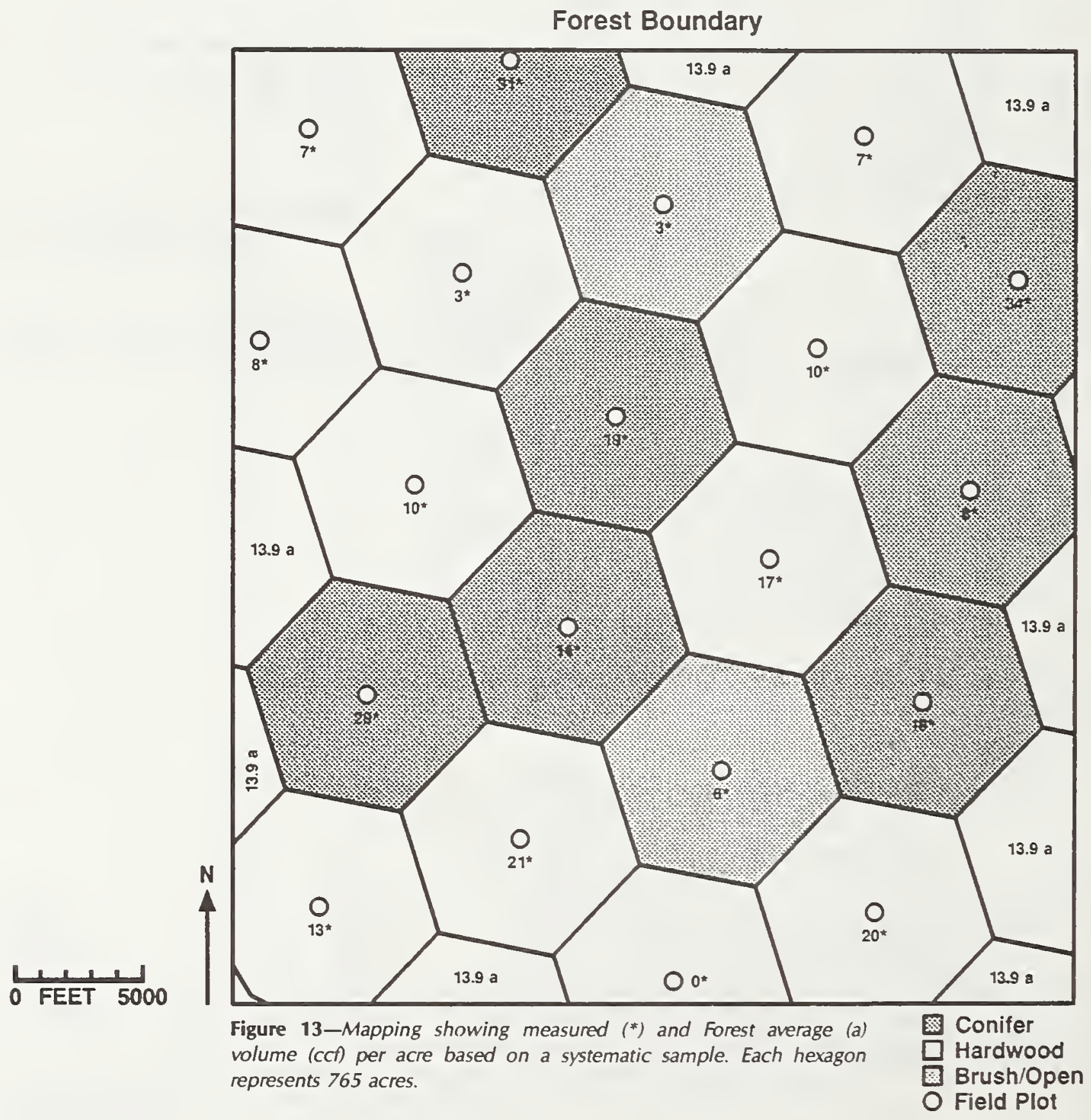


Figure 14 illustrates the use of isolines for mapping volume distribution. The map is produced by considering the total volumes or volumes per acre at each sample point as elevations points. Isolines or contours of equal volumes are then developed through interpolation (Wiant and Knight 1982). Heine (1986) presents a total of four other ways of interpolation.

Partiai mapping involves mapping stands or parts of stands during the course of establishing field plots. In the example shown in figure 15, the field crew delineated the stand boundaries on aerial photography as the sample plots were established using ground referencing. This informa- tion was transferred to a base map. This technique is used by the Rocky Mountain Region (Mehl 1984).

Cost Estimates-The only cost is the field cost.

$$
F=\$ 2,275.31 \text {, or } \$ 0.149 \text { per acre. }
$$

Discussion-Systematic sampling was very common in the Forest Service from about 1930 to the mid-1960's (Stott 1968). It is useful where remote sensing is lacking or where data on multiple resources are desired. Statistical estimates from systematic samples are usually computed from simple random sampling formulae. Experience has

\section{Forest Boundary}

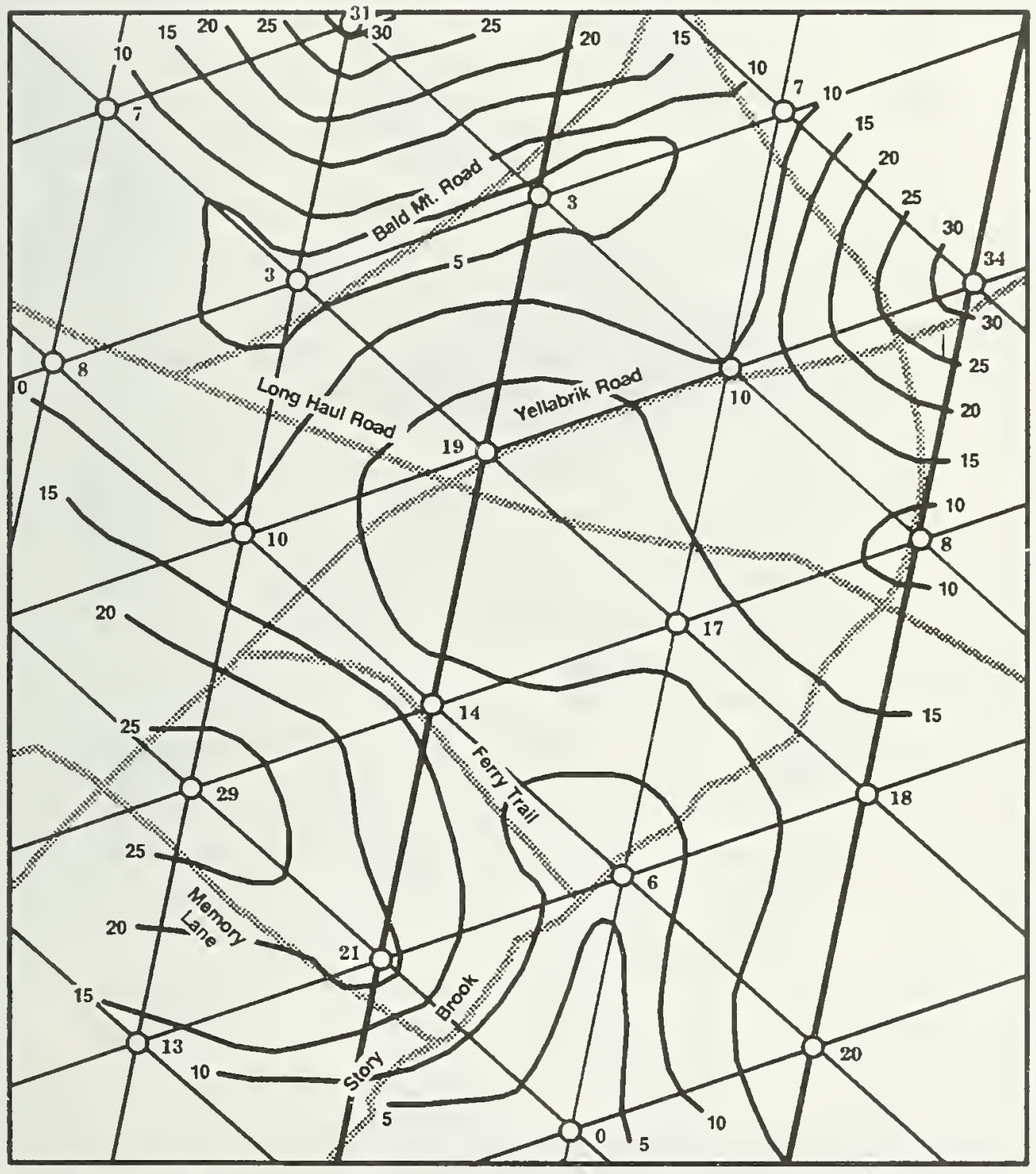

Figure 14-An isoline map of the Enchanted Forest showing contours of volume (cct) per acre based upon interpolation of the systematic sample. 
usually validated the application of these mixed designcomputation procedures. If the reliability of the estimates is extremely important as might be the case for an inventory that was being disputed in court, a systematic sample such as is described could be modified by including some sort of randomization process for subsets of the plots to assure multiple random starts within the area of interest. Computations would then follow the procedures for systematic sampling plans as described in Cochran (1977) or other statistical sampling texts.

Stratified Sampling-Often the forest is heterogeneous with respect to forest type, maturity, or site class. It may be worthwhile to consider stratified sampling if these characteristics are of interest or if the variance within the categories is more homogeneous than the overall forest. In stratified sampling, units of population are grouped together on the basis of similar characteristics. These groups are called strata. Total variance can be reduced by the amount of variance that can be attributed to the difference between the strata. For instance, suppose that a large tract of land had considerable merchantable volume interspersed with recently regenerated stands. Estimates of overall volume and the associated standard errors will be considerably reduced if the forest is partitioned into merchantable and nonmerchantable strata. Stratification may be made after plots are established (post-

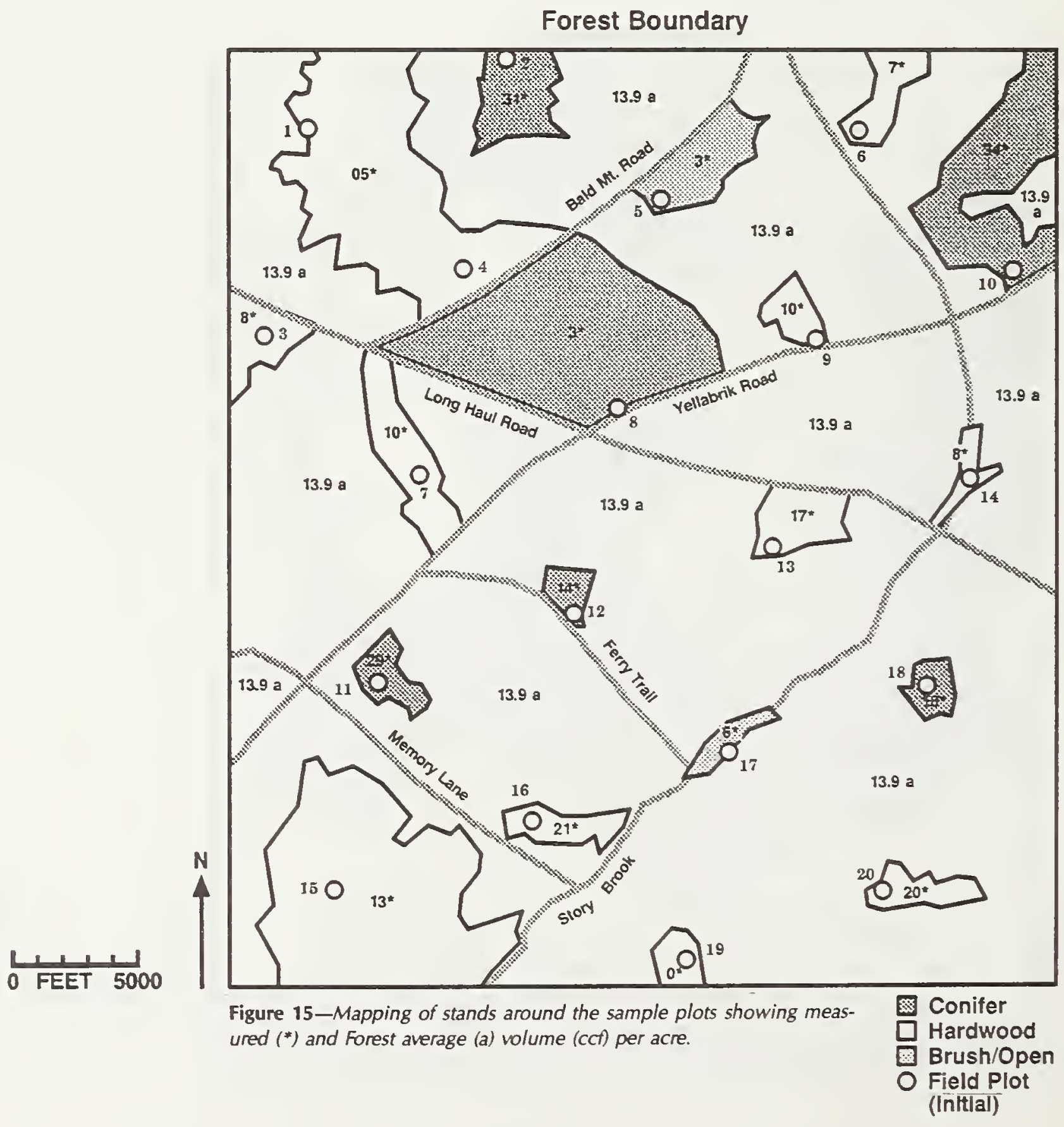


stratification), or it may be done before plots are selected (prestratification).

Poststratification-In a poststratification design, plots are simply grouped by similar characteristics and the variance is computed for each stratum and then pooled for the forest as a whole. The number of samples in a given stratum is not predetermined, so there is a random component to the estimates of standard error and confidence limits. Some strata may have been poorly represented in the sample and estimates for these strata may be highly variable. In some ways post stratification can be likened to establishment of classification strata in remotely sensed multispectral imagery.

Systematic Sample-Table 7 shows the results of an inventory of the Enchanted Forest using poststratification of the same plots established under the systematic sample described above (fig. 12). The plots were group based on vegetation type. There were 7 plots in the conifer type, 11 in the hardwood type, and 3 in the brush/open class.

Statistical Estimates-The estimators are computed first for each sampling strata and then combined for the inventory unit as a whole.

The area in each stratum $\left(A_{i}\right)$ is computed as follows:

$$
A_{i}=A^{*}\left(n_{i} / N_{i}\right)
$$

Where $n_{i}=$ number of plots in stratum.

$$
\begin{aligned}
N_{i}= & \text { total number of plots in inventory. } \\
i= & c \text {, } h \text {, or } b \text { for conifers, hardwoods, or } \\
& \text { brush/open strata respectively } \\
A_{c}= & 15,300^{*}(7 / 20)=5,355 \text { acres of conifers. }
\end{aligned}
$$

For area and volume estimates in the conifer vegetation type, $\mathrm{n}_{\mathrm{c}}=7, \mathrm{~N}_{\mathrm{c}}=5,355$ acres.

To compute the area estimators for wildlife or the snaileater's use within each stratum, all plots classed as having some sign of use are assigned a value of 1 and all other

\begin{tabular}{|c|c|c|c|c|c|}
\hline Stratum & Plot & $\begin{array}{c}\text { Wildlife } \\
\text { use }\end{array}$ & $\begin{array}{l}\text { Wildlife } \\
\text { estimators }\end{array}$ & $\begin{array}{c}\text { Volume/ } \\
\text { acre }\end{array}$ & $\begin{array}{c}\text { Volume } \\
\text { estimators }\end{array}$ \\
\hline \multirow[t]{14}{*}{ Conifer } & 2 & 1 & & 31 & \\
\hline & 8 & 1 & & 19 & \\
\hline & 10 & 0 & & 34 & \\
\hline & 11 & 0 & & 29 & \\
\hline & 12 & 1 & & 14 & \\
\hline & 14 & 0 & & 8 & \\
\hline & 18 & 0 & & 18 & \\
\hline & $\sum n_{c}$ & 3 & & 153 & \\
\hline & 8 & & 0.429 & & 21.857 \\
\hline & $s_{y}^{2}$ & & 0.286 & & 93.143 \\
\hline & $s_{\bar{y}}$ & & 0.202 & & 3.648 \\
\hline & $\% \mathrm{~s}_{\theta}$ & & \pm 47.14 & & \pm 16.68 \\
\hline & $S_{\bar{y}}{ }^{2}{ }_{c}$ & & 0.005 & & 1.628 \\
\hline & $\hat{y}_{c}$ & & 2,295 & & 117,045 \\
\hline
\end{tabular}
plots are given a value of zero.
Table 7-Results of poststratification of a systematic sample of the Enchanted Forest; volumes are in ccf

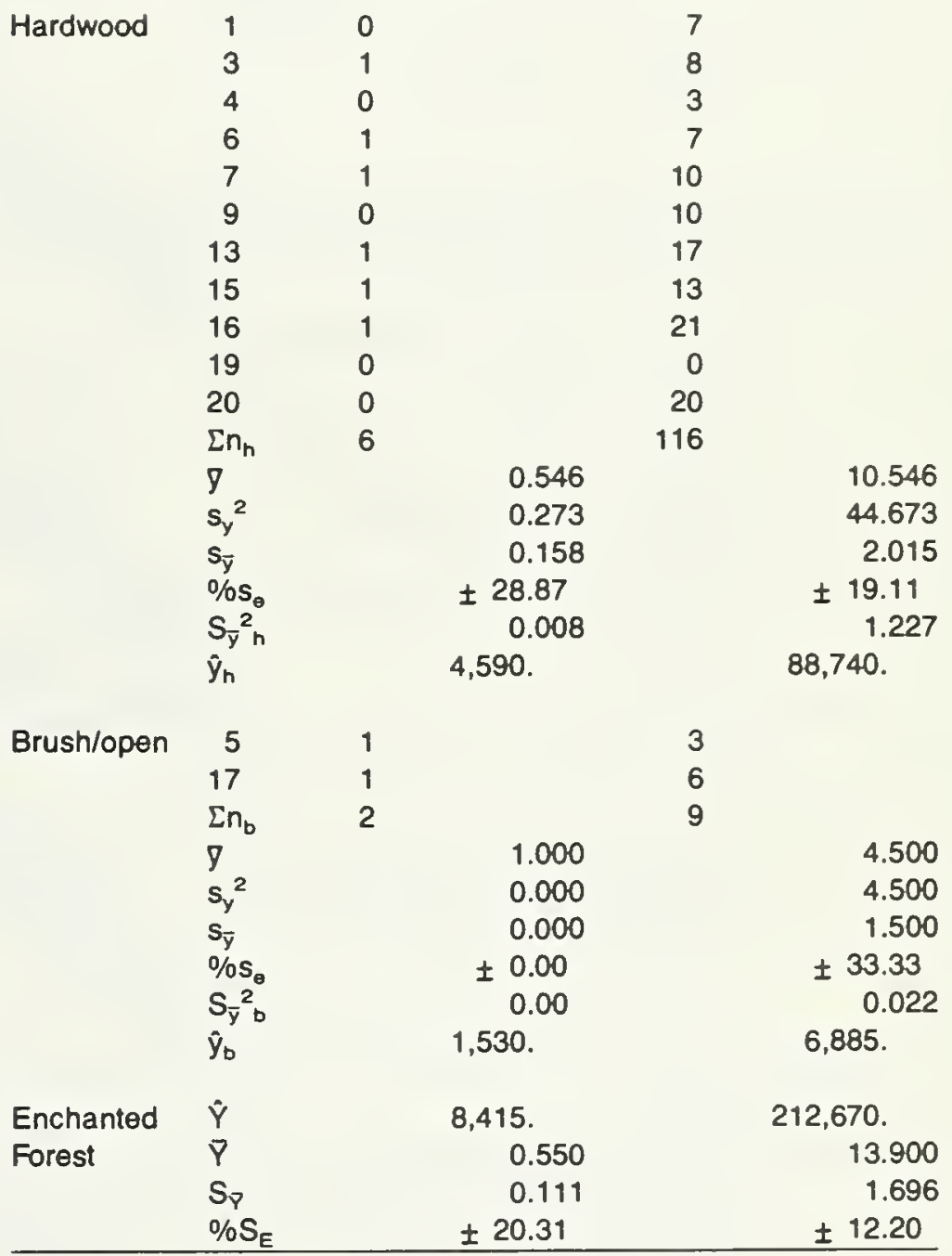


For the conifer (c) stratum:

$$
\begin{aligned}
\bar{y}_{c}= & (1+1+\ldots 0) / 7=0.4286 \text { acres of wildlife } \\
& \text { use per acre of stratum or } 42.9 \text { percent of the } \\
& \text { conifer stratum showed evidence of use. } \\
\left(s_{y}\right)_{c}= & \left\{\left(1^{2}+1^{2}+\ldots 0^{2}\right)-\left[(1+1+\ldots 0)^{2} / 7\right]\right\} / \\
& (7-1)=0.2857 . \\
\left(s_{\bar{y}}\right)_{c}= & (0.2857 / 7)^{1 / 2}=0.2020 \text { standard error for wild- } \\
& \text { life use per acre. Note that the f.p.c. is much } \\
& \text { less than .5 percent and is omitted. } \\
(\%)_{\mathrm{c}}= & (0.2020 / 0.4286) * 100= \pm 47.14 \% . \\
\hat{y}_{c}= & 0.4286 * 5,355=2,295 \text { acres of wildlife use in } \\
& \text { the conifer stratum. }
\end{aligned}
$$

Estimates of variance for a stratum are weighted by the proportion of plots in the stratum in order to obtain estimates for the Forest as a whole:

$$
\begin{aligned}
\left(\mathrm{s}_{\overline{\mathrm{y}}}{ }^{2}\right)_{\mathrm{i}}= & {\left[\mathrm{s}_{\mathrm{y}}{ }^{2} *\left(\mathrm{~N}_{\mathrm{i}} / \mathrm{N}\right)^{2} / \mathrm{n}_{\mathrm{i}}\right] *\left[1-\left(\mathrm{n}_{\mathrm{i}} / \mathrm{N}_{\mathrm{i}}\right)\right] } \\
\left(\mathrm{s}_{\overline{\mathrm{y}}}{ }^{2}\right)_{\mathrm{c}}= & {\left[\left(0.2857 *(5,355 / 15,300)^{2} / 7\right] *[1-(7 /\right.} \\
& 5,355)]=0.0050
\end{aligned}
$$

The same variance estimators are computed for the hardwood and brush/open strata. The area estimates are combined for the Forest as follows where:

$\hat{Y}=$ The total value in the Enchanted Forest.

$$
\hat{\mathrm{Y}}=\left(\hat{\mathrm{y}}_{1}+\hat{\mathrm{y}}_{2}+\ldots+\hat{\mathrm{y}}_{n}\right)
$$

$\hat{Y}=(2,295+4,590+1,530)=8,415$ acres of wildlife use in the Forest.

$\bar{Y}=$ The mean value in the Enchanted Forest.

$$
\overline{\mathrm{Y}}=\hat{\mathrm{Y}} / \mathrm{A}
$$

$\bar{Y}=8,415 / 15,300=0.5500$ proportion of wildlife use.

$S_{\bar{Y}}=$ The standard error of the mean for the Forest computed from the estimates for individual strata (from Freese 1962) is:

$S_{\bar{y}}=\left[\left(s_{\bar{y} 1}{ }^{2}+s_{\bar{y} 2}{ }^{2}+\ldots s_{\bar{y} n}{ }^{2}\right)\right]^{1 / 2}$

$S_{\bar{Y}}=(0.005+0.0075+0)^{1 / 2}=0.1117$ wildlife use per acre.

$\% S_{E}=$ The estimated sampling error of the mean value for the Forest expressed as a percent where:

$$
\% \mathrm{~S}_{\mathrm{E}}=\left(\mathrm{S}_{\overline{\mathrm{Y}}} / \overline{\mathrm{Y}}\right)
$$

$\% S_{E}=(0.1117 / 0.5500) * 100= \pm 20.31 \%$.
For total volume estimates:

$$
\begin{aligned}
\bar{y}_{\mathrm{c}}= & (31+19+\ldots 18) / 7=21.8571 \mathrm{ccf} \text { per acre. } \\
\left(\mathrm{s}_{\mathrm{y}}{ }^{2}\right)_{\mathrm{c}}= & \left\{\left(31^{2}+19^{2}+\ldots 18^{2}\right)-\left[(31+19+\ldots 18)^{2} /\right.\right. \\
& 7]\} /(7-1)=93.1429 . \\
\left(\mathrm{s}_{\bar{y}}\right)_{\mathrm{c}}= & (93.1429 / 7)^{1 / 2}=3.6477 \mathrm{ccf} \text { per acre. } \\
\left(\% \mathrm{~s}_{\mathrm{e}}\right)_{\mathrm{c}}= & (3.6477 / 21.86) * 100= \pm 16.68 \% . \\
\hat{y}_{\mathrm{c}}= & 21.86 * 5,355=117,045.00 \mathrm{ccf} \text { in conifer } \\
& \text { stratum. } \\
\left(\mathrm{s}_{\bar{y}}{ }^{2}\right)_{\mathrm{c}}= & {\left[93.1429 *(5,355 / 15,300)^{2} / 7\right] *[1-(7 /} \\
& 5,355)]^{2} 0.0050 .
\end{aligned}
$$

The same estimators are computed for the hardwood and brush/open strata. The estimates are combined for the Forest as follows where:

$$
\begin{aligned}
\hat{Y}= & (117,045+88,740+6,885)=212,670 \mathrm{ccf} \text { in } \\
& \text { the Forest. } \\
\bar{Y}= & 212,670 / 15,300=13.90 \mathrm{ccf} \text { per acre. } \\
\mathrm{S}_{\bar{Y}}= & (1.6279+1.2269+0.0225)^{1 / 2}=1.6962 \mathrm{ccf} \\
& \text { per acre. } \\
\% \mathrm{~S}_{\mathrm{E}}= & (1.6962 / 13.90) * 100= \pm 12.20 \% .
\end{aligned}
$$

The estimated area and volume by vegetation type are computed similarly. To compute estimates for the conifer type, for example, all plots not classed as conifer are assigned a value of 0 for volume and area. The area of conifer type is 2,295 acres; the area of hardwoods is 4,590 acres; and the area of brush/open is 1,530 acres.

The estimated total volume for each vegetation type is $117,045 \mathrm{ccf}$ for conifer, 88,740 ccf for hardwood, and $6,885 \mathrm{ccf}$ for the brush/open type respectively.

Mapping and Unmeasured Area Estimates-The options are the same as for systematic sampling.

Cost Estimates-The costs are the same as for systematic sampling. The only cost is the field cost.

$\mathrm{F}=\$ 2,275.31$, or $\$ 0.149$ per acre.

Discussion-There is little use of this technique in the USDA Forest Service. The procedure does offer the advantage of lowering the sampling error with no additional field work or costs. It remains something of a mystery why the method has not been widely implemented. Perhaps a combination of circumstances can be invoked for the apparent disuse. Where there is a large potential for stratification in the South, there is also the possibility of rapid forest type change. In much of the West where stratification could be applied, growth rates are 
slow enough that inventories are seldom necessary and hence are performed only near the rotation age on National Forests.

Strip Cruising-These techniques are based on the traditional strip cruise. Plots are laid out in strips or on a grid. The inventory crew maps strips of the Forest as they travel from plot to plot. Under the technique shown in figure 16, a total of 15,833.33 feet of lines were run. During the course of the inventory, a tally was kept of the number of feet of transect line run in each vegetation type. There were 6,792 feet run in the conifer type, 8,208 feet run in the hardwood type, and 833 feet run in the brush/open class. These figures provide the stratum weights.

Statistical Estimates-Table 8 shows the result of the inventory where:

$$
A_{c}=15,300 *(6,792 / 15,833)=6,563 \text { acres. }
$$

For area and volume estimates in the conifer vegetation type, $n_{c}=7, N_{c}=6,563$ acres. The area estimates for the red-spotted snaileater wildlife usage within the conifer stratum are computed as follows. As before, plots having signs of wildlife use are assigned a value of 1 and all other plots are given a value of zero.

\section{Forest Boundary}

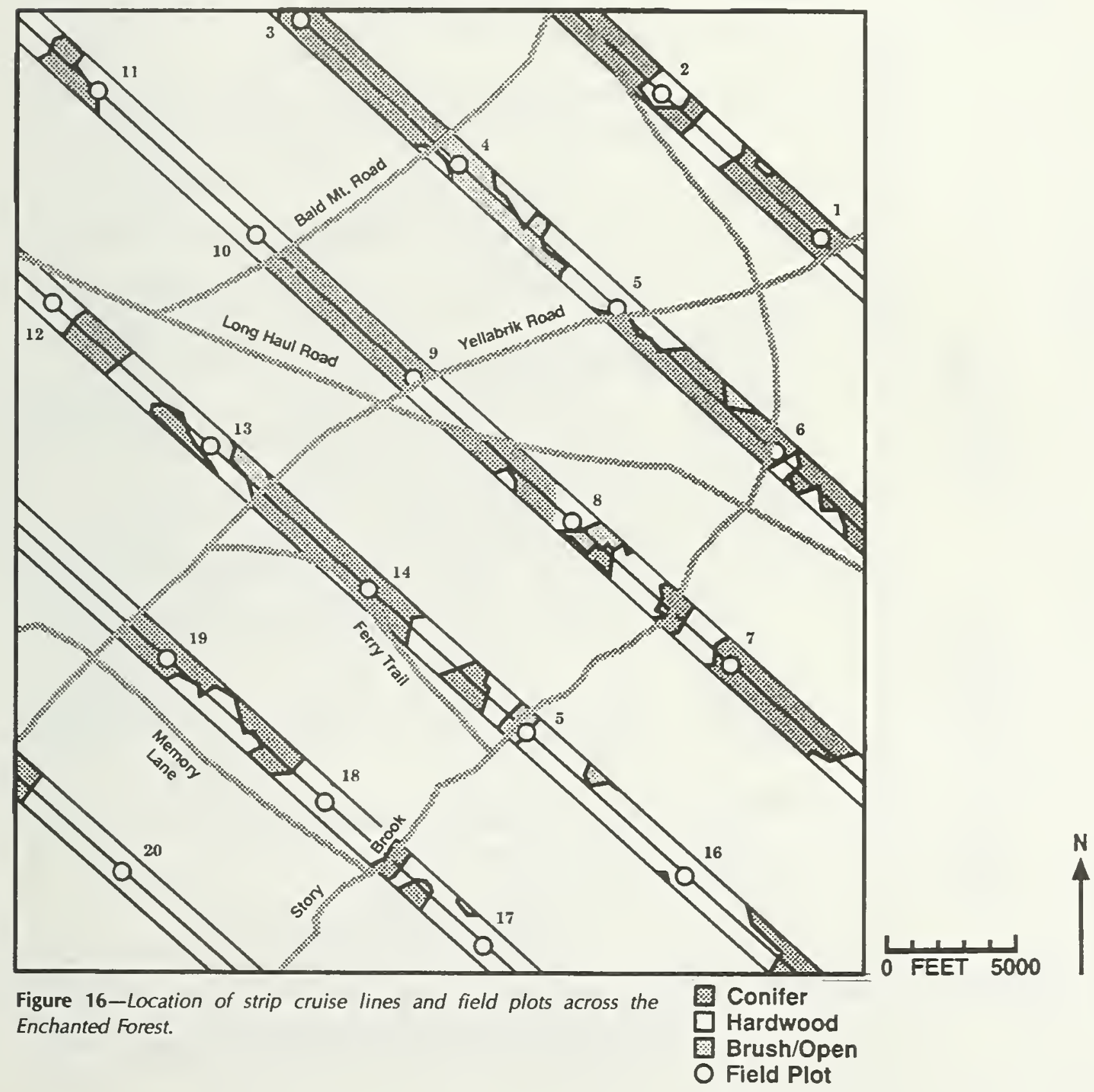


Table 8-Results of an inventory of the Enchanted Forest using strip cruising; volumes are in ccf

\begin{tabular}{|c|c|c|c|c|c|}
\hline Stratum & Plot & $\begin{array}{c}\text { Wildlife } \\
\text { use }\end{array}$ & $\begin{array}{c}\text { Wildlife } \\
\text { estimators }\end{array}$ & $\begin{array}{c}\text { Volume/ } \\
\text { acre }\end{array}$ & $\begin{array}{c}\text { Volume } \\
\text { estimators }\end{array}$ \\
\hline \multirow[t]{14}{*}{ Conifer } & 3 & 1 & & 31 & \\
\hline & 9 & 1 & & 19 & \\
\hline & 1 & 0 & & 34 & \\
\hline & 19 & 0 & & 29 & \\
\hline & 14 & 1 & & 14 & \\
\hline & 6 & 0 & & 8 & \\
\hline & 7 & 0 & & 18 & \\
\hline & $\Sigma n_{c}$ & 3 & & 153 & \\
\hline & g & & 0.429 & & 21.857 \\
\hline & $\mathrm{s}_{\mathrm{y}}{ }^{2}$ & & 0.286 & & 93.143 \\
\hline & $s_{\bar{y}}$ & & 0.202 & & 3.648 \\
\hline & $\% \mathrm{~s}_{\theta}$ & & \pm 47.14 & & \pm 16.69 \\
\hline & $\left(\mathrm{S}_{\bar{y}}^{2}\right)_{c}$ & & 0.008 & & 2.446 \\
\hline & $\hat{\mathbf{y}}_{c}$ & & 2,813 & & 143,448 \\
\hline \multirow[t]{18}{*}{ Hardwood } & 11 & 0 & & 7 & \\
\hline & 12 & 1 & & 8 & \\
\hline & 10 & 0 & & 3 & \\
\hline & 2 & 1 & & 7 & \\
\hline & 13 & 1 & & 10 & \\
\hline & 5 & 0 & & 10 & \\
\hline & 8 & 1 & & 17 & \\
\hline & 20 & 1 & & 13 & \\
\hline & 18 & 1 & & 21 & \\
\hline & 17 & 0 & & 0 & \\
\hline & 16 & 0 & & 20 & \\
\hline & $\Sigma n_{n}$ & 6 & & 116 & \\
\hline & y & & 0.546 & & 10.545 \\
\hline & $\mathrm{s}_{\mathrm{y}}^{2}$ & & 0.273 & & 44.673 \\
\hline & $s_{\bar{y}}$ & & 0.158 & & 2.015 \\
\hline & $\% \mathrm{~s}_{\boldsymbol{e}}$ & & \pm 28.87 & & \pm 19.11 \\
\hline & $\left(S_{\bar{y}}^{2}\right)_{h}$ & & 0.007 & & 1.090 \\
\hline & $\hat{y}_{h}$ & & 4,326 & & 83,647 \\
\hline \multirow[t]{9}{*}{ Brush/open } & 4 & 1 & & 3 & \\
\hline & 15 & 1 & & 6 & \\
\hline & $\Sigma n_{b}$ & 2 & & 9 & \\
\hline & 8 & & 1.000 & & 4.500 \\
\hline & $s_{y}^{2}$ & & 0.000 & & 4.500 \\
\hline & $s_{\bar{y}}$ & & 0.000 & & 1.500 \\
\hline & $\% \mathrm{~s}_{\theta}$ & & \pm 0.00 & & $\pm \mathbf{3 3 . 3 3}$ \\
\hline & $\left(S_{\bar{y}}^{2}\right)_{b}$ & & 0. & & 0.006 \\
\hline & $\hat{y}_{b}$ & & 805. & & 3,622 \\
\hline Enchanted & $\hat{Y}$ & & 7,944 & & 230,717 \\
\hline \multirow[t]{3}{*}{ Forest } & $\bar{Y}$ & & 0.519 & & 15.079 \\
\hline & $S_{p}$ & & 0.119 & & 1.882 \\
\hline & $\% \mathrm{~S}_{\mathrm{E}}$ & & \pm 22.91 & & \pm 12.48 \\
\hline
\end{tabular}

For the conifer (c) stratum:

$$
\begin{aligned}
\bar{y}_{c}= & (1+1+\ldots 0) / 7=0.4286, \text { or } 42.86 \text { percent } \\
& \text { wildlife use of the stratum. } \\
\left(\mathrm{s}_{\mathrm{y}}{ }^{2}\right)_{\mathrm{c}}= & \left\{\left(1^{2}+1^{2}+\ldots 0^{2}\right)-(1+1+\ldots 0)^{2} / 7\right\} /(7-1) \\
& =0.2857 . \\
\left(\mathrm{s}_{\overline{\mathrm{y}}}\right)_{\mathrm{c}}= & (0.2857 / 7)^{1 / 2}=0.2020 . \\
\left(\% \mathrm{~s}_{\mathrm{e}}\right)_{\mathrm{c}}= & (0.2020 / 0.4286) * 100= \pm 47.14 \% . \\
\hat{y}_{\mathrm{c}}= & 0.4286^{*} 6,563=2,812.7 \text { acres of wildlife use } \\
& \text { in the conifer stratum. } \\
\left(\mathrm{s}_{\overline{\mathrm{y}}}{ }^{2}\right)_{\mathrm{c}}= & {\left[0.2857 *(6,563 / 15,300)^{2} / 7\right] *[1-(7 /} \\
& 6,563)]=0.0075 .
\end{aligned}
$$

The same estimators are computed for the hardwood and brush/open strata. The area estimates are combined for the Forest as follows where:

$$
\hat{Y}=(2,813+4,326+805)=7,944 \text { acres of wildlife }
$$
use in the Forest.

We repeat that expressing the acreage is simply a way of dealing with an important classification variable.

$$
\begin{aligned}
\bar{Y}= & 7,944.4 / 15,300=0.5192 \text { proportion of wildlife } \\
& \text { use. } \\
\mathrm{S}_{\bar{Y}}= & (0.0075+0.0067+0)^{1 / 2}=0.1190 \text { wild life use } \\
& \text { per acre. } \\
\% \mathrm{~S}_{\mathrm{E}}= & (0.1190 / 0.5192) * 100= \pm 22.91 \% .
\end{aligned}
$$

For total volume estimates:

$$
\begin{aligned}
\bar{y}_{c}= & (31+19+\ldots 18) / 7=21.8571 \text { ccf per acre. } \\
\left(\mathrm{s}_{\mathrm{y}}{ }^{2}\right)_{\mathrm{c}}= & \left\{\left(31^{2}+19^{2}+\ldots 18^{2}\right)-(31+19+\ldots 18)^{2} /\right. \\
& 7\} /(7-1)=93.143 . \\
\left(\mathrm{s}_{\bar{y}}\right)_{\mathrm{c}}= & (93.143 / 7)^{1 / 2}=3.648 \mathrm{ccf} \text { per acre. } \\
\left(\% \mathrm{~s}_{\mathrm{e}}\right)_{\mathrm{c}}= & (3.6458 / 21.85) * 100= \pm 16.69 \% . \\
\hat{y}_{\mathrm{c}}= & 21.8571 * 6,563=143,448.43 \mathrm{ccf} \text { in conifer } \\
& \text { stratum. } \\
\left(\mathrm{s}_{\overline{\mathrm{y}}}{ }^{2}\right)_{\mathrm{c}}= & {\left.\left[93.1429 *(6,563 / 15,300)^{2}\right) / 7\right] *[1-(7 /} \\
& 6,563)]=2.4457 .
\end{aligned}
$$

The same estimators are computed for the hardwood and brush/open strata.

These estimates are then combined for the Forest as follows where:

$$
\begin{aligned}
\hat{Y}= & (143,448.4286+83,646.5455+3,622.5)= \\
& 230,717.474 \mathrm{ccf} \text { in the Forest. } \\
\bar{Y}= & 230,717.474 / 15,300=15.0796 \mathrm{ccf} \text { per acre. } \\
\mathrm{S}_{\bar{Y}=} & (2.4457+1.09+0.0062)^{1 / 2}=1.8820 \mathrm{ccf} \text { per } \\
& \text { acre } \\
\% \mathrm{~S}_{\mathrm{E}}= & (1.882 / 15.0796)^{*} 100= \pm 12.48 \% .
\end{aligned}
$$


The estimated area and volume by vegetation type are similarly computed. To compute estimates for the conifer type, for example, all plots not classed as conifer are assigned a value of 0 for volume and area. The area of conifer type is 6,563 acres, the area of hardwoods is 7,932 acres, and the area of brush/open is 805 acres.

The estimated total volume for each vegetation type is $143,448 \mathrm{ccf}$ for conifer, 83,646 ccf for hardwood, and $3,623 \mathrm{ccf}$ for the brush/open type respectively.

Mapping and Unmeasured Area Estimates-Areas outside the sampled and mapped strips are assumed to have the average conditions of the inventory unit as a whole (15.08 ccf per acre). Within the mapped strips, unmeasured areas are assigned the average values for the stratum in which they fall. See figure 17.

Cost Estimates-The costs are the same as for systematic sampling. The only cost is the field cost.

$$
F=\$ 2,275 \text {, or } \$ 0.149 \text { per acre. }
$$

Discussion-This technique was used in the early days of the USDA Forest Service, but is seldom used today. Line intersect sampling (a hybrid probability sample and a line transect) has been used to sample downed woody material to evaluate fire hazard potential (Brown 1974, De Vries 1986).

\section{Forest Boundary}

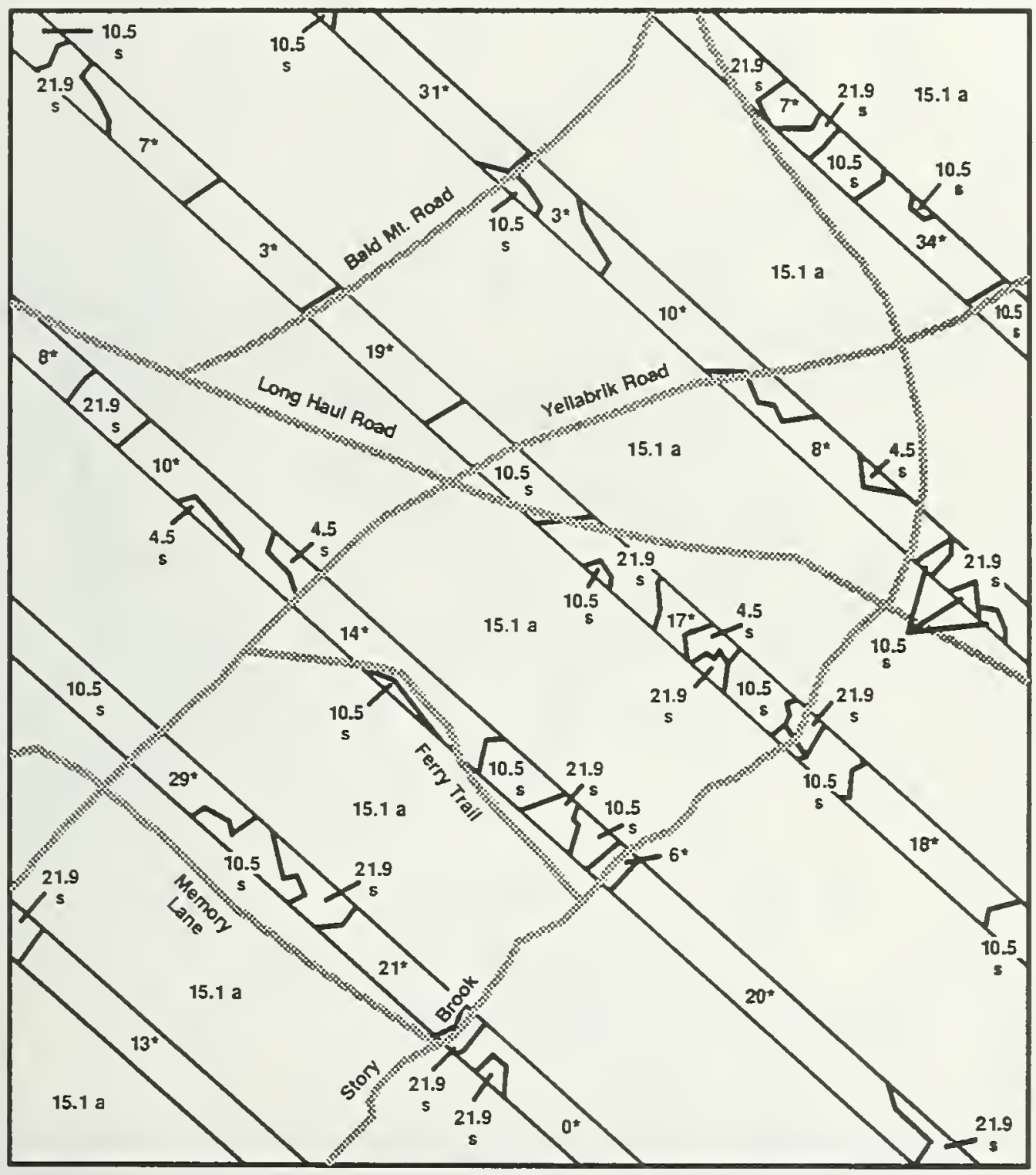

Figure 17-Mapping showing measured (*), stratum average (s), and Forest average (a) volume (cct) per acre based on the strip cruise inventory. 
Prestratification-By prestratifying, a heterogeneous inventory unit is divided into homogeneous subunits (strata). Each stratum is then sampled for additional attributes. The strata estimates are combined to give a population estimate. Stratification has provided satisfactory estimates of the inventory unit as a whole with less field work than if stratification had not been used (Maclean 1972).

The principle means of obtaining prestratification information is usually by interpreting remote sensing imagery. Strata may be formed along many lines, such as overstory density classes, vegetation types, or even administrative units (though this latter may not result in gains in inventory efficiency). Strata should: (1) be logically related to item or items of information sought; (2) exist in nature or be artificially established; (3) represent a relative homogeneous condition with respect to the estimates that can be defined in specific terms; (4) have differentiating criteria easily recognizable from remote sensing, maps, and from the ground; (5) represent a grouping that the manager definitely wants sampled on the ground; and (6) be meaningful to the manger (Lund 1978a and b).

To eliminate potential biases and to keep calculations simple, the same plot configuration should be used throughout the sampling stratum. Plot configuration may be changed between strata but not within.

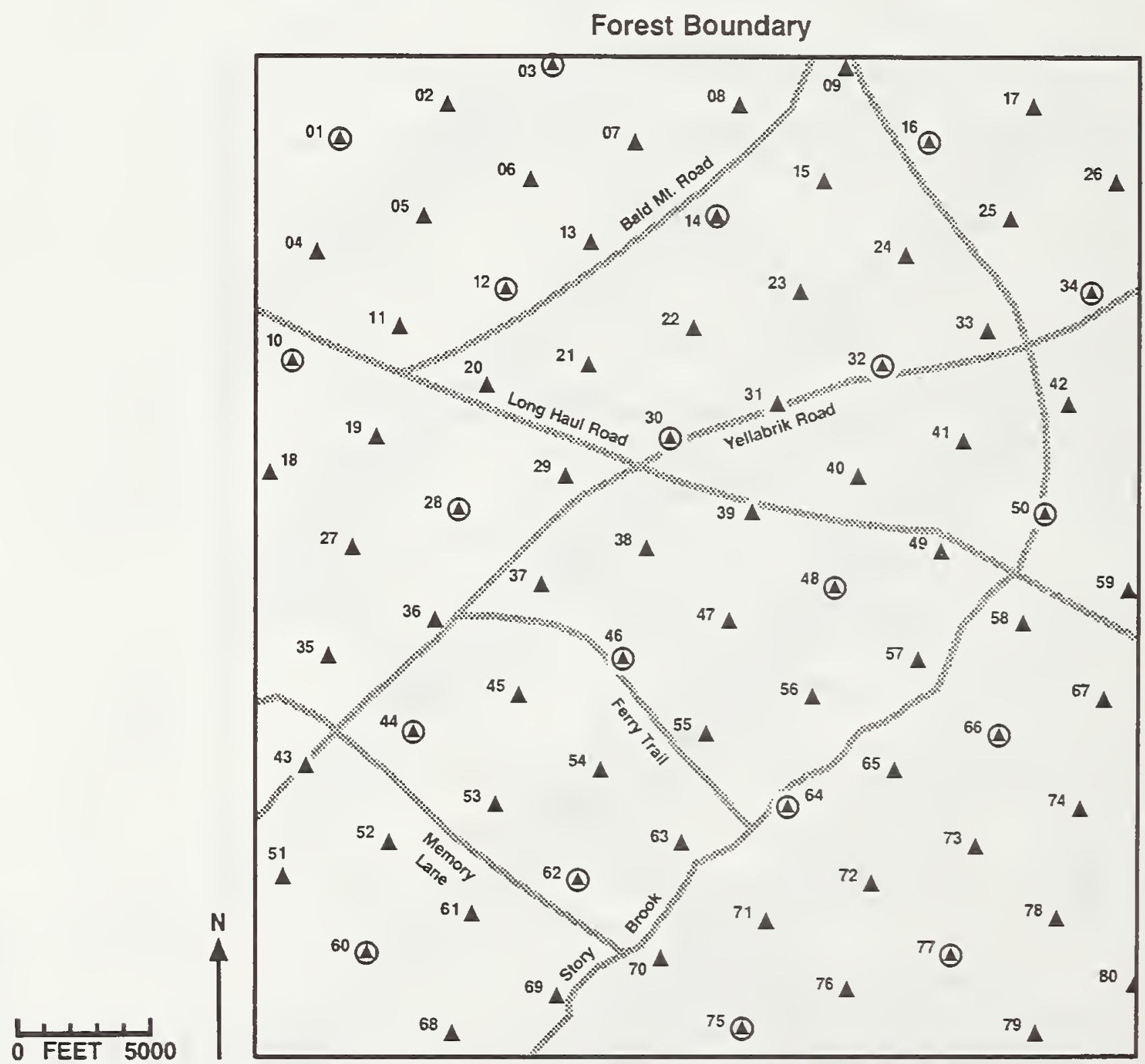

Figure 18-Location of systematic distribution of photo points in the Enchanted Forest. Points are located at 60 degrees and 3,101 feet from one another.
A Photo Point

$\bigcirc$ Field Plot 
Stratified Double Sampling-A grid of points is established across the inventory unit (fig. 18). These points are usually transferred to aerial photos, which are in turn interpreted for attributes to form sampling strata (in this case overstory crown cover or density class). The photointerpreted points are the primary sampling units. These are stratified and subsampled in the field as secondary sampling units (fig. 19). The use of random numbers or a systematic system with a random start may be used to select the secondary sample within each stratum. At least two sample plots must be chosen in each stratum.

In this example, three density classes-low, medium, and high density-were formed. A total of 80 photo points were established: 32 in the low density strata; 25 in the medium density class; and 23 in the high crown cover category. These photo points were subsampled with field plots. Ten photo points were measured in the field in the low density strata; 6 points were field measured in the medium strata; and 4 were measured in the high density class.

Statistical Estimates-The results of an inventory of the Enchanted Forest using the stratified double sample of photo points are shown in table 9, where the area and volume estimators are computed as follows:

\section{Forest Boundary}

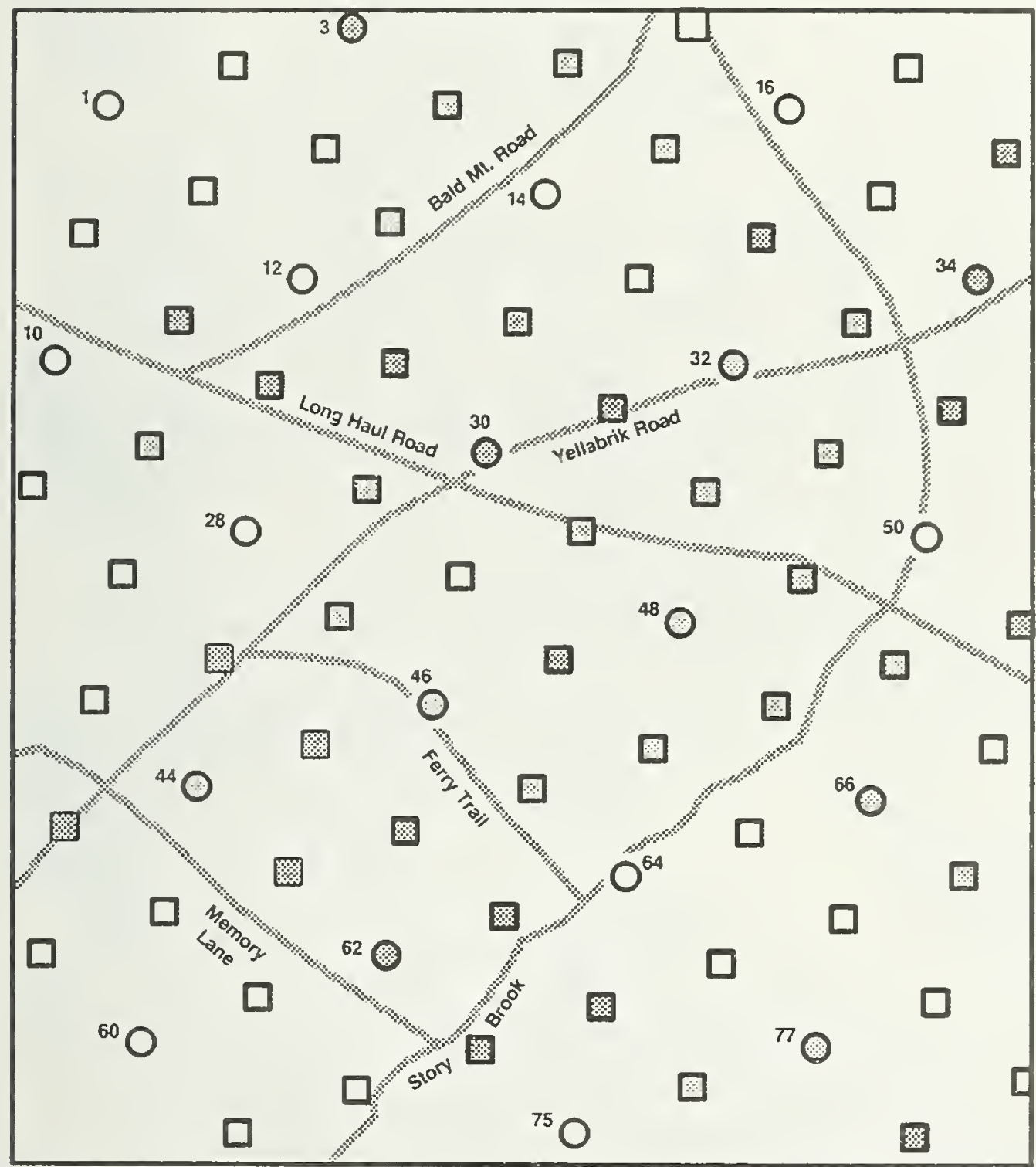

Figure 19-Location of stratified photo points and field samples based upon overstory density classes in the Enchanted Forest.
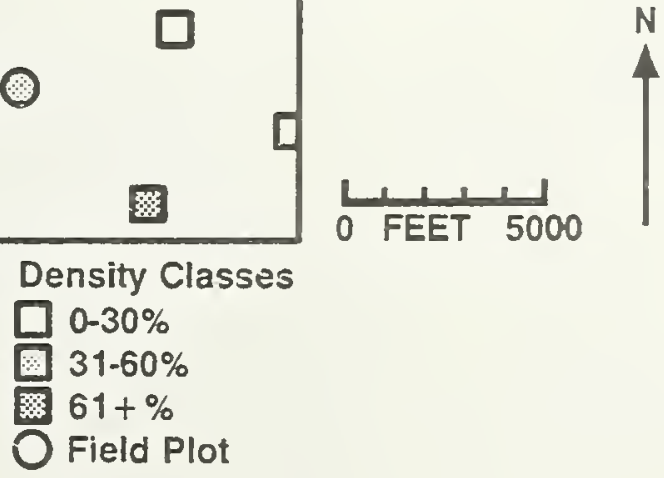
Table 9-Results of an inventory of the Enchanted Forest using a stratified double sample of photo interpreted points; volumes are in ccf

\begin{tabular}{|c|c|c|c|c|c|c|}
\hline Stratum & Point & Vegetation type & Wildlife use & Wildlife estimators & Volume/acre & Volume estimators \\
\hline \multirow[t]{17}{*}{ Low density } & 1 & Hardwood & 0 & & 7 & \\
\hline & 10 & Hardwood & 1 & & 8 & \\
\hline & 12 & Hardwood & 0 & & 3 & \\
\hline & 14 & Brush/open & 1 & & 3 & \\
\hline & 16 & Hardwood & 1 & & 7 & \\
\hline & 28 & Hardwood & 1 & & 10 & \\
\hline & 50 & Conifer & 0 & & 8 & \\
\hline & 60 & Hardwood & 1 & & 13 & \\
\hline & 64 & Brush/open & 1 & & 6 & \\
\hline & 75 & Hardwood & 0 & & 0 & \\
\hline & $\Sigma n_{1}$ & & 6 & & 65 & \\
\hline & 8 & & & 0.600 & & 6.500 \\
\hline & $s_{y}{ }^{2}$ & & & 0.266 & & 14.055 \\
\hline & $s_{\bar{y}}^{*}$ & & & 0.135 & & 0.983 \\
\hline & $\% s_{\theta}$ & & & \pm 22.57 & & \pm 15.12 \\
\hline & $\left(S_{\bar{y}}^{2}\right)_{1}$ & & & 0.003 & & 0.155 \\
\hline & $\hat{y}_{1}$ & & & 3,672 & & 39,780 \\
\hline \multirow[t]{13}{*}{ Medium density } & 32 & Hardwood & 0 & & 10 & \\
\hline & 44 & Conifer & 1 & & 29 & \\
\hline & 46 & Conifer & 0 & & 14 & \\
\hline & 48 & Hardwood & 1 & & 17 & \\
\hline & 66 & Conifer & 0 & & 18 & \\
\hline & 77 & Hardwood & 0 & & 20 & \\
\hline & $\Sigma n_{m}$ & & 2 & & 108 & \\
\hline & $\hat{y}$ & & & 0.333 & & 18.000 \\
\hline & $s_{y}{ }^{2}$ & & & 0.267 & & 41.200 \\
\hline & $s_{\mathrm{y}}^{*}$ & & & 0.184 & & 2.284 \\
\hline & $\% \mathrm{~s}_{\theta}$ & & & \pm 55.14 & & \pm 12.69 \\
\hline & $\left(S_{\bar{y}}^{2}\right)_{m}$ & & & 0.003 & & 0.510 \\
\hline & $\hat{y}_{m}$ & & & 1,594 & & 86,062 \\
\hline \multirow[t]{11}{*}{ High density } & 3 & Conifer & 1 & & 31 & \\
\hline & 30 & Conifer & 1 & & 19 & \\
\hline & 34 & Conifer & 0 & & 34 & \\
\hline & 62 & Hardwood & 1 & & 21 & \\
\hline & $\Sigma n_{h}$ & & 3 & & 105 & \\
\hline & $g$ & & & 0.750 & & 26.250 \\
\hline & $s_{y}^{2}$ & & & 0.250 & & 54.250 \\
\hline & $s_{\bar{y}} *$ & & & 0.227 & & 3.347 \\
\hline & & & & \pm 30.30 & & \pm 12.75 \\
\hline & $\left(S_{\bar{y}}^{2}\right)_{n}$ & & & 0.004 & & 0.926 \\
\hline & $\hat{y}_{h}$ & & & 3,299 & & 115,467 \\
\hline \multirow[t]{4}{*}{ Enchanted Forest } & $\hat{\gamma}$ & & & 8,565 & & 241,310 \\
\hline & 8 & & & 0.559 & & 15.771 \\
\hline & $S_{\vec{p}}$ & & & 0.102 & & 1.261 \\
\hline & $\% S_{E}$ & & & \pm 18.30 & & \pm 8.00 \\
\hline
\end{tabular}


The area in each stratum $\left(A_{1}, A_{m}, A_{h}\right.$, representing low, medium and high density, respectively) is computed as follows:

$$
A_{I}=15,300 *(32 / 80)=6,120 \text { acres. }
$$

For area and volume estimates in the low density type $n_{1}=$ $10, N_{1}=32$ plots.

To compute the area estimators for the snail-eater wildlife use within each stratum, all plots classed as having wildlife use are assigned a value of 1 and all other plots are given a value of 0 . For the low density stratum:

$(\bar{y})_{1}=(0+1+\ldots 0) / 10=0.60$ proportion of wildlife use.

$\left(\mathrm{s}_{\mathrm{y}}{ }^{2}\right)_{\mathrm{l}}=\left\{\left(0^{2}+1^{2}+\ldots 0^{2}\right)-(0+1+\ldots 0)^{2} / 10\right\} /$ $(10-1)=0.2667$.

$\left(\mathrm{s}_{\bar{y}}\right)^{*}{ }_{1}=(0.2667 / 10) *[1-(10 / 32)]^{1 / 2}=0.1354$ wildlife use per plot. Note that a large portion of the sample is drawn, hence the f.p.c. is necessary in the computation.

$\left(\% s_{e}\right)_{1}=(0.1354 / 0.6000) * 100= \pm 22.57 \%$.

$\hat{y}_{1}=0.6000 * 6,120=3,672.0$ acres of wildlife use in the low density stratum.

$\left(s_{\bar{y}}\right)_{1}^{2}=\left[0.2667 *(32 / 80)^{2} / 10\right] *[1-(10 / 32)]=$ 0.0029 .

The same estimators are computed for the medium and high density strata. The area estimates are combined for the Forest as follows where:

$$
\begin{aligned}
\hat{Y}= & (3,672+1,593.75+3,299.0625)= \\
& 8,565.8125 \text { acres of wildlife use in the Forest. } \\
\bar{Y}= & 8,564.8125 / 15,300=0.5598 \text { wildlife use per } \\
& \text { acre. } \\
\mathrm{S}_{\bar{Y}}= & (0.0029+0.0033+0.0043)^{1 / 2}=0.1025 \\
& \text { proportion of wildlife use. } \\
\% S_{E}= & (0.1025 / 0.56) * 100= \pm 18.30 \% .
\end{aligned}
$$

For total volume estimates:

$$
\begin{aligned}
(\bar{y})_{1}= & (7+8+\ldots 0) / 10=6.500 \mathrm{ccf} \text { per acre. } \\
\left(\mathrm{s}_{\bar{y}}{ }^{2}\right)_{1}= & \left\{\left(7^{2}+8^{2}+\ldots 0^{2}\right)-\left[(7+8+\ldots 0)^{2} / 10\right]\right\} / \\
& (10-1)=14.0556 . \\
\left(s_{\bar{y}}\right)_{1}^{*}= & (14.0556 / 10) *[1-(10 / 32)]^{1 / 2}=0.983 \mathrm{ccf} \\
& \text { per acre. } \\
\left(\% \mathrm{~s}_{\mathrm{e}}\right)_{1}= & (0.983 / 6.500) * 100= \pm 15.12 \% . \\
\hat{y}_{1}= & 6.500 * 6,120=39,780 \mathrm{ccf} \text { in the low density } \\
& \text { stratum. } \\
\left(\mathrm{s}_{\bar{y}}{ }^{2}\right)_{1}= & {\left[14.0556 *(32 / 80)^{2} / 10\right] *[1-(10 / 32)]=} \\
& 0.1546 .
\end{aligned}
$$

The same estimators are computed for the medium and high density strata.

The estimates are combined for the Forest as follows where:

$$
\begin{aligned}
\hat{Y}= & (39,780+86,062.5+115,467.1875)= \\
& 241,309.6875 \mathrm{ccf} \text { in the Forest. } \\
\bar{Y}= & 241,309.6875 / 15,300=15.7719 \mathrm{ccf} \text { per acre. } \\
S_{\bar{Y}=} & (0.1546+0.5096+0.9261)^{1 / 2}=1.2611 \mathrm{ccf} \\
& \text { per acre. } \\
\% S_{E}= & (1.2611 / 15.7719) * 100= \pm 8.00 \% .
\end{aligned}
$$

The estimated area and volume by vegetation type are similarly computed. To compute estimates for the conifer type, for example, all plots not classed as conifer are assigned a value of 0 for volume and area. Table 10 shows the results for the conifer type. The area of conifer type is 6,301 acres, the area of hardwoods is 7,774 acres, and the area of brush/open is 1,224 acres. The estimated total volume for each vegetation type is $145,879 \mathrm{ccf}$ for conifer, $89,922 \mathrm{ccf}$ for hardwood, and 5,508 ccf for the brush/ open type respectively.

Mapping and Unmeasured Area Estimates-The options for creating map displays are the same as those given under systematic sampling. Each photo plot has an expansion factor (EF) ur represents an area of 191.25 acres. To illustrate the source of estimates, field sampled photo points retain their measured values. Other photo points take on the stratum averages. All other areas are assigned the average for the inventory unit. See figure 20.

Cost Estimates-The field costs are the same as for the systematic sample plus the cost of purchasing aerial photography of the Forest plus the costs of interpreting 80 points at $\$ 0.02$ per point.

\begin{tabular}{llr} 
Field costs & $=$ & $\$ 2,275$ \\
Aerial photography & $=$ & 489 \\
Photo interpretation & $=$ & 2 \\
\hline Total costs & $=$ & $\$ 2,766$,
\end{tabular}


Table 10-Results and estimates for conifer vegetation type using the stratified double sampling of photo points; volumes are in ccf

\begin{tabular}{|c|c|c|c|c|c|}
\hline Stratum & Point & Volume/acre & Volume estimators & Type & Type estimators \\
\hline \multirow[t]{17}{*}{ Low density } & 1 & 0 & & 0 & \\
\hline & 10 & 0 & & 0 & \\
\hline & 12 & 0 & & 0 & \\
\hline & 14 & 0 & & 0 & \\
\hline & 16 & 0 & & 0 & \\
\hline & 28 & 0 & & 0 & \\
\hline & 50 & 8 & & 1 & \\
\hline & 60 & 0 & & 0 & \\
\hline & 64 & 0 & & 0 & \\
\hline & 75 & 0 & & 0 & \\
\hline & $\Sigma n_{1}$ & 8 & & 1 & \\
\hline & $g$ & & 0.800 & & 0.100 \\
\hline & $s_{y}{ }^{2}$ & & 6.400 & & 1.000 \\
\hline & $s_{\bar{y}}{ }^{*}$ & & 0.663 & & 0.083 \\
\hline & $\% \mathrm{~s}_{\theta}$ & & \pm 82.91 & & \pm 82.91 \\
\hline & $\left(S_{\bar{y}}^{2}\right)_{1}$ & & 0.070 & & 0.001 \\
\hline & $\hat{y}_{1}$ & & 4,896 & & 612. \\
\hline \multirow[t]{13}{*}{ Medium density } & 32 & 0 & & 0 & \\
\hline & 44 & 29 & & 1 & \\
\hline & 46 & 14 & & 1 & \\
\hline & 48 & 0 & & 0 & \\
\hline & 66 & 18 & & 1 & \\
\hline & 77 & 0 & & 0 & \\
\hline & $\Sigma n_{m}$ & 61 & & 3 & \\
\hline & $g^{m}$ & & 10.166 & & 0.500 \\
\hline & $s_{y}{ }^{2}$ & & 148.167 & & 0.300 \\
\hline & $s_{\bar{y}}^{*}$ & & 4.332 & & 0.194 \\
\hline & $\% \mathrm{~s}_{\theta}$ & & \pm 42.61 & & \pm 38.98 \\
\hline & $\left(S_{\bar{y}}\right)_{m}^{2}$ & & 1.833 & & 0.004 \\
\hline & $\hat{y}_{m}$ & & 48,609 & & 2,390 \\
\hline \multirow[t]{11}{*}{ High density } & 3 & 31 & & 1 & \\
\hline & 30 & 19 & & 1 & \\
\hline & 34 & 34 & & 1 & \\
\hline & 62 & 0 & & 0 & \\
\hline & $\Sigma n_{n}$ & 84 & & 3 & \\
\hline & g & & 21.000 & & 0.750 \\
\hline & $s_{y}{ }^{2}$ & & 238.000 & & 0.250 \\
\hline & $\mathrm{s}_{\mathrm{y}}^{*}$ & & 7.010 & & 0.227 \\
\hline & & & \pm 33.38 & & \pm 30.29 \\
\hline & $\left(S_{\bar{\gamma}}\right)^{2}$ & & 4.063 & & 0.004 \\
\hline & $\hat{y}_{n}$ & & 92,373 & & 3,299 \\
\hline \multirow[t]{4}{*}{ Enchanted Forest } & $\hat{Y}$ & & $145,879.125$ & & $6,301.687$ \\
\hline & $\bar{Y}$ & & 9.534 & & 0.411 \\
\hline & $s_{\gamma}$ & & 2.442 & & 0.095 \\
\hline & $\% S_{E}$ & & \pm 25.62 & & \pm 23.13 \\
\hline
\end{tabular}


Discussion-This technique is very common in the United States, particularly by the USDA Forest Service Forest inventory and Analysis Units (Beltz 1984, Cost 1984, Hahn 1984, Born 1984, and Ohmann 1984). Stratified double sampling is particularly useful where aerial photography exists and large areas must be covered in a short period of time. Some attention to the ages of photographs and to the classification of points versus areas of photographs could improve the estimates obtained from the technique. Unfortunately, stratified double sampling is too often applied as if there were no differences in ages of photography and the point classification. These problems are minor though they probably should be considered for applications where areas are the most important factor in the inventory.

Lund (1974) also used this technique for forest inventories in the U.S. Department of Interior Bureau of Land Management, and Lund and Kniesel (1975) used the same process to inventory multiresource values, including herbage production, soil surface factors, soil cover, and deerdays use.

The Northeast FIA unit uses a modification of this technique and sampling with partial replacement (Barnard 1984). Sampling with partial replacement (SPR) is very

Forest Boundary
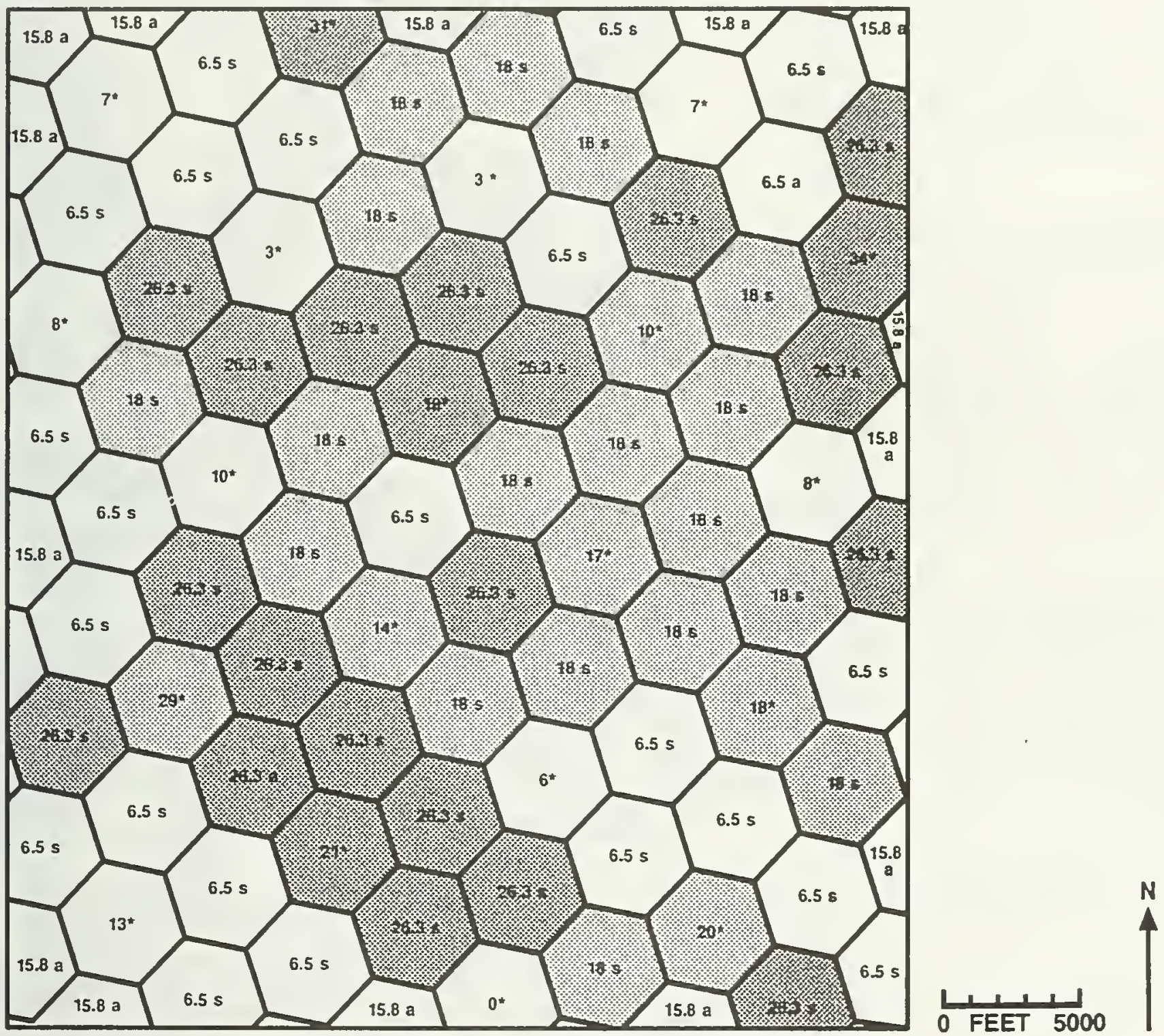

Figure 20-Mapping showing measured (*), stratum average (s), and Forest average (a) volume (cct) per acre based on the stratified double sample of photo points. Each hexagon approximately represents 191 acres.

Density Classes
$0-30 \%$
$31-60 \%$
$61+\%$ 
effective for remeasurements or reinventories when stratum weights remain relatively stable over periods between inventories and the variables of interest are few. There are significant computational and data storage and retrieval costs associated with SPR that must be considered in a practical application of the method. Further discussion of SPR is beyond the scope of this report. The reader may consult the references given at the end of this publication for further details.

Use of Satellite Imagery-Earth-orbiting satellites, such as Landsat, have been applied to research inventories for broad mapping of forest resources and for forming sampling strata (Langley 1975, and Poso 1986). Figure 21 is a simulated satellite scene of the Enchanted Forest. The pixels are 15 acres in size. A sampling frame consisting of 1,020 possible cells is constructed for the Enchanted Forest. Three sampling strata based upon apparent vegetation density or canopy cover are created through classification of the scene. Classification techniques are becoming increasingly automated and produce increasingly repeatable results. While the earliest applications for forestry inventory were overly optimistic about the capabilities of satellite imagery acquisition, cost, interpretation, continuous improvements have made the practical application on a large scale more and more realistic.

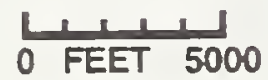

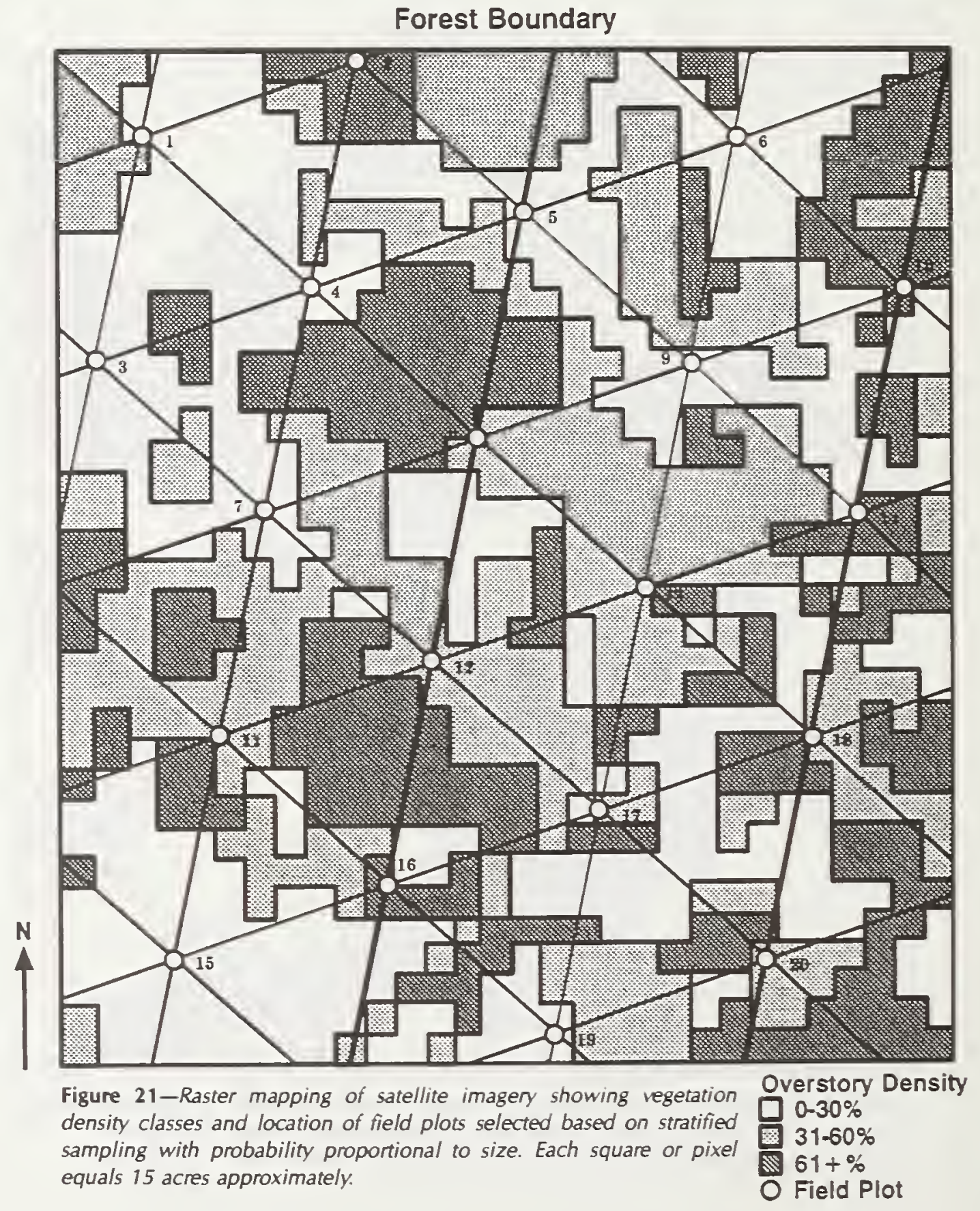


While our example forest is too small to warrant satellite imagery, it does serve to illustrate some possible uses of digital imagery.

Satellite imagery was used to classify pixels into vegetation density classes. Foresters might think of these as crown densities for forest stands older than the youngest seedling and sapling stands. Crown densities were classified thus: 6,240 acres ( 416 cells) at 0 to 30 percent; 5,115 acres ( 341 cells) at 31 to 60 percent; and 3,945 acres ( 263 cells) at 61 percent or greater. The number of cells are used to determine the strata weights.

A grid is superimposed across the classified satellite scene. Potential field plots are established at the grid intersections and grouped by the density classes resulting in a stratified sample of the forest. At least two samples are required per stratum. If the grid does not yield a sample of a particular stratum, the grid intensity can be increased or a special grid may be created for the unmeasured stratum.

Statistical Estimates-The results of the sample of the Enchanted Forest are given in table 11. For area and volume estimates in the low-density type, $n_{1}=9, N_{1}=$ 416 cells.

To compute the area estimators for snaileater use within each stratum, all plots classed as having the wildlife use are assigned a value of 1 and all other plots are given a value of zero. For the low-density stratum:

$\bar{y}_{1}=(0+1+\ldots 0) / 9=0.5556$ proportion of wildlife use acres.

$\left(s_{y}{ }^{2}\right)_{1}=\left\{\left(0^{2}+1^{2}+\ldots 0^{2}\right)-(0+1+\ldots 0)^{2} / 9\right\} /$ $(9-1)=0.2778$.

$\left(s_{\bar{y}}\right)_{\mid}=(0.2778 / 9)^{1 / 2}=0.1757$ standard error of estimate for proportion of wildlife use.

$\left(\% \mathrm{~s}_{\mathrm{e}}\right)_{1}=(0.1757 / 0.5556) * 100= \pm 31.62 \%$.

$\hat{y}_{1}=0.5556 * 6,240=3,466.667$ acres of wildlife use in the low-density stratum.

$\left(S_{\bar{y}}\right)_{1}^{2}=\left[0.2778+(416 / 1020)^{2} / 9\right] *[1-(9 / 416)]=$ 0.005 .
The same estimators are computed for the medium- and high-density strata. The area estimates are combined for the Forest as follows where:

$$
\begin{aligned}
\hat{Y}= & (3,466.6667+2,557.5+2,367)=8,391.1667 \\
& \text { acres of wildlife use in the Forest. } \\
\bar{Y}= & 8,391.1667 / 15,300=54.84 \text { percent wildlife } \\
& \text { use in the area. } \\
S_{\bar{Y}}= & (0.005+0.0055+0.0039)^{1 / 2}=0.1201 \mathrm{ccf} \text { per } \\
& \text { acre. } \\
\% S_{E}= & (0.1201 / 0.5484) * 100= \pm 21.90 \% .
\end{aligned}
$$

For total volume estimates:

$$
\begin{aligned}
\bar{y}_{1}= & (7+8+\ldots 0) / 9=6.5556 \text { ccf per acre. } \\
\left(\mathrm{s}_{\bar{y}}^{2}\right)_{1}= & \left\{\left(7^{2}+8^{2}+\ldots 0^{2}\right)-(7+8+\ldots 0)^{2} /\right. \\
& 9\} /(9-1)=15.7778 . \\
\left(\mathrm{s}_{\bar{y}}\right)_{1}= & (15.78 / 9)^{1 / 2}=1.3240 \mathrm{ccf} \text { per acre. } \\
\left(\% \mathrm{~s}_{\mathrm{e}}\right)_{1}= & (1.324 / 6.56) * 100= \pm 20.20 \% . \\
\hat{y}_{1}= & 6.5556 * 6,240=40,906.6667 \mathrm{ccf} \text { in the } \\
& \text { low-density stratum. } \\
\left(\mathrm{S}_{\bar{y}}\right)_{1}^{2}= & {\left.[15.7778+416 / 1020)^{2} / 9\right] *[1-(9 / 416)]=} \\
& 0.2853 .
\end{aligned}
$$

The same estimators are computed for the medium and high-density strata. The estimates are combined for the Forest as follows where:

$$
\begin{aligned}
\hat{Y}= & (40,906.6667+80,135+98,625)= \\
& 219,666.6667 \mathrm{ccf} \text { total volume in the Forest. } \\
\bar{Y}= & 219,666.6667 / 15,300=14.3573 \mathrm{ccf} \text { per acre. } \\
\mathrm{S}_{\bar{Y}=} & (0.2853+1.1468+0.6326)^{1 / 2}=1.4369 \mathrm{cdf} \\
& \text { per acre. } \\
\% \mathrm{~S}_{\mathrm{E}}= & (1.4369 / 14.3573) * 100= \pm 10.01 \% .
\end{aligned}
$$

The estimated area and volume by vegetation type are similarly computed. To compute estimates for the conifer type, for example, all plots not classed as conifer are assigned a value of 0 for volume and area. Table 12 shows the estimates for the conifer type. The area of conifer type is 5,618 acres, the area of hardwoods is 8,136 acres, and the area of brush/open is 1,546 acres.

The estimated total volume is 123,825 ccf for conifer, $88,646 \mathrm{ccf}$ for hardwood, and 7,195 ccf for the brush/ open type respectively. 
Table 11-Results of an inventory of the Enchanted Forest using stratified satellite imagery; volumes are in ccf

\begin{tabular}{|c|c|c|c|c|c|c|}
\hline Stratum & Plot & Vegetation type & Wildlife use & Wildlife estimators & Volume/acre & Volume estimators \\
\hline \multirow[t]{16}{*}{ Low density } & 1 & Hardwood & 0 & & 7 & \\
\hline & 3 & Hardwood & 1 & & 8 & \\
\hline & 4 & Hardwood & 0 & & 3 & \\
\hline & 5 & Brush/open & 1 & & 3 & \\
\hline & 6 & Hardwood & 1 & & 7 & \\
\hline & 7 & Hardwood & 1 & & 10 & \\
\hline & 14 & Conifer & 0 & & 8 & \\
\hline & 15 & Hardwood & 1 & & 13 & \\
\hline & 19 & Hardwood & 0 & & 0 & \\
\hline & $\Sigma n_{1}$ & & 5 & & 59 & \\
\hline & 8 & & & 0.555 & & 6.555 \\
\hline & $s_{y}^{2}$ & & & 0.278 & & 15.778 \\
\hline & $s_{\bar{y}}$ & & & 0.175 & & 1.324 \\
\hline & $\% s_{\theta}$ & & & \pm 31.62 & & \pm 20.20 \\
\hline & $\left(S_{\bar{y}}^{2}\right)_{1}$ & & & 0.005 & & 0.285 \\
\hline & $\hat{y}_{1}$ & & & 3,466 & & 40,906 \\
\hline \multirow[t]{13}{*}{ Modium density } & 9 & Hardwood & 0 & & 10 & \\
\hline & 11 & Conifer & 1 & & 29 & \\
\hline & 12 & Conifer & 0 & & 14 & \\
\hline & 13 & Hardwood & 1 & & 17 & \\
\hline & 18 & Conifer & 0 & & 18 & \\
\hline & 17 & Brush/open & 1 & & 6 & \\
\hline & $\Sigma n_{m}$ & & 3 & & 94 & \\
\hline & 8 & & & 0.500 & & 15.666 \\
\hline & $\mathrm{s}_{\mathrm{y}}{ }^{2}$ & & & 0.300 & & 62.666 \\
\hline & $s_{\bar{y}}$ & & & 0.224 & & 3.232 \\
\hline & $\% \mathrm{~s}_{\mathrm{e}}$ & & & \pm 44.72 & & \pm 20.63 \\
\hline & $\left(S_{\bar{y}}^{2}\right)_{m}$ & & & 0.006 & & 1.147 \\
\hline & $\hat{y}_{m}$ & & & 2,557 & & 80,135 \\
\hline \multirow[t]{12}{*}{ High density } & 2 & Conifer & 1 & & 31 & \\
\hline & 8 & Conifer & 1 & & 19 & \\
\hline & 10 & Conifer & 0 & & 34 & \\
\hline & 16 & Hardwood & 1 & & 21 & \\
\hline & 20 & Hardwood & 0 & & 20 & \\
\hline & $\Sigma n_{n}$ & & 3 & & 125 & \\
\hline & 8 & & & 0.600 & & 25.000 \\
\hline & $s_{y}{ }^{2}$ & & & 0.300 & & 48.500 \\
\hline & $s_{\bar{y}}$ & & & 0.245 & & 3.115 \\
\hline & $\% \mathrm{~s}_{\mathrm{e}}$ & & & \pm 40.82 & & \pm 12.46 \\
\hline & $\left(S_{\bar{y}}^{2}\right)_{h}$ & & & 0.004 & & 0.633 \\
\hline & $\hat{\mathbf{y}}$ & & & 2,367 & & 98,625 \\
\hline \multirow[t]{4}{*}{ Enchanted Forest } & $\hat{Y}$ & & & 8,391 & & 219,666 \\
\hline & $P$ & & & 0.548 & & 14.357 \\
\hline & $S_{\gamma}$ & & & 0.120 & & 1.436 \\
\hline & $\% S_{E}$ & & & \pm 21.90 & & \pm 10.01 \\
\hline
\end{tabular}


Table 12-Results and estimates for the conifer vegetation type using stratified satellite imagery of the Enchanted Forest; volumes are in cof

\begin{tabular}{|c|c|c|c|c|c|}
\hline Stratum & Plot & Volume/acre & Volume estimators & Type & Type estimators \\
\hline \multirow{16}{*}{ Low density } & 1 & 0 & & 0 & \\
\hline & 3 & 0 & & 0 & \\
\hline & 4 & 0 & & 0 & \\
\hline & 5 & 0 & & 0 & \\
\hline & 6 & 0 & & 0 & \\
\hline & 7 & 0 & & 0 & \\
\hline & 14 & 8 & & 1 & \\
\hline & 15 & 0 & & 0 & \\
\hline & 19 & 0 & & 0 & \\
\hline & $\Sigma n_{1}$ & 8 & & 1 & \\
\hline & 8 & & 0.889 & & 0.111 \\
\hline & $s_{y}{ }^{2}$ & & 7.111 & & 0.111 \\
\hline & $s_{\bar{y}}$ & & 0.889 & & 0.110 \\
\hline & $\% \mathrm{~s}_{\mathrm{o}}$ & & \pm 100 & & \pm 100 \\
\hline & $\left(S_{\bar{y}}\right)^{2}$ & & 0.129 & & 0.002 \\
\hline & $\hat{y}_{1}$ & & 5,546 & & 693. \\
\hline \multirow[t]{13}{*}{ Medium density } & 9 & 0 & & 0 & \\
\hline & 11 & 29 & & 1 & \\
\hline & 12 & 14 & & 1 & \\
\hline & 13 & 0 & & 0 & \\
\hline & 18 & 18 & & 1 & \\
\hline & 17 & 0 & & 0 & \\
\hline & $\Sigma n_{m}$ & 61 & & 3 & \\
\hline & $e^{2}$ & & 10.167 & & 0.500 \\
\hline & $s_{y}{ }^{2}$ & & 148.167 & & 0.300 \\
\hline & $\mathrm{s}_{\bar{y}}$ & & 4.969 & & 0.224 \\
\hline & $\% s_{0}$ & & \pm 48.88 & & \pm 44.33 \\
\hline & $\left(S_{\bar{y}}\right)^{2} \mathrm{~m}$ & & 2.711 & & 0.006 \\
\hline & $\hat{\mathbf{y}}_{\mathrm{m}}$ & & 52,002 & & 2,557 \\
\hline \multirow[t]{12}{*}{ High density } & 2 & 31 & & 1 & \\
\hline & 8 & 19 & & 1 & \\
\hline & 10 & 34 & & 1 & \\
\hline & 16 & 0 & & 0 & \\
\hline & 20 & 0 & & 0 & \\
\hline & $\Sigma n_{n}$ & 84 & & 3 & \\
\hline & 8 & & 16.800 & & 0.600 \\
\hline & $s_{y}^{2}$ & & 266.700 & & 0.300 \\
\hline & $s_{\bar{y}}$ & & 7.303 & & 0.245 \\
\hline & $\% s_{e}$ & & \pm 43.47 & & \pm 40.83 \\
\hline & $\left(S_{\bar{y}}^{2}\right)_{n}$ & & 3.479 & & 0.004 \\
\hline & $\tilde{y}_{h}$ & & 66,276 & & 2,367 \\
\hline \multirow[t]{4}{*}{ Enchanted Forest } & $\hat{\varphi}$ & & 123,825 & & 5,618 \\
\hline & $P$ & & 8.093 & & 0.367 \\
\hline & $s_{p}$ & & 2.513 & & 0.106 \\
\hline & $\% \mathrm{~S}_{\mathrm{E}}$ & & \pm 31.06 & & \pm 29.09 \\
\hline
\end{tabular}


Mapping and Unmeasured Area Estimates-The satellite scene also serves as a rough map of the resources. Areas classified and mapped as having low density, for example, can be assumed to be hardwood vegetation 78 percent of the time and have a volume of $15.78 \mathrm{ccf}$ per acre \pm 19.98 percent based upon the field survey. Pixels containing the field plots may be assigned the measured values. All other pixels are assigned the stratum averages. See figure 22 .

Note that both sampled volumes and stratum averages are shown. In actual practice, only stratum averages are usually displayed in the mapping process. In such in- stances, resource managers need to be aware of the source of the information displayed and the associated sampling errors.

Cost Estimates-The cost estimates include costs incurred from purchases, interpretation of imagery, and field activities.

\begin{tabular}{llr} 
Field costs & $=$ & $\$ 2,275$ \\
Imagery of Forest & $=$ & 61 \\
Interpretation of Forest & $=$ & 382 \\
Mapping & $=$ & 306 \\
\hline Total costs & $=\$ 3,024$, or $\$ 0.198$ per acre.
\end{tabular}

\section{Forest Boundary}

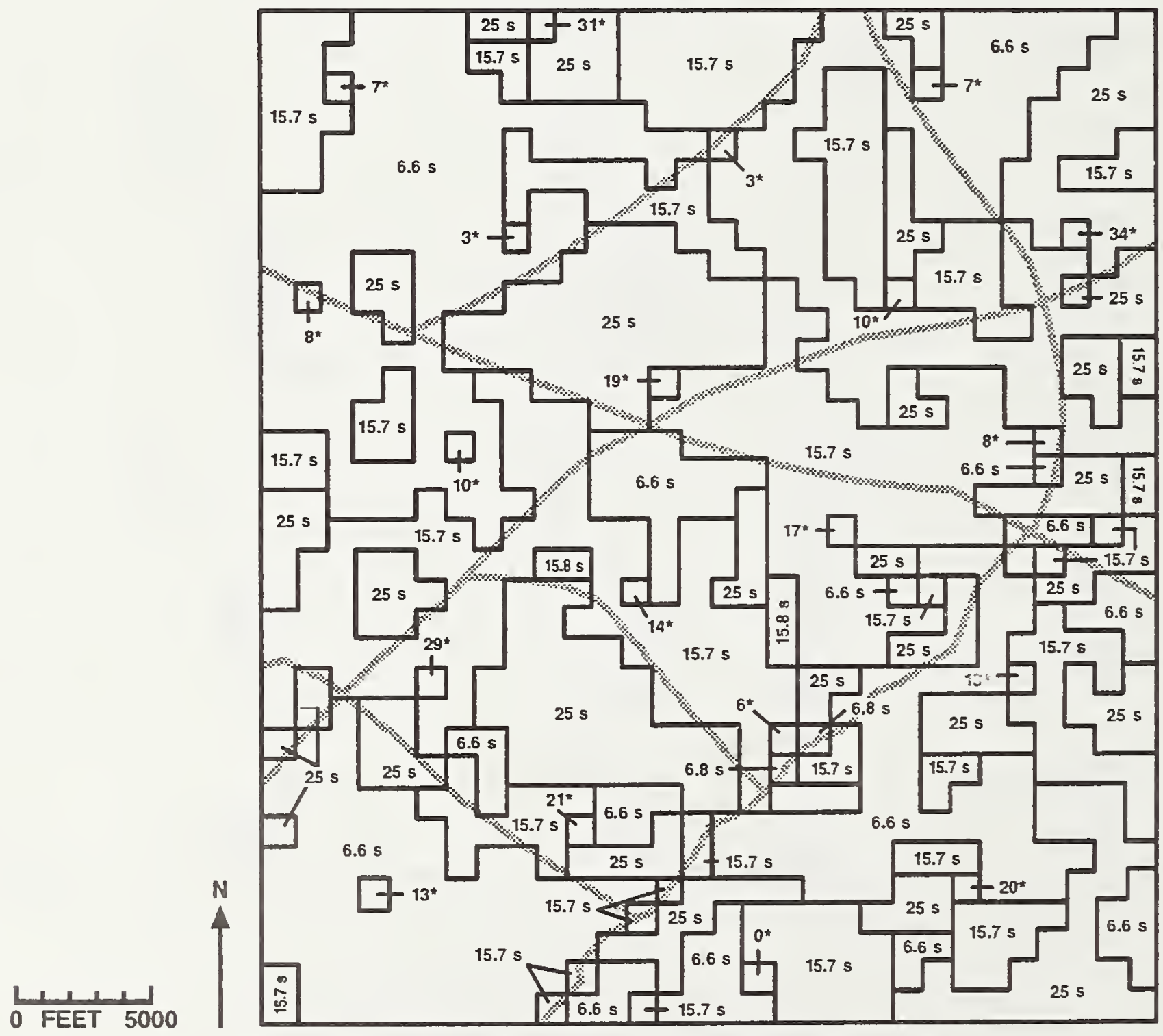

Figure 22-Mapping showing measured (*) and stratum average (s) volume (cct) per acre based on the stratified satellite imagery sample. Each pixel represents 15 acres. 
Discussion-The example given in this report used pixels 15 acres in size. In reality, pixels of $30 \times 30$ meters are common when using Landsat Thematic Mapper or SPOT image data. The California Region uses this technique using Landsat imagery (Bowlin 1984). The Alaska FIA unit uses a technique employing two additional phases of high and low altitude aerial photography (Larson 1984).

The digital nature of many satellite systems creates an instant geographical information system that can be combined with other georeferenced data and used to produce various theme maps (Mattila 1984). A truly practical inventory based on available satellite imagery has been an elusive and illusory goal for nearly 20 years. It has been applied in both industry and forest survey, perhaps only on a show-me scale. There is still a hefty and expensive requirement for equipment and statistical as well as remote sensing expertise. There is increasing evidence that satellite imagery is now the design tool of the present instead of the dream of the future.

\section{Inventories With Prior Stand Mapping}

If all the stands in a compartment or forest have been mapped, the use of these mapped stands as primary sampling units offers several advantages over the use of sample plots. In addition to providing estimates for the inventory unit, mapped stands provide (Stage 1984):

- Opportunities to study spatial relations between stands.

- Easy coordination among resources. The stands can be used as common data sources and can be overlaid upon maps of streams, wildlife "edge" habitat, and nesting sites or other delineations that are represented by lines or points rather than areas.

- More appropriate prescription because the full range of variation within realistically-sized treatment units can be used in analysis.

- Concentrated day-to-day work in nearby areas with potential savings in transportation by using larger crews or local "spike" camps.

- Dual use of the stand data to meet several objectives, such as quality control for stand examination procedures and pre-sale cruising. Estimates generated for stands that were not sampled can be used to establish priorities for more detailed silvicultural examinations or timber cruises thus helping to implement forest plans.
It should be noted that different sampling designs have been developed to deal with different populations. Characteristics of the population should be considered when selecting a sampling design. If we know nothing about the population, then simple random sampling is almost certainly the first method to consider. Populations for which information exists concerning some characteristic such as the area from aerial survey, but not for those variables we wish estimates such as proportion of the area showing wildlife usage, should be sampled using a design that incorporates the known information. Even for these cases certain sampling designs may be appropriate for some mapped conditions and not for others. We will try to illustrate computational methods for a variety of sampling designs and at the same time note the characteristics of the Enchanted Forest that appear to support the use of that particular method or to negate its use.

Inventories using mapped polygons or stands are used to develop forest management plans. The resources and their condition and potential are generally described only in sufficient detail to direct the manager's attention to specific locations within the inventory unit for more intensive planning. Area, volume, and production estimates are usually tied to each polygon or stand (Lund 1985). If plots are established for remeasurement, they are usually established to measure growth and monitor response to treatments. In both cases plot establishment should be done with a good deal of attention being paid to probable time sensitivity of the plots. Time interval before remeasurement should be planned well in advance and should consider the likely rotation of the species or forest type in which the plot is being established.

Stand mapping has been accomplished using satellite imagery (Hame and Tomppo 1987, Tomppo 1987) and this capability will certainly improve in the future. However, for general purposes aerial photography is still adequate. Processing of aerial photographs might be done with electronic scanners in the future and this could well provide a relatively low cost transition technology leading to the use of satellite imagery.

This section examines sampling stands mapped using aerial photography to obtain a forest inventory as well as providing estimates for all stands in the forest. Even though the examples are for timber estimates using aerial photography on a small forest and a relatively few stands, the principles, techniques, and options apply to most natural resource surveys using all forms of remote sensing and any size area. 
To compute statistical estimators, assume that the Enchanted Forest has been mapped into 200 stands (fig. 23), acreage has been determined for each stand, and the boundaries of the stands will not change upon field visitation.

Further assume that a total of 10 sample plots (n) within selected stands will form the secondary sample and will be systematically established by overlaying a grid of equilateral triangles, and plots require 0.5 hours to measure $(\mathrm{m})$. Plot results are expanded for the sample stands. The estimated values for these sampled stands then con- stitute the basis for predicting the inventory for stands that were not sampled in the forest inventory unit. Finally, for simplicity and uniformity of presentation we have consistently computed the finite correction factor for all estimators. This is readily available with computer spreadsheets; however, it would not be necessary (the sampling fraction being much less than .05 ) for hand computation for some of the examples.

For cost estimators, assume the purchase of aerial photography (\$489.60) and the cost of mapping of $\$ 1,147.50$ for the Forest applies to all of the following designs. Stands are the primary sampling unit.

\section{Forest Boundary}

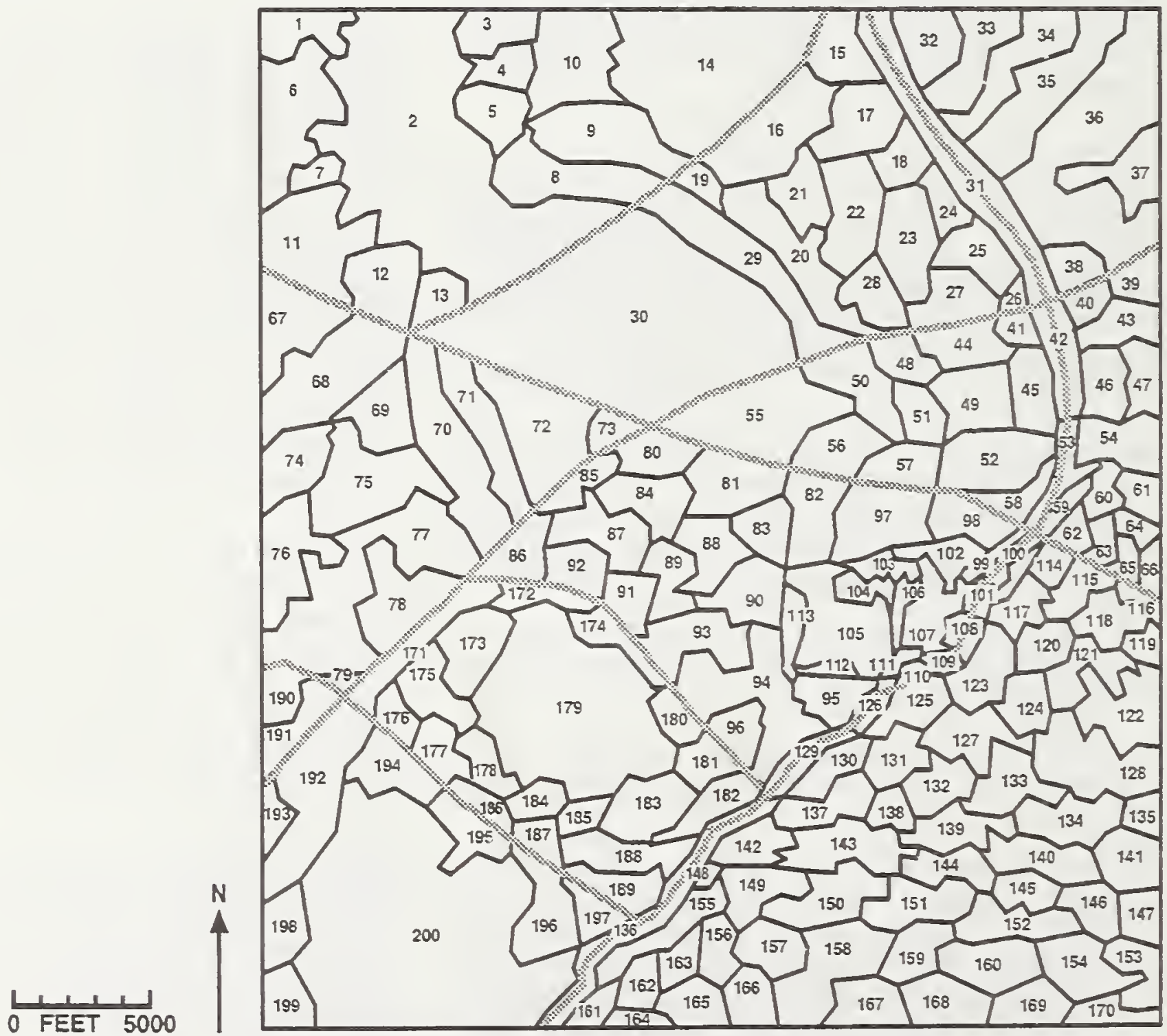

Figure 23-Location of previously mapped stands in the Enchanted Forest showing only stand boundaries and stand identification numbers. 
Using equation $(d), i=224.272(a / 10)^{1 / 2}$

$$
\text { or } \mathbf{i}=70.921 \mathrm{a}^{1 / 2}
$$

where $a$ is the area of the sample stand in acres.

The time $\left(M_{s}\right)$ to traverse and measure a sample stand is

$$
\begin{aligned}
& M_{s}=\left\{(n-1) 70.921 a^{1 / 2}\right\} / 10,560+n(0.5) . \\
& M_{s}=\left\{9\left(0.0067 a^{1 / 2}\right)\right\}+10(0.5) \text { for } 10 \text { plots, } \\
& \text { or } 0.0603 a^{1 / 2}+5 .
\end{aligned}
$$

Stand no. 10 for example, is 120 acres. Using equation (i), $M_{\mathrm{s}}=\left\{0.0603(120)^{1 / 2}\right\}+10(0.5)=5.1$ hours.

The daily travel time (D) is revised as follows:

$$
D=\left[L+\Sigma\left(M_{s}\right)\right] / 8
$$

where $\Sigma(M)=$ the sum of the time to measure all selected stands.

Similarly, total cost of field time $(F)$ is adjusted to:

$$
F=C W\left[\left(L+\Sigma\left(M_{s}\right)+D\right]\right.
$$

Unstratified Sampling-Auxiliary information consists of the location, identification number, and acreage of each stand (see Appendix 2). Given this limited information, the options for selecting stands for sampling are unstratified, equal probability sampling (e.p.s.) and probability proportional to a measure of size (p.p.s.). Note the difference between allocation of a sample with probability proportional to size and to a measure of size. In the first case we must have information regarding size of the variable of interest itself. In the second case a variable that may have a relation to the variable of interest is used as a surrogatein this case the acreage of each stand is used as the selection surrogate.

Equal Probability Sampling (e.p.s.)-Equal probability sampling means that each stand, regardless of acreage, has an equal chance of being selected for measurement. A simple random number generator can be used to select stands by identification number or, if these are not consecutive, a unique whole number may be assigned to them. Figure 24 shows the stands selected for forest inventory. It should be noted that this is not the method that would be preferred for estimating most properties of interest in the Enchanted Forest. The occurrence of very large area units that are an order of magnitude larger than the average stand should be a red flag warning us to use a sampling system other than e.p.s.
However, this example gives us an opportunity to demonstrate the necessity for employing two different estimation techniques for parameters having different sampling distribution characteristics. Wildlife use is sampled by recording the presence or absence of evidence on a single plot in the stand; it is a binary variable. Plotting the data from a sample of 20 stands reveals no trend between this variable and the size of the stand. Consequently, wildlife use or any other variate sampled by a presence/absence indication should be estimated as a simple random sample obtained without replacement. In contrast volume estimates when plotted versus acreage do show a relation between volume and acreage. The relationship is not the classical linear relation through the origin for a ratio and gives some large values that have very low volumes associated with the acreage. This indicates that stratification would be extremely useful, but for this example we are going to ignore the stratification protential in order to demonstrate the use of a weighted mean to compensate for the unequal sizes of stands acreage.

Statistical Estimates-To calculate the estimated mean volume per acre a weighted mean is employed:

$$
\bar{y}_{w}=\Sigma w_{i} y_{i} / \Sigma w_{i}
$$

where $w$ is the stand acreage and $y$ is the continuous variable of interest (volume per acre). A simple unweighted mean is not appropriate when the unequal area stands are sampled with equal probability.

The variance of a weighted mean is equal to:

$$
s_{w}{ }^{2}=\Sigma w_{i}\left(y_{i}-\bar{y}_{w}\right)^{2} / \Sigma w_{i}
$$

The standard error is simply the square root of the weighted variance divided by the number of samples:

$$
s_{w}=\left(s_{w}^{2} / n\right)^{1 / 2}
$$

Finally the percent sampling error $\left(\% \mathrm{~s}_{\mathrm{ew}}\right)$ is:

$$
\% s_{\text {ew }}=\left(s_{w} / \bar{y}_{w}\right) * 100
$$

Note that the above calculations do not account for the variation within the sampled stands from the secondary sampling units. In most cases of broad forest inventories, as illustrated in this section, such variation is rarely computed and is beyond the scope of this publication. An alternative treatment of these computations may be found in Loetsch and Haller (1964). 
Table 13 shows the results of the equal probability sampling where area and volume estimators are calculated as follows.

For area of snaileater use, a proportion estimate is employed: the value one is assigned to stands in which the sample showed evidence of snaileater use, otherwise stands are assigned value zero. Recalling that only a single plot per stand is assessed regardless of area and that the expected value for a proportion is given by:

$$
\bar{y}_{p}=\Sigma\left(n_{i=1}\right) / n_{s}
$$

where $n_{s}$ is the sample size and $n_{i-1}$ is the number of occurrences.

The variance of a proportion is:

$$
\begin{aligned}
s^{2}\left(\bar{y}_{p}\right)= & \bar{y}_{p}\left(1-\bar{y}_{p}\right) \\
\bar{y}_{p}= & (0+1+\ldots+0) / 20=0.500 ; \text { a proportion } \\
& \text { expressing wildlife use per plot. } \\
s^{2}\left(\bar{y}_{p}\right)= & 0.500 *(1-0.500)=0.250 \\
s_{\bar{y}}= & (0.250 / 20)^{1 / 2}=0.162 . \\
\% s_{e w ~}= & 0.162 / 0.500 * 100= \pm 32.40 \% \\
\hat{y} & =0.500 * 15300=7650 .
\end{aligned}
$$

\section{Forest Boundary}

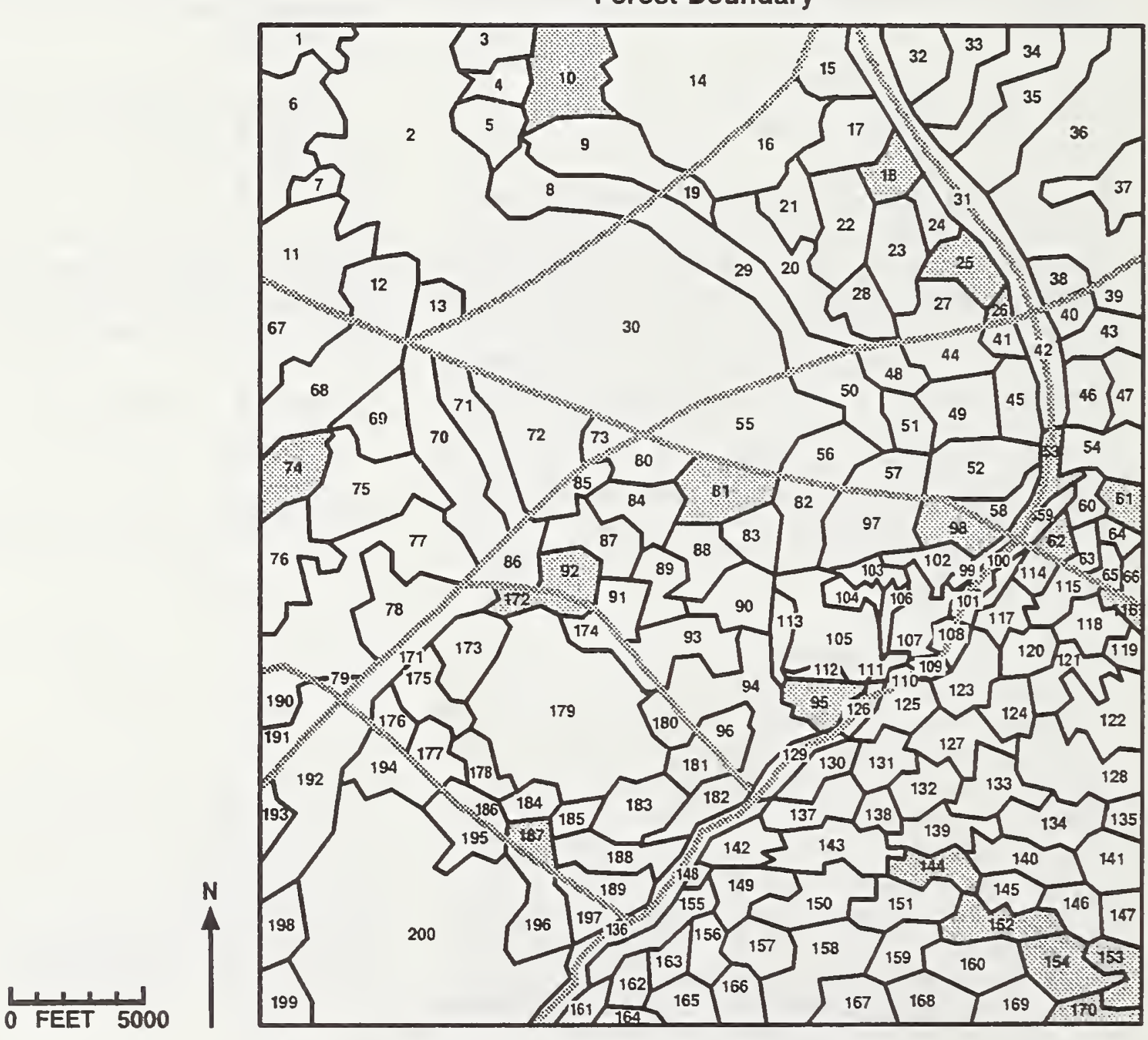

Figure 24-Location of primary sampling units (shaded stands) based upon a random draw of stand numbers using equal probability sampling. 
Table 13-Results of an inventory of the Enchanted Forest using equal probability sampling of mapped stands; area estimates are in acres and volume estimates are in ccf

\begin{tabular}{|c|c|c|c|c|c|c|}
\hline Stand & Area & $\begin{array}{l}\text { Vegetation } \\
\text { type }\end{array}$ & $\begin{array}{c}\text { Wildlife } \\
\text { use }\end{array}$ & $\begin{array}{l}\text { Wildlife } \\
\text { estimators }\end{array}$ & $\begin{array}{c}\text { Volumel } \\
\text { acre }\end{array}$ & $\begin{array}{c}\text { Volume } \\
\text { estimators' }\end{array}$ \\
\hline 18 & 60 & Conifer & 0 & & 21 & \\
\hline 25 & 60 & Hardwood & 1 & & 10 & \\
\hline 98 & 45 & Hardwood & 1 & & 30 & \\
\hline 74 & 60 & Hardwood & 0 & & 15 & \\
\hline 187 & 30 & Hardwood & 1 & & 14 & \\
\hline 26 & 30 & Brush/open & 0 & & 0 & \\
\hline 154 & 75 & Conifer & 1 & & 23 & \\
\hline 144 & 45 & Hardwood & 0 & & 23 & \\
\hline 61 & 30 & Hardwood & 1 & & 12 & \\
\hline 62 & 30 & Brush/open & 0 & & 0 & \\
\hline 152 & 75 & Hardwood & 0 & & 19 & \\
\hline 10 & 120 & Conifer & 1 & & 30 & \\
\hline 172 & 45 & Hardwood & 1 & & 21 & \\
\hline 53 & 30 & Conifer & 0 & & 9 & \\
\hline 95 & 45 & Hardwood & 1 & & 25 & \\
\hline 81 & 90 & Conifer & 0 & & 7 & \\
\hline 116 & 30 & Hardwood & 0 & & 2 & \\
\hline 92 & 45 & Conifer & 1 & & 6 & \\
\hline 170 & 45 & Conifer & 0 & & 31 & \\
\hline 153 & 45 & Conifer & 1 & & 3 & \\
\hline$\Sigma n$ & 1,035 & & 10 & & 301 & \\
\hline 8 & & & & 0.500 & & 16.913 \\
\hline $5 y^{2}$ & & & & 0.250 & & 95.992 \\
\hline$s_{\bar{y}}$ & & & & 0.162 & & 2.191 \\
\hline $\begin{array}{l}\% \mathrm{~s}_{\theta} \\
\hat{Y}\end{array}$ & & & & $\begin{array}{l} \pm 32.40 \\
7,650\end{array}$ & & $\begin{array}{l} \pm 12.96 \\
258,770 .\end{array}$ \\
\hline
\end{tabular}

$1-$ Volume estimates are computed using weighted estimators (equations 19-22).

For per acre and total volume estimates weighted estimators (equations 19-22) are employed:

$$
\begin{aligned}
\bar{y}_{w}= & {[(60 * 21)+(60 * 10)+\ldots+(45 * 3)] /(60+} \\
& 60+\ldots+45)=16.913 \text { ccf per acre. } \\
s_{w}{ }^{2}= & 60(21-16.913)^{2}+60(10-16.913)^{2}+\ldots+ \\
& 45(3-16.913)^{2} / 1035=95.992 . \\
s_{w}= & (95.992 / 20)^{1 / 2}=2.191 . \\
\% s_{\mathrm{w}}= & 2.191 / 16.91 * 100=12.96 \% . \\
\hat{\mathrm{Y}}= & 16.913 * 15,300=258,770 \mathrm{ccf} \text { in the En- } \\
& \text { chanted Forest. }
\end{aligned}
$$

The estimated area and volume by vegetation type are computed analogously. To compute estimates for the conifer type, for example, all plots not classed as conifer are assigned a value of 0 for volume and area. Table 14 shows the estimates for the conifer type. The area of

\begin{tabular}{|c|c|c|c|c|c|}
\hline Stand & Area & $\begin{array}{c}\text { Volume/ } \\
\text { acre }\end{array}$ & $\begin{array}{l}\text { Volume } \\
\text { estimators }\end{array}$ & Type & $\begin{array}{c}\text { Type } \\
\text { estimators }\end{array}$ \\
\hline 18 & 60 & 21 & & 1 & \\
\hline 25 & 60 & 0 & & 0 & \\
\hline 98 & 45 & 0 & & 0 & \\
\hline 74 & 60 & 0 & & 0 & \\
\hline 187 & 30 & 0 & & 0 & \\
\hline 26 & 30 & 0 & & 0 & \\
\hline 154 & 75 & 23 & & 1 & \\
\hline 144 & 45 & 0 & & 0 & \\
\hline 61 & 30 & 0 & & 0 & \\
\hline 62 & 30 & 0 & & 0 & \\
\hline 152 & 75 & 0 & & 0 & \\
\hline 10 & 120 & 30 & & 1 & \\
\hline 172 & 45 & 0 & & 0 & \\
\hline 53 & 30 & 9 & & 0 & \\
\hline 95 & 45 & 0 & & 0 & \\
\hline 81 & 90 & 7 & & 1 & \\
\hline 116 & 30 & 0 & & 0 & \\
\hline 92 & 45 & 6 & & 1 & \\
\hline 170 & 45 & 31 & & 1 & \\
\hline 153 & 45 & 3 & & 1 & \\
\hline$\Sigma n$ & 1,035 & 130 & & 7 & \\
\hline 8 & & & 8.971 & & 0.464 \\
\hline$s_{y}{ }^{2}$ & & & $586,648.716$ & & 870.063 \\
\hline$s_{\bar{y}}$ & & & 2.124 & & 0.082 \\
\hline$\% \mathrm{~s}_{\theta}$ & & & \pm 23.67 & & \pm 17.64 \\
\hline & & & 137,256 & & 7,096 \\
\hline
\end{tabular}
conifer type is 7,096 acres, the area of hardwoods is 6,874 acres, and the area of brush/open is 887 acres.
Table 14-Results and estimates for the conifer vegetation type using equal probability sampling of mapped stands in the Enchanted Forest; area estimates are in acres and volume estimates are in ccf

The estimated total volume is 137,256 ccf for conifer, $121,513 \mathrm{ccf}$ for hardwood, and $0 \mathrm{ccf}$ for the brush/open type, respectively. This last value is strong evidence that we have overlooked an advantageous stratification. It is reasonable to assume that if there is 0 ccf of timber in the brush/open category that we could improve our sampling efficiency by introducing strata that isolate this type.

Stand Estimates-Stands' attributes are estimated from the area estimates. Measured stands can have their observed inventory estimate or they may be assigned as part of the general problem of predicting a volume for each stand in the forest. The former is done in this publication and the inventoried stands are identified with an asterisk. All other stands must be assigned the average for the appropriate stratum or inventory unit. An alternative is to use two types of records-one for predicted values and one for measured. The alternative might become more valuable as the complexity of the inventory 
increased. The estimated volume per acre for the unmeasured stands is $16.9 \mathrm{ccf}$. Estimates for vegetation types are that 49 percent of the area is conifer, 45 percent is hardwood, and 6 percent is brush or open. See figure 25 .

Cost Estimates-The sum of the approximate straight line distance between sample stands as measured from the map is 104,000 feet.

$$
\begin{aligned}
L & =104,000 / 10,560=9.85 \text { hours. } \\
\Sigma\left(M_{s}\right) & =101 \text { hours. } \\
D & =(9.8+101) / 8=13.8 \text { hours. } \\
F & =2(9)[9.8+101+13.8]=\$ 2,243 .
\end{aligned}
$$

Thus:

\begin{tabular}{llr} 
Field costs & $=\$ 2,243$ \\
Aerial photos & $=490$ \\
Mapping & $=1,147$ \\
\hline Total costs & $=\$ 3,880$, or $\$ 0.254$ per acre.
\end{tabular}

Discussion-This technique is seldom used in forest inventories. When polygons or stands are mapped, useful correlated attributes are also noted. Attributes such as vegetation type, density, and height may then be used to

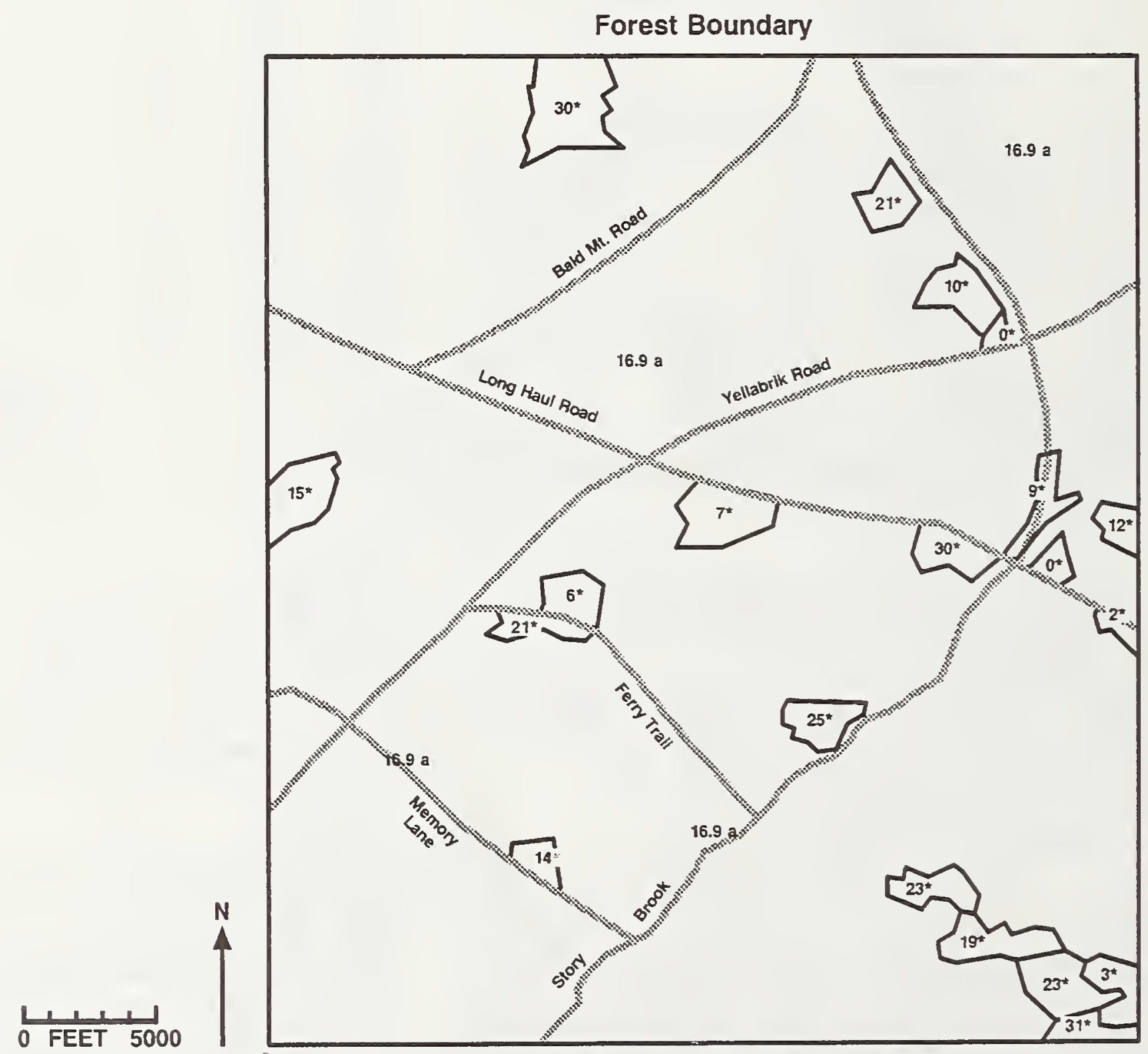

Figure 25-Mapping showing measured $\left({ }^{*}\right)$ and Forest average (a) volume (ccf) per acre based on equal probability sampling of stand numbers. 
develop a stratified sampling plan. However, the procedure might be useful in sampling geo-political divisionsmapped counties within States for example. It might also reasonably be employed where an agency was exploring the forest, such as in large, unmapped tropical areas.

Probability Proportional to Size (p.p.s.) Sampling-There are several possible estimates of size that might be used to develop a sampling frame. Our example is acreage, but this is really a correlated measure of size. Recent sampling developments remind us that there should be a strong positive correlation between the measure of size and the actual variate of interest in order for p.p.s. sampling to provide improvements over simple random sampling. This is not strictly the case in the Enchanted Forest data, but for the purpose of this example there should be little loss in efficiency, and the acreage provides a convenient measure of size. When stands are sampled on the basis of probability proportional to their area, several methods of selecting samples are possible. An intuitively appealing method that yields a sample with probability proportional to area is to place a grid over the forest map. Only those stands in which a grid intersection is located are sampled in the field (fig. 26). Each grid intersection serves as the random

\section{Forest Boundary}

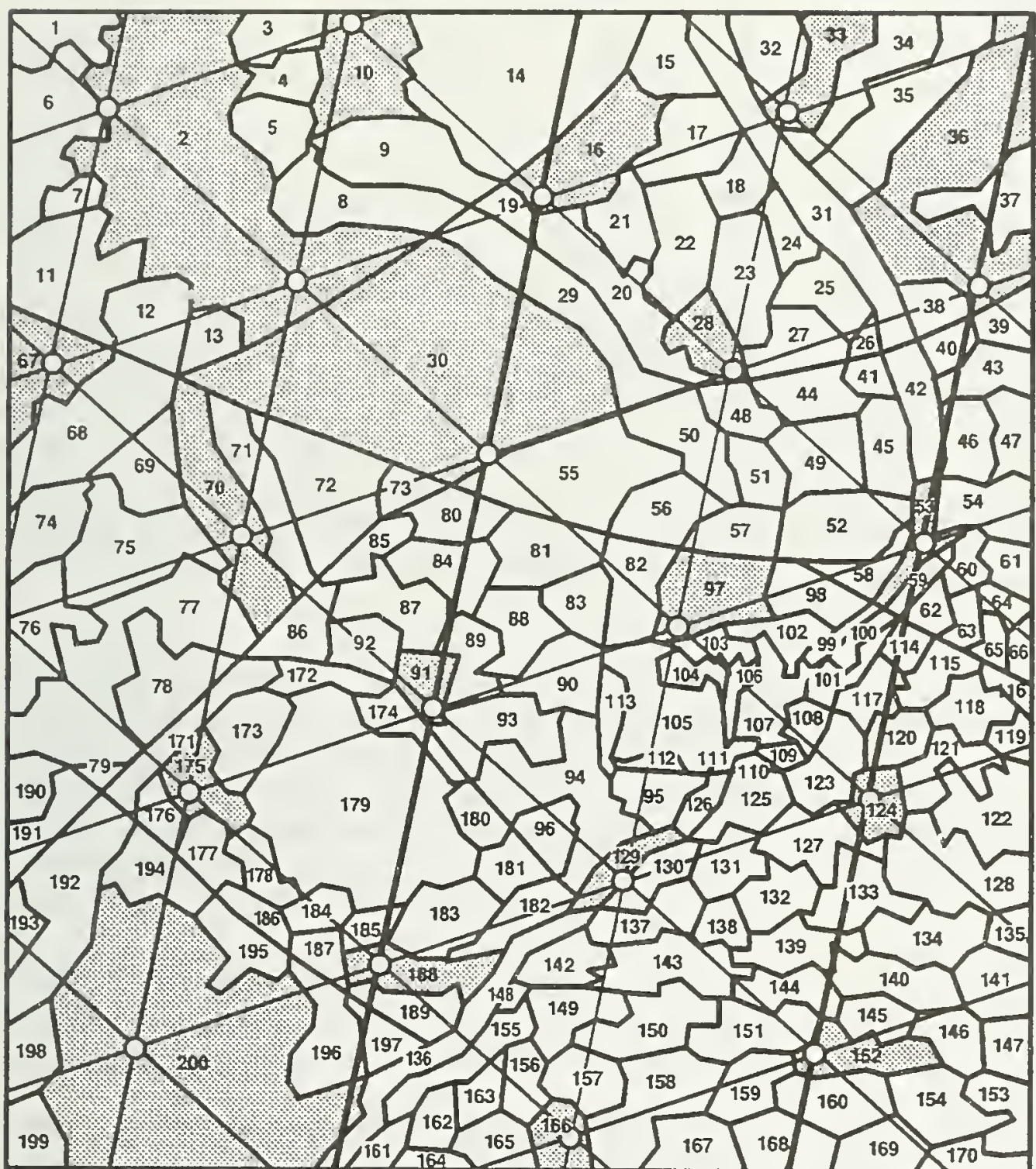

Figure 26-Location of primary sampling units (shaded stands) and initial secondary sampling units using a superimposed grid. The secondary units are located at 60 degrees and 6,203 feet from one another. This provides a selection of stands based upon a probability proportional to their size.

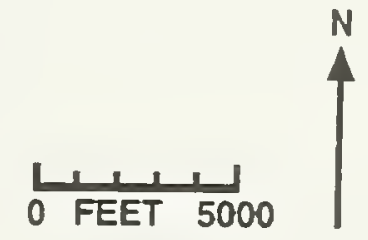

O Field Plot

(Initial) 
starting point for a cluster of sub-plots within the sampled stand.

An alternative stand selection method is to list stands by area and then systematically select sample stands using a random start and a predetermined acre interval (Lund $1978 \mathrm{~b})$. Either method provides a systematic sample of the forest and a sample proportional to size of the stands (i.e., larger stands have a higher probability of being sampled). A further refinement for selection would be the preliminary sorting of the a data base consisting of the measures of size followed by selection using pps. This refinement has some of the qualities of a systematic selection in that a representative distribution of the selected sample will usually be obtained (Stage 1971). Areas and volumes are developed by measuring the sampled stands in the field and expanding the sample to the forest.

Statistical Estimates-The results of a probability proportional to size inventory of the Enchanted Forest are shown in table 15 . Note that stand 2 was selected twice (sampled with replacement). The stand is measured only once, but the stand values per acre are used twice in the calculations. Either grid intersection may be used as the initial starting point for the sample within stand 2 . Forest estimates are computed as follows:

For snaileater area estimates, a value has to be assigned to each sampled stand. To compute the estimators for wildlife use, all sampled stands classed as having wildlife use are assigned a value of 1 and all other stands are given a value of 0 .

$$
\begin{aligned}
\bar{y}_{p}= & (0+1+\ldots 0) / 20=0.55 \text { a proportion express- } \\
& \text { ing wildlife use per plot. } \\
\mathrm{s}^{2}\left(\bar{y}_{\mathrm{p}}\right)= & (0.55)(1-0.55)=0.2475 \\
\mathrm{~s}_{\bar{y}}= & (0.2475 / 20)^{1 / 2}=0.1112 \text { (with replacement } \\
& \text { sampling equation). } \\
\% \mathrm{~s}_{\mathrm{e}}= & (0.1112 / 0.55)^{*} 100= \pm 20.22 \% . \\
\hat{\mathrm{Y}}= & 0.55 * 15,300=8,415 \text { acres of wildlife use in } \\
& \text { the forest. }
\end{aligned}
$$

\begin{tabular}{|c|c|c|c|c|c|}
\hline Stand & $\begin{array}{c}\text { Vegetation } \\
\text { type }\end{array}$ & $\begin{array}{c}\text { Wildlife } \\
\text { use }\end{array}$ & $\begin{array}{c}\text { Wildlife } \\
\text { estimators }\end{array}$ & $\begin{array}{c}\text { Volumel } \\
\text { acre }\end{array}$ & $\begin{array}{c}\text { Volume } \\
\text { estimators }\end{array}$ \\
\hline 2 & Hardwood & 0 & & 3 & \\
\hline 10 & Conifer & 1 & & 30 & \\
\hline 67 & Hardwood & 1 & & 6 & \\
\hline 2 & Hardwood & 0 & & 3 & \\
\hline 16 & Brush/open & 1 & & 3 & \\
\hline 33 & Hardwood & 1 & & 7 & \\
\hline 70 & Hardwood & 1 & & 7 & \\
\hline 30 & Conifer & 1 & & 19 & \\
\hline 28 & Hardwood & 0 & & 9 & \\
\hline 36 & Conifer & 0 & & 32 & \\
\hline 175 & Conifer & 1 & & 26 & \\
\hline 91 & Conifer & 0 & & 8 & \\
\hline 97 & Hardwood & 1 & & 19 & \\
\hline 53 & Conifer & 0 & & 9 & \\
\hline 200 & Hardwood & 1 & & 14 & \\
\hline 188 & Hardwood & 1 & & 22 & \\
\hline 129 & Brush/open & 1 & & 3 & \\
\hline 124 & Conifer & 0 & & 18 & \\
\hline 166 & Hardwood & 0 & & 1 & \\
\hline 152 & Hardwood & 0 & & 19 & \\
\hline$\Sigma n$ & & 11 & & 258 & \\
\hline 8 & & & 0.550 & & 12.900 \\
\hline$s_{\gamma^{2}}{ }^{2}$ & & & 0.248 & & 92.410 \\
\hline$s_{\bar{y}}$ & & & 0.111 & & 2.149 \\
\hline$\% s_{e}$ & & & \pm 20.21 & & \pm 16.66 \\
\hline & & & 8,415 & & 197,370 \\
\hline
\end{tabular}

For total volume estimates:

$$
\begin{aligned}
\bar{y}= & (3+30+\ldots 19) / 20=12.9 \text { ccf per acre. } \\
\mathrm{s}_{y}{ }^{2}= & \left\{\left(3^{2}+30^{2}+\ldots 19^{2}\right)-(3+30+\ldots 19)^{2} /\right. \\
& 20\} /(20-1)=92.41 . \\
\mathrm{s}_{\bar{y}}= & (92.4105 / 20)^{1 / 2}=2.15 \mathrm{ccf} \text { per acre. } \\
\% \mathrm{~s}_{\mathrm{e}}= & (2.1495 / 12.90) * 100= \pm 16.66 \% . \\
\hat{\mathrm{Y}}= & 12.90 * 15,300=197,370 \mathrm{ccf} \text { for the forest. }
\end{aligned}
$$

Table 15-Results of an inventory of the Enchanted Forest using selection of mapped stands based on probability proportional to their size; volume is expressed in ccf

The estimated area and volume by vegetation type are computed similarly. To compute estimates for the conifer type, for example, all sampled stands not classed as conifer are assigned a value of 0 for volume and area. Table 16 shows the estimates for the conifer type. The area of conifer type is 5,355 acres, the area of hardwoods is 8,415 acres, and the area of brush/open is 1,530 acres.

The estimated total volume is $108,630 \mathrm{ccf}$ for conifer, $84,150 \mathrm{ccf}$ for hardwood, and 4,590 ccf for the brush/ open type respectively.

Stand Estimates-Measured stands can be assigned their actual measured values or in some cases it may be more appropriate to estimate their values as part of a 
Table 16-Results and estimates of the conifer vegetation type from an inventory of the Enchanted Forest using mapped stands selected based on probability proportional to their area; volume estimates are expressed in ccf

\begin{tabular}{|c|c|c|c|c|}
\hline Stand & $\begin{array}{c}\text { Volume/ } \\
\text { acre }\end{array}$ & $\begin{array}{c}\text { Volume } \\
\text { estimators }\end{array}$ & Type & $\begin{array}{c}\text { Type } \\
\text { estimators }\end{array}$ \\
\hline 2 & 0 & & 0 & \\
\hline 10 & 30 & & 1 & \\
\hline 67 & 0 & & 0 & \\
\hline 2 & 0 & & 0 & \\
\hline 16 & 0 & & 0 & \\
\hline 33 & 0 & & 0 & \\
\hline 70 & 0 & & 0 & \\
\hline 30 & 19 & & 1 & \\
\hline 28 & 0 & & 0 & \\
\hline 36 & 32 & & 1 & \\
\hline 175 & 26 & & 1 & \\
\hline 91 & 8 & & 1 & \\
\hline 97 & 0 & & 0 & \\
\hline 53 & 9 & & 1 & \\
\hline 200 & 0 & & 0 & \\
\hline 188 & 0 & & 0 & \\
\hline 129 & 0 & & 0 & \\
\hline 124 & 18 & & 1 & \\
\hline 166 & 0 & & 0 & \\
\hline 152 & 0 & & 0 & \\
\hline$\Sigma n$ & 142 & & 7 & \\
\hline 8 & & 7.100 & & 0.350 \\
\hline $\mathrm{s}_{y}{ }^{2}$ & & 127.463 & & 0.239 \\
\hline$s_{\bar{y}}$ & & 2.524 & & 0.109 \\
\hline$\% \mathrm{~s}_{\ominus}$ & & \pm 35.55 & & \pm 31.26 \\
\hline Y & & 108,630 & & 5,355. \\
\hline
\end{tabular}

general computational scheme. Stands that were not measured are assigned the average values of the inventory unit. The average volume per acre for the unmeasured stands is $12.50 \mathrm{ccf}$. Based on the sample, 35 percent of the area is conifer, 55 percent is hardwood and 10 percent is brush. See figure 27.

Cost Estimates-Selection was made by a grid. Each sample stand is approximately equidistant or 6,203 feet from each other. As stand no. 2 was selected twice but measured only once, $n=19$ in this case.

$$
\begin{aligned}
\mathrm{L} & =[(19-1) *(6,203)] / 10,560=10.57 \text { hours. } \\
\Sigma\left(M_{s}\right) & =96.5 \text { hours. } \\
D & =(10.6+96.5) / 8=13.4 \text { hours. } \\
F & =2(9)[10.6+96.5+13.4]=\$ 2,169 .
\end{aligned}
$$

Thus:

\begin{tabular}{ll} 
Field costs & $=\$ 2,169$ \\
Purchase aerial photos & $=490$ \\
Mapping & $=1,148$ \\
\hline Total costs & $=\$ 3,807$, or $\$ 0.249$ per acre.
\end{tabular}

Discussion-This technique is useful when only the boundaries and the area of the mapped polygon are known. In forestry, this is seldom the case. Characteristics of the stands are usually noted from remote sensing and are used for forming sampling strata. The advantage of the method over e.p.s. lies in the simplified computational formulae. All of the statistical estimates revert to the simplest expression of means and variances. The conditions under which these simplifications are justified have been noted above, but are worth reiterating. There must be a strong, positive correlation between the dependent variable and the auxiliary variable used as a measure of size. This may often be the case for timber volume and area of forest, though it is not really the case for our example. There is somewhat less likelihood that p.p.s. sampling formulae simplifications can be justified for the snail-eater. The dependent variable is a binary variable and can rarely have a strong correlation with a continuous variable-like area. Still, the method can be applied in a general inventory if interest in the snaileater is not a pressing wildlife issue that needs special attention. We would not suggest the application of this estimationdesign combination if a high value were placed on the results.

Stratified Sampling - If there is additional (auxiliary) information about each stand such as vegetation type (Appendix 2), stratified sampling offers important advantages over almost any non-stratified method. Refer to the earlier exposition on stratification. Each and every stand must fall into one and only one sampling stratum. For timber inventories, Scott (1984) specifically recommends:

- Mapping stands based upon type, size, and density classes. Note that it may be preferable to stratify geographically because stand size often changes with intensity of management.

- Using these classes to form sampling strata.

- Establishing plots systematically within selected stands.

- Developing means by stratum (vegetation type-sizedensity class) and expanding to total using stratum areas. 
Data from sampled, mapped stands can be extrapolated to unmeasured areas assuming stands do not vary widely within sampling stratum or map classes such as forest type, stand size, and density (Ek, Rose, and Gregersen 1984). As previously discussed, poststratification or prestratification can be used.

Three sampling strata for the Enchanted Forest based upon apparent overstory vegetation type in each stand interpreted from aerial photographs (see Appendix 2) are developed. The strata are conifer vegetation, hardwood vegetation, and brush/open. Figure 28 shows the stands mapped by each stratum. A total of 6,240 acres have been mapped as conifer, 7,965 acres have been mapped as hardwoods, and 1,095 acres mapped as brush/open vegetation type.

Poststratification-Assume a grid of plots has been systematically located as illustrated in figure 26 . We can poststratify by combining the grid and the mapping information, as illustrated in figure 29 and table 17. The mapped

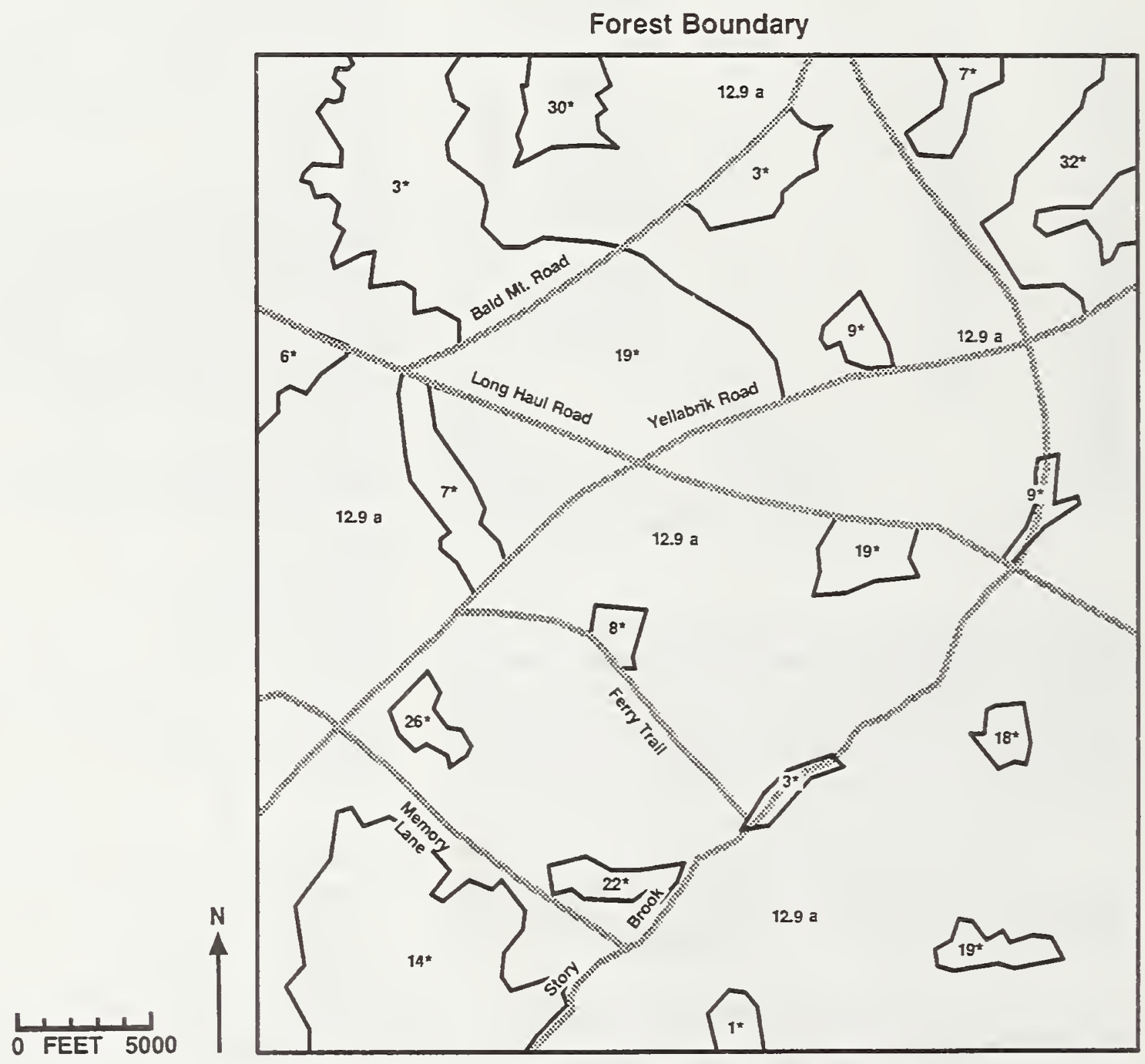

Figure 27-Mapping showing measured (*) and forest average (a) volume (cct) per acre based on sampling proportional to stand size. 
information provides the strata weights. We refer to this process as poststratification with known weights.

Statistical Estimates-For area and volume estimates in the conifer vegetation type $n_{c}=7, N_{c}=6,240$, representing the same number of acres.

To compute the area estimators for the red-spotted snaileater wildlife use within each stratum, all sample stands having evidence of wildlife use are assigned a value of 1 and all other sample stands are given a value of zero.
For the conifer stratum:

$$
\begin{aligned}
\bar{y}_{c}= & (1+1+\ldots 0) / 7=0.4286 \text { a proportion ex- } \\
& \text { pressing wildlife use per plot. } \\
\left(\mathrm{s}_{\mathrm{y}}{ }^{2}\right)_{\mathrm{c}}= & \left\{\left(1^{2}+1^{2}+\ldots 0^{2}\right)-(1+1+\ldots 0)^{2} / 7\right\} /(7-1)- \\
& 0.2857 . \\
\left(\mathrm{s}_{\bar{y}}\right)_{\mathrm{c}}= & (0.2857 / 7)^{1 / 2}=0.2020 . \\
\left(\% \mathrm{~s}_{\mathrm{e}}\right)_{\mathrm{c}}= & (0.2019 / 0.4286) * 100= \pm 47.13 \% . \\
\hat{y}_{c}= & 0.4286^{*} 6,240=2,674 \text { acres of wildlife use } \\
& \text { in the conifer stratum. } \\
\left(\mathrm{S}_{\bar{y}}{ }^{2}\right)_{\mathrm{c}}= & {\left[0.2857^{*}(6,240 / 15,300)^{2} / 7\right]^{*}[1-(7 / 6,240]} \\
= & 0.006781 .
\end{aligned}
$$

\section{Forest Boundary}

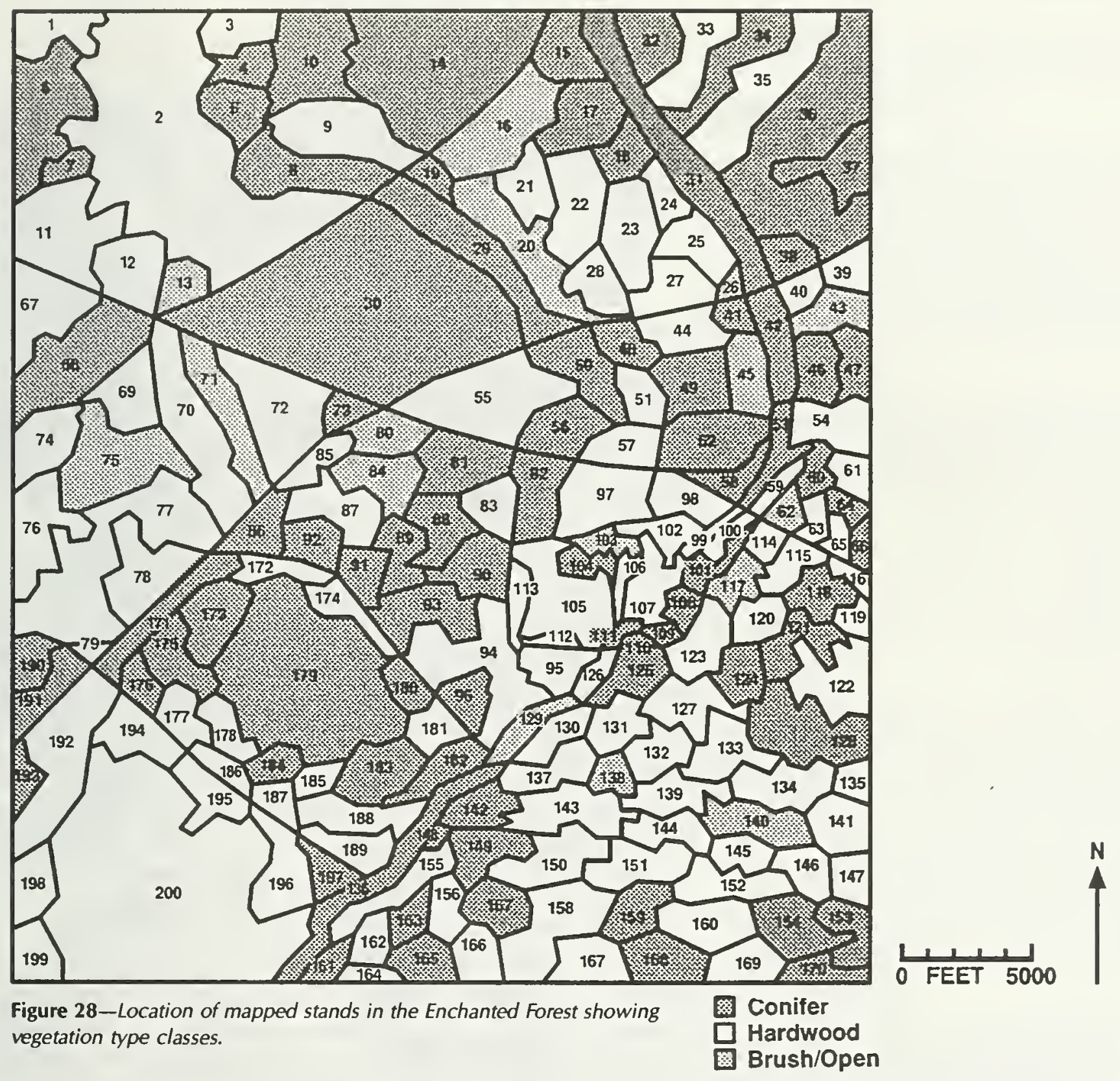


The same estimators are computed for the hardwood and brush/open strata. The area estimates are combined for the Forest as follows where:

$$
\begin{aligned}
\bar{Y}= & (2,674.2857+4,344.5455+1,095)=8,114 \\
& \text { acres of wildlife use in the Forest. } \\
\bar{Y}= & 8,114 / 15,300 * 100=53 \% \text { of area sampled } \\
& \text { with wildlife use in the Forest. } \\
S_{\bar{Y}}= & (0.00678+0.00671)^{1 / 2}=0.1162 . \\
\% S_{E}= & (0.1162 / 0.5303) * 100= \pm 21.90 \% .
\end{aligned}
$$

Next we illustrate computation for total volume in the conifer stratum:

$$
\begin{aligned}
\bar{y}_{c}= & (31+19+\ldots 18) / 7=21.86 \text { ccf per acre. } \\
\left(\mathrm{s}_{\mathrm{y}}{ }^{2}\right)_{\mathrm{c}}= & \left\{\left(31^{2}+19^{2}+\ldots 18^{2}\right)-[(31+19+\right. \\
& \left.\left.\left.(\cdots 34)^{2}\right) / 7\right\}\right\} /(7-1)=93.14 . \\
\left(\mathrm{s}_{\overline{\mathrm{y}}}\right)_{\mathrm{c}}= & (93.1429 / 7)^{1 / 2}=3.6477 \mathrm{cc} \text { per acre. } \\
\left(\% \mathrm{~s}_{\mathrm{e}}\right)_{\mathrm{c}}= & 3.6457 / 21.8571 * 100= \pm 16.68 \% . \\
\hat{\mathrm{y}}_{\mathrm{c}}= & 21.8571 * 6,240=136,389 \mathrm{ccf} \text { in conifer } \\
& \text { stratum. } \\
\left(\mathrm{S}_{\overline{\mathrm{y}}}{ }^{2}\right)_{\mathrm{c}}= & {\left[93.1429 *(6,240 / 15,300)^{2}\right] / 7 *[1-(7 /} \\
& 6,240)]=2.2108 .
\end{aligned}
$$

The same stratum estimators are computed for the hardwood and brush/open strata. The estimates are combined to yield totals for the Forest as follows:

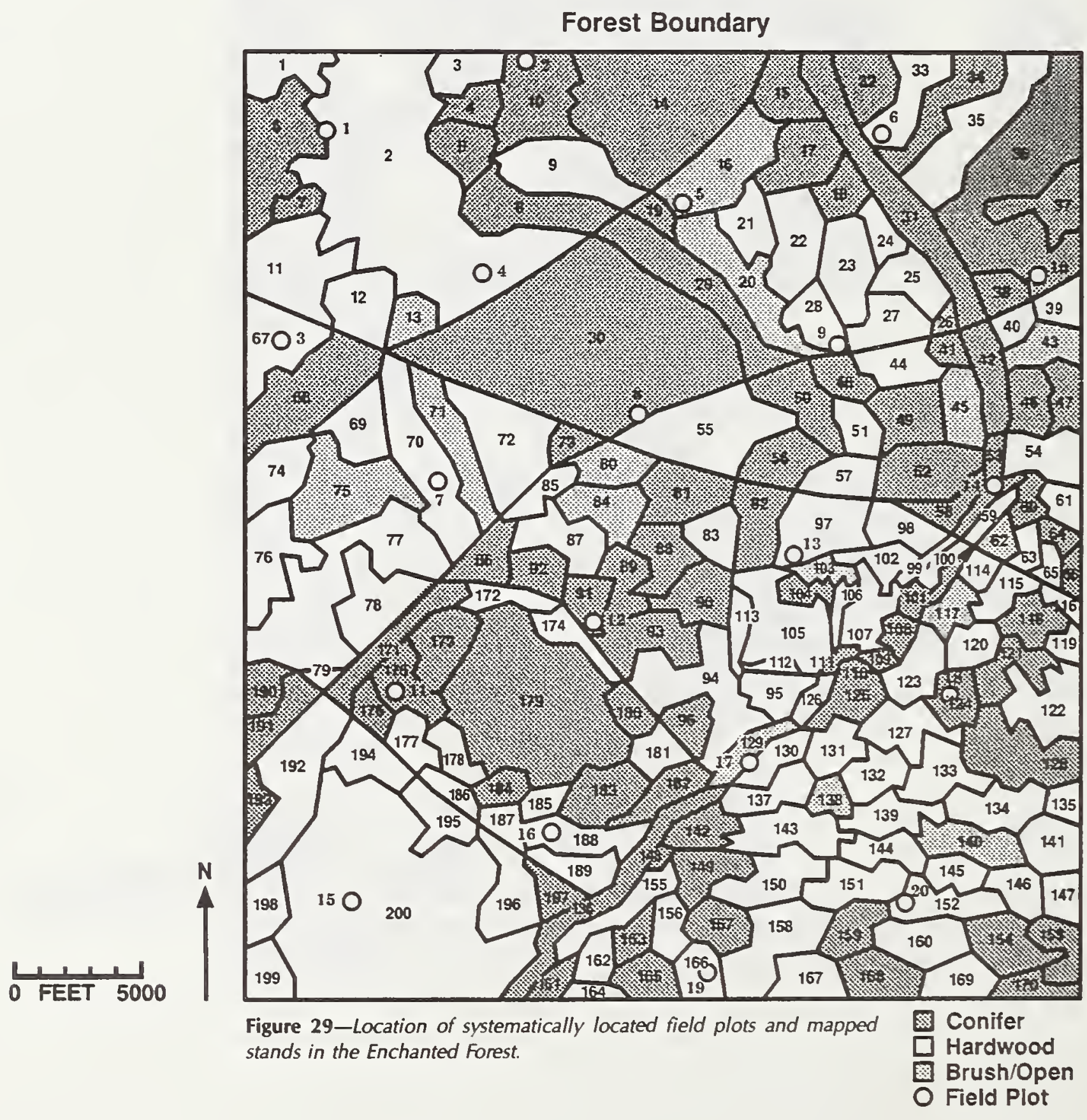


Table 17-Results of an inventory of the Enchanted Forest using post stratification of a systematic sample with mapped stands providing known stratum weights; volumes are expressed in ccf

\begin{tabular}{|c|c|c|c|c|c|}
\hline Stratum & Plot & $\begin{array}{c}\text { Wildlife } \\
\text { use }\end{array}$ & $\begin{array}{c}\text { Wildlife } \\
\text { estimators }\end{array}$ & $\begin{array}{c}\text { Volumel } \\
\text { acre }\end{array}$ & $\begin{array}{c}\text { Volume } \\
\text { estimators }\end{array}$ \\
\hline \multirow{14}{*}{ Conifer } & 2 & 1 & & 31 & \\
\hline & 8 & 1 & & 19 & \\
\hline & 10 & 0 & & 34 & \\
\hline & 11 & 0 & & 29 & \\
\hline & 12 & 1 & & 14 & \\
\hline & 14 & 0 & & 8 & \\
\hline & 18 & 0 & & 18 & \\
\hline & $\Sigma n_{c}$ & 3 & & 153 & \\
\hline & 8 & & 0.429 & & 21.857 \\
\hline & $s_{y}{ }^{2}$ & & 0.286 & & 93.143 \\
\hline & $s_{\bar{y}}^{*}$ & & 0.202 & & 3.646 \\
\hline & $\% \mathrm{~s}_{\theta}$ & & \pm 47.11 & & \pm 16.68 \\
\hline & $\left(S_{\bar{y}}^{2}\right)_{c}$ & & 0.007 & & 2.211 \\
\hline & $\hat{Y}_{c}$ & & 2,674 & & 136,388 \\
\hline \multirow[t]{18}{*}{ Hardwood } & 1 & 0 & & 7 & \\
\hline & 3 & 1 & & 8 & \\
\hline & 4 & 0 & & 3 & \\
\hline & 6 & 1 & & 7 & \\
\hline & 7 & 1 & & 10 & \\
\hline & 9 & 0 & & 10 & \\
\hline & 13 & 1 & & 17 & \\
\hline & 15 & 1 & & 13 & \\
\hline & 16 & 1 & & 21 & \\
\hline & 19 & 0 & & 0 & \\
\hline & 20 & 0 & & 20 & \\
\hline & $\Sigma n_{h}$ & 6 & & 116 & \\
\hline & 8 & & 0.545 & & 10.545 \\
\hline & $\mathrm{s}_{\mathrm{y}}{ }^{2}$ & & 0.273 & & 44.673 \\
\hline & $\mathrm{s}_{\bar{y}}{ }^{*}$ & & 0.157 & & 2.014 \\
\hline & $\% \mathrm{~s}_{\theta}{ }^{*}$ & & \pm 28.85 & & \pm 19.10 \\
\hline & $\left(S_{\bar{y}}{ }^{2}\right)_{h}$ & & 0.007 & & 1.099 \\
\hline & $\hat{Y}_{h}$ & & 4,344 & & 83,994 \\
\hline \multirow{9}{*}{$\begin{array}{l}\text { Brush/ } \\
\text { open }\end{array}$} & 5 & 1 & & 3 & \\
\hline & 17 & 1 & & 6 & \\
\hline & $\Sigma n_{b}$ & 2 & & 9 & \\
\hline & 8 & & 1.000 & & 4.500 \\
\hline & $S_{y}^{2}$ & & 0.000 & & 4.500 \\
\hline & $S_{\bar{y}}{ }^{*}$ & & 0.000 & & 1.498 \\
\hline & $\% \mathrm{~s}_{e}{ }^{*}$ & & \pm 0.00 & & \pm 33.30 \\
\hline & $\left(S_{\bar{y}}\right)^{2}$ & & 0 & & 0.012 \\
\hline & $\hat{Y}_{b}$ & & 1,095 & & 4,927 \\
\hline \multirow{4}{*}{$\begin{array}{l}\text { Enchanted } \\
\text { Forest }\end{array}$} & $\hat{Y}$ & & 8,114 & & 225,311 \\
\hline & $\bar{Y}$ & & 0.530 & & 14.726 \\
\hline & $S_{\bar{\gamma}}$ & & 0.116 & & 1.822 \\
\hline & $\% S_{E}{ }^{*}$ & & \pm 21.90 & & \pm 12.38 \\
\hline
\end{tabular}

$$
\begin{aligned}
\hat{Y}= & (136,389+83,994+4,927)=225,310 \mathrm{ccf} \text { in } \\
& \text { the Forest. } \\
\bar{Y}= & 225,310 / 15,300=14.73 \mathrm{ccf} \text { per acre. } \\
\mathrm{S}_{\bar{Y}}= & (2.211+1.099+0.012)^{1 / 2}=1.8225 \mathrm{ccf} \text { per } \\
& \text { acre. } \\
\% \mathrm{~S}_{\mathrm{E}}= & 1.8225 / 14.7262 * 100= \pm 12.38 \% .
\end{aligned}
$$

The estimated area and volume by vegetation type are computed in the same manner. To compute estimates for the conifer type, for example, all plots not classed as conifer are assigned a value of 0 for volume and area. The area of conifer type is 6,240 acres, the area of hardwoods is 7,965 acres, and the area of brush/open is 1,095 acres.

The estimated total volume is $136,388 \mathrm{ccf}$ for conifer, $83,994 \mathrm{ccf}$ for hardwood, and 4,928 ccf for the brush/ open type, respectively.

Stand Estimates-Stands containing the field plots may be assigned the values from the field measurements. We reiterate that provision be made to indicate the difference between an observed and predicted value. All other stands are assigned average values for the stratum in which they lie. See figure 30; observed values are indicated by asterisk.

Cost Estimates-The costs would be the same as for systematic sampling plus the purchase of aerial photography, interpretation of the entire Forest, and mapping.

\begin{tabular}{llr} 
Field costs & $=\$ 2,275$ \\
Purchase aerial photos & & 489 \\
Mapping & $=1,147$ \\
Interpretation & $=306$ \\
\hline Total costs & $=\$ 4,217$, or $\$ 0.276$ per acre.
\end{tabular}

Discussion-The National Forests in the Eastern (Johnson 1984) and the Southern (Belcher 1984) Regions in conjunction with the North Central (Hahn 1984), Northeast, Southeast (Cost 1984), and Southern (Beltz 1984) Forest Inventory and Analysis Units of the Forest Service employ variations of this technique. FIA field plots serve as the basis for stratification and mapping by the National Forest Regions provides the stratum weights from stand mapping.

Prestratification-Assumptions regarding the known attributes of the Enchanted forest remain the same as for nonstratified sampling examples. 
Equal probability sampling (e.p.s.)-Two or more stands are randomly chosen from each stratum (fig. 31). Consecutive stand numbers can be used as described in the previous section, or a unique stand number can be generated.

Statistical Estimates-Table 18 shows the results of the inventory, where, for the conifer (c) stratum, $n_{c}=8$ sample stands and $\mathrm{N}_{\mathrm{c}}=81$ total stands. To compute the area of snaileater use, an indicator value is assigned to each sampled stand in the stratum. All sampled stands classed as having evidence of the wild life use are assigned a value of 1 and all other sampled stands are given a value

Forest Boundary

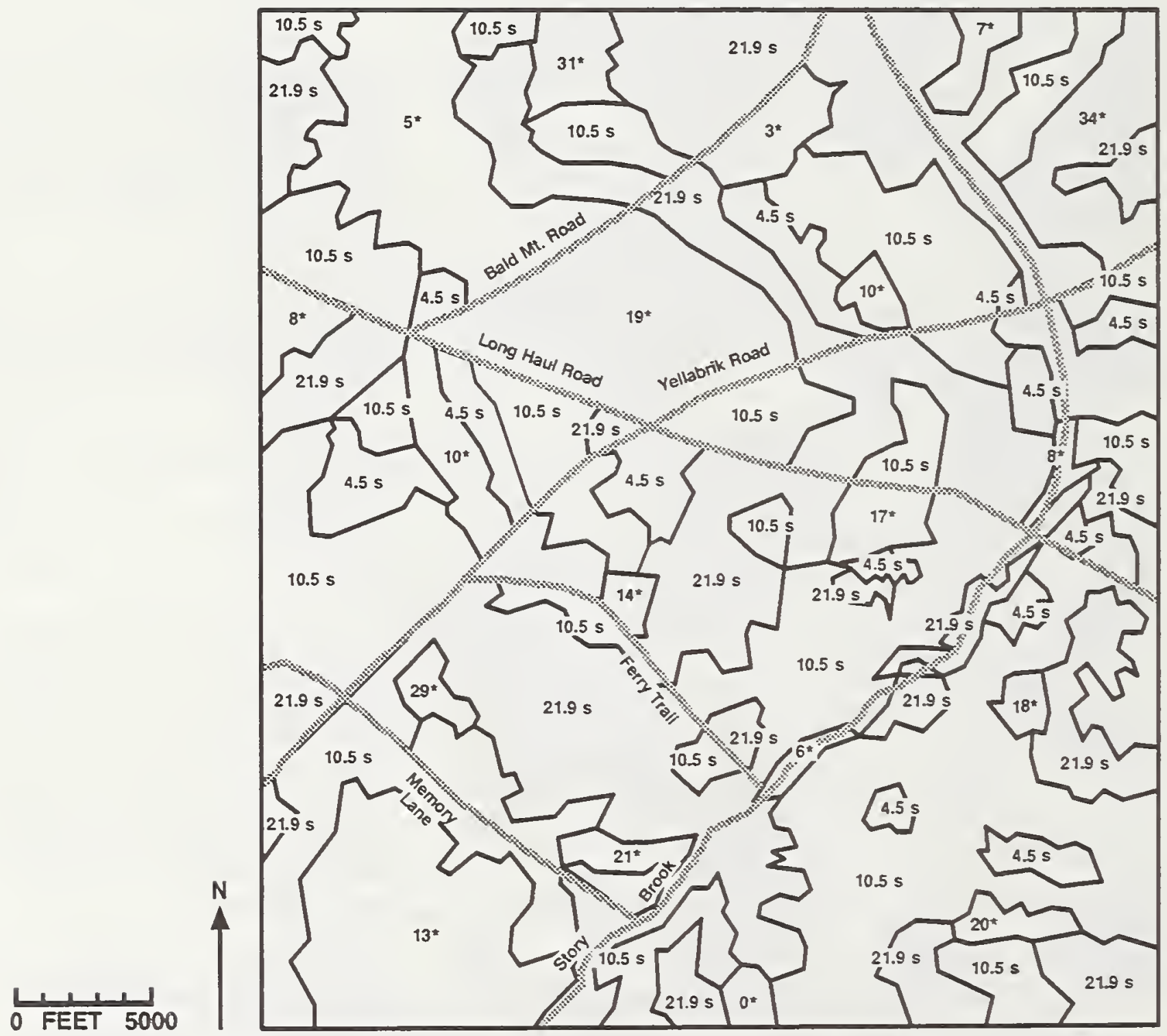

Figure 30-Mapping showing measured (*) and stratum average (5) volume (cct) per acre based on poststratification of systematically located field plots. 
of zero. Computation follows examples presented earlier for a proportion estimator (equations 23 and 24):

$$
\begin{aligned}
\bar{y}_{p c}= & {\left[(60 * 0)+\left(75^{*} 1\right)+\ldots(45 * 1)\right] /(60+75} \\
& +\ldots 45)=0.5588 \text { wildlife use per plot. } \\
\mathrm{s}^{2}\left(\bar{y}_{p}\right)_{c}= & 0.5588^{*}(1-0.5588)=0.2465 \\
\left(s \bar{y}_{p}\right)_{c}= & (0.2465 / 8)^{1 / 2}=0.1755 . \\
\left(\% \mathrm{~s}_{\mathrm{e}}\right)_{\mathrm{c}}= & .1755 / 0.5588^{*} 100=31.41 \% . \\
\hat{\mathrm{Y}}_{\mathrm{c}}= & 0.5588^{*} 6,240=3,487 \text { acres of wildlife use } \\
& \text { in the Enchanted Forest. } \\
\left(\mathrm{S}_{\bar{y}}{ }^{2}\right)_{\mathrm{c}}= & {\left[0.2465 *(6,240 / 15300)^{2} / 8\right] *[1-8 / 6,240] } \\
= & 0.00511 .
\end{aligned}
$$

The same area estimators are computed for the hardwood and brush/open strata. The estimates are combined for the Forest as follows:

$$
\begin{aligned}
\hat{Y}= & (3,487+4,368+0)=7,855 \text { acres for which } \\
& \text { wildlife use is estimated in the Enchanted Forest. } \\
\bar{Y}= & 7,855 / 15,300=0.51 \text { acres showing wildlife } \\
& \text { utilization. } \\
\mathrm{S}_{\bar{Y}}= & {\left[(977,021+637,985+0) / 15,300^{2}\right]^{1 / 2}=} \\
& 0.0831 . \\
\% \mathrm{~S}_{\mathrm{E}}= & (0.0831 / 0.5136)^{*} 100= \pm 16.18 \% .
\end{aligned}
$$

\section{Forest Boundary}

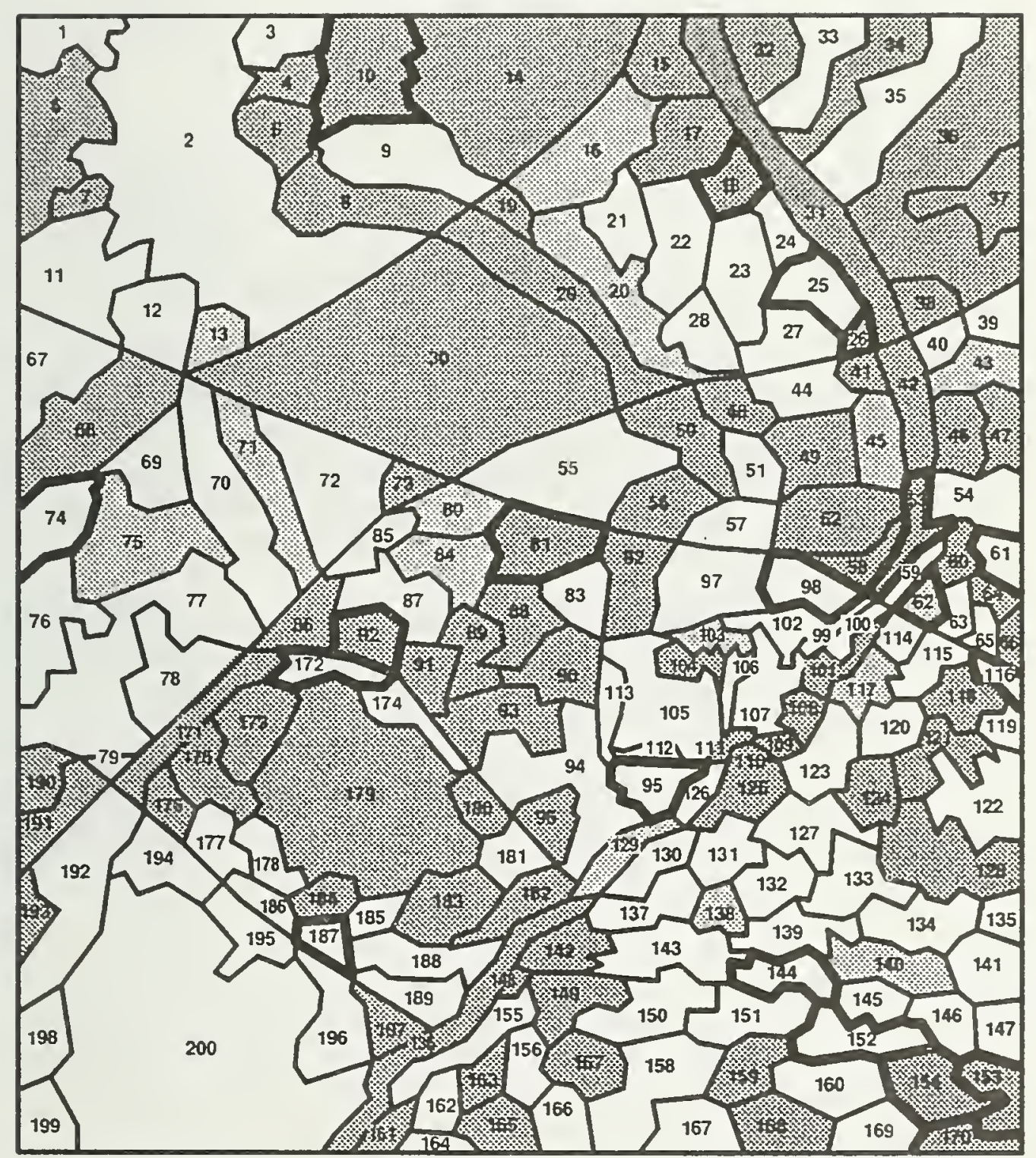

Figure 31-Location of primary sampling units (stands with bold boundaries) based upon a random drawing of stand numbers stratified by vegetation type.

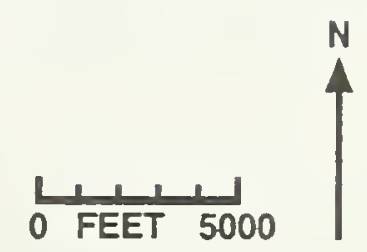

Conifer

$\square$ Hardwood

Brush/Open 
Table 18-Results of an inventory of the Enchanted Forest using stratified mapped stands and equal probability sampling; area estimates are in acres and volume estimates are in ccf

\begin{tabular}{|c|c|c|c|c|c|c|}
\hline Stratum & Stand & Area & $\begin{array}{c}\text { Wildlife } \\
\text { use }\end{array}$ & $\begin{array}{c}\text { Wildlife } \\
\text { estimators }\end{array}$ & $\begin{array}{c}\text { Volumel } \\
\text { acre }\end{array}$ & $\begin{array}{c}\text { Volume } \\
\text { estimators }\end{array}$ \\
\hline \multirow[t]{13}{*}{ Conifer } & 18 & 60 & 0 & & 21 & \\
\hline & 154 & 75 & 1 & & 23 & \\
\hline & 10 & 120 & 1 & & 30 & \\
\hline & 53 & 30 & 0 & & 9 & \\
\hline & 81 & 90 & 0 & & 7 & \\
\hline & 92 & 45 & 1 & & 6 & \\
\hline & 170 & 45 & 0 & & 31 & \\
\hline & 153 & 45 & 1 & & 3 & \\
\hline & $\Sigma n_{c}$ & 510 & 4 & & 130 & \\
\hline & $\nabla$ & & & 0.559 & & 18.205 \\
\hline & $s_{y}{ }^{2}$ & & & 0.246 & & 622,176 \\
\hline & $s_{\bar{y}}$ & & & 0.176 & & 3.436 \\
\hline & $\begin{array}{l}\% \mathrm{~S}_{\theta} \\
\hat{\mathrm{Y}}_{\mathrm{c}} \\
\left(\mathrm{S}_{\overline{-}}\right)^{2}\end{array}$ & & & $\begin{array}{c} \pm 31.41 \\
3,487 \\
.00511\end{array}$ & & $\begin{array}{c} \pm 18.87 \\
113,604 \\
1.964\end{array}$ \\
\hline
\end{tabular}

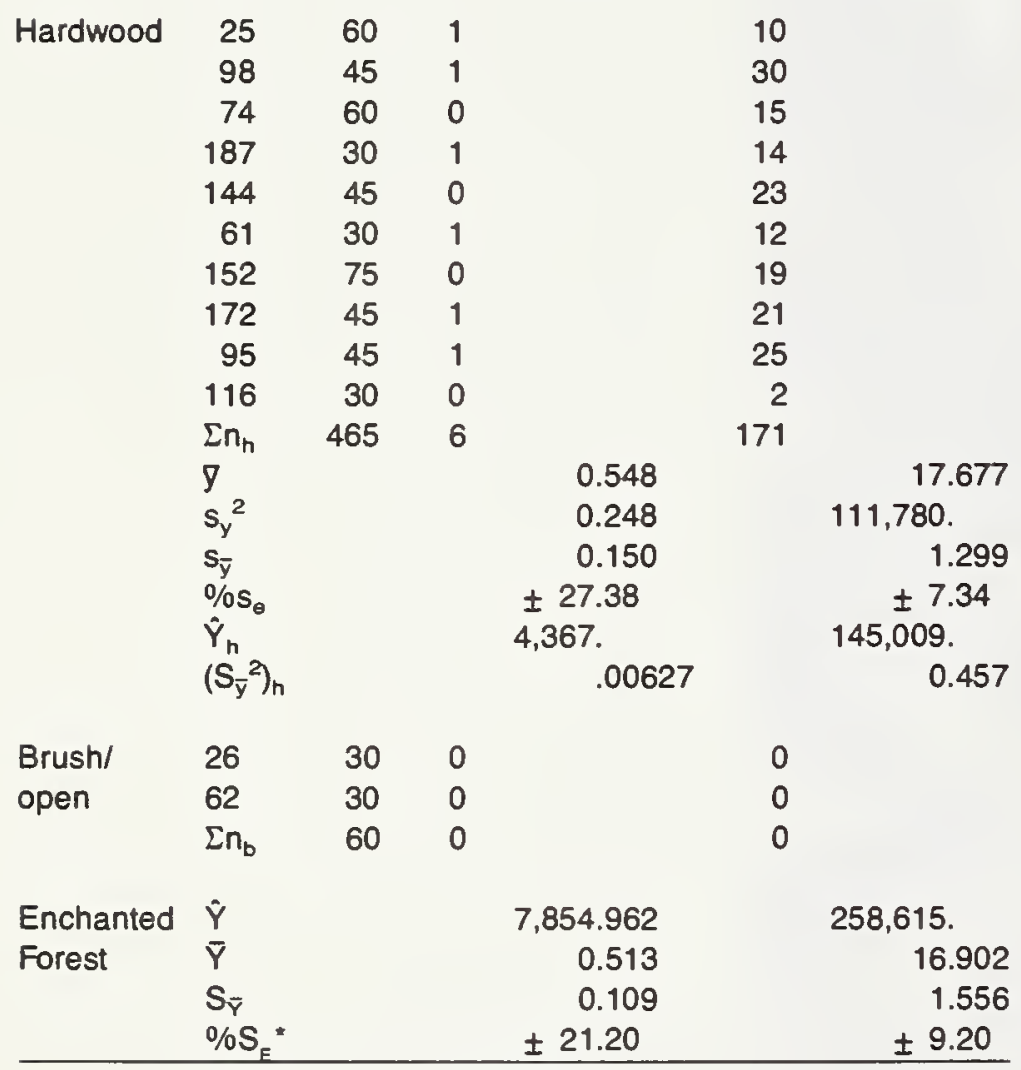

For total volume estimates:

$$
\begin{aligned}
\left(\bar{y}_{w}\right)_{c}= & {[(60 * 21)+(75 * 23)+\ldots(45 * 3)] /(45+60} \\
& +\ldots 45)=18.21 \text { ccf per acre. } \\
\left(s_{w}{ }^{2}\right)_{c}= & \left\{\left[(60 * 21)^{2}+\left(75^{*} 23\right)^{2}+\ldots\left(45^{*} 3\right)^{2}\right)-\right. \\
& {[(2 * 18.2059) *((60 * 21)+(75 * 23)+\ldots} \\
& +(45 * 3))]+\left[\left(18.2059^{2}\right) *\right. \\
& \left.\left.\left(60^{2}+75^{2}+\ldots 45^{2}\right)\right]\right\} /(8-1)=622,176 \\
\left(s_{w}\right)_{c}= & {[1-(8 / 81) / 8]^{1 / 2} *(15,300 / 200) * 622,176^{1 / 2} } \\
& =0.1584 \text { ccf per acre. } \\
\left(\% s_{e w}\right)_{c}= & (0.1584 / 18.2059) * 100= \pm 28.35 \% . \\
\hat{y}_{c}= & 18.2059 * 6,240=113,605 c c f \text { for the conifer } \\
& \text { stratum. } \\
\left(\mathrm{S}_{\bar{y}}{ }^{2}\right)_{c}= & {\left[622176 *(6240 / 15300)^{2} / 8\right] *[1-8 / 6240]=} \\
& 1.9644 .
\end{aligned}
$$

The same estimators are computed for the hardwood and brush/open strata. The estimates are combined for the Forest as follows where:

$$
\begin{aligned}
\hat{Y}= & (113,605+145,010+0)=258,615 \mathrm{ccf} \text { in the } \\
& \text { Forest. } \\
\bar{Y}= & 258,615 / 15,300=16.90 \mathrm{ccf} \text { per acre. } \\
\mathrm{S}_{\bar{Y}}= & (1.964+0.457+0)^{1 / 2}=1.556 \mathrm{ccf} \text { per acre. } \\
\% \mathrm{~S}_{\mathrm{E}}= & (1.5562 / 16.9029) * 100= \pm 9.21 \% .
\end{aligned}
$$

The estimated area and volume by vegetation type are similarly computed. To compute estimates for the conifer type, for example, all sampled stands not classed as conifer are assigned a value of 0 for volume and area. The area of conifer type is 6,240 acres, the area of hardwoods is 7,965 acres, and the area of brush/open is 1,095 acres.

The estimated total volume is 113,605 ccf for conifer, $145,010 \mathrm{ccf}$ for hardwood, and $0 \mathrm{ccf}$ for the brush/open type, respectively.

Stand Estimates-Sampled stand are assigned their observed values. Unmeasured stands are assigned the stratum averages. The average volume per acre for the unmeasured stands is $18.2 \mathrm{ccf}$ for conifers, $17.7 \mathrm{ccf}$ for hardwoods, and $0 \mathrm{ccf}$ for brush. See figure 32. 
Cost Estimates-The costs would be the same as unstratified equal probability sampling plus the cost of interpretation of aerial photos.

\begin{tabular}{llr} 
Field costs & $=\$ 2,244$ \\
Purchase aerial photos & $=490$ \\
Mapping & 1,148 \\
Interpretation & $=306$ \\
\hline Total costs & $=\$ 4,188$, or $\$ 0.274$ per acre.
\end{tabular}

Discussion-The USDI Bureau of Land Management (Baker 1982) used this technique. This technique is easier to implement than probability proportional to size (see next paragraph), but the calculations are more complex.

\section{Forest Boundary}
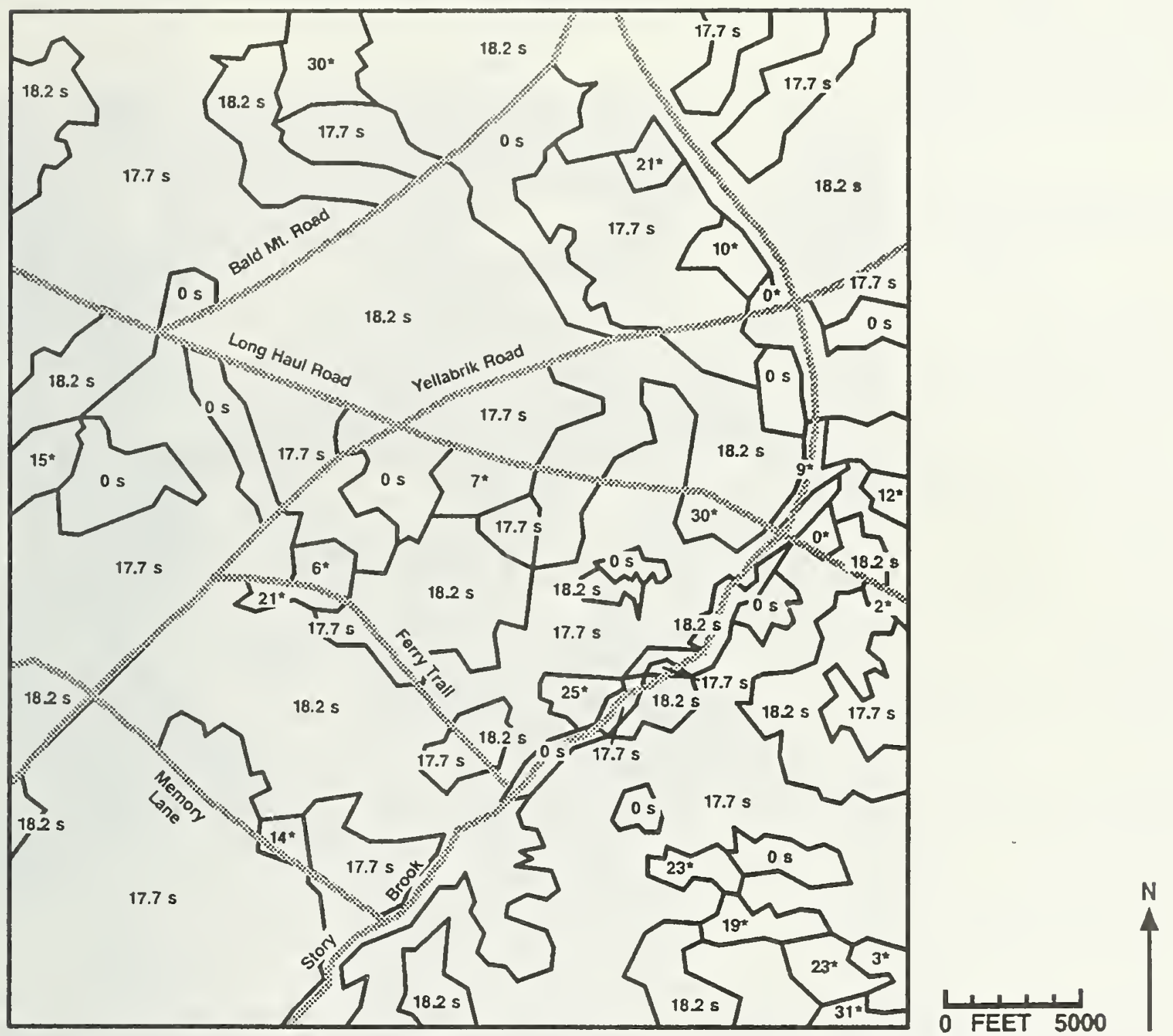

Figure 32-Mapping showing measured (*) and stratum average (s) volume (ccf) per acre based on an equal probability sample of stratified stand numbers. 
Probability Proportional to Size (p.p.s.) SamplingA grid is superimposed over the stratified forest, as was done in figure 26. This provides a stratified sample of stands based on probability proportional to their acreage (fig. 33). At least two stands must be measured in each stratum. The initial plot within each selected stand is located at the grid intersection.

Statistical Estimates-Comments regarding the applicability of p.p.s. methods to unstratified, whole forest are still valid. The relationship between the measure of size and the objective variable needs to be positive and a strong correlation should exist; however, with the partitioning of the brush/open into a separate stratum, these assumptions are probably much more realistic. Still, the Enchanted Forest does not meet them as well as many real forests probably would (the method of generation for the stand volumes resulted in a distribution that does not strongly correlate with stand acreage). Table 19 shows the results of such an inventory.

For the area and volume estimates in the conifer vegetation type, $\mathrm{n}_{\mathrm{c}}=7, \mathrm{~N}_{\mathrm{c}}=6,240$.

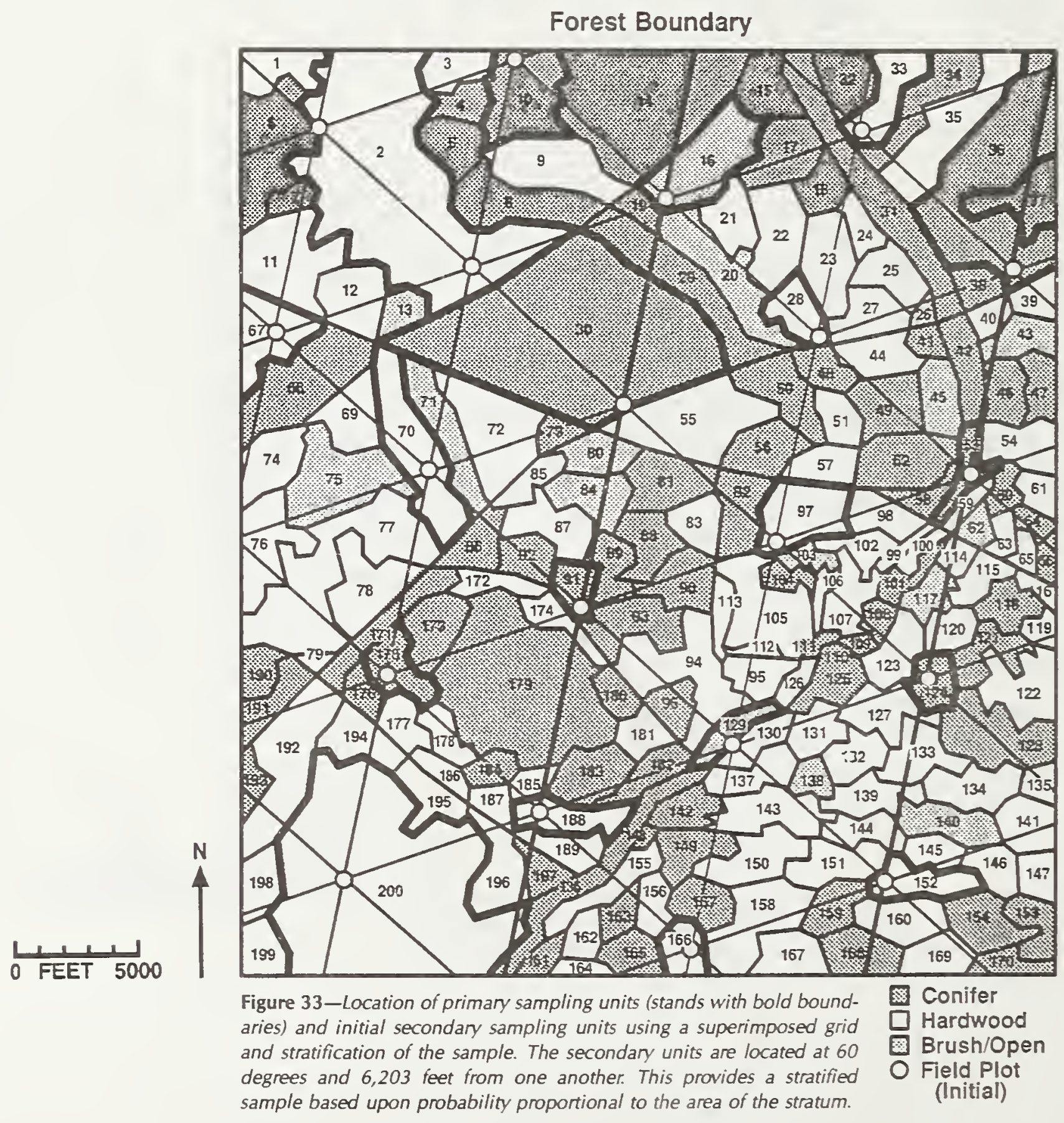


Table 19-Results of an inventory of the Enchanted Forest using stratified mapped stands and selection based upon probability proportional to their area; volume estimates are expressed in ccf

\begin{tabular}{|c|c|c|c|c|c|}
\hline Stratum & Stand & $\begin{array}{c}\text { Wildlife } \\
\text { use }\end{array}$ & $\begin{array}{l}\text { Wildlife } \\
\text { estimators }\end{array}$ & $\begin{array}{c}\text { Volumel } \\
\text { acre }\end{array}$ & $\begin{array}{l}\text { Volume } \\
\text { estimators }\end{array}$ \\
\hline \multirow[t]{14}{*}{ Conifer } & 10 & 1 & & 30 & \\
\hline & 30 & 1 & & 19 & \\
\hline & 36 & 0 & & 32 & \\
\hline & 91 & 0 & & 8 & \\
\hline & 53 & 0 & & 9 & \\
\hline & 124 & 0 & & 18 & \\
\hline & 175 & 1 & & 26 & \\
\hline & $\Sigma n_{c}$ & 3 & & 142 & \\
\hline & 8 & & 0.429 & & 20.287 \\
\hline & $s_{y}{ }^{2}$ & & 0.286 & & 91.571 \\
\hline & $s_{\bar{y}}$ & & 0.202 & & 3.617 \\
\hline & $\% \mathrm{~s}_{\ominus}$ & & \pm 47.14 & & \pm 17.83 \\
\hline & $\left(S_{\bar{y}}\right)_{c}^{2}$ & & 0.007 & & 2.174 \\
\hline & $\dot{\mathrm{Y}}_{\mathrm{c}}$ & & 2,674 & & 126,582 \\
\hline
\end{tabular}

Hardwood

2
2
67
33
70
28
97
200
188
166
152
$\sum n_{h}$
$\mathrm{~J}_{\mathrm{y}}{ }^{2}$
$\mathrm{~s}_{\bar{y}}$
$\% \mathrm{~s}_{\mathrm{e}}$
$\left(\mathrm{S}_{\bar{y}}\right)_{h}^{2}$
$\hat{\mathrm{Y}}_{h}$

Brush/open

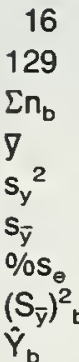

Enchanted
Forest

$\hat{Y}$
$\bar{Y}$
$S_{\bar{Y}}$
$\% S_{E}$

0.000

$\begin{array}{rr}0.000 & 0.000 \\ 0.000 & \pm 0.000\end{array}$

$0.000 \quad 0.000$

1,095 .

3,285 .

209,518
To compute the area estimators for snaileater use within each stratum, all sampled stands having evidence of wildlife use are assigned a value of 1 and all other sampled stands are given a value of 0 . For the conifer stratum:

$$
\begin{aligned}
\bar{y}_{c}= & (1+1+\ldots 1) / 7=0.4286 \text { wildlife use per } \\
& \text { plot. } \\
\left(\mathrm{s}_{y}{ }^{2}\right)_{c}= & \left\{\left(1^{2}+1^{2}+\ldots 1^{2}\right)-(1+1+\ldots 1)^{2} / 7\right\} /(7 \\
& -1)=0.2857 . \\
\left(\mathrm{s}_{\bar{y}}\right)_{c}= & \{0.2857 / 7 *[1-(7 / 6,240)]\}^{1 / 2}=0.2020 \\
& \text { wildlife use per plot. } \\
\left(\% \mathrm{~s}_{\mathrm{e}}\right)_{\mathrm{c}}= & (0.2020 / 0.4286) * 100= \pm 47.14 \% . \\
\hat{\mathrm{Y}}_{\mathrm{c}}= & 0.4286 * 6,240=2,674 \text { acres of wildlife use } \\
& \text { in the conifer stratum. } \\
\left(\mathrm{S}_{\overline{\mathrm{y}}}{ }^{2}\right)_{\mathrm{c}}= & {\left.[0.2857 * 6240 / 15300)^{2} / 7\right] *[1-(7 / 6,240)]=} \\
& 0.00678 .
\end{aligned}
$$

The same estimators are computed for the hardwood and brush/open strata. The area estimates are combined for the Forest as follows, where:

$$
\begin{aligned}
\hat{Y}= & (2,674+4,345+1,095)=8,114 \text { acres of } \\
& \text { wildlife use in the Forest. } \\
\bar{Y}= & 8,113.8312 / 15,300=0.5303 \text { wildlife use in } \\
& \text { the Forest. } \\
\mathrm{S}_{\bar{Y}}= & (0.00678+0.00671+0)^{1 / 2}=0.1162 \text { wildlife } \\
& \text { use per acre. } \\
\% \mathrm{~S}_{\mathrm{E}}= & (0.1162 / 0.5303) * 100= \pm 21.90 \% .
\end{aligned}
$$

For total volume estimates:

$$
\begin{aligned}
\bar{y}_{c}= & (30+19+\ldots 26) / 7=20.2857 \text { ccf per acre. } \\
\left(\mathrm{s}_{\mathrm{y}}{ }^{2}\right)_{\mathrm{c}}= & \left\{\left(30^{2}+19^{2}+\ldots 26^{2}\right)-[((30+19+\ldots\right. \\
& \left.\left.\left.26)^{2}\right) / 7\right]\right\} /(7-1)=91.57 . \\
\left(\mathrm{s}_{\bar{y}}\right)_{\mathrm{c}}= & \left\{(91.5714 / 7) *[1-(7 / 6,240)]^{1 / 2}=3.62 \mathrm{ccf}\right. \\
& \text { per acre. } \\
\left(\% \mathrm{~s}_{\mathrm{e}}\right)_{\mathrm{c}}= & (3.6169 / 20.2857) * 100= \pm 17.83 \% . \\
\hat{\mathrm{y}}_{\mathrm{c}}= & 20.2857 * 6,240=126,583 \mathrm{ccf} \text { in conifer } \\
& \text { stratum. } \\
\left(\mathrm{S}_{\overline{\mathrm{y}}}{ }^{2}\right)_{\mathrm{c}}= & {\left[\left(9\left(.5714 * 6,240^{2}\right) / 7\right] *[1-(7 / 6,240)]=\right.} \\
& 508,796,000 .
\end{aligned}
$$

\begin{tabular}{cc}
$8,114$. & $209,518$. \\
0.530 & 13.694 \\
0.116 & 1.868 \\
\pm 21.90 & \pm 13.64 \\
\hline
\end{tabular}

The same estimators are computed for the hardwood and brush/open strata. The estimates are combined for the Forest as follows where:

$$
\begin{aligned}
\hat{Y}= & (126,583+79,650+3,285)=209,518 \mathrm{ccf} \text { in } \\
& \text { the Forest. } \\
\bar{Y}= & 209,518 / 15,300=13.694 \mathrm{ccf} \text { per acre. } \\
S_{\bar{Y}}= & (2.173+1.319+0)^{1 / 2}=1.8688 \mathrm{ccf} \text { per acre } \\
\% \mathrm{~S}_{E}= & (1.8688 / 13.6940) * 100= \pm 13.65 \% .
\end{aligned}
$$


The estimated area and volume by vegetation type are similarly computed. To compute estimates for the conifer type, for example, all sampled stands not classed as conifer are assigned a value of 0 for volume and area. The area of conifer type is 6,240 acres, the area of hardwoods is 7,965 acres, and the area of brush/open is 1,095 acres.

The estimated total volume is $126,583 \mathrm{ccf}$ for conifer, $79,650 \mathrm{ccf}$ for hardwood, and 3,285 ccf for the brush/ open type, respectively.

Stand Estimates-Measured stands are assigned their actual values. Unmeasured stands are assigned the stratum averages. The average volume per acre for unmeasured conifer stands is $19.5 \mathrm{ccf} ; 10.2 \mathrm{ccf}$ for hardwoods; and $2.0 \mathrm{ccf}$ for brush vegetation types. See figure 34 .

Cost Estimates-The costs would be the same as unstratified probability proportional to size plus the cost of interpretation of aerial photos.

\begin{tabular}{llr} 
Field costs & $=$ & $\$ 2,168$ \\
Purchase aerial photos & & 490 \\
Mapping & $=$ & 1,148 \\
Interpretation & $=$ & 306 \\
\hline Total cost & $=\$ 4,112$, or $\$ 0.269$ per acre.
\end{tabular}

\section{Forest Boundary}

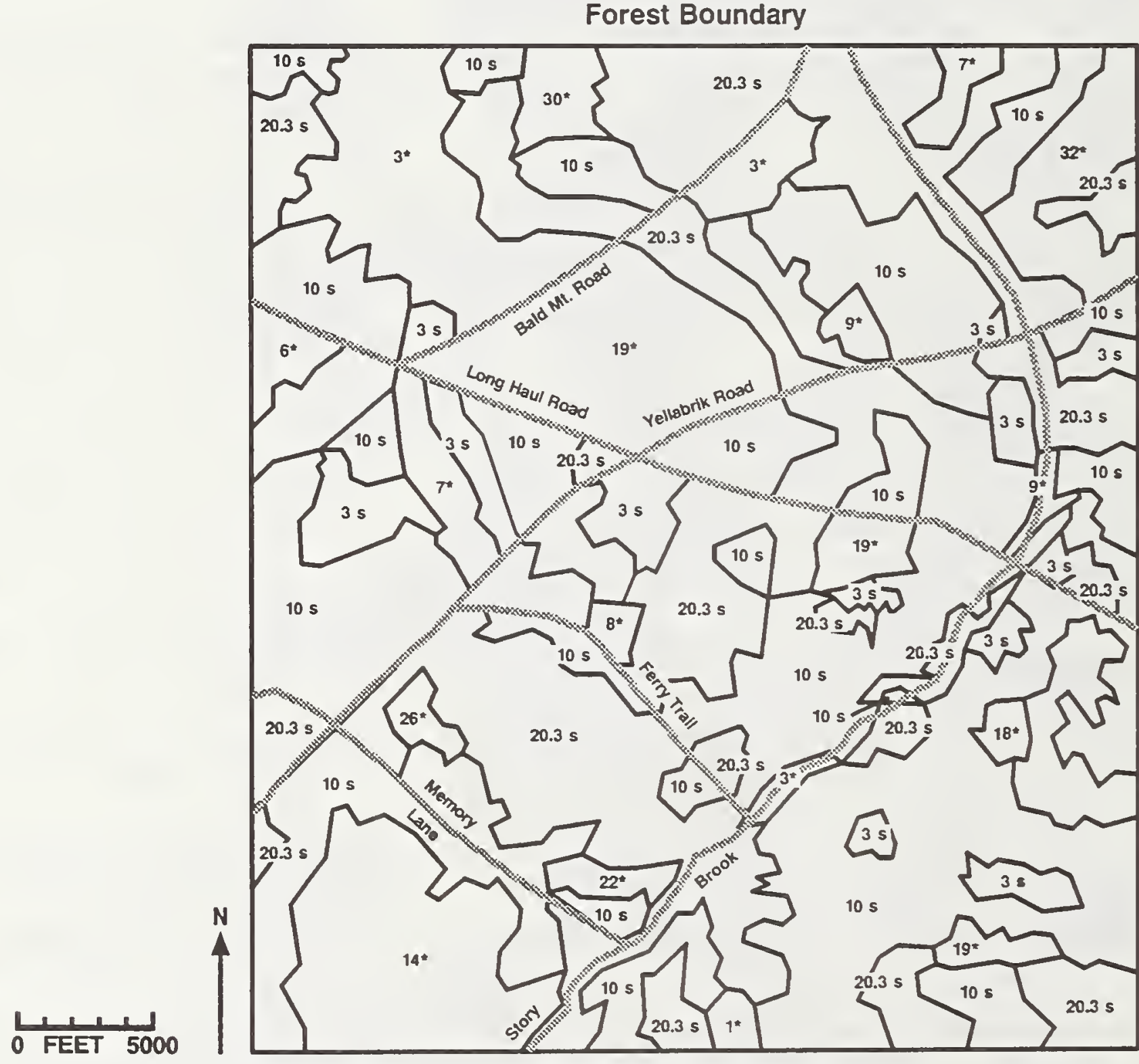

Figure 34-Mapping showing measured (*) and stratum average (s) volume (ccf) per acre based on stratified sampling of stands proportional to their area. 
Discussion-The Northern (Brickell 1984), Rocky Mountain (Mehl 1984), Intermountain (Myers 1984) and California Regions (Bowlin 1984) use this type of inventory design. As an alternative to a grid, Lund (1978b) uses accumulated acres within stands and strata. Stage (1971) provides a similar technique using a sorted list. The end result is nearly the same. The forest is systematically sampled; however, sorting the list assures that the sample will include a range of values for the auxiliary variable that approximates that for the population, an advantage that may well be needed if small numbers of plots are to be sampled. In both cases, the stratum and stands having the largest area have the higher probability of being sampled.
Inventories Using Existing Stand Information

In practice, some stand data may already exist from previous examinations or timber cruises. In such instances, provided the data are current and unbiased, the existing information may be used in addition to establishing new plots.

Assume data exist for stands 2, 10, 16, 28, 30, 33, 36, 53, $67,70,91,97,124,129,152,166,175,188$, and 200 , as shown in figure 35 . 
The total volume and area by vegetation type in the stands that have already been measured are as follows:

$\begin{array}{lcc}\text { Vegetation type } & \text { Area (acres) } & \text { Total volume (ccf) } \\ \text { Conifer } & 1,335 & 30,795 \\ \text { Hardwood } & 2,610 & 20,625 \\ \text { Brush/open } & 165 & 495 \\ \text { Total } & 3,360 & 51,915\end{array}$

The area of snaileater use is 2,280 acres. These estimates were obtained simply by summing the data from the stands that have been measured. This constitutes the existing inventory. Because all of the stands in the existing inventory were measured, there are no sampling errors.

There are two options for using existing stand data. These are: (1) to use the existing data as potential sampling unit information or (2) to combine the existing information with an inventory of the remaining areas. Example statistical calculations are shown for the second option. Cost estimates are not given because the options discussed are extensions of some of the above methods.

Use of the Stand as a Sampling Unit-If in the course of a new inventory, one of the stands for which data already exist is drawn for field sampling, then the data from that stand may be used to compile the inventory. For example, if stand 97 in the new inventory were selected, the stand would not have to be visited in the field, but the existing data from stand 97 would be used in the calculations for the forest. The Rocky Mountain Region (Mehl 1984) uses this procedure.

It is important to note that the stand must be selected in the course of the draw and not purposefully selected because the stand has already heen inventoried. To do the latter can seriously bias the new inventory. Very often existing stand information results from recent stand examinations or timber cruises. Both types of inventories are usually conducted where access is good and timber volumes relatively high, and in areas that have just been or are about to be treated. Such areas may not be representative of the forest as a whole. Hence, for this particular option, data from such sources should only be used when the locations are randomly selected.

This option has the advantage of reducing field costs, but has the disadvantage of not making use of all the available information.
Combining Inventories-The second option is to use all of the existing data as a separate stratum, conduct an inventory of the remaining lands, and then add the figures together.

To select a sample of the remaining stands, we will use stratified probability proportional to size sample selection. However, instead of using a grid to select the sample stands, we will use accumulated acres to illustrate another stand selection technique. This method is described in Lund (1978b).

To use the accumulated acres technique, list the unmeasured stands and their area by strata, then, with the first stand listed, accumulate acres within the stratum as illustrated for the hardwood stratum in table 20 .

Next, determine the number of sample stands to be visited in each stratum. For this exercise, select 10 samples in the hardwood stratum, 8 in the conifer stratum, and 2 in the brush/open vegetation type.

Next, determine the sampling interval (SI) and random start (RS) number for each stratum where:

$$
\mathbf{S I}=\mathbf{A}_{\mathbf{i}} / \mathbf{n}_{\mathbf{i}} \text { (truncated to a whole number) }
$$

Note the remainder (REM). For the hardwood stratum $A_{h}=5,805$ acres. $\mathrm{SI}=5,805 / 10=580$ acres with 5 remaining (REM).

The range (RG) from which we will choose a random start is

$$
\mathbf{R G}=\mathbf{S I}+\mathbf{R E M}
$$

For the hardwood stratum $\left(A_{h}\right), R G=580+5=585$ acres.

Lastly, choose a random number (RS) between 1 and REM. The stand having the accumulated acreage for that number is the first stand chosen for sampling. For the hardwood stratum, we randomly chose a number between 1 and 585. The random number we drew was 84 . Stand no. 3 contains accumulated acres 16 through 90 . Hence acre 84 falls within stand 3 . This is our first sample.

Additional stands are selected at $\mathrm{SI}$ intervals until the desired number of samples have been drawn. Thus for the hardwood stratum, the sample 1 is acre 84 , sample 2 is at $84+580$ or acre 664 (stand no. 23), sample 3 is at acre 1244 (stand 54), etc. 
Table 20-Hardwood acres in uninventoried portions of the Enchanted Forest

\begin{tabular}{|c|c|c|c|c|c|c|c|}
\hline Stand no. & Acres & Accumulated acres & Sample no. & Stand no. & Acres & Accumulated acres & Sample no. \\
\hline 1 & 45 & 45 & & 116 & 30 & 3,285 & \\
\hline 3 & 45 & 90 & 1 & 119 & 30 & 3,315 & \\
\hline 9 & 165 & 255 & & 120 & 60 & 3,375 & \\
\hline 11 & 150 & 405 & & 122 & 90 & 3,465 & \\
\hline 12 & 60 & 465 & & 123 & 45 & 3,510 & \\
\hline 21 & 60 & 525 & & 126 & 30 & 3,540 & \\
\hline 22 & 90 & 615 & & 127 & 75 & 3,615 & 7 \\
\hline 23 & 75 & 690 & 2 & 130 & 45 & 3,660 & \\
\hline 24 & 45 & 735 & & 131 & 45 & 3,705 & \\
\hline 25 & 60 & 795 & & 132 & 45 & 3,750 & \\
\hline 27 & 60 & 855 & & 133 & 60 & 3,810 & \\
\hline 35 & 165 & 1,020 & & 134 & 75 & 3,885 & \\
\hline 39 & 30 & 1,050 & & 135 & 30 & 3,915 & \\
\hline 40 & 15 & 1,065 & & 137 & 60 & 3,975 & \\
\hline 44 & 60 & 1,125 & & 139 & 60 & 4,035 & \\
\hline 51 & 45 & 1,170 & & 141 & 45 & 4,080 & \\
\hline 54 & 75 & 1,245 & 3 & 143 & 90 & 4,170 & 8 \\
\hline 55 & 240 & 1,485 & & 144 & 45 & 4,215 & \\
\hline 57 & 75 & 1,560 & & 145 & 45 & 4,260 & \\
\hline 59 & 15 & 1,575 & & 146 & 60 & 4,320 & \\
\hline 61 & 30 & 1,605 & & 147 & 45 & 4,365 & \\
\hline 63 & 15 & 1,620 & & 150 & 60 & 4,425 & \\
\hline 65 & 30 & 1,650 & & 151 & 60 & 4,485 & \\
\hline 69 & 90 & 1,740 & & 155 & 60 & 4,545 & \\
\hline 72 & 165 & 1,905 & 4 & 156 & 45 & 4,590 & \\
\hline 74 & 60 & 1,965 & & 158 & 135 & 4,725 & 9 \\
\hline 76 & 75 & 2,040 & & 160 & 75 & 4,800 & \\
\hline 77 & 285 & 2,325 & & 162 & 30 & 4,830 & \\
\hline 78 & 120 & 2,445 & 5 & 164 & 30 & 4,860 & \\
\hline 79 & 15 & 2,460 & & 167 & 60 & 4,920 & \\
\hline 83 & 30 & 2,490 & & 169 & 60 & 4,980 & \\
\hline 85 & 45 & 2,535 & & 172 & 45 & 5,025 & \\
\hline 87 & 60 & 2,595 & & 174 & 45 & 5,070 & \\
\hline 94 & 120 & 2,715 & & 177 & 45 & 5,115 & \\
\hline 95 & 45 & 2,760 & & 178 & 45 & 5,160 & \\
\hline 98 & 45 & 2,805 & & 181 & 60 & 5,220 & \\
\hline 99 & 15 & 2,820 & & 185 & 30 & 5,250 & \\
\hline 100 & 30 & 2,850 & & 186 & 30 & 5,280 & \\
\hline 102 & 60 & 2,910 & & 187 & 30 & 5,310 & 10 \\
\hline 105 & 165 & 3,075 & 6 & 189 & 45 & 5,355 & \\
\hline 106 & 15 & 3,090 & & 192 & 135 & 5,490 & \\
\hline 107 & 45 & 3,135 & & 194 & 75 & 5,565 & \\
\hline 110 & 15 & 3,150 & & 195 & 60 & 5,625 & \\
\hline 112 & 15 & 3,165 & & 196 & 90 & 5,715 & \\
\hline 113 & 30 & 3,195 & & 198 & 45 & 5,760 & \\
\hline 114 & 15 & 3,210 & & 199 & 45 & 5,805 & \\
\hline 115 & 45 & 3,255 & & & & & \\
\hline
\end{tabular}


The same process is repeated for each stratum until all strata are sampled. There are a total of 5,805 acres in the hardwood type, 4,905 acres in the conifer type, and 930 acres in the brush/open class. A total of 10, 8 , and 2 plots are chosen in each stratum respectively.

The stands sampled in this new inventory of the Enchanted Forest are shown in figure 36 . Table 21 shows the inventories combined using the existing data as a new stratum.

Statistical estimates-For area and volume estimates in the conifer vegetation type, $\mathrm{n}=8$ and $\mathrm{N}=4,905$ acres.

To compute the area estimators for the snaileater use within each stratum, all sampled stands having evidence of the wildlife use are assigned a value of 1 and all other sampled stands are given a value of 0 .

$$
\begin{aligned}
\bar{y}_{c}= & (1+0+\ldots 0) / 8=0.5000 \text { wildlife use per } \\
& \text { plot. } \\
\left(\mathrm{s}_{\bar{y}}{ }^{2}\right)_{c}= & \left\{\left(1^{2}+0^{2}+\ldots 0^{2}\right)-\left[(1+0+\ldots 0)^{2} / 8\right]\right\} /(8-1) \\
& =0.2857 . \\
\left(\mathrm{s}_{\bar{y}}\right)_{\mathrm{c}}= & \{0.2857 / 8 *[1-(8 / 4,905)]\}^{1 / 2}=0.1890 \text { wild- } \\
& \text { life use per plot. } \\
\left(\% \mathrm{~s}_{\mathrm{e}}\right)_{\mathrm{c}}= & (0.1890 / 0.2857) * 100= \pm 37.80 \% . \\
\hat{\mathrm{y}}_{\mathrm{c}}= & 0.2857 * 4,905=2,452 \text { acres of wildlife use } \\
& \text { in the conifer stratum. } \\
\left(\mathrm{S}_{\overline{\mathrm{y}}}{ }^{2}\right)_{\mathrm{c}}= & {\left[0.2857 *(4905 / 15300)^{2} / 8\right] *[1-8 / 4905]=} \\
& 0.00366 .
\end{aligned}
$$

\section{Forest Boundary}

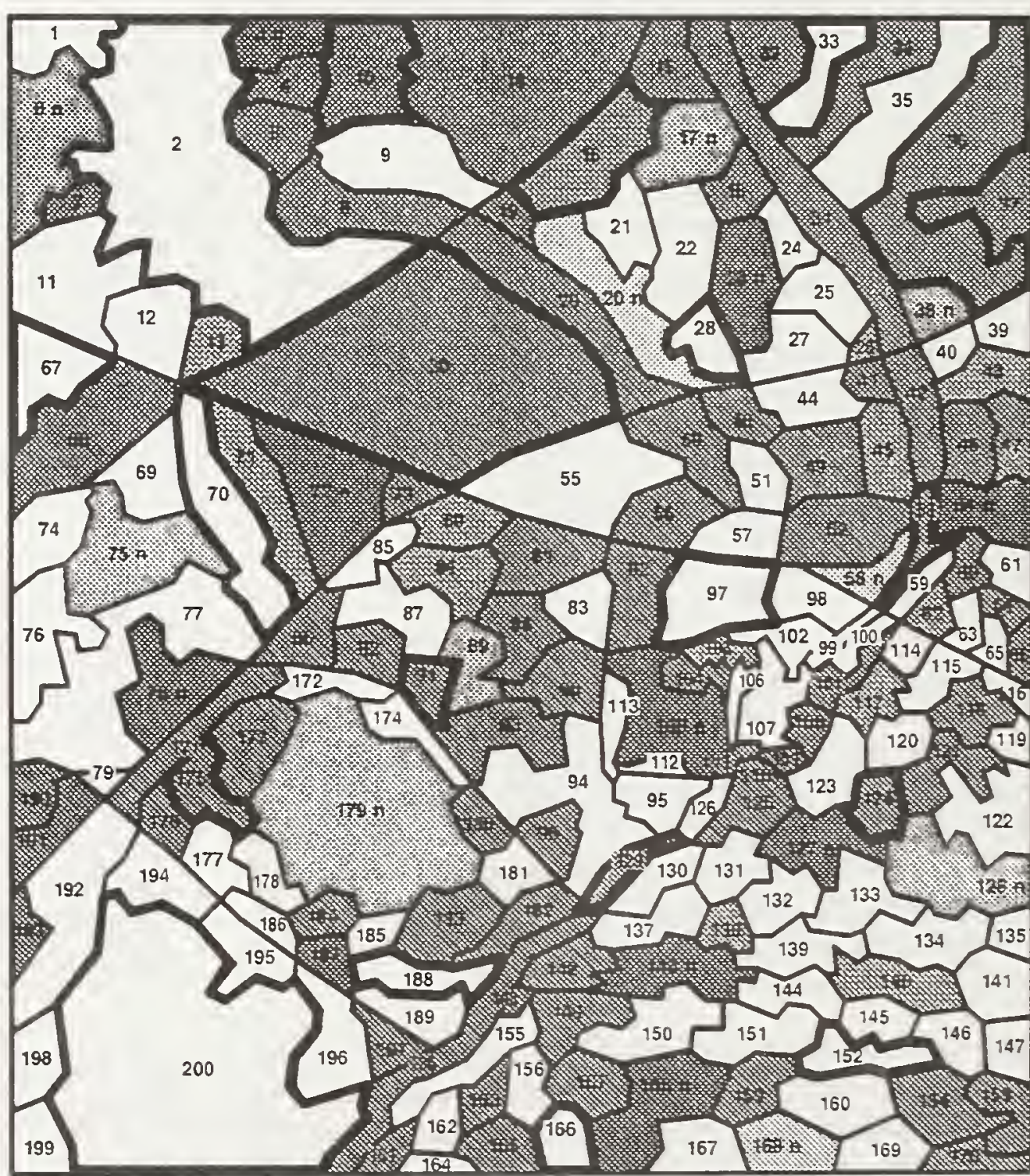

Figure 36-Location of previously measured stands (stands with bold boundaries) and new sampling units $(n)$ in the Enchanted forest.

Conifer Hardwood Brush/Open 
Table 21-Results of a combined inventory of the Enchanted Forest using stratified mapped stands and selection base upon probability proportional to their area; volumes are expressed in ccf

\begin{tabular}{|c|c|c|c|c|c|c|c|c|c|c|c|}
\hline Stratum & Stand & $\begin{array}{c}\text { Wildlife } \\
\text { use }\end{array}$ & $\begin{array}{c}\text { Wildlife } \\
\text { estimators }\end{array}$ & $\begin{array}{c}\text { Volumel } \\
\text { acre }\end{array}$ & $\begin{array}{c}\text { Volume } \\
\text { estimators }\end{array}$ & Stratum & Stand & $\begin{array}{c}\text { Wildlife } \\
\text { use }\end{array}$ & $\begin{array}{c}\text { Wildlife } \\
\text { estimators }\end{array}$ & $\begin{array}{c}\begin{array}{c}\text { Volumel } \\
\text { acre }\end{array} \\
\end{array}$ & $\begin{array}{c}\text { Volume } \\
\text { estimators }\end{array}$ \\
\hline \multirow{16}{*}{ Conifer } & 6 & 1 & & 16 & & \multirow{7}{*}{ Hardwood } & g & & 0.700 & & 19.100 \\
\hline & 17 & 0 & & 12 & & & $s_{y}{ }^{2}$ & & 0.233 & & 89.211 \\
\hline & 38 & 0 & & 4 & & & $s_{\bar{y}}$ & & 0.152 & & 2.987 \\
\hline & 58 & 1 & & 23 & & & $\% \mathrm{~s}_{\mathrm{e}}$ & & \pm 21.82 & & \pm 15.63 \\
\hline & 89 & 0 & & 4 & & & $\left(S_{\bar{y}}\right)^{2}{ }_{h}$ & & 0.003 & & 1.282 \\
\hline & 128 & 1 & & 12 & & & $\hat{Y}_{h}$ & & 4,063 & & 110,875 \\
\hline & 168 & 1 & & 22 & & & & & & & \\
\hline & 179 & 0 & & 26 & & \multirow[t]{9}{*}{ Brush/open } & 20 & 1 & & 0 & \\
\hline & $\Sigma n_{c}$ & 4 & & 119 & & & 75 & 0 & & 3 & \\
\hline & 8 & & 0.500 & & 14.875 & & $\Sigma n_{b}$ & 1 & & 3 & \\
\hline & $\mathrm{s}_{y}{ }^{2}$ & & 0.286 & & 70.696 & & 8 & & 0.500 & & 1.500 \\
\hline & $s_{\bar{y}}$ & & 0.189 & & 2.973 & & $s_{y}^{2}$ & & 0.500 & & 4.500 \\
\hline & $\% \mathrm{~s}_{\mathrm{e}}$ & & \pm 37.79 & & \pm 19.98 & & $s_{\bar{y}}$ & & 0.500 & & 1.500 \\
\hline & $\left(S_{\bar{y}}\right)^{2}{ }_{c}$ & & 0.004 & & 0.906 & & $\% \mathrm{~s}_{\mathrm{e}}$ & & \pm 100.00 & & \pm 100.00 \\
\hline & $\hat{y}_{c}$ & & 2,452 & & 72,961 & & $\left(\mathrm{~S}_{\bar{y}}{ }^{2}\right)_{b}$ & & 0.001 & & 0.008 \\
\hline & & & & & & & $\dot{\mathrm{Y}}_{\mathrm{b}}$ & & 465. & & 1,395 \\
\hline \multirow[t]{12}{*}{ Hardwood } & 3 & 0 & & 28 & & & & & & & \\
\hline & 23 & 1 & & 27 & & \multirow[t]{7}{*}{ Existing data } & $\bar{y}_{d}$ & & 0.623 & & 14.184 \\
\hline & 54 & 0 & & 3 & & & $s_{y}{ }^{2}$ & & 0.000 & & 0.000 \\
\hline & 72 & 1 & & 15 & & & $s_{\bar{y}}^{\prime}$ & & 0.000 & & 0.000 \\
\hline & 78 & 1 & & 30 & & & $\% \mathrm{~s}_{\mathrm{e}}$ & & 0.00 & & 0.00 \\
\hline & 105 & 1 & & 29 & & & $\left(S_{\bar{y}}\right)^{2}{ }_{d}$ & & \pm 0 & & \pm 0 \\
\hline & 127 & 0 & & 23 & & & $\dot{\mathrm{Y}}_{\mathrm{d}}$ & & 2,280 & & 51,915 \\
\hline & 143 & 1 & & 11 & & & & & & & \\
\hline & 158 & 1 & & 12 & & \multirow{4}{*}{$\begin{array}{l}\text { Enchanted } \\
\text { Forest }\end{array}$} & $\hat{Y}$ & & 9,261 & & 237,147 \\
\hline & 187 & 1 & & 13 & & & $\bar{\gamma}$ & & 0.605 & & 15.499 \\
\hline & $\Sigma n_{h}$ & 7 & & 191 & & & $S_{\bar{\gamma}}$ & & 0.089 & & 1.482 \\
\hline & & & & & & & $\% \mathrm{~S}_{E}{ }^{*}$ & & \pm 14.73 & & \pm 9.56 \\
\hline
\end{tabular}

The same estimators are computed for the hardwood and brush/open strata as well as for the existing information. The snaileater area estimates are combined for the Forest as follows where:

$$
\begin{aligned}
& \hat{\mathrm{Y}}=(2,452+4,064+465+2,280)=9,261 \text { acres } \\
& \text { of wildlife use in the Forest. } \\
& \overline{\mathrm{Y}}= 9,261 / 15,300=0.6053 \text { wildlife use in the } \\
& \text { Forest. } \\
& \mathrm{S}_{\overline{\mathrm{Y}}}=(0.00366+0.00335+0.00092+0)^{1 / 2}= \\
& 0.0892 \text { wildlife use per acre. } \\
& \% \mathrm{~S}_{\mathrm{E}}=(0.0892 / 0.6053) * 100= \pm 14.73 \% . \\
& \text { For total volume within the conifer stratum calculate the } \\
& \text { estimates as follows: } \\
& \bar{y}_{\mathrm{C}}=(16+12+\ldots 26) / 8=14.88 \text { ccf per acre. } \\
&\left(\mathrm{s}_{\overline{\mathrm{y}}}\right)_{\mathrm{c}}=\left\{\left(16^{2}+12^{2}+\ldots 26^{2}\right)-\left[(16+12+\ldots 26)^{2} /\right.\right. \\
&8]\} /(8-1)=70.70 .
\end{aligned}
$$
$S_{\bar{Y}}=(0.00366+0.00335+0.00092+0)^{1 / 2}=$ 0.0892 wildlife use per acre.

$$
\begin{aligned}
\left(\mathrm{s}_{\overline{\mathrm{y}}}\right)_{\mathrm{c}}= & {\left[(70.6964 / 8) *[1-(8 / 4,905)]^{1 / 2}=2.97 \mathrm{ccf}\right.} \\
& \text { per acre. } \\
\left(\% \mathrm{~s}_{\mathrm{e}}\right)_{\mathrm{c}}= & (2.97 / 14.87) * 100= \pm 19.97 \% . \\
\hat{\mathrm{y}}_{\mathrm{c}}= & 14.8750 * 4,905=72,962 \mathrm{ccf} \text { in the conifer } \\
& \text { stratum. } \\
\left(\mathrm{S}_{\overline{\mathrm{y}}}{ }^{2}\right)_{\mathrm{c}}= & {\left[70.696 *(4905 / 15300)^{2} / 8\right] *[1-8 / 4905]=} \\
& 0.906 .
\end{aligned}
$$

The same estimators are computed for the hardwood and brush/open strata as for the existing information.

$$
\begin{aligned}
\hat{Y}= & (72,962+110,875+1,395+51,915)= \\
& 237,147 \mathrm{ccf} \text { in the remainder of the Forest. } \\
Y= & 237,147 / 15,300=15.50 \text { ccf per acre. } \\
S_{\bar{Y}}= & (0.906+1.282+0.008+0)^{1 / 2}=1.4823 \mathrm{ccf} \\
& \text { per acre. } \\
\% S_{E}= & (1.4823 / 15.4998) * 100= \pm 9.56 \% .
\end{aligned}
$$


The total estimates of area and volume by vegetation type are similarly computed. Combined estimates are 6,240 acres for the conifer type, 7,965 acres for the hardwood, and 1,095 acres for the brush/open type. Volume estimates are 103,757 ccf for the conifer type, 131,500 ccf for the hardwood, and 1,890 ccf for the brush/open type.

Stand Estimates-Previously measured and newly measured stands are assigned their actual values. Unmeasured stands are assigned the stratum averages from the new inventory. The average volume per acre for unmeasured conifer stands is $14.9 \mathrm{ccf}, 19.1 \mathrm{ccf}$ for hardwoods and 1.5 ccf for brush vegetation types. See figure 37.
Discussion-This application makes use of all available information and permits the calculation of sampling errors in which a good deal of credibility can be placed. It is the method that would be preferred if there were no additional information on portions of the forest.

\section{Complete Enumeration}

Complete enumeration of stands requires visiting and measuring every stand in the compartment. Sample plots are virtually always established within the stands rather than measuring every tree. The Southern (Belcher 1984) and Eastem Regions (Johnson 1984) have used this technique.
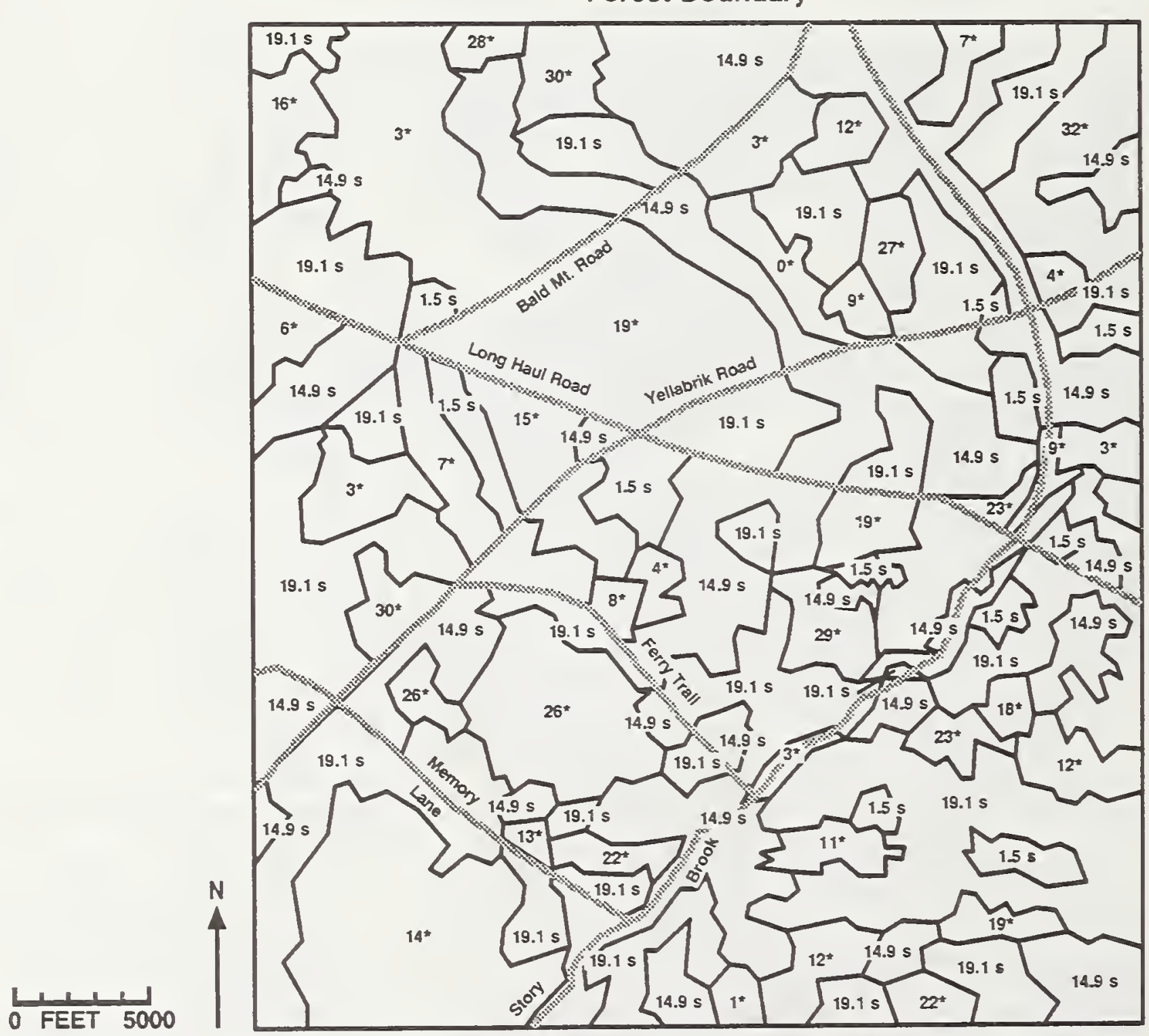

Figure 37-Mapping showing measured (*) and stratum average (s) volume (cct) per acre based on the combined inventory of the Enchanted Forest. 
Statistical Estimates-The results of a complete enumeration of the Enchanted Forest are given appendix 2. The red-spotted snaileater usage is 7,905 acres. Volume results are shown in figure 38 and table 22.

Since all stands are represented in the sample, a sampling error ought not be computed from the equations presented in this publication. It may be possible to approximate a sampling error using a more sophisticated statistical approach such as jackknifing or simulation if there is some way of obtaining the within-stand variation. Usually, we assume that within-stand variation is very much smaller than between-stand variation in the computation of sampling
Table 22-Results of complete enumeration of stands in the Enchanted Forest; volumes are expressed in ccf

\begin{tabular}{lrrr}
\hline Vegetation type & Acres & Total volume & Volume per acre \\
\hline Conifer & 6,240 & 106,515 & 17.05 \\
Hardwood & 7,965 & 112,170 & 14.08 \\
Brush/open & 1,095 & 1,410 & 1.29 \\
Total & 15,300 & 220,095 & 14.39 \\
\hline
\end{tabular}

\section{Forest Boundary}
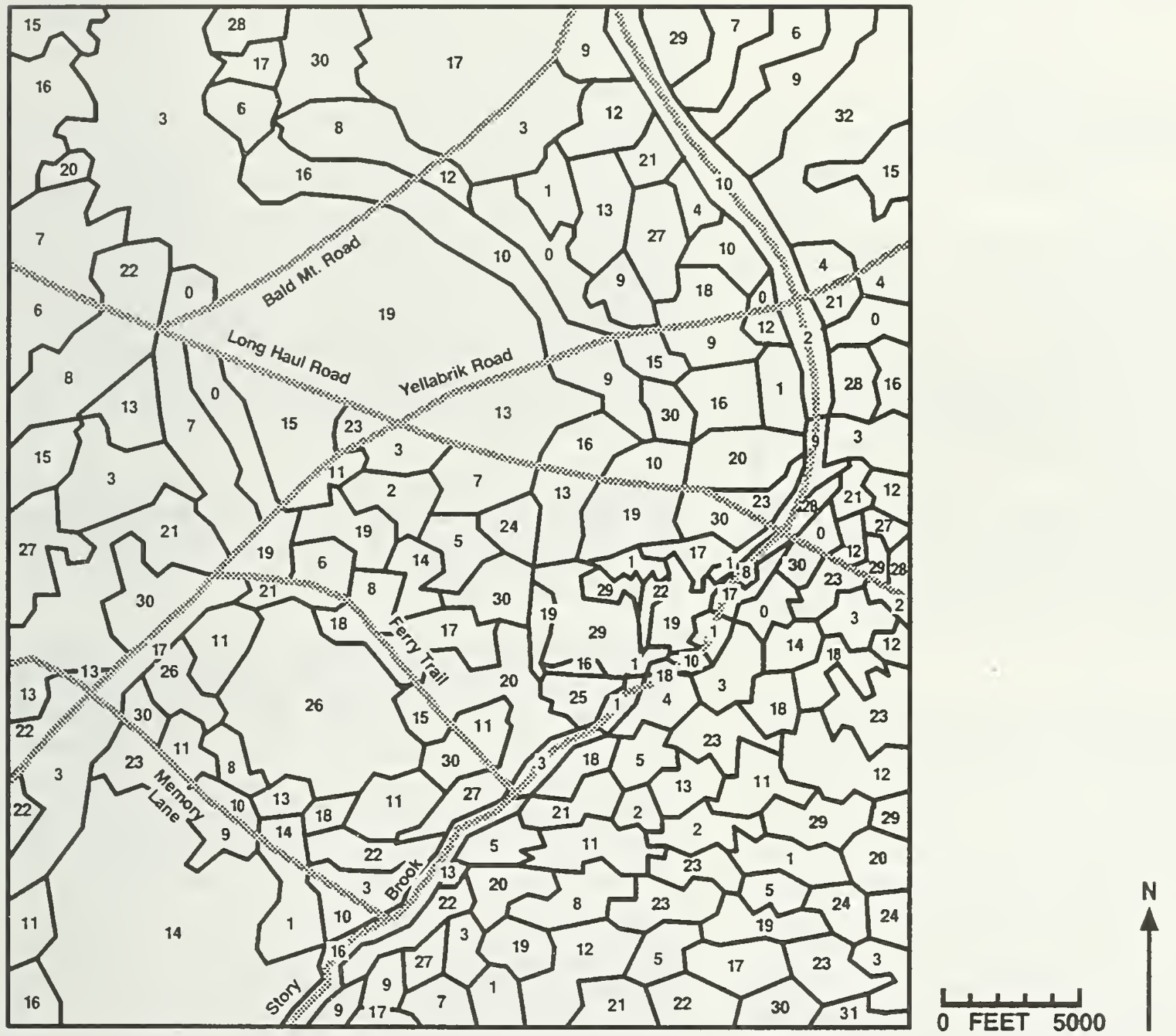

Figure 38-Mapping showing volume (cct) per acre using complete enumeration of all stands in the Enchanted Forest. 
error; however, this may not be the case and in the case of complete enumeration some estimate of within-stand variability could provide us with valuable information on the remaining variability. These procedures might often be appropriate, but require substantial statistical computing and are beyond the scope of this publication.

Cost Estimates-Purchase of aerial photography and mapping is required. Each stand is visited in the field and 10 plots are established in each stand. Assume that it takes 1 hour to move between stands and to start the measurement of each stand.

$$
\begin{aligned}
& \mathrm{L}=(200-1)(1)=199 \text { hours. } \\
& \Sigma\left(M_{s}\right)=1,011 \text { hours. } \\
& D=(199+1,011) / 8=151.3 \text { hours. } \\
& F=2(9)[199+1,011+151.2]=\$ 24,503.4 \\
& \text { Field costs } \quad=\$ 24,503 \\
& \text { Purchase aerial photos }=\quad 490 \\
& \text { Mapping }=1,148 \\
& \text { Total costs } \quad=\$ 26,141 \text {, or } \$ 1.709 \text { per acre }
\end{aligned}
$$

Note that there is no photo interpretation, as all information will come from the field samples.

\section{Summary of Forest Inventories}

The inventory objectives were to estimate the area used by the red-spotted snaileater, the total volume of the forest by cover type, and the volume per acre for each stand.

We repeat the warning that no statistical comparison of the reliability of forest inventories is possible from the examples presented. Additional replications in different situations would be required. Nevertheless, some general observations can be made.

Table 23 shows the results and costs for estimating total ccf volume by the various designs described. Costs were recomputed to a common \pm 10 percent sampling error using equation ( $f$ ).

Statistical Estimators - Estimates are reported for both the Forest as a whole and for individual stands.

Forest Estimates-Of the designs illustrated, the stratified double sample tended to give more precise total results and the systematic sample and unstratified probability proportional to size sampling the least. This must be attributed to the characteristics of the population being sampled. In the latter case the more sophisticated sam- pling designs were in fact applied as if there was ignorance of the major differences between the volumes in the two forested strata and the essentially nonforested brush/open stratum.

Calculations, when probability-proportional-to-size sampling is used, are less complicated than when stands of unequal size are selected with equal probability, as previously illustrated. Oderwald, Wel!man, and Buhyoff (1979) confirm this observation. The simplicity of estimation procedures is a factor in favor of probability-proportionalto-size (area) sampling of stands. The actual calculation will likely be done with a computer in the context of a developed inventory system, but the simplicity of the estimation equations will aid understanding by users. Probability-proportional-to-size sampling is usually with replacement. Thus sampling probability is proportional to size, and the constant of proportionality does not vary between the selection of one unit and the next. In sampling small populations some precision is given up by sampling with replacement. The finite population correction ( $f p c$ ) cannot be used. Probability-proportional-to-size sampling without replacement is possible, but, because the constant of size proportionality changes each time a sampling unit is selected, the error estimation equation becomes more complicated. The characteristics of the population to be sampled and the distribution across subsampled elements of the population must be considered when applying a computational method.

All options showed a reduction in sampling error when stratification was introduced. Even with the small area of the forest and relatively few stands, the benefits of sampling are easily seen.

Assuming the same variation and number of stands sampled, the sampling error would remain nearly constant for forests near the size of the Enchanted Forest and having a similar number of stands (i.e., measure only 20 stands of 1,000 stands using stratified probability proportional to size sampling and arrive at a sample error of \pm 15 percent for the forest). However, the area of the inventory should remain at approximately the same order of magnitude. Thus, if one had a forest of 1 million acres divided in 50,000 stands, one could not use the same technique and intensity to achieve the same sampling error. Several factors weigh on this. The population change from one scale to the next is probably the most significant factor. It is unlikely that an inventory performed on an area of 150,000 acres would retain the same variability. A second consideration is that it is unlikely that the objectives of a 
Table 23-Summary of achieved sampling errors for estimating total volume (cct) for various designs for the inventory of the Enchanted Forest

\begin{tabular}{|c|c|c|c|c|c|c|c|c|}
\hline Inventory design & Sampling error & Field costs & Field costs ${ }^{1}$ & Imagery & Interpretation & Mapping & Total costs ${ }^{1}$ & Cost/acre ${ }^{1}$ \\
\hline & $\%$ & $\$$ & $\$$ & $\$$ & $\$$ & $\$$ & $\$$ & $\$$ \\
\hline Systematic & 15.4454 & $2,275.31$ & $5,427.99$ & 0.00 & 0.00 & 0.00 & $5,427.99$ & 0.355 \\
\hline System. w/poststratification & 12.2032 & $2,275.31$ & $3,388.35$ & 0.00 & 0.00 & 0.00 & $3,388.35$ & 0.221 \\
\hline Strip cruise & 12.4805 & $2,275.31$ & $3,544.09$ & 0.00 & 0.00 & 0.00 & $3,544.09$ & 0.232 \\
\hline Double samp. w/estimated wts. & 7.9957 & $2,275.31$ & $1,454.63$ & 489.60 & 1.60 & 0.00 & $1,945.83$ & 0.127 \\
\hline Stratified satellite imagery & 10.0082 & $2,275.31$ & $2,279.04$ & 61.20 & 382.50 & 306.00 & $3,025.75$ & 0.198 \\
\hline Equal probability sampling & 9.3388 & $2,243.59$ & $1,956.71$ & 489.60 & 0.00 & $1,147.50$ & $3,593.81$ & 0.235 \\
\hline Probability prop. to area & 16.6631 & $2,168.43$ & $6,020.84$ & 489.60 & 0.00 & $1,147.50$ & $7,657.94$ & 0.501 \\
\hline Stratification w/known wts. & 12.3757 & $2,275.31$ & $3,484.82$ & 489.60 & 306.00 & $1,147.50$ & $5,427.92$ & 0.355 \\
\hline Stratified e.p.s. & 12.9600 & $2,243.59$ & $3,768.37$ & 489.60 & 306.00 & $1,147.50$ & $5,711.47$ & 0.373 \\
\hline Stratified p.p.s. & 13.6466 & $2,168.43$ & $4,038.26$ & 489.60 & 306.00 & $1,147.50$ & $5,981.36$ & 0.391 \\
\hline Combined inventories & 9.5630 & $2,168.43$ & $1,983.05$ & 489.60 & 232.80 & $1,147.50$ & $3,852.95$ & 0.252 \\
\hline Complete enumeration & 0.0000 & $24,496.16$ & $24,496.16^{*}$ & 489.60 & 0.00 & $1,147.50$ & $26,141.40^{\circ}$ & $1.709^{*}$ \\
\hline
\end{tabular}

${ }^{1}$ At 10-percent sampling error computed using equation $\mathrm{f}$.

* Cost estimates for complete enumeration cannot be computed for a 10-percent sampling error.

much larger inventory would remain the same as that of the small area. Additional criteria for initiating an inventory of an area larger by an order of magnitude are very likely to increase the required sampling intensity in order that important resources receive sufficient samples to allow for meaningful results. As a general rule, as the size of an inventory increases the practical intensity may have to increase unless strong correlation to auxiliary data exists. Of course, by increasing the sample size (number of plots or stands visited) the sample error would decrease.

By using probability proportional to size sampling and stratification, one can reduce the sample error by using the same sample intensity or achieve the same sample error with less field work (i.e., measure fewer stands).

When all strata of interest are known, prestratification is preferred to poststratification because one is assured that all strata of interest can and will be sampled. The same cannot be said of poststratification.

Individual Stand Estimates-The ability to generate statistics for each stand depends on how much prior knowledge is available.

Appendix 3 shows side by side comparisons of volume estimates by various designs for the stands within the Enchanted Forest. As one might expect, there are considerable differences between the assigned values and the ground truth. Again stratification appears to improve the resolution of the inventory. While a sampling error cannot be computed for each stand, estimates of the sampling error are available for each stratum.
Where stratification is not used, the sampling error of the whole forest may be examined to give some hint as to the reliability of each stand estimate though prior knowledge is limited.

Stand estimates can be further refined using inventory data. If relationships can be established between variables that can be easily interpreted from aerial photos (such as height) and variables that are best measured or determined from field observations (such as volume), prediction equations can be developed to assist in future stand mapping. For example, assume overstory heights ( $h$ ) were estimated for each photo plot. A regression is developed between the heights and volume for photo points that were measured in the field (see Freese (1962) for formulation), where volume per acre $(\mathrm{v})$ is:

$$
v=-0.3271+0.317 h(h)
$$

When the height $(h)=$ zero, $v$ is set to zero, and the coefficient of determination is 0.94 .

The equation can be applied using the nonfield measured photo points to derive volume estimates for each photo point (see fig. 18). When the stands are eventually mapped, the overstory heights can be interpreted from aerial photos and volumes per acre can be predicted for each stand without further field work. Lund (1974) used this technique for forest inventories in the U.S. Department of Interior, Bureau of Land Management, and Lund and Kniesel (1975) used the same process to predict multiresource values such as deer-days use and forage production. 
If the stands are already mapped and heights interpreted, as in the case of the stratified probability proportional to area sample, the predicted values can be directly applied and a volume map generated. The second-to-last column of Appendix 3 and figure 39 give the results of such an exercise using equation (24). This technique was used by Brickell (1984) and is an economical technique for obtaining stand estimates. Langley (1983) used a similar technique and incorporates the results in a geographic information system.
Cost Estimates-The comparison of inventory design costs involving no prior mapping versus prior mapping is clear. If it is the case that mapping is never to be undertaken, then our examples indicate that the costs do not justify if for inventory alone. Overall, the actual cost incurred for inventories without mapping was less. This result may be due primarily to assumptions. However, the eventual use of an inventory by a forest manager and resource specialist virtually always requires stand mapping. Thus, the cost of mapping is just delayed, not avoided. Prior mapping is

\section{Forest Boundary}

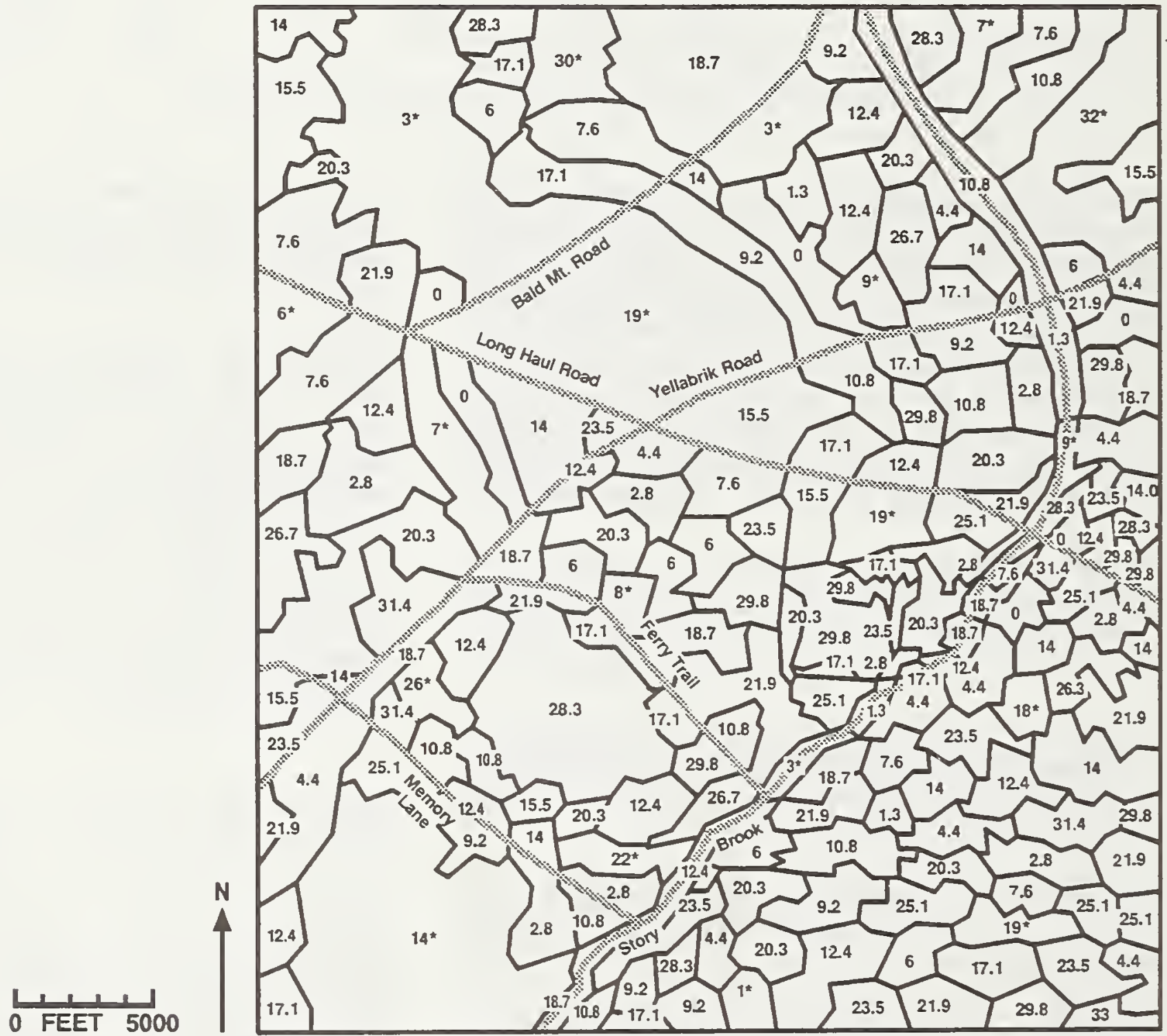

Figure 39-Mapping showing measured (*) and predicted volumes (cct) per acre based upon a stratified sample of stands proportional to their size and predictions base upon photo-interpreted heights of the overstory. 
cheaper in the long run because the area information is collected only once. If mapping is delayed, the area information must first be derived from the sample plots and then be rectified when mapping is complete; this incurs additional time and cost that is avoided with prior stand mapping.

The comparison of costs necessary to achieve a \pm 10 percent sampling error shows that the gains in sampling precision may outweigh the costs of mapping.

The cost of introducing randomization into an inventory design that provides the foundation for a statistical sample is minimal. The cost of an inventory of two stands that are selected for probability sampling is no greater than one based on a subjective sample with preconceived bias.

Inventory costs generally tend to increase with increasing complexity of the sampling design. Equal probability sampling may be more or less expensive than probabilityproportional-to-size sampling. When using probabilityproportional-to-size sampling, larger area stands are more likely to be selected than in equal probability sampling. Measurement of larger stands may require more field time than small stands because more area has to be traversed. It should be clear that only slightly more large area stands would be included; thus increases in costs could be minimal.

Stratified sampling also offers savings. In nearly all the cases demonstrated here, stratification offered lower total costs at equitable sampling errors even though the costs of forming the stratum were added.

MacLean (1972) confirms this relationship. In general, stratified sampling results in increased information for a given cost because (Mendenhall, Ott, and Scheaffer 1971):

1. The data are usually more homogeneous within each stratum than in the population as a whole. Hence, fewer samples are usually needed.

2. The cost of conducting the actual sampling may be less for stratified random sampling than for simple random sampling because of administrative convenience. Plots falling in the brush stratum, for example, could possibly have been measured with a one person crew. Without that prior knowledge, a two person crew would have been sent to the plot location.
3. Separate estimates of population parameters can be obtained for each stratum without additional sampling. Estimates for each vegetation type were assured, where as without stratification this could not be guaranteed.

Key to Options - A rough key or guide to selection of inventory designs based on available information is as follows:

1. Stand mapping available?
a. Yes. Go to 4.
b. No. Go to 2 .

2. Aerial photography available?

a. Yes. Use stratified double sampling.

b. No. Go to 3.

3. Satellite imagery available?

a. Yes. Use stratified satellite technique.

b. No. Use systematic sample.

4. Stand characteristics available?

a. Yes. Use stratified equal-probability sampling or probability-proportional-to-size sampling.

b. No. Use equal probability sampling or probabilityproportional-to-size design.

In all cases, existing data should be incorporated appropriately. In evaluating existing information, consider the age of the data and the definitions and standards, sample design, and control used in gathering the information (Lund and Schreucier 1980). Old information may be updated by accounting techniques (i.e., subtracting timber harvested) or by modeling techniques to "grow" the stands forward in time. 
There are many ways of obtaining stand and forest information to produce spatially distributed resource information. They range from measuring every tree in every stand to the use of very light samples and multistage or multiphase sampling, including satellite imagery at the highest level. Each method, indeed even repetitions of the same method, will produce slightly different results. This report has presented some of the most common designs in use by the USDA Forest Service and other agencies along with the statistics that allow us to judge the accuracy of these designs.

The objective of the inventory and the funds available will determine which technique to use. Complete enumeration is often impractical unless the benefits of increased precision outweigh the costs, as might be the case for an extremely valuable resource. Even then, the measurement error of a complete enumeration may be larger than the error obtained from sampling.

No matter which sampling technique is used, it is always assumed that the sampling unit represents the actual condition. This is a serious consideration that is often evaded in the preparation of an inventory. It is extremely important that the sample represent the population of interest. For example, a low-quality product of the forest, such as hardwood removals in a primarily softwood market area, might be poorly represented in a sample designed to monitor the flow of harvested softwoods.

Statistical sampling and subjective sampling should not be mixed. If, for example, one selects stands to be measured using probability proportional to the size of the mapped unit and then measures the stand using subjective sampling, inferences about the result, estimates of reliability, and other desirable characteristics of sampling will be compromised. If stands within a compartment are subjectively selected for sampling and plots are randomly established within the stand, one should not attempt to compute the variance and sample errors for the compartment using the formulas presented here. Errors may be calculated for the stand, however. There are valid techniques for arriving at an estimate of the variance, but they should be prepared by a statistician.
For stand inventories, the systematic distribution generally gives the best results, as long as there are no systematic regularities in the forest that correspond to the sample installations. For forest inventories, at least based on the examples given in this report, prior stand mapping is desirable and stratification reduces the sampling error. Stand estimates can be generated by prediction equations where correlations are relatively high (say greater than 0.6 to 0.7$)$. Where correlations are low, stratification is also useful for providing rough stand estimates based upon stratum means.

Where stand mapping is not available, the use of cells, isolines, partial mapping, or digital satellite reconnaissance may yield useful spatial information.

The examples presented in this chapter represent simple, straightforward application of basic statistical sampling formulae to increasingly complex inventory situations. Estimates of area, wildlife use, and wood volume may all be computed using these basic statistical formulae. While we are recommending the application of these design and computational formulae for many situations, we are also obliged to advise readers that there have been important advances in the area of survey (inventory) sampling. When a single attribute is the major interest, there are sampling strategies that can provide important gains in efficiency and cost that are beyond the scope of this primer (e.g., Schreuder and Wood 1986; Green 1987; Gregoire et al. 1987).

Even though the examples used in this report dealt generally with a timber inventory situation, the options and techniques can be used for most resource inventories, such as surveys of wildlife habitat and range allotments.

Readers are encouraged to consult the publications listed in the sections on References Cited and Additional Selected References. These provide the details not contained in this report. 
Ananitis, Loukas G.; Reich, Robin M. 1988. Sampling simulation with a microcomputer. Gainsville, FL: University of Florida, Department of Forestry. 30 p. Unpublished manuscript.

Avery, Thomas Eugene. 1975. Natural resources measurements. $2 \mathrm{~d}$ ed. New York: McCraw-Hill Book Co. 399 p.

Avery, Thomas Eugene; Burkhart, Harold E. 1983. Forest measurements. 3d ed. New York: McGraw-Hill. 331 p.

Baker, John N. 1982. Soil vegetation inventory method-what do we have, and where is it? In: Brann, Thomas B; House, Louis O; Lund, H. Gyde, tech. coords. In-place resource inventories: principles and practices: Proceedings of a national workshop; 1981 August 9-14; Orono, ME. SAF 82-02. Bethesda, MD: Society of American Foresters: 330-332.

Barnard, Joseph E. 1984. Forest inventory and analysis in the Northeast. In: Lund, H. Gyde, ed. Preparing for the 21st century: Proceedings of the forest land inventory workshop; 1984 March 26-30; Denver, CO. Washington, DC: U.S. Department of Agriculture, Forest Service, Timber Management Staff: 79-85.

Belcher, David M. 1984. Current inventory situation of the National Forest System, Southern Region. In: Lund, H. Gyde, ed. Preparing for the 21 st century: Proceedings of the forest land inventory workshop; 1984 March 26-30; Denver, CO. Washington, DC: U.S. Department of Agriculture, Forest Service, Timber Management Staff: 190-193.

Beltz, Roy C. 1984. Southern forest survey. In: Lund, H. Gyde, ed. Preparing for the 21 st century: Proceedings of the forest land inventory workshop; 1984 March 26-30; Denver, CO. Washington, DC: U.S. Department of Agriculture, Forest Service, Timber Management Staff: 60-64.

Bitterlich, W. 1959. TThe technique of the relascope. Efficient forest mensuration work with the mirror relascope.] Centralblatt ges. Forstw. 76(2): 1-35.

Born, J. David. 1984. Forest survey status at the Intermountain Station: Part II-techniques. In: Lund, H. Gyde, ed. Preparing for the $21 \mathrm{st}$ century: Proceedings of the forest land inventory workshop; 1984 March 26-30; Denver, CO. Washington, DC: U.S. Department of Agriculture, Forest Service, Timber Management Staff: 100-108.

Bowlin, Harry L. 1984. Timber inventories in Region 5. In: Lund, $\mathrm{H}$. Gyde, ed. Preparing for the 21 st century: Proceedings of the forest land inventory workshop; 1984 March 26-30, Denver, CO. Washington, DC: U.S. Department of Agriculture, Forest Service, Timber Management Staff: 169-188.

Brann, Thomas B.; House, Louis O.; Lund, H. Gyde, tech. coords. 1982. In-place resource inventories: principles and practices: Proceedings of a national workshop; 1981 August 9-14, Orono, ME. SAF 82-02. Bethesda, MD: Society of American Foresters: 1101 p.

Brickell, Jim. 1984. National forest inventories in the Northern Region. In: Lund, H. Gyde, ed. Preparing for the 21 st century: Proceedings of the forest land inventory workshop; 1984 March 26-30; Denver, CO. Washington, DC: U.S. Department of Agriculture, Forest Service, Timber Management Staff: 142-147.

Brown, James K. 1974. Handbook for inventorying downed woody material. Gen. Tech. Rep. INT-16. Ogden, UT: U.S. Department of Agriculture, Forest Service, Intermountain Forest and Range Experiment Station. 24 p.

Canadian Forest Inventory Committee. 1978. A guide to Canadian forest inventory terminology and usage. $2 d$ ed. Ottawa, Ontario: Environment Canada, Forestry Service. 57 p.

Cochran, William G. 1977. Sampling techniques. 3d ed. New York: John Wiley and Sons. 428 p.

Conant, Francis; Rogers, Peter; Baumgardner, Marion; McKell, Cyrus. 1983. Resource inventory and baseline study methods for developing countries. Washington, DC: American Association for the Advancement of Science: AAAS 83-3.539 p.

Cost, Noel D. 1984. Current inventory situation of the FIA unit in the Southeast. In: Lund, H. Gyde, ed. Preparing for the 21 st century: Proceedings of the forest land inventory workshop; 1984 March 26-30; Denver, CO. Washington, DC: U.S. Department of Agriculture, Forest Service, Timber Management Staff: 65-75.

Costello, Thomas R.; Lund, H. Gyde. 1978. BLM's standard, nonstandard, stand inventory system. Paper presented at 69th Western Forestry Conference; 1978 December 6; Sacramento, CA. 13 p.

Cunia, Tiberius. 1982. The needs and basis of sampling. In: Brann, Thomas B.; House, Louis O.; Lund, H. Gyde, tech. coords. In-place resource inventories principles and practices: Proceedings of a national workshop; 1981 August 9-14; Orono, ME. SAF 82-02. Bethesda, MD: Society of American Foresters: 315-325.

Daubenmire, R. F. 1968. Forest vegetation of eastern Washington and northern Idaho. Pullman, WA: Washington State University; Agriculture Experiment Station; Tech. Bull. 60. 104 p.

De Vries, Pieter G. 1986. Sampling theory for forest inventory. A teach-yourself course. Berlin: Springer-Verlag. 399 p.

Ek, Alan R; Scott, Charles T.; Zeisler, Thomas A.; Benesallah, Driss. 1984. Cluster sampling: from theory to practice. In: LaBau, Vemon J.; Kerr, Calvin L. Inventory forest and other vegetation of the high altitude and high latitude regions; 1984 July 23-26; Fairbanks, AK. SAF 84-11. Bethesda, MD: Society of American Foresters: 78-81.

Ek, Alan R.; Rose, Dietmer W.; Gregersen, Hans M. 1984. Inventory design and the ten-plots-per-stand syndrome. Northern Journal of Applied Forestry. 1(4): 76-79.

Ford-Robertson, F. C., ed. 1971. Terminology of forest science, technology practice and products. English-language version. The Multilingual Forestry Terminology Series No. 1. Washington, DC: Society of American Foresters. 349 p.

Francis, Richard E. 1978. Current rangeland inventory methodscompatibility toward an ecological base? In: Lund, H. Gyde; LaBau, Vernon נ.; Ffolliott, Peter F.; Robinson, David W., eds. Integrated inventories of renewable natural resources: Proceedings of the workshop; 1978 January 8-12; Tucson, AZ. Gen. Tech. Rep. RM-55. Fort Collins, CO: U.S. Department of Agriculture, Forest Service: 91-103.

Freese, Frank. 1965. Elementary forest sampling. Agric. Handb. 232. Washington, DC: U.S. Department of Agriculture. 91 p.

Green, E. J. ; Strawderman, William E. 1988. Combining inventory data with model predictions. In: Ek, A. R.; Shifley, S. R.; Burk, T. E., eds. Forest growth modelling and prediction: Proceedings of the IUFRO Conference; 1987 August 23-27; Minneapolis, MN. Gen. Tech. Rep. NC-120. St. Paul, MN: U.S. Department of Agriculture, Forest Service, North Central Forest Experiment Station: 676-682.

Green, Edwin J. 1987. Empirical Bayes procedures for updating forest inventories. In: Forests, the World, \& the Profession: Proceedings of the Sociery of American Foresters National Convention; 1986 October 5-8; Birmingham, AL. SAF 87-02. Bethesda, MD: Society of American Foresters: 67-69.

Gregoire, Timothy G.; Valentine, Harry T.; Furnival, George M., 1987. Importance sampling in forest inventon: In: Forests, the World, \& the Profession: Proceedings of the Society of American Foresters National Convention; 1986 October 5-8; Birmingham, AL. SAF 87-02. Bethesda, MD: Society of American Foresters: 70-73.

Grosenbaugh, L. R. 1955. Better diagnosis and prescription in southem torest management. Occas. Pap. 145. New Orleans, LA: U.S. Department of Agriculture, Forest Service, Southern Forest Experiment Station. $27 \mathrm{p}$.

Hahn, Jerold T. 1984. Forest inventory in the North Central Region-data 
bases, sampling procedures and data processing. In: Lund, H. Gyde, ed. Preparing for the $21 \mathrm{st}$ century: Proceedings of the forest land inventory workshop; 1984 March 26-30; Denver, CO. Washington, DC: U.S. Department of Agriculture, Forest Service, Timber Management Staff: 86-93.

Hame, Toumas; Tomppo, Erkki. 1987. Stand-based forest inventory from satellite images. In: Jaakkola, Sipi; Poso, Simo; Roiko-Jokela, Pentti, eds. Remote sensir.g-aided forest inventory; 1986 December 10-12; Hyytiala, Finland. Res. Notes No. 19. Helsinki, Finland: University of Helsinki: 45-46.

Hamilton, David A. 1979. Setting precision for resource inventories: the manager and the mensurationist. Journal of Forestry. 77(10): 667-670.

Hansen, Mark H. 1984. Timber Resources of Wisconsin's northeast survey unit, 1983. Res. Bull. NC-78. St. Paul, MN: U.S. Department of Agriculture, Forest Service, North Central Forest Experiment Station. $88 \mathrm{p}$.

Hansen, Mark H.; Hahn, Jerold T. 1983. Estimation of sampling error associated with timber change projection. In: Bell, John F.; Atterbury, Toby, eds. Renewable resource inventories for monitoring changes and trends: Proceedings; 1983 August 15-19; Corvallis, OR. SAF 83-14. Corvallis, OR: Oregon State University: 546-549.

Hanson, Russell E. 1979. Preparation of maps for manual digitizing. Res. Inv. Notes. BLM 22. Denver, CO: U.S. Department of Interior, Bureau of Land Management, Denver Service Center. 1-8.

Heine, George W. 1986. A study of two-dimensional interpretation methods. In: Proceedings of Geographic Information Systems Workshop; 1986 April 1-4; Atlanta, GA. Falls Church, VA: American Society for Photogrammetry and Remote Sensing: 420.

Hoffer, Roger M. 1982. Determining the kind of remote sensing data to use. In: Brann, Thomas B.; House, Louis O.; Lund, H. Gyde, tech. coords. In-place resource inventories: principles and practices: Proceedings of a national workshop; 1981 August 9-14; Orono, ME. SAF 82-02. Bethesda, MD: Society of American Foresters: 242-249.

Johnson, Alfred M. 1984. Current inventory situation Region 9. In: Lund, H. Gyde, ed. Preparing for the 21st century: Proceedings of the forest land inventory workshop; 1984 March 26-30; Denver, CO. Washington, DC: U.S. Department of Agriculture, Forest Service, Timber Management Staff: 194-205.

Kendall, Maurice G.; Buckland, William R. 1971. A dictionary of statistical terms. 3d ed. New York: Hafner Publishing Co. 166 p.

LaBau, Vernon J. 1981. An application of two-phased sampling methods for determining sample intensities in multiresource vegetation assessments. In: Lund, H. Gyde; Caballero, Miguel; Hamre, R. H.; Driscoll, Richard S.; Bonner, William, tech. coords. Arid land resource inventories: developing cost-efficient methods: Proceedings; 1980 November 30-December 6; La Paz, Mexico. Gen. Tech. Rep. WO-28. Washington, DC: U.S. Department of Agriculture, Forest Service: 369-376.

Lachowski, Henry M. 1984. Aerial photography utility guide. In: Lund, H. Gyde, ed. Preparing for the 21st century: Proceedings of the forest land inventory workshop; 1984 March 26-30; Denver, CO. Washington, DC: U.S. Department of Agriculture, Forest Service, Timber Management Staff: 284-285.

Langley, Philip G. 1975. Multistage variable probability sampling: theory and use in estimating timber resources from space and aircraft photography. Ph.D. dissertation. Berkeley, CA: University of California: 1975. $101 \mathrm{p}$.

Langley, Philip G. 1983. Integrating a geographic information system into the inventory process. In: Bell, John F.; Atterbury, Toby, eds. Renewable resource inventories for monitoring changes and trends: Proceedings: 1983 August 15-19; Corvallis, OR. SAF 83-14. Corvallis, OR: Oregon State University: $279-282$.
Larson, Frederic R. 1984. The Alaska integrated inventory system. In: Lund, H. Gyde, ed. Preparing for the 21 st century: Proceedings of the forest land inventory workshop; 1984 March 26-30; Denver, CO. Washington, DC: U.S. Department of Agriculture, Forest Service, Timber Management Staff: 126-141.

Laux, Jim; Darden, Tom; Larson, Milo [and others]. 1984. Workshop issues, conclusions, and recommendations. In: Lund, H. Gyde, ed. Preparing for the 21 st century: Proceedings of the forest land inventory workshop; 1984 March 26-30; Denver, CO. Washington, DC: U.S. Department of Agriculture, Forest Service, Timber Management Staff: 8-11.

Loetsch, F.; Haller, K. E. 1964. Forest inventory volume I. Statistics of forest inventory and information from aerial photographs. Munchen, West Germany: Bayerischer Landwirtschaftsverlag Gmbh. 436 p.

Lund, H. Gyde. 1974. So we know what we have-but where is it? In: Cunia, T. ed: Proceedings monitoring forest environment through successive sampling; 1974 June 24-26; Syracuse, NY. Syracuse, NY: State University of New York: 133-141.

Lund, H. Gyde. 1978a. In-place multiple resource inventories at budget prices. Res. Inv. Notes. BLM 13. Denver, CO: U.S. Department of Interior, Bureau of Land Management, Denver Service Center: 1-7.

Lund, H. Gyde. 1978b. Type maps, stratified sampling and P.P.S. Res. Inv. Notes. BLM 15. Denver, CO: U.S. Department of Interior, Bureau of Land Management, Denver Service Center: 1-14.

Lund, H. Gyde. 1979. Uniformly distributing samples within a type island. Res. Inv. Notes. BLM 22. Denver, CO: U.S. Department of Interior, Bureau of Land Management, Denver Service Center: 13-20.

Lund, H. Gyde, ed. 1984. Preparing for the 21 st century: Proceedings of the forest land inventory workshop; 1984 March 26-30; Denver, CO. Washington, DC: U.S. Department of Agriculture, Forest Service, Timber Management Staff: 334 p.

Lund, H. Gyde. 1985. Designing inventories to support multiple decisions. In: Forest resource inventories: appraisal tools for decision making. Proceedings; 1985 April 26-28; Venice, Italy. (in press) 11 p.

Lund, H. Gyde. 1986a. A primer on integrating resource inventories. Gen. Tech. Rep. WO-49. Washington, DC: U.S. Department of Agriculture, Forest Service. $64 \mathrm{p}$.

Lund, $\mathrm{H}$. Gyde. 1986b. Existing information and the sorcerer's apprentice. In: Oderwald, Richard G.; Burkhart, Harold E.; Burk, Thomas E., eds. Use of auxiliary information in natural resource inventories: Proceedings; 1985 October 1-2; Blacksburg, VA. SAF 86-01. Blacksburg, VA: Virginia Polytechnic Institute and State University, School of Forestry and Wildlife Resources: 1-8.

Lund, H. Gyde. NFS Timber inventory costs. 1987. 2410-1 Letter dated August 27, 1987. On file at Washington, DC: U.S. Department of Agriculture, Forest Service. 15 p.

Lund, H. Gyde; Kniesel, Matt, Jr. 1975. Multiple resource inventory system. In: Meadows, John; Bare, Bruce; Ware, Kenneth; Row, Clark, eds. Systems analysis and resource management; 1975 August 11-13; Athens, GA. Athens, GA: University of Georgia: 433-441.

Lund, H. Gyde; Schreuder, Hans T. 1980. Aggregating inventories. Res. Eval. Newsletter 4. Fort Collins, CO: U.S. Department of Agriculture, Forest Service, Rocky Mountain Forest and Range Experiment Station: $1-3$.

MacLean, Colin D. 1972. Photo stratification improves northwest timber volume estimates. Res. Paper PNW-150. Portland, OR: U.S. Department of Agriculture, Forest Service, Pacific Northwest Forest and Range Experiment Station. $10 \mathrm{p}$.

Matern, Bertil. 1960. Spatial variation. Meddelanden Fran, Statens Skogsforskningsinstitut, Band 49, Nr 5; 144 p.

Mattila, Eero. 1984. Survey of forest resource of Finnish Lapland using multiphase systematic sampling. In: LaBau, Vernon J.; Kerr, Calvin, eds. 
Proceedings of inventorying forest and other vegetation of the high latitude and high altitude regions; 1984 July 23-26; Fairbanks, AK. SAF 84-11. Bethesda, MD: Society of American Foresters: 55-60.

Mehl, Mel. 1984. Resource information management in Region 2. In: Lund, H. Gyde, ed. Preparing for the 21 st century: Proceedings of the forest land inventory workshop; 1984 March 26-30; Denver, CO. Washington, DC: U.S. Department of Agriculture, Forest Service, Timber Management Staff: 148-157.

Mendenhall, William; Ott, Lyman; Scheaffer, Richard L. 1971. Elementary survey sampling. Belmont, CA: Wadsworth Publishing Company, Inc. $247 \mathrm{p}$.

Morris, Meredith J. 1982. Plot configurations for multiresource purposes in the west. In: Brann, Thomas B.; House, Louis O.; Lund, H. Gyde, tech. coords. In-place resource inventories: principles and practices: Proceedings of a national workshop; 1981 August 9-14; Orono, ME. SAF 82-02. Bethesda, MD: Society of American Foresters: 375-378.

Mueller-Dombois, Dieter; Ellenberg, Heinz. 1974. Aims and methods of vegetation ecology. New York: John Wiley \& Sons. $547 p$.

Myers, Doug. 1984. Current timber inventory situation in R-4. In: Lund, $H$. Gyde, ed. Preparing for the 21st century: Proceedings of the forest land inventory workshop; 1984 March 26-30; Denver, CO. Washington, DC: U.S. Department of Agriculture, Forest Service, Timber Management Staff: 162-168.

Myers, Wayne L.; Shelton, Ronald L. 1980. Survey methods for ecosystem management. New York: John Wiley \& Sons. 403 p.

Nelson, DeVon. 1984. Resource data base. In: Lund, H. Gyde, ed. Preparing for the 21st century: Proceedings of the forest land inventory workshop; 1984 March 26-30; Denver, CO. Washington, DC: U.S. Department of Agriculture, Forest Service, Timber Management Staff: 296-300.

Nichols, J. D. Multi-stage and multi-phase sampling. 1979. Res. Inv. Notes BLM 18. Denver, CO: U.S. Department of Interior, Bureau of Land Management, Denver Service Center: 1-5.

Norton, B. E.; Tuhy, Joel; Jensen, Sherman; Young, Richard. 1982. An approach to classification of riparian vegetation. In: Brann, Thomas B.; House, Louis O.; Lund, H. Gyde, tech. coords. In-place resource inventories: principles and practices: Proceedings of a national workshop; 1981 August 9-14; Orono, ME. SAF 82-02. Bethesda, MD: Society of American Foresters: 191-198.

Oderwald, R. G.; Wellman, J. D.; Buhyoff, G.J. 1979. Unequal probability sampling with replacement and without replacement. Res. Inv. Notes. BLM 22. Denver, CO: U.S. Department of Interior, Bureau of Land Management, Denver Service Center: 9-12.

Ohmann, Janet L. 1984. Meeting wildlife habitat information needs in the Pacific Coast States-a forest inventory and analysis approach. In: Lund, H. Gyde, ed. Preparing for the 21 st century: Proceedings of the forest land inventory workshop; 1984 March 26-30; Denver, CO. Washington, DC: U.S. Department of Agriculture, Forest Service, Timber Management Staff: 116-125.

Poso, Simo. 1986. Towards the integrated use of satellite data for forest inventories: a methodological perspective. In: Schmid-Haas, Paul, ed. Inventorying and monitoring endangered forests: Proceeding of IUFRO Conference; 1985 August 19-24; Zurich, Switzerland. Birmensdorf, Switzerland: Eidgenossiche Anstalt fur das forstliche Versuchswesen: 317-319.

Schreuder, H. T.; Wood, G. B., 1986. The choice between designdependent and model-dependent sampling. Can. J. For. Res. 16:260265.

Scott, Charles T. 1982. Plot configurations in the east for multiresources. In: Brann, Thomas B.; House, Louis O.; Lund, H. Gyde, tech. coords. In-place resource inventories: principles and practices: Proceedings of a national workshop; 1981 August 9-14; Orono, ME. SAF 82-02. Bethesda, MD: Society of American Foresters: 379-382

Scott, Charles T. 1984. A case for point samples. In: Lund, H. Gyde, ed. Preparing for the 21 st century: Proceedings of the forest land inventory workshop; 1984 March 26-30; Denver, CO. Washington, DC: U.S. Department of Agriculture, Forest Service, Timber Management Staff: 252-256.

Shiflet, Thomas N.; Snyder, Dale E. 1982. What is mapping? In: Brann, Thomas B.; House, Louis O.; Lund, H. Gyde, tech. coords. In-place resource inventories: principles and practices: Proceedings of a national workshop; 1981 August 9-14; Orono, ME. SAF 82-02. Bethesda, MD: Society of American Foresters: 17-18

Snedecor, George W.; Cochran, William G. 1974. Statistical methods. 6th ed. Ames, IA: lowa State University Press. 593 p.

Stage, Albert R. 1971. Sampling with probability proportional to size from a sorted list. Res. Pap. INT-88. Ogden, UT: U.S. Department of Agriculture, Forest Service, Intermountain Forest and Range Experiment Station. 16 p.

Stage, Albert R. 1984. The case for mapped stands. In: Lund, H. Gyde, ed. Preparing for the $21 \mathrm{st}$ century: Proceedings of the forest land inventory workshop; 1984 March 26-30; Denver, CO. Washington, DC: U.S. Department of Agriculture, Forest Service, Timber Management Staff: 244-251.

Stage, Albert R.; Alley, Jack R. 1972. An inventory design using stand examinations for planning and programming timber management. Res. Pap. INT-126. Ogden, UT: U.S. Department of Agriculture, Forest Service, Intermountain Forest and Range Experiment Station. $17 \mathrm{p}$.

Steers, C. A.; Hajek, B. F. 1979. Determination of map unit composition by a random selection of transects. Soil Science Society of America Journal 43: 156-160

Stott, Calvin B. 1968. A short history of continuous forest inventory East of the Mississippi. J. For. 66(11): 834-837.

Thomas, C. E. 1986. Stein rule estimation of county level inventory statistics. In : Oderwald, R. G., Burkhart, H. E., Burk, T. E., eds. Use of auxiliary information in natural resource inventories; 1985 October 1-2; Blacksburg, VA. SAF 86-01. Blacksburg, VA: Virginia Polytechnic and State University: 45-54.

Tomppo, Erkki. 1987. Stand delineation and estimation of stand variates by means of satellite images. In: Jaakkola, Sipi; Poso, Simo; RoikoJokela, Pentti, eds. Remote sensing-aided forest inventory; 1986 December 10-12; Hyytiala, Finland. Res. Notes. No. 19. Helsinki, Finland: University of Helsinki: $60-76$

United States Department of Agriculture, Forest Service. 1962. Developing the data framework for effective timber management. Misc. Pub. 25. Ogden, UT: U.S. Department of Agriculture, Forest Service, Intermountain Forest and Range Experiment Station. 13 p.

Valentine, Keith. Mapping-the Cinderella task of inventory. 1984. In: LaBau, Vernon J.; Kerr, Calvin L., eds. Proceedings inventorying forest and other vegetation of the high latitude and high altitude regions; 1984 July 23-26; Fairbanks, AK. SAF 84-11. Bethesda, MD: Society of American Foresters: 28-34.

Wenger, Karl F., ed. 1984. Forestry handbook. 2d ed. New York: John Wiley \& Sons. 1335 p.

Wiant, Harry V., Jr. 1976. Elementary 3P sampling. Bull. 650T. Morgantown, WV: West Virginia University Agricultural and Forestry Experiment Station. $31 \mathrm{p}$.

Wiant, Harry V., Jr.; Knight, Robert. 1982. Use of isolines for mapping biomass. In: Brann, Thomas B.; House, Louis O.; Lund, H. Gyde, tech. coords. In-place resource inventories: principles and practices: Proceedings of a national workshop; 1981 August 9-14; Orono, ME. SAF 82-02. Bethesda, MD: Society of American Foresters: 230-231. 


\section{Mapping, Classification, Remote Sensing}

Aldrich, Robert C. 1979. Remote sensing of wildland resources: a state-of-the-art review. Gen. Tech. Rep. RM-71. Fort Collins, CO: U.S. Department of Agriculture, Forest Service, Rocky Mountain Forest and Range Experiment Station. 56 p.

Avery, Thomas Eugene. 1978. Forester's guide to aerial photo interpretation. Agric. Handb. 308. Washington, DC: U.S. Department of Agriculture. $41 \mathrm{p}$.

Bonnor, G. M. 1968. A comparison of photo and ground measurements of canopy density. Forestry Chronicle 44(3): 12-16.

Driscoll, Richard S.; Merkel, Daniel L.; Radloff, David L.; Snyder, Dale E. 1984. An ecological land classification framework for the United States. Misc. Publi. 1439. Washington, DC: U.S. Department of Agriculture. $56 \mathrm{p}$.

Greer, Jerry D., ed. 1988. Remote sensing for resource inventory, planning and monitoring: Proceedings of the Second Forest Service Remote Sensing Applications Conference; 1988 April 11-15; Slidell, LA and NSTL, MS. Falls Church, VA: American Society of Photogrammetry and Remote Sensing. 445 p.

Klock, G. O.; Jordan, L. E., III; Gum P. 1986. A forest vegetation inventory with Landsat imagery for use with fire management strategies. In: Proceedings of geographic information systems workshop; 1986 April 1-4; Atlanta, GA. Falls Church, VA: American Society for Photogrammetry and Remote Sensing: 293.

Jaakola, Sipi; Poso, Simo; Roiko-Jokela, Pentti. eds. 1987. Remote sensing-aided forest inventory. Seminars organized by SNS (Samarbetsnamden fur Nordisk Skogforskning) and Taksaattoriklubi (Forest Mensurationist Club). 1986 December 10-12; Hyytiala, Finland. Res. Notes. No. 19. Helsinki, Finland: University of Helsinki. 215 p.

Myhre, Richard J. 1982. The role of aerial photography in multiresource inventories-techniques and tests in applications research. In: Technical papers: 1982 ACSM-ASP Convention, American Society of Photogrammetry; 1982 March 14-20; Denver, CO. Falls Church, VA: American Society of Photogrammetry: 585-594.

Paine, David P. 1981. Aerial photography and image interpretation for resource management. New York: John Wiley and Sons. 571 p.

Poso, Simo., ed. 1988. Satellite imageries for forest inventory and monitoring: experiences, methods, perspectives. Proceedings of the IUFRO Subject Group S 4.02.05 Meeting; 1988 August 29-September 2; Helsinki, Finland. Res. Notes. No. 21. Helsinki, Finland: University of Helsinki. 214 p.

Valentine, K. W. G. 1981. How soil map units and delineations change with survey intensity and map scale. Canadian Journal of Soil Science 61(4): 535-551.

Wertz, W. A.; Arnold, J. F. 1972. Land systems inventory. Ogden, UT: U.S. Department of Agriculture, Forest Sevice, Intermountain Region. 12 p.

\section{Statistics and Sampling}

Burk, T. E.; Ek, A. R. 1982. Application of empirical Bayes//ames-Stein procedures to simultaneous estimation problems in forest inventory. Forest Science 28: 753-771.

Byrne, John C.; Stage, Albert R. 1988. A data structure for describing sampling designs to aid in compilation of stand attributes. Gen. Tech. Rep. INT-247. Ogden, UT: U.S. Department of Agriculture, Forest Service, Intermountain Research Station. 20 p.

Draper, N. R.; Smith, H. 1982. Applied regression analysis. 2d ed. New York: John Wiley and Sons. 407 p.

Freese, Frank. 1967. Elementary statistical methods for foresters. Agric. Handb. 317. Washington, DC: U.S. Department of Agriculture. 87 p.
Houseman, Earl E. 1975. Area frame sampling in agriculture. SRS No. 20. Washington, DC: U.S. Department of Agriculture, Statistical Reporting Service. $79 \mathrm{p}$.

Slonim, Morris James. 1960. Sampling. New York: Simon and Schuster. $144 \mathrm{p}$.

Stage, Albert R. 1974. Playing with probabilities: one key to meeting information objectives. In: Frayer, W. E.; Hartman, George B.; Bower, David R., eds. Inventory Design and Analysis: Proceedings of a workshop; 1974 July 23-25; Fort Collins, CO. Fort Collins, CO: Colorado State University: 18-37.

\section{Plot Configuration}

Beers, T. W.; Miller, C. I. 1964. Point sampling: research results, theory, and applications. Lafayette, IN: Purdue University Agricultural Experiment Station; Res. Bull. 786. 56 p.

Dilworth, J. R.; Bell, J. F. 1963. Variable plot cruising. Corvallis, OR: Oregon State University Book Stores, Inc. 107 p.

Meeuwig, Richard O.; Budy, Jerry E. 1981. Point and line-intersect sampling in pinyon-juniper woodlands. Gen. Tech. Rep. INT-104. Ogden, UT: U.S. Department of Agriculture, Forest Service, Intermountain Forest and Range Experiment Station. 38 p.

Pechanec, Joseph Fo; Stewart, George. 1940. Sagebrush-grass range sampling studies: size and structure of sampling unit. American Society of Agronomy Journal 32(9): 669-682.

Stage, A. R. 1958. An aid for comparing variable plot radius with fixed plot radius cruise designs. Journal of Forestry. 56(8): 593.

Wiant, Harry V., fr. 1987. When square plots are more efficient than circular ones. West Virginia Forestry Notes Circular 142: 8.

Wiant, Harry V., Jr.; Yandle, David O. 1980. Optimum plot size for cruising sawtimber in eastern forests. Journal of Forestry 78: 642-643.

Zeide, Boris. 1980. Plot size optimization. Forest Science 26: 251-257.

\section{Forest Inventory}

Frayer, W. E., ed. 1979. Forest resource inventories-volumes 1 and II. Proceedings of a workshop; 1979 July 23-26; Fort Collins, CO. Fort Collins, CO: Colorado State University, Department of Forest and Wood Sciences. 1037 p.

Frayer, W. E.; Hartman, George B.; Bower, David R., eds. 1974. Inventory design and analysis. Proceedings of a workshop; 1974 July 23-25; Fort Collins, CO. Fort Collins, CO: Colorado State University. 368 p.

Husch, B. Planning a forest inventory. 1978. FAO Forestry Ser. 4, Forestry and Forest Product Studies 17. Rome: Food and Agriculture Organization. $121 \mathrm{p}$.

Husch, Bertram; Miller, Charles I.; Beers, Thomas W. 1972. Forest mensuration. $2 d$ ed. New York: Ronald Press. 410 p.

Kuusela, Kulleno; Nyyssonen, Aarne, eds. 1983. Forest inventory for improved management. Proceedings of the IUFRO Subject Group 4.02 meeting; 1983 September 5-9; Helsinki, Finland. Re-earch Notes No. 17. Helsinki, Finland: University of Helsinki, Dept. of Forest Mensuration and Management. 207 p.

Loetsch, F.; Zoehrer, F.; Haller, K.E. Forest inventory volume II. Munchen, West Germany: Bayerischer Landwirtschaftsverlag Gmbh. 1973. 469 p. Spurr, Stephen H. 1952. Forest inventory. New York: Ronald Press. 476 p.

\section{Special Inventories}

Costello, Thomas R.; Pettijohn, Linn. 1978. Intensive forest inventory-a selected bibliography. Tech. Note 319. Denver, CO: U.S. Department of Interior, Bureau of Land Management, Denver Service Center. $61 p$ 
Food and Agriculture Organization of the United Nations. 1981. Manual of "forest inventory with special reference to mixed tropical forests. Forestry Paper 27. Rome: Food and Agriculture Organization of the United Nations. 200 p.

Fox, D.G.; Bernabo, J.C., Hood, B. 1987. Guidelines for measuring the physical, chemical and biological condition of wilderness ecosystems. Gen. Tech. Rep. RM-146. Fort Collins, CO: U.S. Department of Agriculture, Forest Service, Rocky Mountain Forest and Range Experiment Station. 48 p.

LaBau, Vernon J.; Kerr, Calvin L., eds. 1984. Inventorying forest and other vegetation of the high latitude and high altitude regions. Proceedings of an international symposium; 1984 July 23-26; Fairbanks, AK. SAF 84-11. Bethesda, MD: Society of American Foresters. 296 p.

Lund, H. Gyde; Caballero, Miguel; Hamre, R. H.; Driscoll, Richard S.; Bonner, William, tech. coords. 1981. Arid land resource inventories: developing cost-efficient methods: Proceedings; 1980 November 30December 6; La Paz, Mexico. Gen. Tech. Rep. WO-28. Washington, DC: U.S. Department of Agriculture, Forest Service. 620 p.

Lund, H. Gyde; Caballero-Deloya, Miguel; Villarreal-Canton, Raul, eds. 1987. Land and resource evaluation for national planning in the tropics: Proceedings of the intemational conference and workshop; 1987 January 25-31; Chetumal, Mexico. Gen. Tech. Rep. WO-39. Washington, DC: U.S. Department of Agriculture, Forest Service. 524 p.

Lund, H. Gyde; LaBau, Vernon J.; Ffolliott, Peter F.; Robinson, David W., tech. coords. 1978. Integrated inventories of renewable natural resources: Proceedings of the workshop; 1978 January 8-12; Tucson, AZ. Gen. Tech. Rep. RM-55. Fort Collins, CO: U.S. Department of Agriculture, Forest Service, Rocky Mountain Forest and Range Experiment Station. 482 p.

International Union of Forest Research Organization. 1978. National forest inventory. Proceedings; 1978 June 18-26; Bucharest, Romania. Bucharest, Romania: Institutul de Cercetari si Amenajari Silvice. 655 p.
Schlatterer, Ed; Lund, H. Gyde, eds. 1984. Proceedings of the Inventory integration workshop; 1984 October 15-19; Portland, OR: Washington, DC: U.S. Department of Agriculture, Forest Service, Range and Timber Management Staffs. $165 \mathrm{p}$.

Society of American foresters. 1984. Regeneration sumeys. Reprint from New Forests for a Changing World. Proceedings of the 1983 SAF National Convention; 1983 October 16-20; Portland, OR. Bethesda, MD: Society of American Foresters. $48 p$.

\section{Monitoring}

Bell, John F.; Atterbury, Toby, eds. 1983. Renewable resource inventories for monitoring changes and trends; 1983 August 15-19; Corvallis, OR. SAF 83-14. Corvallis, OR: Oregon State University; 1983. 737 p.

Cunia, Tiberius, ed. 1974. IUFRO proceedings, monitoring forest environment through successive sampling; 1974 June 24-26; Syracuse, NY. Syracuse, NY: State College of Environmental Sciences and Forestry, University of New York. 390 p.

Curtis, Robert O. 1983. Procedures for establishing and maintaining permanent plots for silvicultural and yield research. Gen. Tech. Rep. PNW-155. Portland, OR: U.S. Department of Agriculture, Forest Service, Pacific Northwest Forest and Range Experiment Station. 56 p.

Schmid-Haas, Paul., ed. 1986. Inventorying and monitoring endangered forests. Proceedings of IUFRO conference; 1985 August 19-24; Zurich, Switzerland. Birmensdorf, Switzerland: Eidgenossiche Anstalt fur das forstliche Versuchswesen. $404 p$.

Schmid-Haas, Paul., ed. 1988. Inventorying and monitoring forests. Proceedings of the 18th IUFRO World Congress; 1986 September 7-21; Ljubjana, Yugoslavia. Nogent s/ Marne, France: Association Silva Arbres, Forets et Societes. Pages unnumbered.

Synnott, T. J. 1979. A manual of permanent plot procedures for tropical rainforest. Trop. For. Pap. 14. Oxford, England: University of Oxford, Commonwealth Forestry Institute. $67 \mathrm{p}$. 


\section{Statistical Estimators}

$\mathrm{A}=$

The total area of the inventory unit in acres.

$\mathrm{a}=\quad$ The area of a sampling unit or a plot in acres.

$n=\quad$ The number of sampling units or plots established.

$y_{j}=$

()$^{1 / 2}=$

$N=$ units in the entire population where:

$\mathbf{N}=\mathbf{A} / \mathbf{a}$

$\bar{y}=\quad$ The estimated mean value of interest, such as volume per acre (ccf) where:

$\bar{y}=\left(\Sigma y_{i}\right) / n$

$\mathrm{s}_{\mathrm{y}}{ }^{2}=\quad$ The estimated variance of individual values of $y$ where:

$s_{y}{ }^{2}=\left\{\Sigma y_{i}{ }^{2}-\left(\Sigma y_{i}\right)^{2} / n\right\} /(n-1)$

$\mathrm{s}_{\mathrm{y}}=$

The estimated standard deviation of $y$ where:

$s_{y}=\left(s_{y}{ }^{2}\right)^{1 / 2}$

$\mathrm{s}_{\bar{y}}=$

The estimated standard error of the mean for a simple random sample. For sampling without replacement $\left({ }^{*}\right)$ :

$\mathrm{s}_{\overline{\mathrm{y}}}{ }^{*}=\left\{\mathrm{s}_{\mathrm{y}}{ }^{2} / \mathrm{n} *[1-(\mathrm{n} / \mathrm{N})]\right\}^{1 / 2}$

or for where sampling is with replacement:

$s_{\bar{y}}=\left(s_{\mathbf{y}}{ }^{2} / n\right)^{1 / 2}$

The expression $[1-(n / N)]$ is known as the finite population correction or f.p.c. If $(n / N)$ is less than 0.05 , the f.p.c. is commonly ignored and equation (6) is used.

$\mathrm{s}_{\mathrm{e}}=$

The estimated sampling error of the mean value such as mean volume per acre (cct) where:

$s_{e}=s_{\bar{y}} / \bar{y}$

$\% s_{\mathbf{e}}=\quad$ The estimated sampling error of the mean value (such as mean ccf volume per acre) expressed as a percent where:

$\% s_{e}=\left(s_{\bar{y}} / \bar{y}\right) * 100$

$\hat{Y}=$

$\mathrm{n}=$

$\mathrm{s}_{\mathrm{yb}}=$

$A_{i}=$

where $\mathrm{B}=$

The estimated total value (such as total ccf volume) in the population where:

$\hat{\mathrm{Y}}=\overline{\mathrm{y}}{ }^{*} \mathrm{~A}$

The estimated number of sampling units necessary to sample within certain prescribed precision and confidence limits.

$\mathrm{n}=\left[\left(\mathrm{t} * \mathrm{~s}_{\mathrm{y}}\right) /\left(\mathrm{s}_{\mathrm{e}} * \overline{\mathrm{y}}\right)\right]^{2}$

where $\mathrm{t}=$ Student's " $\mathrm{t}$ " which is a value establishing a level of probability. The values of " $\mathrm{t}$ " have been tabulated and are available in most statistical textbooks including those referenced in this report.

A first approximation guess of the standard deviation from a very small or preliminary survey.

$$
s_{y b}=B / 3 \text { or } B / 4
$$

the estimated range from the smallest to the largest value likely to be encountered in sampling.

The field plot expansion factor.

$\mathrm{EF}=\mathrm{A} / \mathrm{n}$

The area in stratum $\mathrm{i}$. In the primer $\mathrm{i}=$ $c, h, b$ for example.

$A_{i}=A *\left(n_{i} / N_{i}\right)$

where $n_{i}=$ number of plots in stratum.

$N_{i}=$ total number of plots in inventory. 
$\left(s_{\bar{y}}{ }^{2}\right)_{i}=$

weighted stratum variance.

$\left(s_{\bar{y}}{ }^{2}\right)_{i}=\left[\left(s_{y}{ }^{2} *\left(N_{i} / N\right)^{2} / n_{i}\right] *\left[1-\left(n_{i}\right]\right.\right.$

$\left.\left.N_{i}\right)\right]$

$\hat{Y}=$

The total value for a resource in the Enchanted Forest.

$\hat{\mathrm{Y}}=\Sigma\left(\hat{\mathrm{Y}}_{\mathrm{i}}\right)$

$\overline{i^{\prime}}=$

The mean value in the Enchanted Forest.

$\bar{Y}=\hat{Y} / \mathbf{A}$

$S_{\bar{Y}}=$

The standard error of the mean for the Forest.

$S_{\bar{\gamma}}=\left[\Sigma\left(S_{\bar{y}}^{2}{ }_{i}\right)\right]^{1 / 2}$

$\% \mathrm{~S}_{\mathrm{E}}=\quad$ The estimated sampling error of the mean value for the Forest expressed as a percent where:

$\% S_{E}=\left(S_{\bar{Y}} / \bar{Y}\right)^{*} 100$

$\bar{y}_{w}=\quad$ The estimated mean volume per acre for the Forest when using equal probability sampling of stands. An alternative description of the estimator, $\bar{y}_{r}$, is the weighted mean of stand per acre values, with the per acre value for each stand weighted by its acreage.

$\bar{y}_{w}=\Sigma w_{i} y_{i} / \Sigma w_{i}$

where $a_{i}=$ area in acres in sampled stand and

$y_{i}=\quad$ value per acre in sampled stand.

$\mathrm{s}_{\mathrm{w}}{ }^{2}=\quad$ The weighted variance.

$S_{w}^{2}=\Sigma w_{i}\left(y_{i}-\bar{y}_{w}\right) / \Sigma w_{i}$

$s_{w}=\quad$ the weighted standard error of the mean value.

$s_{w}=\left(s_{w}{ }^{2} / n\right)^{1 / 2}$

$\% \mathrm{~s}_{\mathrm{ew}}=\quad$ the percent sampling error.

$\% \mathrm{~s}_{\mathrm{ew}}=\left(\mathrm{s}_{\mathrm{w}} / \bar{y}_{\mathrm{w}}\right) * 100$

$\bar{y}_{p}=\quad$ expected value for a proportion.

$\bar{y}_{p}=\Sigma\left(n_{i=1}\right) / n_{s}$

where $n_{s}$ is the sample size and $n_{i-1}$ is the number of occurences.

$s^{2}\left(\bar{y}_{p}\right)=\quad$ the variance of a proportion.

$s^{2}\left(\bar{y}_{p}\right)=\bar{y}_{p}\left(1-\bar{y}_{p}\right)$

$v=\quad$ The predicted volume per acre using photo interpreted heights of the overstory.

$v=-0.3271+0.317 h(h)$

where $h=$ height of the overstory in feet. When the height $(h)=$ zero, $v$ is set to zero.

\section{Cost Estimators}

$\mathrm{C}=$

$W=$

$M=$

$\mathrm{n}=$

$\mathrm{L}=$

where $\mathrm{i}=$
The size of the field crew. Size of crew $=1$ person for subjective samples; 2 persons for statistical samples and complete enumeration.

The hourly wage per person in dollars. Hourly wage $=\$ 9.00$ per person.

The time per crew to measure each sampling unit in hours. Plot measurement time in hours $=0.167$ hour for subjective samples; 0.5 hour for statistical samples; and 1 hour for complete enumeration.

The number of sampling units to be measured.

The travel time between sampling units in hours. Time (in hours) traveling between sampling units (L) varies with distance or interval between plots (I) or (i) and number of sampling units (n). It is assumed that a crew travels at a speed of 10,560 feet per hour through the woods. For statistical sampling:

$L=[(n-1) i] / 10,560$

interval in feet between sample plots or points. 
$D=\quad$ The daily travel time to and from the inventory unit in hours (D). For simplicity it is assumed that for each 8 hours spent within the inventory unit, 1 hour is spent in total travel time to and from the inventory unit.

$$
D=[L+n(M)] / 8
$$

$\mathrm{F}=$

The field cost in dollars.

$$
F=C W\{[L+n(M)]+D\}
$$

$1=$

The interval between plot centers in feet based on equilateral triangles.

$$
I=224.272^{*}(\mathrm{~A} / \mathrm{n})^{1 / 2}
$$

The metric equivalent is

$$
I=107.456 *(\mathrm{~A} / \mathrm{n})^{1 / 2}
$$

where $I$ is expressed in meters and $A$ in hectares.

$\$ \mathrm{Se}_{\mathrm{D}}=\quad$ Field costs in dollars that would be required to achieve a specified percent sampling error.

$$
\$ \mathrm{Se}_{\mathrm{D}}=\$ *\left(\% \mathrm{~s}_{\mathrm{e}} / \% \mathrm{~s}_{\mathrm{eD}}\right)^{2}
$$

where $\$=$ total field cost in dollars for a particular option.

$\% \mathrm{Se}_{\mathrm{D}}=\quad$ the desired sampling error in percent.

$M=\quad$ The time to measure 1 plot (includes subplots).

$$
M=\{[(n-1)(i)] / 10,560\}+n(0.5)
$$

Where $\mathrm{n}$ is the number of subplots and $\mathrm{i}$ is the interval in feet between subplots.

$$
i=70.921 \text { (a) } 1 / 2
$$

where $\mathrm{a}$ is the area of the sample stand in acres.

$M_{\mathrm{s}}=$

$M_{s}$

The

The time to traverse and measure a sample stand when each plot takes 0.5 hour to measure and there are 10 plots to establish.

$$
\begin{gathered}
M_{s}=\left\{(n-1)\left[0.0067(a)^{1 / 2}\right\}+n(0.5)\right. \\
\text { for } 10 \text { plots }
\end{gathered}
$$

The daily travel time (D) is revised as follows:

$$
D=\left[L+\Sigma\left(M_{s}\right)\right] / 8
$$

where $\Sigma(M)=$ the sum of the time to measure all selected stands.

Similarly, total cost of field time $(F)$ is adjusted to:

$$
\mathbf{F}=\mathrm{CW}\left[\left(\mathrm{L}+\Sigma\left(\mathrm{M}_{\mathrm{s}}\right)+\mathrm{D}\right]\right.
$$

$\mathrm{SI}=$

The sampling interval for each stratum.

$$
\begin{aligned}
& \mathbf{S I}=\mathbf{A}_{\mathrm{i}} / \mathbf{n}_{\mathrm{i}} \\
& \text { (truncated to a whole number) }
\end{aligned}
$$

$\mathrm{RG}=\quad$ The range from which a random start is chosen.

$$
\mathbf{R G}=\mathbf{S I}+\mathbf{R E M}
$$

where REM = the remainder in the division performed using equation (l). 


\section{Appendix 2: Stand Characteristics of the Enchanted Forest}

Stand data based on complete enumeration. For vegetation type: 1 - hardwoods; 2 - conifers; and 3 = brush/open. For density: $1=0-30 \%$ canopy cover; $2=$ $31-60 \%$ canopy cover; and $3-61+\%$ canopy cover. For wildlife use: $0=$ no use; 1 - used.

\begin{tabular}{|c|c|c|c|c|c|}
\hline Stand no. & Wildlife use & Vegetation type & Acres & Ccflacre & Density \\
\hline 1 & 0 & 1 & 45 & 15 & 2 \\
\hline 2 & 0 & 1 & 720 & 3 & 1 \\
\hline 3 & 0 & 1 & 45 & 28 & 3 \\
\hline 4 & 1 & 2 & 45 & 17 & 2 \\
\hline 5 & 0 & 2 & 75 & 6 & 1 \\
\hline 6 & 1 & 2 & 135 & 16 & 2 \\
\hline 7 & 0 & 2 & 15 & 20 & 2 \\
\hline 8 & 0 & 2 & 135 & 16 & 2 \\
\hline 9 & 1 & 1 & 165 & 8 & 1 \\
\hline 10 & 1 & 2 & 120 & 30 & 3 \\
\hline 11 & 0 & 1 & 150 & 7 & 1 \\
\hline 12 & 1 & 1 & 60 & 22 & 3 \\
\hline 13 & 0 & 3 & 45 & 0 & 1 \\
\hline 14 & 0 & 2 & 330 & 17 & 2 \\
\hline 15 & 0 & 2 & 45 & 9 & 1 \\
\hline 16 & 1 & 3 & 120 & 3 & 1 \\
\hline 17 & 0 & 2 & 90 & 12 & 2 \\
\hline 18 & 0 & 2 & 60 & 21 & 3 \\
\hline 19 & 0 & 2 & 15 & 12 & 2 \\
\hline 20 & 1 & 3 & 180 & 0 & 1 \\
\hline 21 & 0 & 1 & 60 & 1 & 1 \\
\hline 22 & 0 & 1 & 90 & 13 & 2 \\
\hline 23 & 1 & 1 & 75 & 27 & 3 \\
\hline 24 & 0 & 1 & 45 & 4 & 1 \\
\hline 25 & 1 & 1 & 60 & 10 & 2 \\
\hline 26 & 1 & 3 & 30 & 0 & 1 \\
\hline 27 & 0 & 1 & 60 & 18 & 2 \\
\hline 28 & 0 & 1 & 60 & 9 & 2 \\
\hline 29 & 1 & 2 & 105 & 10 & 2 \\
\hline 30 & 1 & 2 & 675 & 19 & 3 \\
\hline 31 & 1 & 2 & 150 & 10 & 1 \\
\hline 32 & 0 & 2 & 45 & 29 & 3 \\
\hline 33 & 1 & 1 & 90 & 7 & 1 \\
\hline 34 & 0 & 2 & 75 & 6 & 1 \\
\hline 35 & 1 & 1 & 165 & 9 & 1 \\
\hline 36 & 0 & 2 & 360 & 32 & 3 \\
\hline 37 & 0 & 2 & 75 & 15 & 2 \\
\hline 38 & 0 & 2 & 30 & 4 & 1 \\
\hline 39 & 0 & 1 & 30 & 4 & 1 \\
\hline 40 & 1 & 1 & 15 & 21 & 3 \\
\hline 41 & 1 & 2 & 30 & 12 & 2 \\
\hline 42 & 0 & 2 & 60 & 2 & 1 \\
\hline 43 & 0 & 3 & 60 & 0 & 1 \\
\hline 44 & 1 & 1 & 60 & 9 & 1 \\
\hline 45 & 0 & 3 & 60 & 1 & 1 \\
\hline
\end{tabular}

\begin{tabular}{|c|c|c|c|c|c|}
\hline Stand no. & Wildlife use & Vegetation type & Acres & Cct/acre & Density \\
\hline 46 & 1 & 2 & 75 & 28 & 3 \\
\hline 47 & 0 & 2 & 30 & 16 & 2 \\
\hline 48 & 1 & 2 & 60 & 15 & 1 \\
\hline 49 & 1 & 2 & 75 & 16 & 2 \\
\hline 50 & 0 & 2 & 75 & 9 & 1 \\
\hline 51 & 0 & 1 & 45 & 30 & 3 \\
\hline 52 & 0 & 2 & 120 & 20 & 2 \\
\hline 53 & 0 & 2 & 30 & 9 & 1 \\
\hline 54 & 0 & 1 & 75 & 3 & 1 \\
\hline 55 & 1 & 1 & 240 & 13 & 2 \\
\hline 56 & 1 & 2 & 60 & 16 & 2 \\
\hline 57 & 0 & 1 & 75 & 10 & 2 \\
\hline 58 & 1 & 2 & 30 & 23 & 3 \\
\hline 59 & 0 & 1 & 15 & 28 & 3 \\
\hline 60 & 1 & 2 & 15 & 21 & 3 \\
\hline 61 & 1 & 1 & 30 & 12 & 2 \\
\hline 62 & 0 & 3 & 30 & 0 & 1 \\
\hline 63 & 1 & 1 & 15 & 12 & 2 \\
\hline 64 & 1 & 2 & 30 & 27 & 3 \\
\hline 65 & 1 & 1 & 30 & 29 & 3 \\
\hline 66 & 0 & 2 & 30 & 28 & 3 \\
\hline 67 & 1 & 1 & 60 & 6 & 1 \\
\hline 68 & 1 & 2 & 165 & 8 & 1 \\
\hline 69 & 1 & 1 & 90 & 13 & 2 \\
\hline 70 & 1 & 1 & 150 & 7 & 1 \\
\hline 71 & 0 & 3 & 105 & 0 & 1 \\
\hline 72 & 1 & 1 & 165 & 15 & 2 \\
\hline 73 & 1 & 2 & 15 & 23 & 3 \\
\hline 74 & 0 & 1 & 60 & 15 & 2 \\
\hline 75 & 0 & 3 & 135 & 3 & 1 \\
\hline 76 & 1 & 1 & 75 & 27 & 3 \\
\hline 77 & 1 & 1 & 285 & 21 & 2 \\
\hline 78 & 1 & 1 & 120 & 30 & 3 \\
\hline 79 & 1 & 1 & 15 & 13 & 2 \\
\hline 80 & 1 & 3 & 45 & 3 & 1 \\
\hline 81 & 0 & 2 & 90 & 7 & 1 \\
\hline 82 & 1 & 2 & 90 & 13 & 2 \\
\hline 83 & 1 & 1 & 30 & 24 & 3 \\
\hline 84 & 1 & 3 & 75 & 2 & 1 \\
\hline 85 & 0 & 1 & 45 & 11 & 2 \\
\hline 86 & 0 & 2 & 60 & 19 & 2 \\
\hline 87 & 1 & 1 & 60 & 19 & 2 \\
\hline 88 & 0 & 2 & 60 & 5 & 2 \\
\hline 89 & 0 & 2 & 60 & 4 & 1 \\
\hline 90 & 0 & 2 & 60 & 30 & 3 \\
\hline
\end{tabular}


Appendix 2-continued.

\begin{tabular}{|c|c|c|c|c|c|}
\hline Stand no. & Wildlife use & Vegetation type & Acres & Ccf/acre & Density \\
\hline 91 & 0 & 2 & 60 & 8 & 2 \\
\hline 92 & 1 & 2 & 45 & 6 & 1 \\
\hline 93 & 0 & 2 & 75 & 17 & 2 \\
\hline 94 & 0 & 1 & 120 & 20 & 2 \\
\hline 95 & 0 & 1 & 45 & 25 & 3 \\
\hline 96 & 1 & 2 & 45 & 11 & 2 \\
\hline 97 & 1 & 1 & 75 & 19 & 2 \\
\hline 98 & 1 & 1 & 45 & 30 & 2 \\
\hline 99 & 1 & 1 & 15 & 1 & 1 \\
\hline 100 & 1 & 1 & 30 & 8 & 1 \\
\hline 101 & 1 & 2 & 45 & 17 & 3 \\
\hline 102 & 0 & 1 & 60 & 17 & 1 \\
\hline 103 & 1 & 3 & 30 & 1 & 3 \\
\hline 104 & 0 & 2 & 15 & 29 & 2 \\
\hline 105 & 1 & 1 & 165 & 29 & 2 \\
\hline 106 & 0 & 1 & 15 & 22 & 1 \\
\hline 107 & 0 & 1 & 45 & 19 & 2 \\
\hline 108 & 1 & 2 & 30 & 1 & 3 \\
\hline 109 & 0 & 2 & 15 & 10 & 3 \\
\hline 110 & 1 & 1 & 15 & 18 & 2 \\
\hline 111 & 0 & 2 & 15 & 1 & 3 \\
\hline 112 & 0 & 1 & 15 & 16 & 2 \\
\hline 113 & 0 & 1 & 30 & 19 & 1 \\
\hline 114 & 1 & 1 & 15 & 30 & 2 \\
\hline 115 & 1 & 1 & 45 & 23 & 3 \\
\hline 116 & 1 & 1 & 30 & 2 & 1 \\
\hline 117 & 0 & 3 & 30 & 0 & 1 \\
\hline 118 & 1 & 2 & 30 & 3 & 1 \\
\hline 119 & 1 & 1 & 30 & 12 & 1 \\
\hline 120 & 0 & 1 & 60 & 14 & 2 \\
\hline 121 & 0 & 2 & 60 & 18 & 2 \\
\hline 122 & 0 & 1 & 90 & 23 & 3 \\
\hline 123 & 0 & 1 & 45 & 3 & 1 \\
\hline 124 & 0 & 2 & 30 & 18 & 2 \\
\hline 125 & 1 & 2 & 45 & 4 & 1 \\
\hline 126 & 0 & 1 & 30 & 1 & 1 \\
\hline 127 & 0 & 1 & 75 & 23 & 3 \\
\hline 128 & 1 & 2 & 120 & 12 & 2 \\
\hline 129 & 1 & 3 & 45 & 3 & 1 \\
\hline 130 & 1 & 1 & 45 & 18 & 2 \\
\hline 131 & 1 & 1 & 45 & 5 & 1 \\
\hline 132 & 0 & 1 & 45 & 13 & 2 \\
\hline 133 & 0 & 1 & 60 & 11 & 1 \\
\hline 134 & 1 & 1 & 75 & 29 & 3 \\
\hline 135 & 1 & 1 & 30 & 29 & 2 \\
\hline 136 & 0 & 2 & 120 & 16 & 2 \\
\hline 137 & 0 & 1 & 60 & 21 & 3 \\
\hline 138 & 1 & 3 & 30 & 2 & 1 \\
\hline 139 & 1 & 1 & 60 & 2 & 1 \\
\hline 140 & 0 & 3 & 75 & 1 & 1 \\
\hline 141 & 0 & 1 & 45 & 20 & 3 \\
\hline 142 & 0 & 2 & 45 & 5 & 1 \\
\hline 143 & 1 & 1 & 90 & 11 & 1 \\
\hline 144 & 0 & 1 & 45 & 23 & 2 \\
\hline 145 & 0 & 1 & 45 & 5 & 1 \\
\hline
\end{tabular}

\begin{tabular}{|c|c|c|c|c|c|}
\hline Stand no. & Wildlife use & Vegetation type & Acres & Ccflacre & Density \\
\hline 146 & 1 & 1 & 60 & 24 & 3 \\
\hline 147 & 0 & 1 & 45 & 24 & 1 \\
\hline 148 & 1 & 2 & 15 & 13 & 2 \\
\hline 149 & 0 & 2 & 60 & 20 & 3 \\
\hline 150 & 1 & 1 & 60 & 8 & 1 \\
\hline 151 & 0 & 1 & 60 & 23 & 3 \\
\hline 152 & 0 & 1 & 75 & 19 & 2 \\
\hline 153 & 1 & 2 & 45 & 3 & 1 \\
\hline 154 & 1 & 2 & 75 & 23 & 3 \\
\hline 155 & 0 & 1 & 60 & 22 & 3 \\
\hline 156 & 1 & 1 & 45 & 3 & 1 \\
\hline 157 & 0 & 2 & 60 & 19 & 2 \\
\hline 158 & 1 & 1 & 135 & 12 & 2 \\
\hline 159 & 1 & 2 & 60 & 5 & 1 \\
\hline 160 & 0 & 1 & 75 & 17 & 2 \\
\hline 161 & 1 & 2 & 30 & 9 & 1 \\
\hline 162 & 1 & 1 & 30 & 9 & 1 \\
\hline 163 & 1 & 2 & 30 & 27 & 3 \\
\hline 164 & 0 & 1 & 30 & 17 & 2 \\
\hline 165 & 0 & 2 & 60 & 7 & 1 \\
\hline 166 & 0 & 1 & 45 & 1 & 1 \\
\hline 167 & 0 & 1 & 60 & 21 & 2 \\
\hline 168 & 1 & 2 & 75 & 22 & 3 \\
\hline 169 & 1 & 1 & 60 & 30 & 3 \\
\hline 170 & 0 & 2 & 45 & 31 & 3 \\
\hline 171 & 1 & 2 & 60 & 17 & 2 \\
\hline 172 & 1 & 1 & 45 & 21 & 3 \\
\hline 173 & 1 & 2 & 75 & 11 & 2 \\
\hline 174 & 1 & 1 & 45 & 18 & 2 \\
\hline 175 & 1 & 2 & 60 & 26 & 2 \\
\hline 176 & 0 & 2 & 30 & 30 & 3 \\
\hline 177 & 0 & 1 & 45 & 11 & 2 \\
\hline 178 & 1 & 1 & 45 & 8 & 1 \\
\hline 179 & 0 & 2 & 420 & 26 & 3 \\
\hline 180 & 0 & 2 & 45 & 15 & 2 \\
\hline 181 & 0 & 1 & 60 & 30 & 3 \\
\hline 182 & 0 & 2 & 45 & 27 & 3 \\
\hline 183 & 1 & 2 & 90 & 11 & 1 \\
\hline 184 & 1 & 2 & 30 & 13 & 2 \\
\hline 185 & 1 & 1 & 30 & 18 & 2 \\
\hline 186 & 1 & 1 & 30 & 10 & 1 \\
\hline 187 & 1 & 1 & 30 & 14 & 2 \\
\hline 188 & 1 & 1 & 75 & 22 & 3 \\
\hline 189 & 0 & 1 & 45 & 3 & 1 \\
\hline 190 & 0 & 2 & 30 & 13 & 2 \\
\hline 191 & 0 & 2 & 45 & 22 & 3 \\
\hline 192 & 0 & 1 & 135 & 3 & 1 \\
\hline 193 & 0 & 2 & 30 & 22 & 3 \\
\hline 194 & 1 & 1 & 75 & 23 & 3 \\
\hline 195 & 0 & 1 & 60 & 9 & 2 \\
\hline 196 & 0 & 1 & 90 & 1 & 1 \\
\hline 197 & 1 & 2 & 30 & 10 & 1 \\
\hline 198 & 0 & 1 & 45 & 11 & 1 \\
\hline 199 & 0 & 1 & 45 & 16 & 2 \\
\hline 200 & 1 & 1 & 810 & 14 & 1 \\
\hline
\end{tabular}


Stand estimates of volume per acre by various inventory designs. $U=$ unstratified. $S=$ stratified. EPS = equal probability sampling. PPS = probability proportional to size. PI Height $=$ height of overstory vegetation in feet as measured from aerial photography. Predicted CCF/AC =

\begin{tabular}{|c|c|c|c|c|c|c|c|}
\hline $\begin{array}{c}\text { Stand } \\
\text { no. }\end{array}$ & $\begin{array}{l}\text { U-EPS- } \\
\text { CCFIAC }\end{array}$ & $\begin{array}{l}\text { U-PPS- } \\
\text { CCFIAC }\end{array}$ & $\begin{array}{l}\text { S-EPS- } \\
\text { CCF/AC }\end{array}$ & $\begin{array}{l}\text { S-PPS- } \\
\text { CCFIAC }\end{array}$ & $\begin{array}{c}\text { PI } \\
\text { height }\end{array}$ & $\begin{array}{l}\text { Predicted } \\
\text { CCFIAC }\end{array}$ & $\begin{array}{c}\text { CCFI } \\
\text { AC }\end{array}$ \\
\hline 1 & 16.9 & 12.9 & 17.7 & 10.2 & 45 & 14.0 & $15^{*}$ \\
\hline 2 & 16.9 & $3.0^{*}$ & 17.7 & $3.0^{*}$ & 15 & $3.0^{*}$ & $3^{*}$ \\
\hline 3 & 16.9 & 12.9 & 17.7 & 10.2 & 90 & 28.3 & $28^{*}$ \\
\hline 4 & 16.9 & 12.9 & 18.2 & 19.5 & 55 & 17.1 & $17^{\star \prime}$ \\
\hline 5 & 16.9 & 12.9 & 18.2 & 19.5 & 20 & 6.0 & $6^{*}$ \\
\hline 6 & 16.9 & 12.9 & 18.2 & 19.5 & 50 & 15.5 & $16^{*}$ \\
\hline 7 & 16.9 & 12.9 & 18.2 & 19.5 & 65 & 20.3 & $20^{*}$ \\
\hline 8 & 16.9 & 12.9 & 18.2 & 19.5 & 55 & 17.1 & $16^{*}$ \\
\hline 9 & 16.9 & 12.9 & 17.7 & 10.2 & 25 & 7.6 & 8* \\
\hline 10 & $30.0^{*}$ & $30.0^{*}$ & $30.0^{*}$ & $30.0^{*}$ & 95 & $30.0^{*}$ & $30^{*}$ \\
\hline 11 & 16.9 & 12.9 & 17.7 & 10.2 & 25 & 7.6 & $7^{*}$ \\
\hline 12 & 16.9 & 12.9 & 17.7 & 10.2 & 70 & 21.9 & 22 * \\
\hline 13 & 16.9 & 12.9 & 0.0 & 3.0 & 0 & $0.0^{*}$ & $0^{*}$ \\
\hline 14 & 16.9 & 12.9 & 18.2 & 19.5 & 60 & 18.7 & $17^{\star}$ \\
\hline 15 & 16.9 & 12.9 & 18.2 & 19.5 & 30 & 9.2 & 9* \\
\hline 16 & 16.9 & $3.0^{\star}$ & $0.0^{*}$ & $3.0^{*}$ & 10 & $3.0^{*}$ & $3^{*}$ \\
\hline 17 & 16.9 & 12.9 & 18.2 & 19.5 & 40 & 12.4 & $12^{*}$ \\
\hline 18 & $21.0^{*}$ & 12.9 & $21.0^{*}$ & 19.5 & 65 & 20.3 & $21^{*}$ \\
\hline 19 & 16.9 & 12.9 & 18.2 & 19.5 & 45 & 14.0 & $12^{*}$ \\
\hline 20 & 16.9 & 12.9 & 0.0 & 3.0 & 0 & 0.0 & $0^{*}$ \\
\hline 21 & 16.9 & 12.9 & 17.7 & 10.2 & 5 & 1.3 & 1 * \\
\hline 22 & 16.9 & 12.9 & 17.7 & 10.2 & 40 & 12.4 & $13^{*}$ \\
\hline 23 & 16.9 & 12.9 & 17.7 & 10.2 & 85 & 26.7 & $27^{*}$ \\
\hline 24 & 16.9 & 12.9 & 17.7 & 10.2 & 15 & 4.4 & $4^{*}$ \\
\hline 25 & $10.0^{*}$ & 12.9 & $10.0^{*}$ & 10.2 & 45 & 14.0 & $10^{*}$ \\
\hline 26 & $0.0^{*}$ & 12.9 & $0.0^{*}$ & 3.0 & 0 & 0.0 & $0^{*}$ \\
\hline 27 & 16.9 & 12.9 & 17.7 & 10.2 & 55 & 17.1 & $18 *$ \\
\hline 28 & 16.9 & $9.0^{*}$ & 17.7 & $9.0^{*}$ & 35 & $9.0^{*}$ & $9^{*}$ \\
\hline 29 & 16.9 & 12.9 & 18.2 & 19.5 & 30 & 9.2 & $10^{*}$ \\
\hline 30 & 16.9 & $19.0^{*}$ & 18.2 & $19.0^{*}$ & 70 & $19.0^{*}$ & $19 *$ \\
\hline 31 & 16.9 & 12.9 & 18.2 & 19.5 & 35 & 10.8 & $10 *$ \\
\hline 32 & 16.9 & 12.9 & 18.2 & 19.5 & 90 & 28.3 & $29 *$ \\
\hline 33 & 16.9 & $7.0^{*}$ & 17.7 & $7.0^{*}$ & 30 & $7.0^{*}$ & $7^{*}$ \\
\hline 34 & 16.9 & 12.9 & 18.2 & 19.5 & 25 & 7.6 & $6^{*}$ \\
\hline 35 & 16.9 & 12.9 & 17.7 & 10.2 & 35 & 10.8 & 9* \\
\hline 36 & 16.9 & $32.0^{*}$ & 18.2 & $32.0^{\circ}$ & 100 & $32.0^{*}$ & $32^{*}$ \\
\hline 37 & 16.9 & 12.9 & 18.2 & 19.5 & 50 & 15.5 & $15^{*}$ \\
\hline 38 & 16.9 & 12.9 & 18.2 & 19.5 & 20 & 6.0 & $4^{*}$ \\
\hline 39 & 16.9 & 12.9 & 17.7 & 10.2 & 15 & 4.4 & $4^{*}$ \\
\hline 40 & 16.9 & 12.9 & 17.7 & 10.2 & 70 & 21.9 & $21^{\circ}$ \\
\hline 41 & 16.9 & 12.9 & 18.2 & 19.5 & 40 & 12.4 & $12^{*}$ \\
\hline 42 & 16.9 & 12.9 & 18.2 & 19.5 & 5 & 1.3 & $2^{*}$ \\
\hline 43 & 16.9 & 12.9 & 0.0 & 3.0 & 0 & 0.0 & $0^{*}$ \\
\hline 44 & 16.9 & 12.9 & 17.7 & 10.2 & 30 & 9.2 & $9^{*}$ \\
\hline 45 & 16.9 & 12.9 & 0.0 & 3.0 & 10 & 2.8 & $1^{*}$ \\
\hline
\end{tabular}

Calculated volume per acre using regression equation (25) and photo interpreted heights. Last column is ground truth ccf for the stand. ${ }^{*}=$ Measured on the ground. All other values for volume per acre are either Forest or stratum averages or are predicted values.

\begin{tabular}{|c|c|c|c|c|c|c|c|}
\hline $\begin{array}{l}\text { Stand } \\
\text { no. }\end{array}$ & $\begin{array}{l}\text { U-EPS- } \\
\text { CCFIAC }\end{array}$ & $\begin{array}{l}\text { U-PPS- } \\
\text { CCFIAC }\end{array}$ & $\begin{array}{l}\text { S-EPS- } \\
\text { CCFIAC }\end{array}$ & $\begin{array}{l}\text { S-PPS- } \\
\text { CCFIAC }\end{array}$ & $\begin{array}{c}\text { PI } \\
\text { height }\end{array}$ & $\begin{array}{l}\text { Predicted } \\
\text { CCFIAC }\end{array}$ & $\begin{array}{c}\text { CCFI } \\
\mathrm{AC}\end{array}$ \\
\hline 46 & 16.9 & 12.9 & 18.2 & 19.5 & 95 & 29.8 & $28^{\circ}$ \\
\hline 47 & 16.9 & 12.9 & 18.2 & 19.5 & 60 & 18.7 & $16^{*}$ \\
\hline 48 & 16.9 & 12.9 & 18.2 & 19.5 & 55 & 17.1 & $15^{\circ}$ \\
\hline 49 & 16.9 & 12.9 & 18.2 & 19.5 & 50 & 15.5 & $16^{*}$ \\
\hline 50 & 16.9 & 12.9 & 18.2 & 19.5 & 35 & 10.8 & $9^{*}$ \\
\hline 51 & 16.9 & 12.9 & 17.7 & 10.2 & 95 & 29.8 & $30^{\circ}$ \\
\hline 52 & 16.9 & 12.9 & 18.2 & 19.5 & 65 & 20.3 & $20^{*}$ \\
\hline 53 & $9.0^{*}$ & $9.0^{*}$ & $9.0^{\circ}$ & $9.0^{*}$ & 30 & $9.0^{\circ}$ & $9^{\circ}$ \\
\hline 54 & 16.9 & 12.9 & 17.7 & 10.2 & 15 & 4.4 & $3^{*}$ \\
\hline 55 & 16.9 & 12.9 & 17.7 & 10.2 & 50 & 15.5 & $13^{*}$ \\
\hline 56 & 16.9 & 12.9 & 18.2 & 19.5 & 55 & 17.1 & $16^{\star}$ \\
\hline 57 & 16.9 & 12.9 & 17.7 & 10.2 & 40 & 12.4 & $10^{*}$ \\
\hline 58 & 16.9 & 12.9 & 18.2 & 19.5 & 70 & 21.9 & $23^{*}$ \\
\hline 59 & 16.9 & 12.9 & 17.7 & 10.2 & 90 & 28.3 & $28^{\circ}$ \\
\hline 60 & 16.9 & 12.9 & 18.2 & 19.5 & 75 & 23.5 & $21 *$ \\
\hline 61 & $12.0^{*}$ & 12.9 & $12.0^{\star}$ & 10.2 & 45 & 14.0 & $12^{*}$ \\
\hline 62 & $0.0^{*}$ & 12.9 & $0.0^{\star}$ & 3.0 & 0 & 0.0 & $0^{*}$ \\
\hline 63 & 16.9 & 12.9 & 17.7 & 10.2 & 40 & 12.4 & $12^{*}$ \\
\hline 64 & 16.9 & 12.9 & 18.2 & 19.5 & 90 & 28.3 & $27^{*}$ \\
\hline 65 & 16.9 & 12.9 & 17.7 & 10.2 & 95 & 29.8 & $29^{*}$ \\
\hline 66 & 16.9 & 12.9 & 18.2 & 19.5 & 95 & 29.8 & $28^{*}$ \\
\hline 67 & 16.9 & $6.0^{\star}$ & 17.7 & $6.0^{*}$ & 35 & $6.0^{\circ}$ & $6^{*}$ \\
\hline 68 & 16.9 & 12.9 & 18.2 & 19.5 & 25 & 7.6 & $8^{*}$ \\
\hline 69 & 16.9 & 12.9 & 17.7 & 10.2 & 40 & 12.4 & $13^{\circ}$ \\
\hline 70 & 16.9 & $7.0^{*}$ & 17.7 & $7.0^{\star}$ & 30 & $7.0^{*}$ & $7^{*}$ \\
\hline 71 & 16.9 & 12.9 & 0.0 & 3.0 & 0 & 0.0 & $0^{*}$ \\
\hline 72 & 16.9 & 12.9 & 17.7 & 10.2 & 45 & 14.0 & $15^{*}$ \\
\hline 73 & 16.9 & 12.9 & 18.2 & 19.5 & 75 & 23.5 & $23^{*}$ \\
\hline 74 & $15.0^{\star}$ & 12.9 & $15.0^{*}$ & 10.2 & 60 & 18.7 & $15^{*}$ \\
\hline 75 & 16.9 & 12.9 & 0.0 & 3.0 & 10 & 2.8 & 3* \\
\hline 76 & 16.9 & 12.9 & 17.7 & 10.2 & 85 & 26.7 & $27^{*}$ \\
\hline 77 & 16.9 & 12.9 & 17.7 & 10.2 & 65 & 20.3 & 21 * \\
\hline 78 & 16.9 & 12.9 & 17.7 & 10.2 & 100 & 31.4 & $30^{*}$ \\
\hline 79 & 16.9 & 12.9 & 17.7 & 10.2 & 45 & 14.0 & $13^{*}$ \\
\hline 80 & 16.9 & 12.9 & 0.0 & 3.0 & 15 & 4.4 & $3^{*}$ \\
\hline 81 & $7.0^{*}$ & 12.9 & $7.0^{\circ}$ & 19.5 & 25 & 7.6 & $7^{*}$ \\
\hline 82 & 16.9 & 12.9 & 18.2 & 19.5 & 50 & 15.5 & $13^{*}$ \\
\hline 83 & 16.9 & 12.9 & 17.7 & 10.2 & 75 & 23.5 & 24 " \\
\hline 84 & 16.9 & 12.9 & 0.0 & 3.0 & 10 & 2.8 & $2^{*}$ \\
\hline 85 & 16.9 & 12.9 & 17.7 & 10.2 & 40 & 12.4 & $11^{\circ}$ \\
\hline 86 & 16.9 & 12.9 & 18.2 & 19.5 & 60 & 18.7 & $19 *$ \\
\hline 87 & 16.9 & 12.9 & 17.7 & 10.2 & 65 & 20.3 & $19 *$ \\
\hline 88 & 16.9 & 12.9 & 18.2 & 19.5 & 20 & 6.0 & $5^{*}$ \\
\hline 89 & 16.9 & 12.9 & 18.2 & 19.5 & 20 & 6.0 & 4* \\
\hline 90 & 16.9 & 12.9 & 18.2 & 19.5 & 95 & 29.8 & 30 * \\
\hline
\end{tabular}


Stand U-EPS- U-PPS- S-EPS- S-PPS- PI Predicted CCFI no. CCFIAC CCFIAC CCFIAC CCFIAC height CCFIAC AC

\begin{tabular}{|c|c|c|c|c|c|c|c|}
\hline 91 & 16.9 & 8.0* & 18.2 & $8.0^{*}$ & 35 & $8.0^{\circ}$ & $8^{*}$ \\
\hline 92 & $6.0^{*}$ & 12.9 & $6.0^{\circ}$ & 19.5 & 20 & 6.0 & $6^{*}$ \\
\hline 93 & 16.9 & 12.9 & 18.2 & 19.5 & 60 & 18.7 & $17^{*}$ \\
\hline 94 & 16.9 & 12.9 & 17.7 & 10.2 & 70 & 21.9 & $20 *$ \\
\hline 95 & $25.0^{*}$ & 12.9 & $25.0^{*}$ & 10.2 & 80 & 25.1 & $25^{*}$ \\
\hline 96 & 16.9 & 12.9 & 18.2 & 19.5 & 35 & 10.8 & $11^{*}$ \\
\hline 97 & 16.9 & $19.0^{*}$ & 17.7 & $19.0^{*}$ & 60 & $19.0^{*}$ & $19^{*}$ \\
\hline 98 & $30.0^{*}$ & 12.9 & $30.0^{*}$ & 10.2 & 80 & 25.1 & $30^{*}$ \\
\hline 99 & 16.9 & 12.9 & 17.7 & 10.2 & 10 & 2.8 & $1^{*}$ \\
\hline 100 & 16.9 & 12.9 & 17.7 & 10.2 & 25 & 7.6 & $8^{*}$ \\
\hline 101 & 16.9 & 12.9 & 18.2 & 19.5 & 60 & 18.7 & $17^{*}$ \\
\hline 102 & 16.9 & 12.9 & 17.7 & 10.2 & 55 & 17.1 & $17^{*}$ \\
\hline 103 & 16.9 & 12.9 & 0.0 & 3.0 & 10 & 2.8 & 1 \\
\hline 104 & 16.9 & 12.9 & 18.2 & 19.5 & 95 & 29.8 & $29^{*}$ \\
\hline 105 & 16.9 & 12.9 & 17.7 & 10.2 & 95 & 29.8 & $29^{*}$ \\
\hline 106 & 16.9 & 12.9 & 17.7 & 10.2 & 75 & 23.5 & $22 *$ \\
\hline 107 & 16.9 & 12.9 & 17.7 & 10.2 & 65 & 20.3 & $19^{*}$ \\
\hline 108 & 16.9 & 12.9 & 18.2 & 19.5 & 10 & 2.8 & 1 " \\
\hline 109 & 16.9 & 12.9 & 18.2 & 19.5 & 40 & 12.4 & $10^{*}$ \\
\hline 110 & 16.9 & 12.9 & 17.7 & 10.2 & 55 & 17.1 & $18^{*}$ \\
\hline 111 & 16.9 & 12.9 & 18.2 & 19.5 & 10 & 2.8 & $1^{*}$ \\
\hline 112 & 16.9 & 12.9 & 17.7 & 10.2 & 55 & 17.1 & $16^{*}$ \\
\hline 113 & 16.9 & 12.9 & 17.7 & 10.2 & 65 & 20.3 & $19^{*}$ \\
\hline 114 & 16.9 & 12.9 & 17.7 & 10.2 & 100 & 31.4 & $30^{*}$ \\
\hline 115 & 16.9 & 12.9 & 17.7 & 10.2 & 80 & 25.1 & $23^{*}$ \\
\hline 116 & $2.0^{*}$ & 12.9 & $2.0^{*}$ & 10.2 & 15 & 4.4 & $2^{*}$ \\
\hline 117 & 16.9 & 12.9 & 0.0 & 3.0 & 0 & 0.0 & $0^{*}$ \\
\hline 118 & 16.9 & 12.9 & 18.2 & 19.5 & 10 & 2.8 & $3^{*}$ \\
\hline 119 & 16.9 & 12.9 & 17.7 & 10.2 & 45 & 14.0 & $12^{*}$ \\
\hline 120 & 16.9 & 12.9 & 17.7 & 10.2 & 45 & 14.0 & $14^{*}$ \\
\hline 121 & 16.9 & 12.9 & 18.2 & 19.5 & 65 & 20.3 & $18^{*}$ \\
\hline 122 & 16.9 & 12.9 & 17.7 & 10.2 & 70 & 21.9 & $23^{*}$ \\
\hline 123 & 16.9 & 12.9 & 17.7 & 10.2 & 15 & 4.4 & $3^{*}$ \\
\hline 124 & 16.9 & $18.0^{\circ}$ & 18.2 & $18.0^{*}$ & 60 & $18.0^{*}$ & $18^{*}$ \\
\hline 125 & 16.9 & 12.9 & 18.2 & 19.5 & 15 & 4.4 & $4^{*}$ \\
\hline 126 & 16.9 & 12.9 & 17.7 & 10.2 & 5 & 1.3 & $1^{*}$ \\
\hline 127 & 16.9 & 12.9 & 17.7 & 10.2 & 75 & 23.5 & $23^{*}$ \\
\hline 128 & 16.9 & 12.9 & 18.2 & 19.5 & 45 & 14.0 & $12^{*}$ \\
\hline 129 & 16.9 & $3.0^{*}$ & 0.0 & $3.0^{*}$ & 10 & $3.0^{*}$ & 3" \\
\hline 130 & 16.9 & 12.9 & 17.7 & 10.2 & 60 & 18.7 & $18^{*}$ \\
\hline 131 & 16.9 & 12.9 & 17.7 & 10.2 & 25 & 7.6 & $5^{*}$ \\
\hline 132 & 16.9 & 12.9 & 17.7 & 10.2 & 45 & 14.0 & $13^{*}$ \\
\hline 133 & 16.9 & 12.9 & 17.7 & 10.2 & 40 & 12.4 & $11^{*}$ \\
\hline 134 & 16.9 & 12.9 & 17.7 & 10.2 & 100 & 31.4 & $29^{*}$ \\
\hline 135 & 16.9 & 12.9 & 17.7 & 10.2 & 95 & 29.8 & $29^{*}$ \\
\hline 136 & 16.9 & 12.9 & 18.2 & 19.5 & 60 & 18.7 & $16^{*}$ \\
\hline 137 & 16.9 & 12.9 & 17.7 & 10.2 & 70 & 21.9 & $21^{*}$ \\
\hline 138 & 16.9 & 12.9 & 0.0 & 3.0 & 5 & 1.3 & 2 \\
\hline 139 & 16.9 & 12.9 & 17.7 & 10.2 & 15 & 4.4 & 2 \\
\hline 140 & 16.9 & 12.9 & 0.0 & 3.0 & 10 & 2.8 & $1^{*}$ \\
\hline 141 & 16.9 & 12.9 & 17.7 & 10.2 & 70 & 21.9 & $20^{\circ}$ \\
\hline 142 & 16.9 & 12.9 & 18.2 & 19.5 & 20 & 6.0 & $5^{*}$ \\
\hline 143 & 16.9 & 12.9 & 17.7 & 10.2 & 35 & 10.8 & $11^{*}$ \\
\hline 144 & $23.0^{*}$ & 12.9 & $23.0^{*}$ & 10.2 & 65 & 20.3 & $23^{*}$ \\
\hline 145 & 16.9 & 12.9 & 17.7 & 10.2 & 25 & 7.6 & $5^{*}$ \\
\hline
\end{tabular}

Stand U-EPS- U-PPS- S-EPS- S-PPS- PI Predicted CCFI no. CCFIAC CCFIAC CCFIAC CCFIAC height CCFIAC AC

\begin{tabular}{|c|c|c|c|c|c|c|c|}
\hline 146 & 16.9 & 12.9 & 17.7 & 10.2 & 80 & 25.1 & $24^{*}$ \\
\hline 147 & 16.9 & 12.9 & 17.7 & 10.2 & 80 & 25.1 & $24^{*}$ \\
\hline 148 & 16.9 & 12.9 & 18.2 & 19.5 & 40 & 12.4 & $13^{*}$ \\
\hline 149 & 16.9 & 12.9 & 18.2 & 19.5 & 65 & 20.3 & 20 * \\
\hline 150 & 16.9 & 12.9 & 17.7 & 10.2 & 30 & 9.2 & $8^{*}$ \\
\hline 151 & 16.9 & 12.9 & 17.7 & 10.2 & 80 & 25.1 & $23^{*}$ \\
\hline 152 & $19.0^{*}$ & $19.0^{*}$ & $19.0^{*}$ & $19.0^{*}$ & 70 & $19.0^{*}$ & $19^{*}$ \\
\hline 153 & $3.0^{\prime \prime}$ & 12.9 & $3.0^{*}$ & 19.5 & 15 & 4.4 & $3^{*}$ \\
\hline 154 & 23.0 & 12.9 & 23.0 & 19.5 & 75 & 23.5 & $23^{*}$ \\
\hline 155 & 16.9 & 12.9 & 17.7 & 10.2 & 75 & 23.5 & $22 *$ \\
\hline 156 & 16.9 & 12.9 & 17.7 & 10.2 & 15 & 4.4 & $3^{*}$ \\
\hline 157 & 16.9 & 12.9 & 18.2 & 19.5 & 65 & 20.3 & $19^{*}$ \\
\hline 158 & 16.9 & 12.9 & 17.7 & 10.2 & 40 & 12.4 & $12^{*}$ \\
\hline 159 & 16.9 & 12.9 & 18.2 & 19.5 & 20 & 6.0 & $5^{*}$ \\
\hline 160 & 16.9 & 12.9 & 17.7 & 10.2 & 55 & 17.1 & $17^{*}$ \\
\hline 161 & 16.9 & 12.9 & 18.2 & 19.5 & 35 & 10.8 & $9 *$ \\
\hline 162 & 16.9 & 12.9 & 17.7 & 10.2 & 30 & 9.2 & 9 \\
\hline 163 & 16.9 & 12.9 & 18.2 & 19.5 & 90 & 28.3 & $27^{*}$ \\
\hline 164 & 16.9 & 12.9 & 17.7 & 10.2 & 55 & 17.1 & $17^{*}$ \\
\hline 165 & 16.9 & 12.9 & 18.2 & 19.5 & 30 & 9.2 & $7^{*}$ \\
\hline 166 & 16.9 & $1.0^{*}$ & 17.7 & $1.0^{*}$ & 5 & $1.0^{*}$ & $1^{*}$ \\
\hline 167 & 16.9 & 12.9 & 17.7 & 10.2 & 75 & 23.5 & $21^{*}$ \\
\hline 168 & 16.9 & 12.9 & 18.2 & 19.5 & 70 & 21.9 & $22 "$ \\
\hline 169 & 16.9 & 12.9 & 17.7 & 10.2 & 95 & 29.8 & $30 *$ \\
\hline 170 & $31.0^{*}$ & 12.9 & $31.0^{*}$ & 19.5 & 105 & 33.0 & $31^{*}$ \\
\hline 171 & $16.9^{\circ}$ & 12.9 & 18.2 & 19.5 & 60 & 18.7 & $17^{*}$ \\
\hline 172 & $21.0^{*}$ & 12.9 & $21.0^{*}$ & 10.2 & 70 & 21.9 & $21^{*}$ \\
\hline 173 & 16.9 & 12.9 & 18.2 & 19.5 & 40 & 12.4 & $11^{\circ}$ \\
\hline 174 & 16.9 & 12.9 & 17.7 & 10.2 & 55 & 17.1 & $18^{*}$ \\
\hline 175 & 16.9 & $26.0^{*}$ & 18.2 & $26.0^{*}$ & 85 & $26.0^{*}$ & $26^{*}$ \\
\hline 176 & 16.9 & 12.9 & 18.2 & 19.5 & 100 & 31.4 & $30^{*}$ \\
\hline 177 & 16.9 & 12.9 & 17.7 & 10.2 & 35 & 10.8 & $11^{*}$ \\
\hline 178 & 16.9 & 12.9 & 17.7 & 10.2 & 35 & 10.8 & $8 *$ \\
\hline 179 & 16.9 & 12.9 & 18.2 & 19.5 & 90 & 28.3 & $26^{*}$ \\
\hline 180 & 16.9 & 12.9 & 18.2 & 19.5 & 55 & 17.1 & $15^{*}$ \\
\hline 181 & 16.9 & 12.9 & 17.7 & 10.2 & 95 & 29.8 & $30^{*}$ \\
\hline 182 & 16.9 & 12.9 & 18.2 & 19.5 & 85 & 26.7 & $27^{*}$ \\
\hline 183 & 16.9 & 12.9 & 18.2 & 19.5 & 40 & 12.4 & $11^{*}$ \\
\hline 184 & 16.9 & 12.9 & 18.2 & 19.5 & 50 & 15.5 & $13^{*}$ \\
\hline 185 & 16.9 & 12.9 & 17.7 & 10.2 & 65 & 20.3 & $18^{*}$ \\
\hline 186 & 16.9 & 12.9 & 17.7 & 10.2 & 40 & 12.4 & $10^{*}$ \\
\hline 187 & $14.0^{\circ}$ & 12.9 & $14.0^{\circ}$ & 10.2 & 45 & 14.0 & $14^{*}$ \\
\hline 188 & 16.9 & $22.0^{*}$ & 17.7 & $22.0^{\circ}$ & 65 & $22.0^{*}$ & $22^{*}$ \\
\hline 189 & 16.9 & 12.9 & 17.7 & 10.2 & 10 & 2.8 & $3^{*}$ \\
\hline 190 & 16.9 & 12.9 & 18.2 & 19.5 & 50 & 15.5 & $13^{*}$ \\
\hline 191 & 16.9 & 12.9 & 18.2 & 19.5 & 75 & 23.5 & $22^{\circ}$ \\
\hline 192 & 16.9 & 12.9 & 17.7 & 10.2 & 15 & 4.4 & $3^{*}$ \\
\hline 193 & 16.9 & 12.9 & 18.2 & 19.5 & 70 & 21.9 & 22 \\
\hline 194 & 16.9 & 12.9 & 17.7 & 10.2 & 80 & 25.1 & $23^{*}$ \\
\hline 195 & 16.9 & 12.9 & 17.7 & 10.2 & 30 & 9.2 & 9 \\
\hline 196 & 16.9 & 12.9 & 17.7 & 10.2 & 10 & 2.8 & \\
\hline 197 & 16.9 & 12.9 & 18.2 & 19.5 & 35 & 10.8 & $10^{*}$ \\
\hline 198 & 16.9 & 12.9 & 17.7 & 10.2 & 40 & 12.4 & $11^{\circ}$ \\
\hline 199 & 16.9 & 12.9 & 17.7 & 10.2 & 55 & 17.1 & $16^{*}$ \\
\hline 200 & 16.9 & $14.0^{*}$ & 17.7 & $14.0^{*}$ & 50 & $14.0^{\circ}$ & $14^{*}$ \\
\hline
\end{tabular}




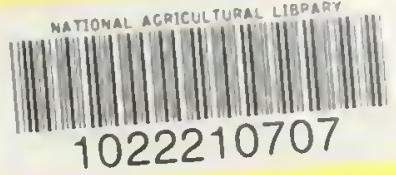




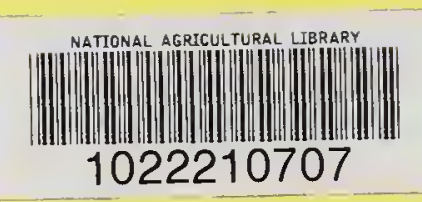

